\title{
Characterization of the Unique Flagellar Hook Structure of the Spirochetes Borrelia burgdorferi and Treponema denticola
}

\author{
Kelly Ann Heintzelman Miller \\ West Virginia University
}

Follow this and additional works at: https://researchrepository.wvu.edu/etd

\section{Recommended Citation}

Miller, Kelly Ann Heintzelman, "Characterization of the Unique Flagellar Hook Structure of the Spirochetes Borrelia burgdorferi and Treponema denticola" (2013). Graduate Theses, Dissertations, and Problem Reports. 4983.

https://researchrepository.wvu.edu/etd/4983

This Dissertation is protected by copyright and/or related rights. It has been brought to you by the The Research Repository @ WVU with permission from the rights-holder(s). You are free to use this Dissertation in any way that is permitted by the copyright and related rights legislation that applies to your use. For other uses you must obtain permission from the rights-holder(s) directly, unless additional rights are indicated by a Creative Commons license in the record and/ or on the work itself. This Dissertation has been accepted for inclusion in WVU Graduate Theses, Dissertations, and Problem Reports collection by an authorized administrator of The Research Repository @ WVU.

For more information, please contact researchrepository@mail.wvu.edu. 
Characterization of the Unique Flagellar Hook Structure of the Spirochetes Borrelia burgdorferi and Treponema denticola

Kelly Ann Heintzelman Miller

Dissertation submitted to the School of Medicine at West Virginia University in partial fullfillment of the requirements for the degree of

Doctor of Philosophy in Immunology and Microbial Pathogenesis

Nyles W. Charon, Ph.D., Chair Michael R. Miller, Ph.D. Thomas Elliott, Ph.D. Slawomir Lukomski, Ph.D. Rita Rio, Ph.D.

Department of Microbial Pathogenesis and Immunology Morgantown, WV

2013

Keywords: flagella, hook, Borrelia burgdorferi, Treponema denticola, mass spectrometry, peptide cross-linking, spirochete 


\title{
ABSTRACT \\ Characterization of the Unique Flagellar Hook Structure of the Spirochetes Borrelia burgdorferi and Treponema denticola
}

\author{
Kelly Ann Heintzelman Miller
}

The long-term goal of this project is to better understand Borrelia burgdorferi and Treponema denticola motility as it relates to pathogenesis. The structure of the spirochete periplasmic flagella is unique when compared to externally located flagella. One unusual characteristic is the flagellar hook, which serves as a universal joint coupling rotation of the membrane bound motor complex to the flagellar filament. The hook is composed of approximately $120 \mathrm{FlgE}$ monomers, and in bacteria with externally located flagella, these structures readily disassociate into monomers $(\sim 50 \mathrm{kDa})$ when treated with heat and detergent. However, in spirochetes the FlgE monomers form a large mass of over $250 \mathrm{kDa}$. We hypothesize that this high molecular weight complex (HMWC) is the result of covalent cross-linking of FlgE proteins. Cross-linking of bacterial flagella proteins has not been examined previously. Our goals are to thoroughly characterize the cross-linking in the B.burgdorferi and $T$. denticola hook proteins. We anticipate that once we have this information, new drugs could be developed to inhibit this cross-linking, which we anticipate will severely affect the spirochetes' motility and virulence capability. Thus, the proposed project's long-term goal is centered on developing new drug treatments for Lyme disease as well as other spirochetal diseases, including syphilis. We found that the HMWC of both $B$. burgdorferi and $T$. denticola are stable to a variety of denaturants and is not an artifact of boiling. Previously, western blot analysis was the sole indication that spirochetes crosslink their flagellar hook proteins. By making several modifications to the published procedure for isolating periplasmic flagella, I was able to obtain enough hook protein of both $B$. burgdorferi and $T$. denticola for mass spectrometry analysis. The mass spectrometry analysis confirmed that the spirochete HMWC is composed of FlgE, identified FlgE as the sole protein in these complexes, and that in specific regions the mass spectrometry patterns are different for the monomer and HMWC. We observed that $T$. denticola FlgE over-expressed in Escherichia coli forms a stable HMWC in vitro, and used the in vitro HMWC to study the effects of both chemical treatments and point mutations on HMWC formation. Finally, I propose a mechanism of cross-linking that is consistent with the mass spectrometry, biochemical, and mutational analyses. We hypothesize that FlgE cross-linking strengthens the hook structure for optimal spirochete motility. 


\section{Acknowledgements}

I wish to dedicate this work to my snuggle buddy Kodiak Lee. You are the joy that keeps me going over day through the highs and lows. You have taught me patience and make me laugh when I'm about to cry.

There are several people I would like to thank for support and guidance through this journey.

Thank God. Without him, nothing is possible.

My husband Eric for patience, listening to me vent, and comforting me when stressed.

My parents for their support, time, and taking care of Kodiak.

Milinda for being a rock and maintaining my sanity. Giving me support both inside and outside of lab.

My mentors Nyles and Mike for taking on one more graduate student before retirement, letting me work on a really cool project, guiding me through this process, and for being good friends.

My friends Amanda, Dacie, and Chrissy. For always being there, for good times, and helping me with the job search.

Andy Cockburn for listening and good suggestions. You always looked at things from a different angle and gave fresh ideas.

My committee: Thomas Elliott, Slawomir Lukomski, and Rita Rio for ideas, suggestions, looking over results with me, assisting in experimental design, and facilitating my scientific development. 
Collaborators: Chris Li (SUNY, Buffalo), Brian Crane (Cornell), Jun Liu (University of Texas), MD Motaleb (ECU), Justin Hettick (NIOSH), Melissa Caimano (University of Connecticut), Roger Hendrix and Bob Duda (University of Pittsburgh). Thank you for your contributions to this project.

My dogs Lucky and Reba for stress relief and nice walks. 


\section{Table of Contents}

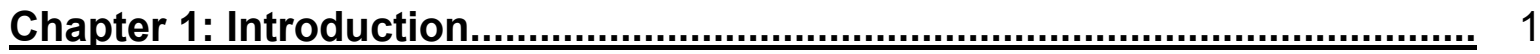

Medical Importance of T. denticola.................................................... 2

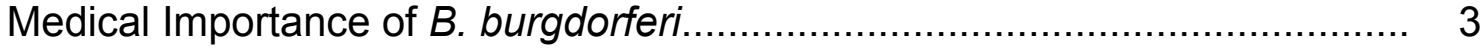

Flagellar structure and motility........................................................... 4

Structure of periplasmic flagella and how spirochetes swim........................ 12

Motility as a virulence factor of spirochetes............................................. 15

Covalent bonding of peptides in microorganisms...................................... 17

Methodology to detecting and deciphering cross-links................................. 22

Indirect evidence of cross-linking in spirochete flagella................................ 23

Research objectives..................................................................... 25

References......................................................................... 26

Chapter 2: Initial characterization of the FlgE high molecular weight complex of Borrelia burgdorferi........................................................................ 39

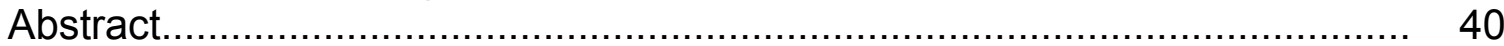

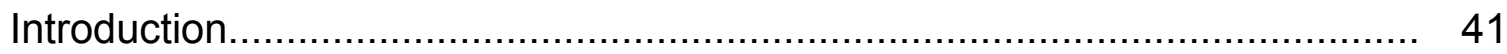

Materials and Methods................................................................ 43

Results and Discussion............................................................... 48

References......................................................................... 59

Chapter 3: The biochemistry of the Treponema denticola FlgE high

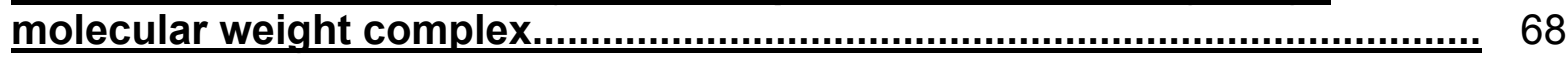

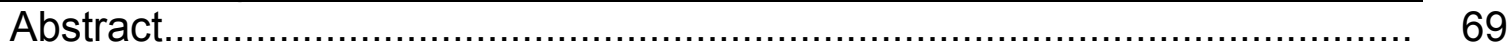

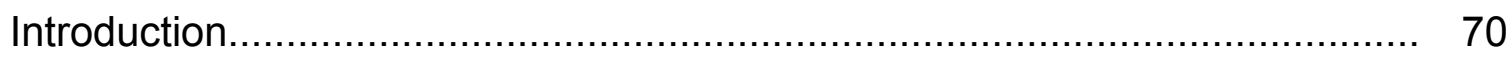

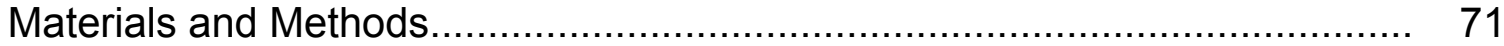

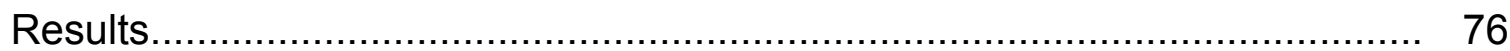

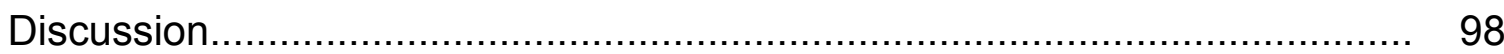

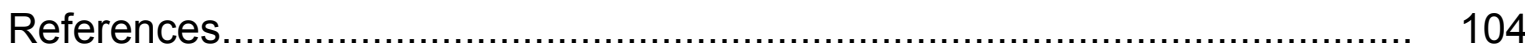

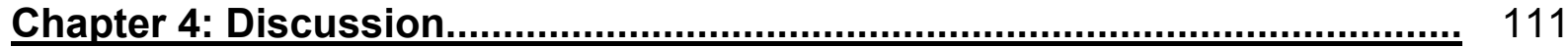

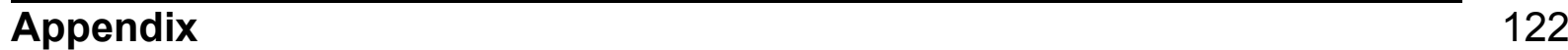

The unique paradigm of spirochete motility and chemotaxis........................ 130

Visualizing the sequential assembly of bacterial flagella in Borrelia 154

burgdorferi by cryo-electron tomography. 


\section{List of Figures}

Figure 1.1: Flagellar components of S. enterica.................................. 4

Figure 1.2: Proposed structure of trimers of the flagellar hook and filament proteins.................................................................................... 6

Figure 1.3: Structure of the flagellar hook as a whole, highlighting the D2 domain.

Figure 1.4: Diagram displaying B. burgdorferi structure and swimming.......... 13

Figure 1.5: Proposed mechanism of HK97 capsid cross-linking................... 19

Figure 1.6: Model of pili assembly in C. diptheriae..................................... 21

Figure 1.7: Western blot analysis of $B$. burgdorferi and $T$. denticola whole cell lysates using FlgE antibody............................................................. 24

Figure 2.1: Synthesis of the HMWC under different phases of growth........... 49

Figure 2.2: Synthesis of HMWC under different growth conditions................ 51

Figure 2.3: PF isolation using lysozyme or mutanolysin............................ 52

Figure 2.4: Cryo-EM image of PFs, $\Delta$ fliK mutant, and polyhooks.................. 53

Figure 2.5: Immunoblot analysis of PFs and $\Delta$ fliK mutant.......................... 54

Figure 2.6: MS analysis of the HMWCs isolated from PFs and polyhooks..... 58

Figure 3.1: Expression of FlgE in T. denticola whole cell lysates................... 78

Figure 3.2: FlgE western blot analysis of periplasmic flagella either boiled or treated with chemical denaturants.......................................................... 79

Figure 3.3: Coomassie stained SDS-PAGE of purified T. denticola rFIgE...... 80

Figure 3.4: Western blot analysis of the rFlgE HMWC treated with denaturants using polyclonal FlgE antibody....

Figure 3.5: MS analysis of $\mathrm{rFlgE}$ and polyhooks isolated from tap mutant cells...

Figure 3.6: T. denticola FlgE primary sequence.

Figure 3.7: Effect of heating monomeric FlgE on HMWC formation.

Figure 3.8: Effect of ammonium sulfate concentration on rFlgE HMWC formation

Figure 3.9: Effect of $\mathrm{NaCl}$ on HMWC formation

90

Figure 3.10: Effect of $\mathrm{pH}$ and ammonium sulfate on rFlgE HMWC formation..

Figure 3.11: Effect of $\mathrm{pH}$ on the rFlgE HMWC.

Figure 3.12: Effect of $\beta M E$ on rFlgE HMWC formation

Figure 3.13: Effect of D181A substitution mutation on rFlgE HMWC

formation

Figure 3.14: Effect of N175A, N179A, and N175AN179A substitution

mutations on rFlgE HMWC formation.

Figure 3.15: Effect of C178A substitution mutation on rFlgE HMWC formation.

Figure 3.16: Homology modeling of $T$. denticola FlgE onto the Salmonella model. 


\section{List of Tables}

Table 2.1: Primers used to generate the $\Delta$ fliK mutant

Appendix Table A1: Peptides identified in MS analysis of $B$. burgdorferi periplasmic flagella.

Appendix Table A2: Peptides identified in MS analysis of $B$. burgdorferi polyhooks.

Appendix Table A3: Peptides identified in MS analysis of $T$. denticola polyhooks. 


\section{List of Abbreviations}

AS ammonium sulfate

$\beta M E \quad$ betamercaptoethanol

Cryo-EM cryo-electron microscopy

$\Delta \quad$ deletion mutant

HMWC high molecular weight complex

$\mathrm{GuHCl}$ guanidine hydrochloride

IPTG isopropyl- $\beta$-thiogalactoside

MS mass spectrometry

PBS phosphate buffered saline

PCR polymerase chain reaction

PVDF polyvinylidene difluoride

PF periplasmic flagella

rFlgE recombinant FlgE

SDS-PAGE sodium dodecyl sulfate polyacrylamide gel electrophoresis

UPLC ultra-performance liquid chromatography

qTOF quadruple time of flight mass spectrometer 
Amino Acid abbreviations

$\begin{array}{ll}\text { C } & \text { Cysteine } \\ \text { D } & \text { Aspartic acid } \\ \text { E } & \text { Glutamic acid } \\ \text { K } & \text { Lysine } \\ \text { N } & \text { Asparagine } \\ \text { T } & \text { Threonine }\end{array}$




\section{Chapter 1: Introduction}

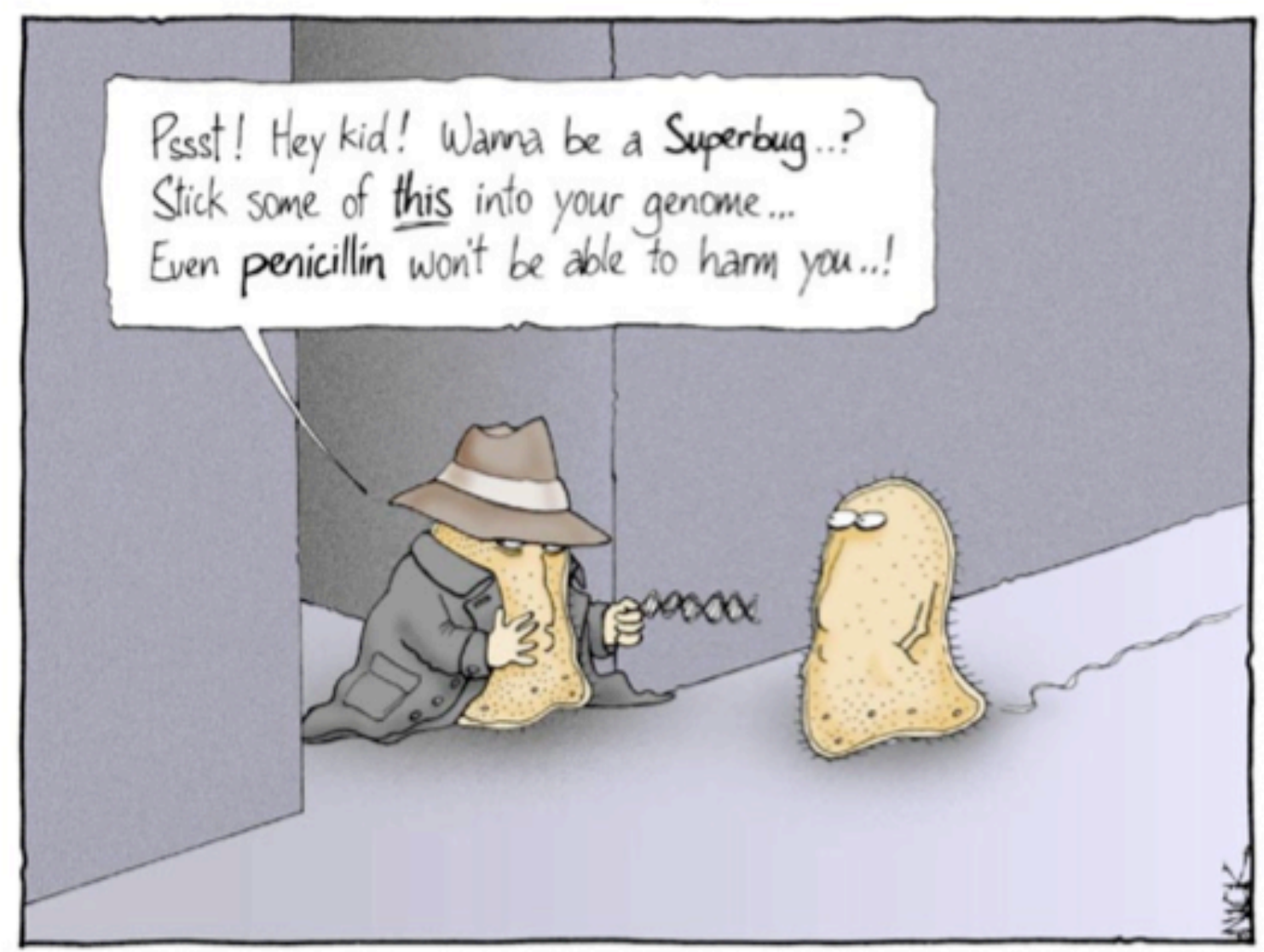

It was on a short-cut through the hospital kitchens that Albert was first approached by a member of the Antibiotic Resistance.

As illustrated by the cartoon, antibiotic resistance is a growing problem around the world. Antibiotic resistance is a challenge for treating bacterial infections; as a result, it is important to develop novel/additional strategies for combating infections. Resistance has been reported in spirochetes. Resistance to azithromycin, which was commonly used to treat syphilis, has been reported in Treponema pallidum (6). A multi-drug efflux pump (Bes protein complex) that is a homologue to the TolC efflux system in Escherichia coli has been discovered in Borrelia burgdorferi. B. burgdorferi Bes protein mutants had significantly lower minimum inhibitory concentrations (greater 
susceptibility) than the wild type strain for a variety of antibiotics, including penicillin and tetracycline (7).

The purpose of this work was to chemically characterize and increase our understanding of the flagellar hook proteins of B. burgdorferi and Treponema denticola. Whereas the FlgE hook proteins of other bacteria associate via non-covalent interactions, studies suggest spirochete FlgE proteins are covalently cross-linked $(2,8$, 9). Characterizing the unique structure and biochemistry of the hook protein may allow for the production of FlgE cross-linking inhibitors, which in turn could lead to new treatment modalities for spirochete infections.

\section{Medical importance of $T$. denticola}

T. denticola resides in the oral cavity, and these anaerobic spirochetes are associated with poor dental health. Examples of dental problems include gingivitis, chronic peritonitis, and acute necrotizing ulcerative gingivitis (10-12). There is a positive correlation between the number of oral spirochetes (including $T$. denticola) located in the mouth and the severity of periodontal disease (13-20). T. denticola associates with both host cells and other bacteria (forming a biofilm) in order to cause disease. $T$. denticola is a member of the "red complex" along with Porphyromonas gingivalis and Tannerella forsythia (21). T. denticola and $P$. gingivalis co-inhabit deep pockets in subgingival plaque. Isolation of subgingival plaque from periodontal patients before and 
after treatment revealed a synergistic relationship between $T$. denticola and $P$. gingivalis (22-27).

\section{Medical importance of B. burgdorferi}

B. burgdorferi is the causative agent of Lyme disease, which is the most common arthropod transmitted infection in the United States $(28,29)$. Hard body ticks of the genus Ixodes serve as the vector; the specific species varies by geographical location. The deer tick, Ixodes scapularis, transmits the disease in the northeastern United States. Ixodes pacificus and Ixodes ricinus are the carriers in the western United States and Europe, respectively (28). Ixodes ticks feed on a variety of mammals; rodents and migratory birds serve as the primary reservoirs of infection $(29,30)$.

The infection, which begins at the skin at the site of the tick bite, disseminates to several organs and organ systems. Infected individuals experience a variety of symptoms, and asymptomatic infection is common (31-33). The most commonly affected organs and tissues include the skin, heart, joints, and the nervous system $(28,34,35)$. Approximately $75 \%$ of infected individuals develop the classic Lyme associated bullseye rash, which is referred to as erythema migrans $(36,37)$. 


\section{Flagellar structure and motility}

\section{Enteric bacteria as a model for flagellar structure and motility}

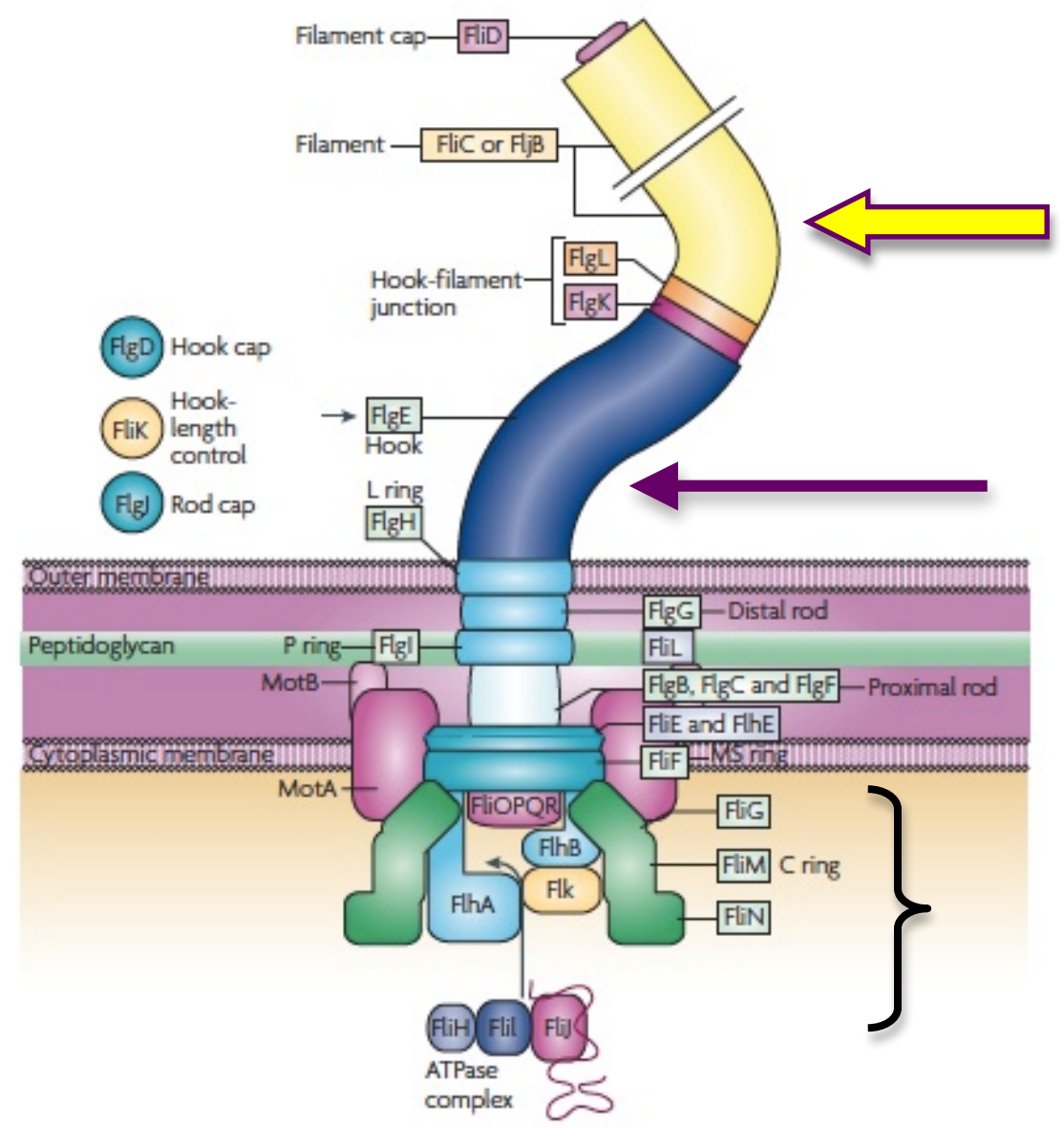

Figure 1.1: Flagellar components of $\boldsymbol{S}$. enterica. This project has focused on the hook, which is indicated by the purple arrow. The yellow arrow is pointing to the filament or propeller, and the black bracket is highlighting the basal body motor. This figure is adapted from (38).

\section{Flagellar composition}

The flagellum is used by many bacterial species as a mode of motility and consists of three major parts: the basal body, the hook, and the filament (Figure 1.1, adapted from 
(38). Flagellar structure, assembly, and regulation have been most extensively studied in Salmonella enterica serovar Typhimiurium (hereto referred to as S. enterica), and as

a result, $S$. enterica serves as a model system. The inner most part embedded in the membrane is the basal body, which serves as an engine or motor. The largest part of the flagellum, which is composed of several thousand flagellin subunits, is the filament. The filament, which acts as a propeller, is on average $10 \mu \mathrm{m}$ long in S. enterica. In between the basal body and the filament is the hook, which functions as a universal joint and is responsible for transmitting torque from the basal body motor to the filament. The hook is $55 \mathrm{~nm}$ long and consists of over 120 copies of a single protein, FlgE (38).

\section{Structure of the flagellar hook}

A combination of $\mathrm{x}$-ray crystallography and cryo-electron microscopy (cryo-EM) have been used to examine the structure of the flagellar hook in S. enterica in fine detail $(4$, 39). As previously stated, the flagellar hook functions as a universal joint, transmitting torque from the basal body motor to the filament (40). Two hook associated proteins (HAP1 and HAP3 also called FlgL and FlgK) act as adaptors and are located between the hook and filament. The hook and filament share some properties; they are both hollow tubular structures that must be relatively rigid in order to perform their function (39).

The hook differs from the filament in that it must also be flexible $(4,39,40)$.

Crystallization of a fragment of $S$. enterica FlgE combined with cryo-EM provides insight 
as to how the hook is able to be both strong and flexible $(4,39)$. Four domains (listed from inner core to outside) were identified in the hook D0, Dc, D1, and D2 (Figure 1.2). The residues composing the inner core (D0), where the least flexibility is required, are tightly packed and form a coiled coil of $\alpha$-helices similar to the filament. The $\mathrm{N}$-terminal and C-terminal regions of the primary sequence that compose the D0 domain of the hook are positioned differently (in relation to each other) than the $\mathrm{N}$ and C-terminal regions of the filament. The $\mathrm{C}$-terminal $\alpha$-helix is longer than the $\mathrm{N}$-terminal helix, and both helices are angled. The angle of the helices and the gap between them allows the bending required for the hook to function as a joint (4). Figure 1.2, adapted from (4), shows the proposed structures of trimers of the hook and filament proteins.

A

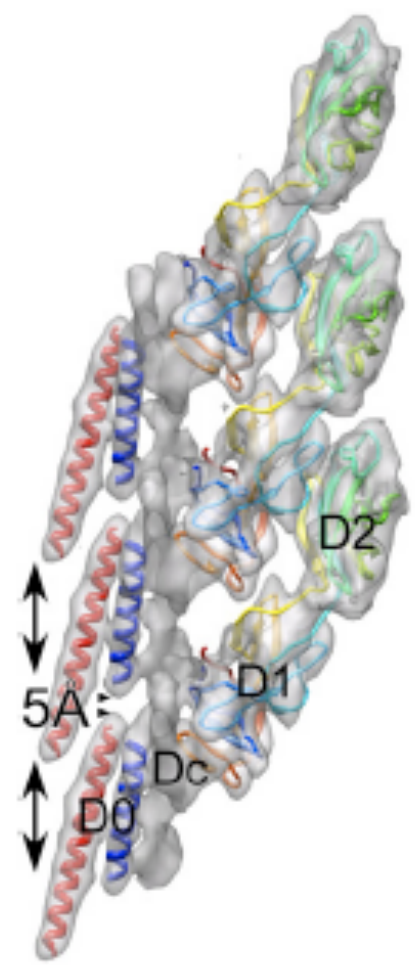

B

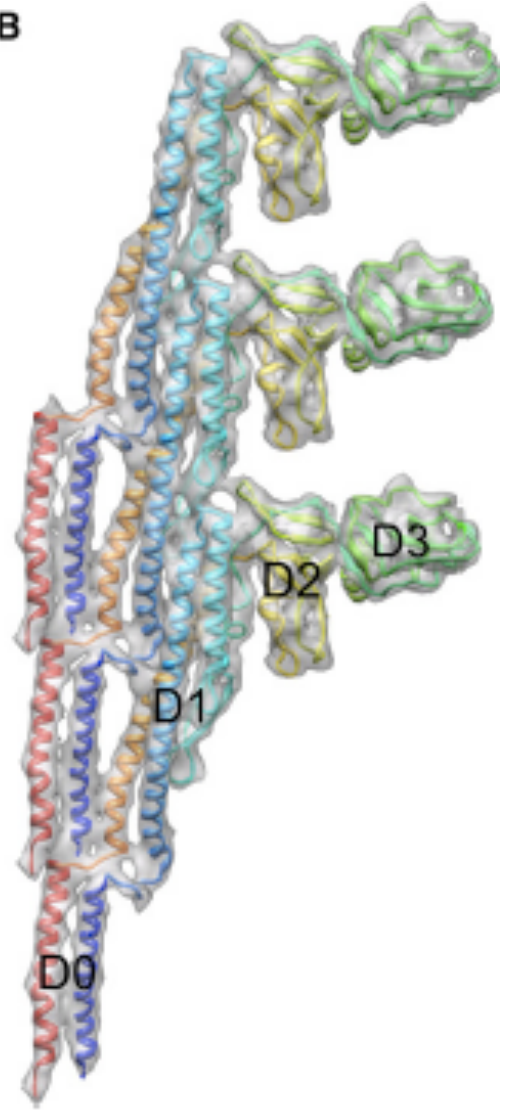

Figure 1.2: Proposed structure of trimers of the flagellar hook (A) and filament (B) proteins. The hook and filament are both hollow, cylindrical structures that must be strong to perform their function. The hook must be flexible in addition to being strong. Differences in packing and orientation of the domains between the hook and filament permits the flexibility required by the hook (4). 


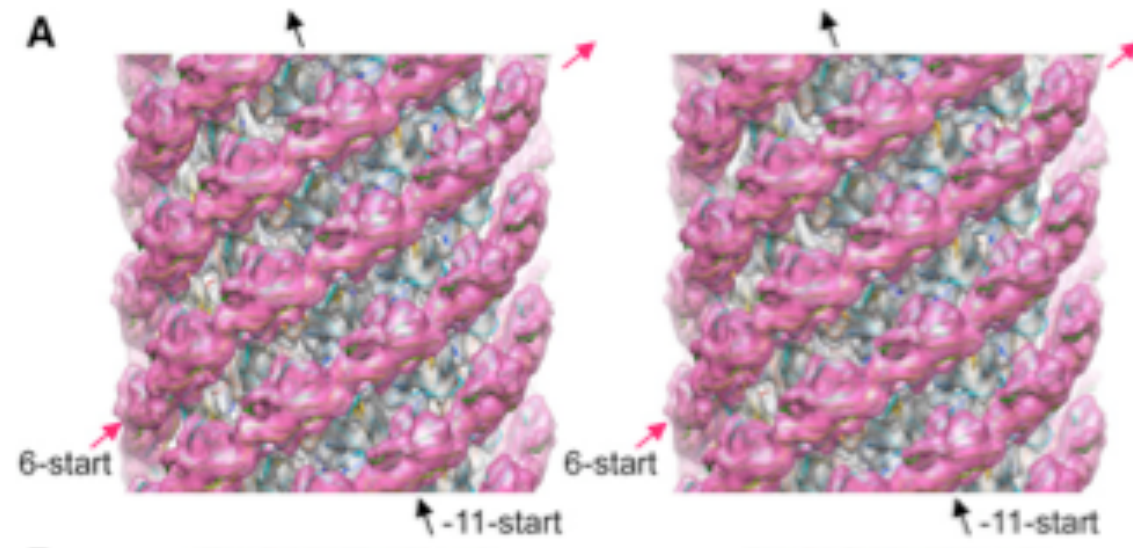

Figure 1.3: Structure of the flagellar hook as a whole, highlighting the D2 domain in magenta. The two major helical lines are the 6-start and 11 -start. The direction of the helices is indicated by the arrows (4).

Going from the inner to the outer layers of the hook, increasing flexibility is required because the outer domain has the greatest degree of extension/compression difference $(4,39)$. The Dc domain is cylindrically packed and forms a mesh with the outermost (D2) domain. The cylindrical packing and the formed mesh provide the hook with twisting stability (4). The loose packing of the outer two domains (D1 and D2) gives the hook flexibility. Figure 1.3 shows the cylindrical array and symmetry of the D2 domain. The D1 domain is loosely packed in all directions, whereas the D2 domain contains strong contacts between residues of the 6-start helix. There are wide gaps between the 6-start helices of the D2 domain that allows flexibility while the residues among a particular helix are bound by strong interactions (Figure 1.3) $(4,39)$.

Evidence for the universal joint function of the hook is not limited to structural information obtained from crystallization studies. Genetic modifications paired with streptavidin binding were used to directly observe hook dynamics in Echerichia coli. Binding of straptavidin molecules to the hook increased stiffness and reduced hook flexibility. The hook was unable to function as a universal joint when flexibility was reduced. Cells that had stiffened hooks failed to form bundles and displayed atypical 
swimming behavior. These results directly support the idea of the hook functioning as a universal joint (40).

\section{Assembly of the S. enterica flagellum}

The majority of flagellar subunits are located outside of the cell and therefore require a secretion mechanism as part of the assembly process. The majority of secreted flagellar proteins use a type three secretion system (T3SS). The flagellar secretion channel is a narrow $2.5 \mathrm{~nm}$; therefore, the secreted peptides must be partially or completely unfolded during the secretion process (38).

Several proteins, both membrane bound and soluble, are involved in the secretion process. Membrane proteins involved in flagellar assembly are: FlhA, FlhB, FliF, FliO, FliP, FliQ, and FliR. First FliF, which forms the MS ring, becomes embedded in the membrane. Then other membrane proteins follow, using the MS ring as a base. The soluble proteins involved are: Flil, which is an ATPase, FliH, which is a negative regulator of the ATPase, and the chaperone FliJ. Together, the soluble protein members of the secretion process function to increase the efficiency of secretion (38).

Flagellar secretion occurs at a rapid rate of several thousand amino acids/second, which is too fast to be explained by ATP hydrolysis alone; therefore, there must be an additional energy source. Both flagellar secretion and rotation require the proton motive force. Flagellar secretion still occurs in the absence of ATP hydrolysis, but the process 
is much slower. ATP hydrolysis, although dispensable for secretion, increases the efficiency of secretion $(41,42)$.

\section{Transcriptional regulation of flagella genes and assembly in S. enterica}

There are over 60 flagellar genes. These genes are categorized into three classes based on promoter type in the majority of flagellated bacteria, including S. enterica. These three gene classes form a hierarchy that is regulated at the transcriptional level. Class I is composed of the $f l h D C$ master operon. Class I activates the o70 promoter of class II genes. Class II consists of genes that encode proteins that make up the hook basal body structure as well as the regulatory proteins FliA (o28) and FlgM. FliA and FlgM regulate the switch from class II to class III; in addition, FliA and FlgM are also products of class III transcription (38).

Once the hook basal body is assembled, the $\sigma 28$ promoters of the class III genes are transcribed (38). The interaction of the regulators FlgM and FliA is responsible for the switch from early (hook basal body) to late (flagellin) substrates. When FlgM is bound to FliA, genes that encode early substrates are transcribed because $\sigma 28$ is unable to bind RNA polymerase (class II on, class III off). Once the hook reaches $55 \mathrm{~nm}$ in length, FlgM is secreted. Secretion of FlgM allows $\sigma 28$ to bind RNA polymerase, and class III genes are transcribed (38). 


\section{Role of the hook in flagellar regulation}

Assembly of the hook serves as major checkpoint in transcriptional regulation of flagellar assembly; proper hook length ( $55 \mathrm{~nm}$ for $\mathrm{S}$. enterica) allows flagellar secretion to switch from early to late substrates and secretion of FlgM. FliK and FlhB are involved in hook length determination. FliK is secreted with early (rod/hook) substrates (43). FliK interacts with hook proteins and FlhB (44). Once the hook reaches the proper length of $55 \mathrm{~nm}$, FlhB undergoes auto-cleavage between residues N269 and P270 (45). Both FlhB-FliK interaction and FlhB auto-cleavage are required for flagellar secretion to switch from early to late substrates $(38,46)$.

The fliK and flhB N269A (unable to undergo auto-cleavage) mutants have different phenotypes (46). S. enterica flik mutants produce longer hooks (poly-hooks) than wildtype cells. Although hook growth does not stop at $55 \mathrm{~nm}$ in fliK cells, it does slow down. These results suggest that something in addition to FliK is involved in hook length determination (47). A large range of hook lengths (range does not peak at $55 \mathrm{~nm}$ ) is produced by cleavage defective $f / h B$ mutants, and the fliK/flhB N269A double mutants have the same phenotype as flhB N269A mutants. Together these results indicate that FlhB cleavage is able to regulate hook length to a degree in the absence of FliK (46).

Several models of hook length regulation have been proposed. The data can all be explained by the ratio of FlgE/FliK being the determining factor of hook length. The simplest explanation is that FliK measures FlgE over time (temporal regulation). If FliK 
makes more measurements over a period of time, the hook is shorter than $55 \mathrm{~nm}$. In other words, hooks are shorter if one increases the amount of FliK (maintaining the same level of FlgE) or decreases the amount of FlgE (while maintaining the same level of FliK). Hook length is longer than $55 \mathrm{~nm}$ under the opposite condition: less FliK measurements over time (increasing the FlgE/FliK ratio) (46).

\section{An exception to the norm: Flagellar regulation in B. burgdorferi}

B. burgdorferi is unique in that flagellar protein synthesis is not regulated at the transcriptional level. The genome sequence of $B$. burgdorferi differs from the genomes of bacteria that use the transcriptional cascade of control described above in that there are no homologues of the regulatory genes fliA and flgM, and there are no $\sigma 28$ consensus sequences. Rather all motility operons appear to be under $\sigma 70$ control (48).

In addition to the promoter structure of the $B$. burgdorferi genome being unique, construction and analysis of motility mutants provides additional evidence that $B$. burgdorferi does not regulate its motility genes at the transcriptional level $(2,49-52)$. $B$. burgdorferi flaB- (major flagellin) mutants had decreased levels of FlaA (minor flagellin), but the flaA mRNA transcript was not decreased (49). B. burgdorferi flgE mutants had decreased amounts of the flagellin proteins FlaA and FlaB as expected; however, protein levels of other class III products (chemotaxis proteins CheA2, CheY3, CheX, and CheW3) were unaffected. Additionally, the mRNA transcript of flaA and flaB of the flgE- cells were transcribed at the same level as wild type, and there was no turnover of 
FlaB protein. Together, these results indicate that the hook of $B$. burgdorferi is not a checkpoint of flagellar synthesis at the transcriptional level (2).

Construction of a deletion mutant and over-expression mutant of carbon storage regulator $A$ (csrA) provides additional evidence of post-transcriptional regulation of $B$. burgdorferi flagellar synthesis. $c s r A^{-}$(deletion) and $c s r A^{+}$(over expression) mutants had opposite effects on FlaB protein levels and flagella morphology. csrA cells had $4 \mathrm{x}$ the amount of FlaB protein as wild-type cells, and $c s r A^{+}$cells had $75 \%$ less FlaB protein than wild-type cells. Neither mutation affected the flaB mRNA transcript level. csrA ${ }^{-}$ produced flagellar filaments that were longer than wild-type filaments, and the flagellar ribbons interdigitated with one another and wrapped around the cell more tightly than in wild-type cells. The motility of $c s r A^{-}$was indistinguishable from the motility of wild-type cells. On the other hand, cells over-expressing $\operatorname{csr} A\left(\operatorname{csrA}^{+}\right)$had shorter flagella and less flagella per cell than wild-type cells and were non-motile. Results of electrophoretic mobility shift assays and qRT-PCR demonstrated that CsrA negatively regulated flagellar synthesis by inhibiting FlaB translation (50).

\section{Structure of periplasmic flagella of spirochetes and how spirochetes swim}

Spirochete motility is unique compared to the well-studied model of S. enterica motility. The sub-terminally attached flagella are not externally located; rather, the flagella reside in the periplasmic space (periplasmic flagella), between the outer membrane sheath and the protoplasmic cell cylinder, which makes the motility of spirochetes more complicated than their externally flagellated counterparts (3). S. enterica has two modes 
of swimming (runs and tumbles), whereas spirochetes have three modes: run, flex, and

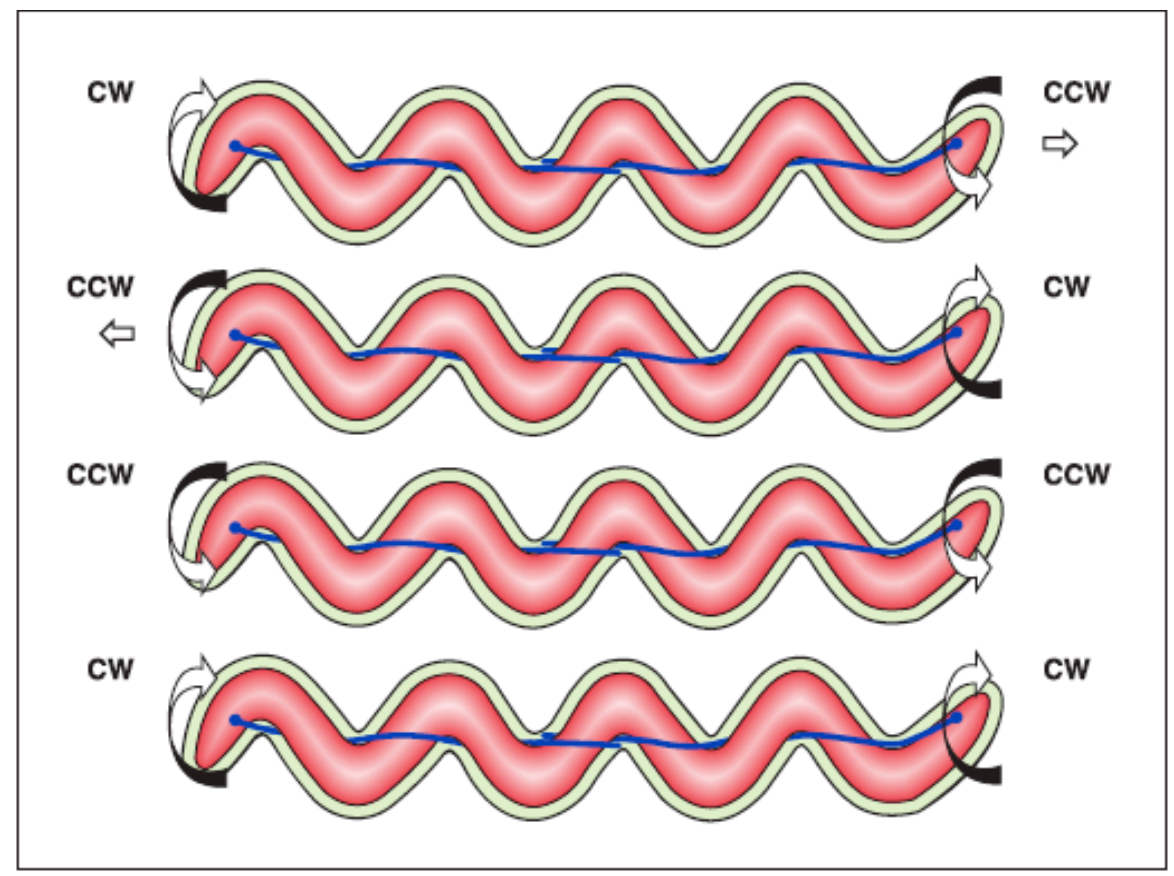

Figure 1.4: Diagram displaying $B$. burgdorferi structure and swimming. For simplification, only one periplasmic flagellum per end is shown. The bottom two forms are associated with flexing (3).

reverse (3). When both flagellar ribbons are rotating the same direction (clockwise or counter clockwise as viewed along the flagella from its distal end to where it inserts at the cell end), a spirochete tumbles or flexes. Running occurs when the two ribbons are rotating in opposite directions, and the direction of spirochete movement depends upon which ribbon is rotating counter clockwise. As a result, in order to reverse, the direction of rotation of both bundles must be switched (3) (Figure 1.4).

\section{Periplasmic flagella influence cell structure}

The periplasmic flagella of spirochetes influence cell structure in addition to providing motility. The periplasmic flagella have the most extreme effect on the morphology of $B$. burgdorferi. In $B$. burgdorferi, there are 7-11 flagella in each ribbon, and the two ribbons overlap in the middle of the cell $(50,53)$. Wild-type cells form a flat wave, whereas, flaB- 
mutants do not produce flagella and are rod-shaped $(54,55)$. The periplasmic flagella also influence the cell morphology of the helical spirochetes $T$. denticola (56) and Treponema phagedenis (57). In T. denticola there are two periplasmic flagella located at each end of the cell that overlap in the middle. Wild-type cells often have a twisted, irregular shape (Some cells were right handed helices) but mutants that lack flagella fail to form the twisted-like morphology (56). Unlike B. burgdorferi and T. denticola, the periplasmic flagella of $T$. phagedenis do not overlap in the middle. As a result, the shape at the ends of the cell (as opposed to the shape of the entire cell) is changed to accommodate the periplasmic flagella (57).

Another difference between spirochete and $S$. enterica flagella is the presence of two types of filament proteins: FlaA and FlaB. The minor flagellin protein FlaA forms a sheath, and the major flagellin protein makes up the core $(3,49,58-60)$. The FlaB proteins share sequence homology with FliC of $S$. enterica and other flagellin proteins $(61,62)$. In addition to spirochetes having multiple types of filament proteins, several spirochetes including Treponema and Brachyspira have three FlaB proteins $(63,64)$; however, $B$. burgdorferi only has one FlaB protein (55). Construction of mutants in Brachyspira hyodysenteriae of individual (63) and multiple (64) flagellin genes has been informative regarding the function of the individual proteins. B. hyodysenteria assembles flagella and continues to be motile when any of the flagellin genes are mutated, but this motility differs from the motility of wild-type cells. Swarm plate assays and velocity determinations via computerized cell tracking demonstrated that flagellin mutants were less motile than wild-type cells $(63,64)$. Dark field microscopy was used to examine 
periplasmic flagella structure. Specifically, helix pitch and diameter were measured and handedness of the helix determined. The structure was only significantly changed in one single mutant, the fla $A^{-}$mutant. These studies have found that $B$. hyodysenteria FlaA forms a sheath around the FlaB core and influences helical shape (63).

Construction of double mutants demonstrated that the individual filament proteins do not equally contribute to motility. Specifically, FlaB1 and FlaB2 had a larger impact on motility than FlaB3, and there is some redundancy in the function of FlaB1 and FlaB2. The flaB1flaB2 double mutant, which produced hollow tubes of FlaA with no FlaB core, was the only mutant that was completely non-motile. Single mutants of either flaB1- or flaB2- were partially motile (64). In summary, spirochetes have multiple filament proteins, and these proteins contribute to flagellar morphology and motility.

Additionally, spirochetes swim faster in highly viscous, gel-like medium than in lowviscosity medium; this is the opposite pattern of what is observed in most bacteria containing external flagella $(3,55,65-67)$. Both the unique structure and the ability of these organisms to swim in viscous gel-like environments are likely to be critical for the disease process. Recent real time intravital imaging of $B$. burgdorferi combined with use of gelatin matrices suggests that the ability to swim in viscous environments is important for the disease process (68). 


\section{Motility as a virulence factor of spirochetes}

\section{Motility and periodontal disease}

T. denticola, like the majority of spirochetes, is invasive and motile $(10,11,69,70)$. Analysis of motility $\left(f l g E^{-}\right)$and chemotaxis $(c h e A, d m c)$ mutants demonstrated that both motility and chemotaxis are used by $T$. denticola in order to penetrate tissue layers in vitro. Non-motile flgE mutants were not able to penetrate an oral epithelial cell layer. Mutants that were chemotaxis deficient and completely motile penetrated the tissue but had decreased penetration of the oral epithelial cell layer as compared to wild-type cells (71). Additionally, motility has been implicated in the ability of $T$. denticola to evade the host response. Peritoneal macrophages were able to uptake more flgE cells than wild type cells as measured by immunoflorescence and real time PCR (72).

\section{Motility and Lyme disease}

Intravital microscopy has been used to observe green fluorescent protein labeled $B$. burgdorferi swimming in the infected tissues of mice. B. burgdorferi would interact with and bind to the vascular endothelium, and migration through the endothelium required motility $(73,74)$. Analysis of non-motile mutants provides additional evidence that motility is required for $B$. burgdorferi infectivity. For example, fla $B^{-}$mutants are nonmotile and avirulent (75). Also, fliG1 ${ }^{-}$mutants were unable to translate in viscous media and were non-infectious in mice (76). Recently, chemotaxis has been shown to be essential for $B$. burgdorferi infectivity in addition to motility. Mutants of the gene 
encoding the chemotaxis histidine kinase (cheA2) were unable to cause disease in mice (77).

\section{Covalent bonding of peptides in microorganisms}

Cross-linking is defined as when one macromolecule is covalently bonded to another. Protein-protein cross-linking among bacterial proteins is relatively rare. The two most studied examples are phage head proteins (eg lambda phage HK97), and Grampositive bacteria pili proteins, including those from Streptococcus pyogenes and Corynebacterium diptheriae (78-80). Additionally, cross-linking has been identified in

Bacillus spore coat proteins $(81,82)$. Protein-protein cross-linking brings considerable strength to the final structure; cross-linking protects proteins from proteolysis and mechanical and chemical stresses. In both bacteriophage HK97 and Streptococcus pyogenes, cross-linking has been shown to result from the formation of an amide isopeptide bond joining lysine $(K)$ to asparagine $(N)$ residues between proteins $(78,83$, 84). Additionally, in Gram (+) pili, an isopeptide bond occurs between $\mathrm{K}$ and threonine (T) residues (1). Depending on the system, cross-linking can occur auto-catalytically, or in some cases is trans enzyme catalyzed $(5,78)$.

\section{Cross-linking of bacteriophage HK97 head proteins}

HK97 belongs to the same class as the well-studied Escherichia coli phage lambda; HK97 is a temperate double stranded DNA containing E. coli phage (85). Double 
stranded DNA phage heads undergo expansion prior to DNA packaging. Expansion introduces significant physical pressure to the head proteins, and as a result double stranded DNA phages have adopted a variety of strategies for coping with this stress. For example, lambda uses the auxiliary protein gpD to aid in stability (86). Unlike lambda, HK97 does not utilize accessory proteins for head stability; instead the head proteins are covalently bonded to one another in a form that resembles the chainmail worn by medieval knights (87).

HK97 heads are composed of over 400 covalent cross-links; these cross-links are all composed of intermolecular isopeptide bonds between a $\mathrm{K}$ residue of one subunit and an $\mathrm{N}$ residue of another subunit $(83,84,88)$. Cross-linking of head proteins occurs in vitro as well as in vivo, and cross-linking does not require the addition of co-factors or enzymes (83). Mutational analysis confirmed that the mechanism of intermolecular isopeptide formation was autocatalytic. Several amino acid substitutions were constructed for glutamic acid $(E)$ residue E363. These mutants containing the amino acid substitutions varied in their ability to cross-link, and none of the mutants were as efficient as the wild type. These results confirmed that residue E363 is responsible for catalyzing the cross-linking reaction shown below (5). 


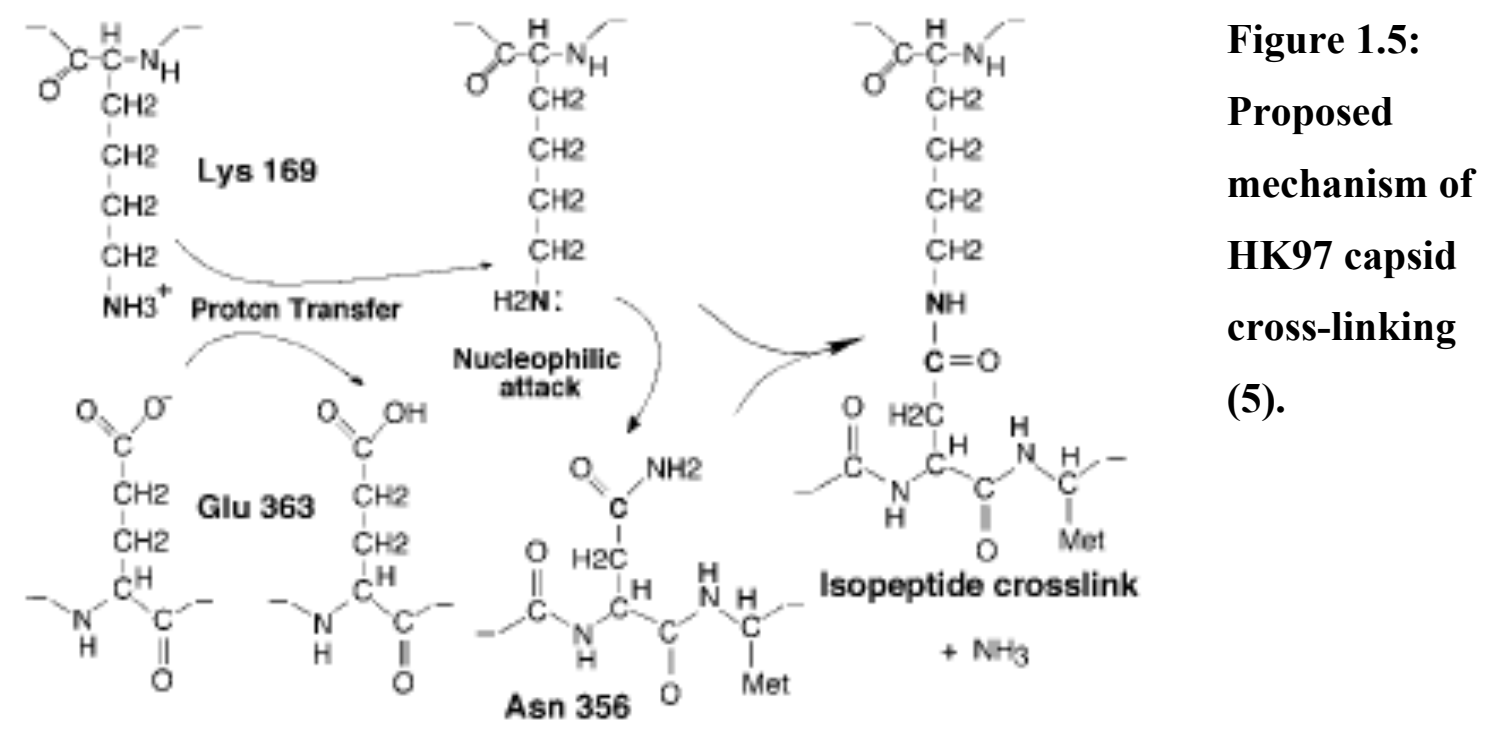

Based on x-ray modeling and mutagenesis studies, the autocatalytic mechanism of intermolecular isopeptide formation was deciphered. During head expansion, the three residues required for cross-linking (K169, N356, and E363) are brought into close proximity within a hydrophobic pocket. The surrounding hydrophobic residues promote residue neutrality; it is energetically favorable for E363 to act as a base, removing a proton from K169. When $\mathrm{K} 169$ is in an uncharged state, the nitrogen is able to act as a nucleophile, attacking the carbonyl carbon of N356. The end result is an isopeptide bond between K169 and N356 with the loss of ammonia (5) (Figure 1.5).

\section{Cross-linking of Gram positive bacteria pili proteins}

Pili are external bacterial appendages that facilitate adhesion to host molecules and are involved in gliding motility in Gram-negative and Gram-positive bacteria. The carefully organized covalently cross-linked pili of Gram-positive bacteria are extremely narrow (2 
$\mathrm{nm}$ thick) and over a hundred units long. The covalent bonding of pili (Spa proteins) is composed of intramolecular and intermolecular isopeptide bonds (89).

The intramolecular isopeptide bonds are formed by an autocatalytic mechanism that is similar to the autocatalysis of HK97 head proteins $(5,78)$. In the case of pili, the reaction can be catalyzed by either a aspartic acid (D) or glutamic acid $(E)$ residue $(78,89)$. Following extraction of a proton from the side group of $\mathrm{K}$, the autocatalytic mechanism of pili undergoes the same process of isopeptide formation as the HK97 head proteins, and the end result is a K-N isopeptide $(5,78)$.

The long chains of covalently cross-linked Spa proteins (intermolecular isopeptide bonds) that make up the pili are assembled by sortases, which are cysteine (C) residue specific transpeptidases (89). In sortase mediated cross-linking, the pili function as both a substrate and nucleophile (1). Sortases contain the active site motif of TLXTC and recognize the substrate motif of I/LCP/AXTG. The sortase $\mathrm{C}$ of the active site cleaves the T-G bond of the pili substrate. This cleavage results in an acyl enzyme (thioester) intermediate. Nucleophilic attack by a K residue of another pili protein resolves the thioester and displaces the sortase. The end result is a K-T isopeptide bond between Spa proteins $(1,89)$ (Figure 1.6). 


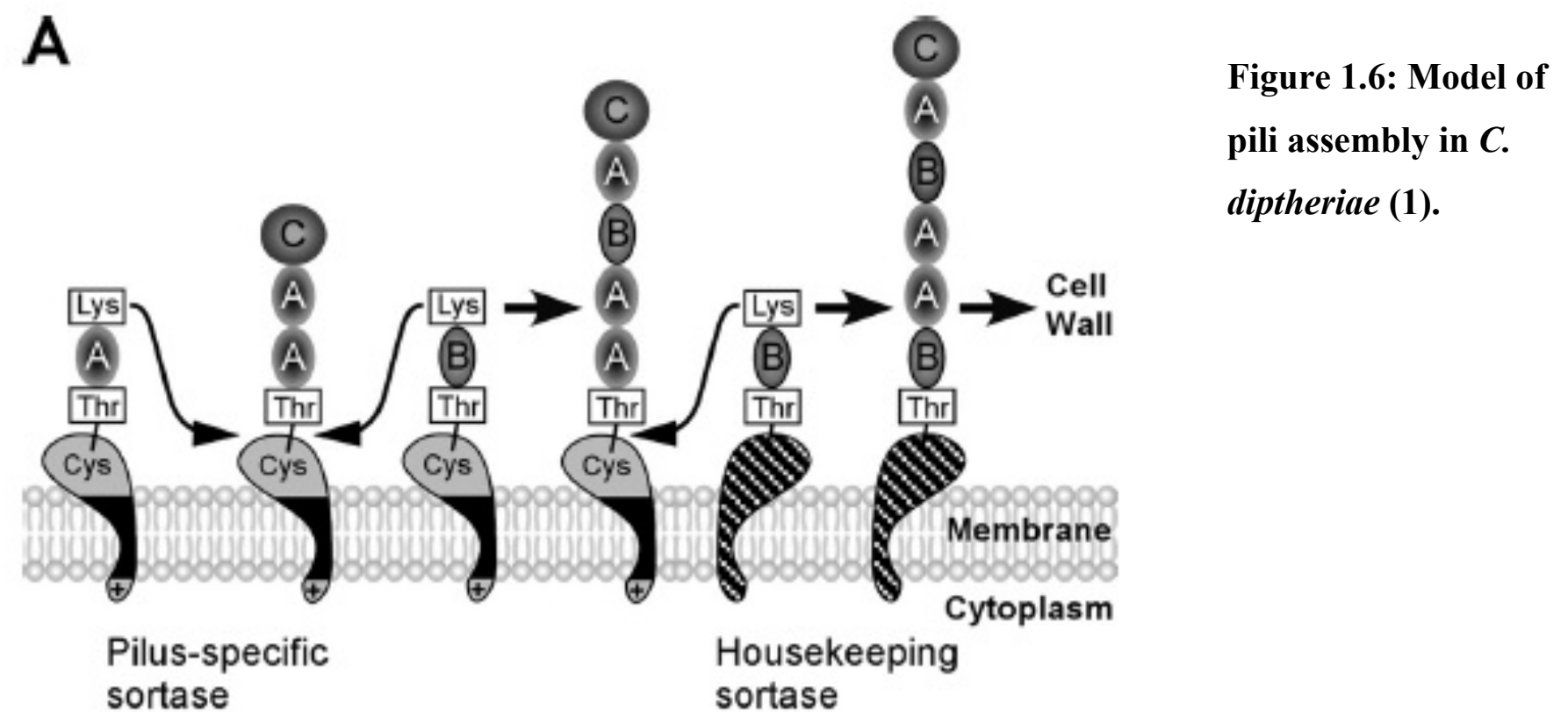

\section{Cross-linking of Bacillus spore proteins}

Sporulation is a strategy used by gram-positive bacteria, members of the Bacillus and Clostridium genre, to survive harsh conditions (ie lack of nutrition availability). The spore coat contains over 40 proteins, and several of these proteins have been observed to cross-link in Bacillus species $(81,82,90,91)$. Cross-linking of spore proteins has not been characterized as extensively as that of HK-97 head proteins and pili proteins.

Tgl, a transglutaminase, has been shown to be required for cross-linking of the spore protein GerQ $(81,82)$, and mutational analyses have shown that the active site of $\mathrm{Tgl}$ is required for GerQ cross-linking (82). Transglutaminases form covalent bonds between $\mathrm{K}$ and glutamine $(\mathrm{Q})$ residues, and mutational analysis showed that the three $\mathrm{N}$-terminal $\mathrm{K}$ residues $(\mathrm{K} 2, \mathrm{~K} 4, \mathrm{~K} 5)$ of GerQ are required for Tgl mediated cross-linking (90). In 
addition to GerQ, Tgl was shown to catalyze cross-linking of three unidentified spore polypeptides (82). The Cot spore proteins have also been observed to cross-link. Unlike GerQ cross-linking, transglutaminase is not required, and K-Q residues do not make up the cross-link. Instead, the tyrosine rich proteins contain di-tyrosine cross-links (82).

To summarize, cross-linking of peptides can involve different residues, and the mechanism can be either enzyme dependent or independent. The advantage of being protected from proteolysis and harsh conditions is shared among the different types of cross-links.

\section{Methodology to detecting and deciphering cross-links}

Having described what cross-linking is, why it occurs, and how it occurs, I will now explain how cross-linking is identified. The idea of covalently bound peptides in the microbial world began with the observation of high molecular weight complexes (HMWC's) in polyacrylamide gels. In the case of phage head and pili proteins, HMWC's are detected by SDS-PAGE after extensive boiling. These masses are considerably larger than the expected monomer, and may not even enter a $7 \%$ acrylamide running gel $(79,88)$. Furthermore, these masses are not readily dissociated into monomers by treatments that disrupt up non-convalent bonds; these reactions include incubations with guanidine hydrochloride ( $\mathrm{GuHCl}$ ), urea, and formic acid. To determine if the crosslinking is mediated by disulfide bonds, dithiothreitol (DTT) and mercaptoethanol (BME) are used to disassociate such bonds $(79,88)$. Confirmation of cross-linking is based on 
identifying the specific amino acids involved, and determining the nature of the crosslinked bond. Peptide digestion, mapping and mass spectrometry have been used to identify the residues involved in both HK97 and Gram-postive pili proteins $(78,83,88)$. Site-directed mutagenesis is used for confirmation of the residues involved $(5,78,84)$.

\section{Indirect evidence of cross-linking in spirochete flagella}

Construction of $f l g E$ mutants provided the initial evidence that the flagellar hook proteins of spirochetes are cross-linked. Immunoblot analysis of whole cell lysates from wildtype, flgE'- mutants and $f l g E^{+}$(complemented cells) provided surprising results. When lysates or purified flagella from other bacteria such as $S$. enterica are run on SDSPAGE and probed with FlgE antibody, bands are present at the molecular weight of monomeric FlgE (92). In the spirochetes B. burgdorferi, T. denticola, T. pallidum, and T. phagedenis a HMWC is observed in addition to the monomeric band $(2,8,9,93)$ (Figures 1.7). 


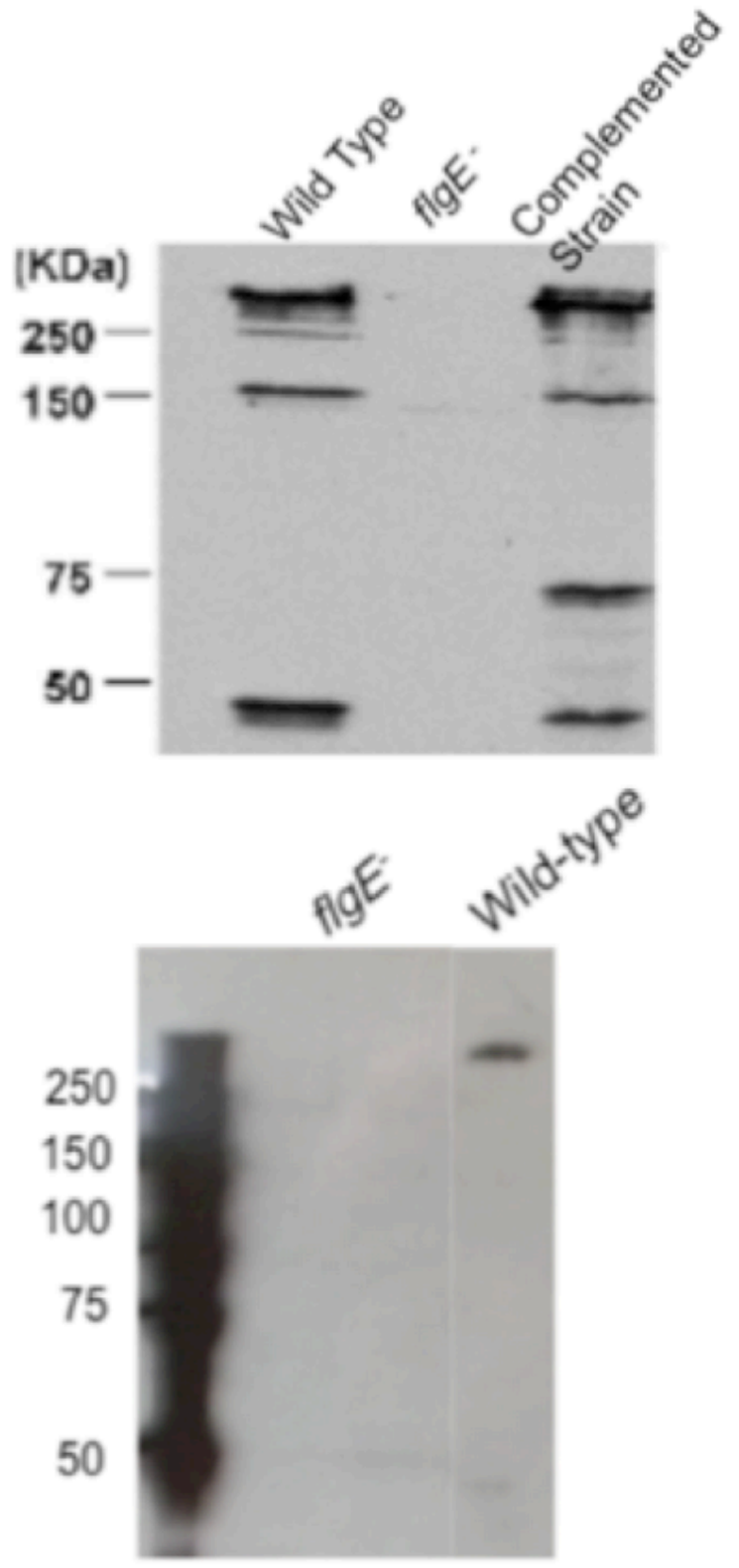

Figure 1.7: Top: Western blot of $B$. burgdorferi cell lysates using polyclonal FlgE antibody (2). Bottom: Western blot analysis of T. denticola cell lysates using FlgE antibody. 
The HMWC is present in wild-type and complemented cells, but is absent in flgEmutants $(2,8,9,93)$ (Figure 1.7). The HMWC is present in purified flagella and hook basal bodies in addition to whole cell lysates $(2,93)$. Additionally, we have confirmed that the HMWC of $B$. burgdorferi and $T$. denticola is predominantly FlgE by MS (K.A. Miller, M.R. Miller, and N.W. Charon, submitted).

\section{Research Objectives}

The long-term goal of this project is to better understand B. burgdorferi and $T$. denticola motility as it relates to pathogenesis. Cross-linking of bacterial flagella proteins has not been examined previously. Our goals are to thoroughly characterize the cross-linking in the B.burgdorferi and $T$. denticola hook proteins (FlgE). We anticipate that once we have this information, new drugs could be developed to inhibit this cross-linking, which we anticipate will severely affect the spirochetes' motility and virulence capability. Thus, the proposed project's long-term goal is centered on developing new drug treatments for Lyme disease as well as other spirochetal diseases, including syphilis.

The objectives of this project are to analyze FlgE cross-linking in B.burgdorferi and $T$. denticola. Specifically, we have focused on identifying the amino acid residues responsible for the covalent bonding between the FlgE subunits and characterizing the cross-linking mechanism. These results are likely to be relevant to other spirochetes including Treponema pallidum. 


\section{Research Hypothesis}

The flagellar hook proteins (FlgE) of $B$. burgdorferi and $T$. denticola are covalently cross-linked to each other.

\section{References}

1. Guttilla IK, Gaspar AH, Swierczynski A, Swaminathan A, Dwivedi P, Das A, Ton-That H. 2009. Acyl enzyme intermediates in sortase-catalyzed pilus morphogenesis in gram-positive bacteria. Journal of bacteriology 191:5603-5612.

2. Sal MS, Li C, Motalab MA, Shibata S, Aizawa S, Charon NW. 2008. Borrelia burgdorferi uniquely regulates its motility genes and has an intricate flagellar hook-basal body structure. Journal of bacteriology 190:1912-1921.

3. Charon NW, Goldstein SF. 2002. Genetics of motility and chemotaxis of a fascinating group of bacteria: the spirochetes. Annu Rev Genet 36:47-73.

4. Fujii T, Kato T, Namba K. 2009. Specific arrangement of alpha-helical coiled coils in the core domain of the bacterial flagellar hook for the universal joint function. Structure 17:1485-1493.

5. Dierkes LE, Peebles CL, Firek BA, Hendrix RW, Duda RL. 2009. Mutational analysis of a conserved glutamic acid required for self-catalyzed cross-linking of bacteriophage HK97 capsids. J Virol 83:2088-2098.

6. Katz KA, Klausner JD. 2008. Azithromycin resistance in Treponema pallidum. Curr Opin Infect Dis 21:83-91. 
7. Bunikis I, Denker K, Ostberg Y, Andersen C, Benz R, Bergstrom S. 2008. An RND-type efflux system in Borrelia burgdorferi is involved in virulence and resistance to antimicrobial compounds. PLoS Pathog 4:e1000009.

8. Limberger RJ, Slivienski LL, El-Afandi MC, Dantuono LA. 1996.

Organization, transcription, and expression of the 5 ' region of the fla operon of Treponema phagedenis and Treponema pallidum. Journal of bacteriology 178:4628-4634.

9. Chi B, Limberger RJ, Kuramitsu HK. 2002. Complementation of a Treponema denticola flgE mutant with a novel coumermycin A1-resistant $\mathrm{T}$. denticola shuttle vector system. Infection and immunity 70:2233-2237.

10. Ellen RP, Galimanas VB. 2005. Spirochetes at the forefront of periodontal infections. Periodontology 2000 38:13-32.

11. Sela MN. 2001. Role of Treponema denticola in periodontal diseases. Crit Rev Oral Biol Med 12:399-413.

12. Riviere GR, Wagoner MA, Baker-Zander SA, Weisz KS, Adams DF, Simonson L, Lukehart SA. 1991. Identification of spirochetes related to Treponema pallidum in necrotizing ulcerative gingivitis and chronic periodontitis. The New England journal of medicine 325:539-543.

13. Newman HN. 1990. Plaque and chronic inflammatory periodontal disease. A question of ecology. J Clin Periodontol 17:533-541.

14. Simonson LG, Goodman CH, Morton HE. 1990. Quantitative immunoassay of Treponema denticola serovar C in adult periodontitis. J Clin Microbiol 28:14931496. 
15. Simonson LG, Goodman CH, Bial JJ, Morton HE. 1988. Quantitative relationship of Treponema denticola to severity of periodontal disease. Infection and immunity 56:726-728.

16. Listgarten MA, Hellden L. 1978. Relative distribution of bacteria at clinically healthy and periodontally diseased sites in humans. J Clin Periodontol 5:115132.

17. Riviere GR, DeRouen TA. 1998. Association of oral spirochetes from periodontally healthy sites with development of gingivitis. J Periodontol 69:496501.

18. Riviere GR, DeRouen TA, Kay SL, Avera SP, Stouffer VK, Hawkins NR. 1997. Association of oral spirochetes from sites of periodontal health with development of periodontitis. J Periodontol 68:1210-1214.

19. Riviere GR, Smith KS, Carranza N, Jr., Tzagaroulaki E, Kay SL, Dock M. 1995. Subgingival distribution of Treponema denticola, Treponema socranskii, and pathogen-related oral spirochetes: prevalence and relationship to periodontal status of sampled sites. J Periodontol 66:829-837.

20. Socransky SS, Haffajee AD, Smith C, Dibart S. 1991. Relation of counts of microbial species to clinical status at the sampled site. J Clin Periodontol 18:766775.

21. Socransky SS, Haffajee AD, Cugini MA, Smith C, Kent RL, Jr. 1998. Microbial complexes in subgingival plaque. J Clin Periodontol 25:134-144. 
22. Simonson LG, McMahon KT, Childers DW, Morton HE. 1992. Bacterial synergy of Treponema denticola and Porphyromonas gingivalis in a multinational population. Oral microbiology and immunology 7:111-112.

23. Riviere GR, Smith KS, Carranza N, Jr., Tzagaroulaki E, Kay SL, Dock M, Zhu X, DeRouen TA. 1996. Associations between Porphyromonas gingivalis and oral treponemes in subgingival plaque. Oral microbiology and immunology 11:150155.

24. Kigure T, Saito A, Seida K, Yamada S, Ishihara K, Okuda K. 1995. Distribution of Porphyromonas gingivalis and Treponema denticola in human subgingival plaque at different periodontal pocket depths examined by immunohistochemical methods. J Periodontal Res 30:332-341.

25. Nilius AM, Spencer SC, Simonson LG. 1993. Stimulation of in vitro growth of Treponema denticola by extracellular growth factors produced by Porphyromonas gingivalis. J Dent Res 72:1027-1031.

26. Simonson LG, Robinson PJ, Pranger RJ, Cohen ME, Morton HE. 1992. Treponema denticola and Porphyromonas gingivalis as prognostic markers following periodontal treatment. J Periodontol 63:270-273.

27. Takeuchi Y, Umeda M, Sakamoto M, Benno Y, Huang Y, Ishikawa I. 2001. Treponema socranskii, Treponema denticola, and Porphyromonas gingivalis are associated with severity of periodontal tissue destruction. J Periodontol 72:13541363.

28. Steere AC, Coburn J, Glickstein L. 2004. The emergence of Lyme disease. J Clin Invest 113:1093-1101. 
29. Radolf JD, Caimano MJ, Stevenson B, Hu LT. 2012. Of ticks, mice and men: understanding the dual-host lifestyle of Lyme disease spirochaetes. Nature reviews. Microbiology 10:87-99.

30. Kurtenbach K, Hanincova K, Tsao JI, Margos G, Fish D, Ogden NH. 2006. Fundamental processes in the evolutionary ecology of Lyme borreliosis. Nature reviews. Microbiology 4:660-669.

31. Hanrahan JP, Benach JL, Coleman JL, Bosler EM, Grabau JC, Morse DL. 1984. Epidemiologic features of Lyme disease in New York. Yale J Biol Med 57:643-650.

32. Steere AC, Taylor E, Wilson ML, Levine JF, Spielman A. 1986. Longitudinal assessment of the clinical and epidemiological features of Lyme disease in a defined population. The Journal of infectious diseases 154:295-300.

33. Gustafson R, Jaenson TG, Gardulf A, Mejlon H, Svenungsson B. 1995. Prevalence of Borrelia burgdorferi sensu lato infection in Ixodes ricinus in Sweden. Scand J Infect Dis 27:597-601.

34. Barthold SW, de Souza MS, Janotka JL, Smith AL, Persing DH. 1993. Chronic Lyme borreliosis in the laboratory mouse. Am J Pathol 143:959-971.

35. Saba S, VanderBrink BA, Perides G, Glickstein LJ, Link MS, Homoud MK, Bronson RT, Estes M, 3rd, Wang PJ. 2001. Cardiac conduction abnormalities in a mouse model of Lyme borreliosis. J Interv Card Electrophysiol 5:137-143.

36. Smith RP, Schoen RT, Rahn DW, Sikand VK, Nowakowski J, Parenti DL, Holman MS, Persing DH, Steere AC. 2002. Clinical characteristics and 
treatment outcome of early Lyme disease in patients with microbiologically confirmed erythema migrans. Ann Intern Med 136:421-428.

37. Wormser GP. 2006. Clinical practice. Early Lyme disease. The New England journal of medicine 354:2794-2801.

38. Chevance FF, Hughes KT. 2008. Coordinating assembly of a bacterial macromolecular machine. Nature reviews. Microbiology 6:455-465.

39. Samatey FA, Matsunami H, Imada K, Nagashima S, Shaikh TR, Thomas DR, Chen JZ, Derosier DJ, Kitao A, Namba K. 2004. Structure of the bacterial flagellar hook and implication for the molecular universal joint mechanism. Nature 431:1062-1068.

40. Brown MT, Steel BC, Silvestrin C, Wilkinson DA, Delalez NJ, Lumb CN, Obara B, Armitage JP, Berry RM. 2012. Flagellar hook flexibility is essential for bundle formation in swimming Escherichia coli cells. Journal of bacteriology 194:3495-3501.

41. Paul K, Erhardt M, Hirano T, Blair DF, Hughes KT. 2008. Energy source of flagellar type III secretion. Nature 451:489-492.

42. Minamino T, Namba K. 2008. Distinct roles of the Flil ATPase and proton motive force in bacterial flagellar protein export. Nature 451:485-488.

43. Minamino T, Gonzalez-Pedrajo B, Yamaguchi K, Aizawa SI, Macnab RM. 1999. FliK, the protein responsible for flagellar hook length control in Salmonella, is exported during hook assembly. Molecular microbiology 34:295-304. 
44. Minamino T, Moriya N, Hirano T, Hughes KT, Namba K. 2009. Interaction of FliK with the bacterial flagellar hook is required for efficient export specificity switching. Molecular microbiology 74:239-251.

45. Minamino T, Macnab RM. 2000. Domain structure of Salmonella FlhB, a flagellar export component responsible for substrate specificity switching. Journal of bacteriology 182:4906-4914.

46. Erhardt M, Hirano T, Su Y, Paul K, Wee DH, Mizuno S, Aizawa S, Hughes KT. 2010. The role of the FliK molecular ruler in hook-length control in Salmonella enterica. Molecular microbiology 75:1272-1284.

47. Koroyasu S, Yamazato M, Hirano T, Aizawa SI. 1998. Kinetic analysis of the growth rate of the flagellar hook in Salmonella typhimurium by the population balance method. Biophys J 74:436-443.

48. Fraser CM, Casjens S, Huang WM, Sutton GG, Clayton R, Lathigra R, White O, Ketchum KA, Dodson R, Hickey EK, Gwinn M, Dougherty B, Tomb JF, Fleischmann RD, Richardson D, Peterson J, Kerlavage AR, Quackenbush J, Salzberg S, Hanson M, van Vugt R, Palmer N, Adams MD, Gocayne J, Weidman J, Utterback T, Watthey L, McDonald L, Artiach P, Bowman C, Garland S, Fuji C, Cotton MD, Horst K, Roberts K, Hatch B, Smith HO, Venter JC. 1997. Genomic sequence of a Lyme disease spirochaete, Borrelia burgdorferi. Nature 390:580-586.

49. Motaleb MA, Sal MS, Charon NW. 2004. The decrease in FlaA observed in a flaB mutant of Borrelia burgdorferi occurs posttranscriptionally. Journal of bacteriology 186:3703-3711. 
50. Sze CW, Morado DR, Liu J, Charon NW, Xu H, Li C. 2011. Carbon storage regulator $\mathrm{A}(\mathrm{Csr} A(\mathrm{Bb}))$ is a repressor of Borrelia burgdorferi flagellin protein FlaB. Molecular microbiology 82:851-864.

51. Ge Y, Charon NW. 1997. Molecular characterization of a flagellar/chemotaxis operon in the spirochete Borrelia burgdorferi. FEMS Microbiol Lett 153:425-431.

52. Ge Y, Old IG, Girons IS, Charon NW. 1997. The flgK motility operon of Borrelia burgdorferi is initiated by a sigma 70-like promoter. Microbiology 143 ( $\mathrm{Pt}$ 5):1681-1690.

53. Kudryashev M, Cyrklaff M, Baumeister W, Simon MM, Wallich R, Frischknecht F. 2009. Comparative cryo-electron tomography of pathogenic Lyme disease spirochetes. Molecular microbiology 71:1415-1434.

54. Sartakova ML, Dobrikova EY, Motaleb MA, Godfrey HP, Charon NW, Cabello FC. 2001. Complementation of a nonmotile flaB mutant of Borrelia burgdorferi by chromosomal integration of a plasmid containing a wild-type flaB allele. Journal of bacteriology 183:6558-6564.

55. Motaleb MA, Corum L, Bono JL, Elias AF, Rosa P, Samuels DS, Charon NW. 2000. Borrelia burgdorferi periplasmic flagella have both skeletal and motility functions. Proceedings of the National Academy of Sciences of the United States of America 97:10899-10904.

56. Ruby JD, Li H, Kuramitsu H, Norris SJ, Goldstein SF, Buttle KF, Charon NW. 1997. Relationship of Treponema denticola periplasmic flagella to irregular cell morphology. Journal of bacteriology 179:1628-1635. 
57. Charon NW, Goldstein SF, Curci K, Limberger RJ. 1991. The bent-end morphology of Treponema phagedenis is associated with short, left-handed, periplasmic flagella. Journal of bacteriology 173:4820-4826.

58. Ge Y, Charon NW. 1997. An unexpected flaA homolog is present and expressed in Borrelia burgdorferi. Journal of bacteriology 179:552-556.

59. Li C, Sal M, Marko M, Charon NW. 2010. Differential regulation of the multiple flagellins in spirochetes. Journal of bacteriology 192:2596-2603.

60. Limberger RJ, Charon NW. 1986. Treponema phagedenis has at least two proteins residing together on its periplasmic flagella. Journal of bacteriology 166:105-112.

61. Norris SJ, Charon NW, Cook RG, Fuentes MD, Limberger RJ. 1988. Antigenic relatedness and $\mathrm{N}$-terminal sequence homology define two classes of periplasmic flagellar proteins of Treponema pallidum subsp. pallidum and Treponema phagedenis. Journal of bacteriology 170:4072-4082.

62. Wilson DR, Beveridge TJ. 1993. Bacterial flagellar filaments and their component flagellins. Can J Microbiol 39:451-472.

63. Li C, Corum L, Morgan D, Rosey EL, Stanton TB, Charon NW. 2000. The spirochete FlaA periplasmic flagellar sheath protein impacts flagellar helicity. Journal of bacteriology 182:6698-6706.

64. Li C, Wolgemuth CW, Marko M, Morgan DG, Charon NW. 2008. Genetic analysis of spirochete flagellin proteins and their involvement in motility, filament assembly, and flagellar morphology. Journal of bacteriology 190:5607-5615. 
65. Kimsey RB, Spielman A. 1990. Motility of Lyme disease spirochetes in fluids as viscous as the extracellular matrix. The Journal of infectious diseases 162:12051208.

66. Ruby JD, Charon NW. 1998. Effect of temperature and viscosity on the motility of the spirochete Treponema denticola. FEMS Microbiol Lett 169:251-254.

67. Pietrantonio F, Noble PB, Amsel R, Chan EC. 1988. Locomotory characteristics of Treponema denticola. Can J Microbiol 34:748-752.

68. Harman MW, Dunham-Ems SM, Caimano MJ, Belperron AA, Bockenstedt LK, Fu HC, Radolf JD, Wolgemuth CW. 2012. The heterogeneous motility of the Lyme disease spirochete in gelatin mimics dissemination through tissue. Proceedings of the National Academy of Sciences of the United States of America 109:3059-3064.

69. Peters SR, Valdez M, Riviere G, Thomas DD. 1999. Adherence to and penetration through endothelial cells by oral treponemes. Oral microbiology and immunology 14:379-383.

70. Riviere GR, Weisz KS, Adams DF, Thomas DD. 1991. Pathogen-related oral spirochetes from dental plaque are invasive. Infection and immunity 59:33773380.

71. Lux R, Miller JN, Park NH, Shi W. 2001. Motility and chemotaxis in tissue penetration of oral epithelial cell layers by Treponema denticola. Infection and immunity 69:6276-6283. 
72. Gaibani P, Vocale C, Ambretti S, Cavrini F, Izard J, Miragliotta L, Pellegrino MT, Sambri V. 2010. Killing of Treponema denticola by mouse peritoneal macrophages. J Dent Res 89:521-526.

73. Moriarty TJ, Norman MU, Colarusso P, Bankhead T, Kubes P, Chaconas G. 2008. Real-time high resolution 3D imaging of the lyme disease spirochete adhering to and escaping from the vasculature of a living host. PLoS Pathog 4:e1000090.

74. Norman MU, Moriarty TJ, Dresser AR, Millen B, Kubes P, Chaconas G. 2008. Molecular mechanisms involved in vascular interactions of the Lyme disease pathogen in a living host. PLoS Pathog 4:e1000169.

75. Sultan SZ, Manne A, Stewart PE, Bestor A, Rosa PA, Charon NW, Motaleb MA. 2013. Motility is crucial for the infectious life cycle of Borrelia burgdorferi. Infection and immunity 81:2012-2021.

76. Li C, Xu H, Zhang K, Liang FT. 2010. Inactivation of a putative flagellar motor switch protein FliG1 prevents Borrelia burgdorferi from swimming in highly viscous media and blocks its infectivity. Molecular microbiology 75:1563-1576.

77. Sze CW, Zhang K, Kariu T, Pal U, Li C. 2012. Borrelia burgdorferi Needs Chemotaxis To Establish Infection in Mammals and To Accomplish Its Enzootic Cycle. Infection and immunity 80:2485-2492.

78. Kang HJ, Coulibaly F, Clow F, Proft T, Baker EN. 2007. Stabilizing isopeptide bonds revealed in gram-positive bacterial pilus structure. Science 318:16251628. 
79. Ton-That H, Schneewind O. 2003. Assembly of pili on the surface of Corynebacterium diphtheriae. Molecular microbiology 50:1429-1438.

80. Hendrix RW. 2005. Bacteriophage HK97: assembly of the capsid and evolutionary connections. Adv Virus Res 64:1-14.

81. Ragkousi K, Setlow P. 2004. Transglutaminase-mediated cross-linking of GerQ in the coats of Bacillus subtilis spores. Journal of bacteriology 186:5567-5575.

82. Zilhao R, Isticato R, Martins LO, Steil L, Volker U, Ricca E, Moran CP, Jr., Henriques AO. 2005. Assembly and function of a spore coat-associated transglutaminase of Bacillus subtilis. Journal of bacteriology 187:7753-7764.

83. Duda RL, Hempel J, Michel H, Shabanowitz J, Hunt D, Hendrix RW. 1995. Structural transitions during bacteriophage HK97 head assembly. J Mol Biol 247:618-635.

84. Duda RL, Martincic K, Hendrix RW. 1995. Genetic basis of bacteriophage HK97 prohead assembly. J Mol Biol 247:636-647.

85. Dhillon EK, Dhillon TS, Lai AN, Linn S. 1980. Host range, immunity and antigenic properties of lambdoid coliphage HK97. J Gen Virol 50:217-220.

86. Sternberg N, Weisberg R. 1977. Packaging of coliphage lambda DNA. II. The role of the gene D protein. J Mol Biol 117:733-759.

87. Duda RL. 1998. Protein chainmail: catenated protein in viral capsids. Cell 94:5560.

88. Popa MP, McKelvey TA, Hempel J, Hendrix RW. 1991. Bacteriophage HK97 structure: wholesale covalent cross-linking between the major head shell subunits. J Virol 65:3227-3237. 
89. Hendrickx AP, Budzik JM, Oh SY, Schneewind O. 2011. Architects at the bacterial surface - sortases and the assembly of pili with isopeptide bonds. Nature reviews. Microbiology 9:166-176.

90. Monroe A, Setlow P. 2006. Localization of the transglutaminase cross-linking sites in the Bacillus subtilis spore coat protein GerQ. Journal of bacteriology 188:7609-7616.

91. Placido D, Fernandes CG, Isidro A, Carrondo MA, Henriques AO, Archer M. 2008. Auto-induction and purification of a Bacillus subtilis transglutaminase (Tgl) and its preliminary crystallographic characterization. Protein Expr Purif 59:1-8.

92. Bonifield HR, Yamaguchi S, Hughes KT. 2000. The flagellar hook protein, FlgE, of Salmonella enterica serovar typhimurium is posttranscriptionally regulated in response to the stage of flagellar assembly. Journal of bacteriology 182:4044-4050.

93. Limberger RJ, Slivienski LL, Samsonoff WA. 1994. Genetic and biochemical analysis of the flagellar hook of Treponema phagedenis. Journal of bacteriology 176:3631-3637. 


\section{Chapter 2: Initial characterization of the FIgE hook high molecular weight complex of Borrelia burgdorferi}

Kelly A. Miller ${ }^{1}$, Md. A. Motaleb², Jun Liü ${ }^{3}$ Bo Hu³, Melissa J. Caimano ${ }^{4}$, Michael R. Miller $^{5}$, Nyles W. Charon ${ }^{1 *}$

${ }^{1}$ Department of Microbiology, Immunology, and Cell Biology Robert C. Byrd Health Sciences Center, West Virginia University, Morgantown, WV, United States of America

${ }^{2}$ Department of Microbiology and Immunology, East Carolina University, Greenville, NC, United States of America

${ }^{3}$ Department of Pathology and Laboratory Medicine, Medical School, University of Texas Health Science Center at Houston, Houston, TX, United States of America.

${ }^{4}$ Department of Medicine, University of Connecticut Health Center, 263 Farmington Avenue, Farmington, CT, United States of America

${ }^{5}$ Department of Biochemistry, Robert C. Byrd Health Sciences Center, West Virginia University, Morgantown, WV, United States of America.

*E-mail: ncharon@hsc.wvu.edu; phone 304-293-4170

This work was submitted for publication in PLOS One. 


\begin{abstract}
The spirochete periplasmic flagellum has many unique attributes. One unusual characteristic is the flagellar hook. This structure serves as a universal joint coupling rotation of the membrane-bound motor to the flagellar filament. The hook is comprised of about $120 \mathrm{FlgE}$ monomers, and in most bacteria these structures readily dissociate to monomers $(\sim 50 \mathrm{kDa})$ when treated with heat and detergent. However, in spirochetes the FlgE monomers form a large mass of over $250 \mathrm{kDa}$ [referred to as a high molecular weight complex (HMWC)] that is stable to these and other denaturing conditions. In this communication, we examined specific aspects with respect to the formation and structure of this complex. We found that the Lyme disease spirochete Borrelia burgdorferi synthesized the HMWC throughout the in vitro growth cycle, and also in vivo when implanted in dialysis membrane chambers in rats. The HMWC was stable to formic acid, which supports the concept that the stability of the HMWC is dependent on covalent cross-linking of individual FlgE subunits. Mass spectrometry analysis of the HMWC from both wild type periplasmic flagella and polyhooks from a newly constructed $\Delta$ flik mutant indicated that other proteins besides FlgE were not covalently joined to the complex, and that FlgE was the sole component of the complex. In addition, mass spectrometry analysis also indicated that the HMWC was composed of a polymer of the FlgE protein with both the $\mathrm{N}$ - and $\mathrm{C}$-terminal regions remaining intact. These initial studies set the stage for a detailed characterization of the HMWC. Covalent crosslinking of FlgE with the accompanying formation of the HMWC we propose strengthens the hook structure for optimal spirochete motility.
\end{abstract}




\section{Introduction}

Spirochetes are a ubiquitous monophyletic motile phylum of bacteria, with many species causing disease [1]. These organisms, which are either helical or flat-waves, have a unique structure, as the organelles responsible for motility, referred to as the periplasmic flagella (PFs), reside between the outer membrane and protoplasmic cell cylinder. Each PF is attached to one cell end and extends towards the opposite end of the cell. Rotation of these relatively rigid organelles generates perturbations and wave propagation along the length of the relatively flexible cell cylinder such that the spirochetes efficiently translate even in viscous gel-like material. Thus, the PFs need to exert substantial force on the cell cylinder to generate these backward moving waves [2-4].

Spirochetes also have several unique attributes with respect to their PFs. Each PF consists of a membrane imbedded motor where the basal body complex resides, a hook region that serves as universal joint, and the filament $[2,3]$. Thus, in many respects, the $\mathrm{PF}$ is similar in structure to the external flagellum of other bacteria. In contrast to the flagellum filament of most other bacteria, the PF filament consists of multiple protein species with a protein sheath surrounding the entire or part of the filament core. For example, Treponema and Brachyspira species have three different filament core proteins referred to as FlaB1, FlaB2, and FlaB3, and a sheath protein referred to as FlaA [2,3]. Borrelia burgdorferi has only one core protein referred to as FlaB and a sheath protein referred to as FlaA. Mutants that lack any of these proteins are deficient in motility $[5,6]$. In B. burgdorferi, mutants that lack FlaB are completely 
deficient in PFs, are non-motile, and are non-infectious $[7,8]$. The PF motor is also unique. Recent cryoelectron microscopy (cryo-EM) results suggest a specialized collar is associated with the motor in the vicinity of the peptidoglycan layer, but the function of the collar is presently unknown $[9,10]$. In addition, its cytoplasmic C-ring complex is considerably larger than that of other bacteria. The larger C-ring complex in spirochetes is believed to enable the PFs to exert more torque such that the PFs promote wave propagation along the cell length [10].

Another unique attribute of spirochetes, which is the focus of this report, is their flagellar hook. The hook is a hollow tubular structure, approximately $61 \mathrm{~nm}$ long in $B$. burgdorferi, and is composed of at least $120 \mathrm{FlgE}$ proteins [11]. FlgE is a well conserved protein among bacteria. Several reports indicate that FlgE of spirochetes form a stable, high molecular weight complex (HMWC) that is unique. Thus, western blots of whole cell lysates and in some cases purified PFs of B. burgdorferi, Treponema denticola, Treponema pallidum, and Treponema phagedenis probed with polyclonal FlgE antibodies react with a protein(s) located near the top of a gel, sometimes even in the stacking gel, with a mass greater than $250 \mathrm{kDa}$ [11-14]. This HMWC is considerably larger than the monomer ( 50 kDa) [11,13-15]. In contrast, in bacteria with external flagella, western blots probed with FlgE antibody show reactivity exclusively at the molecular weight of monomeric FlgE $[16,17]$. The ability of spirochete FlgE to form a HMWC is similar to electrophoretic patterns found with covalent cross-linked proteins. For example, the head proteins of phage HK97 that infects Escherichia coli, and the pili proteins of Gram positive bacteria such as Streptococcus pyogenes and Corynebacterium diptheriae also form HMWCs when analyzed by sodium dodecyl 
sulfate polyacrylamide gel electrophoresis (SDS-PAGE) [18,19]. In addition, HMWCs from spirochete FlgE, HK97, and Gram positive pili are stable to a variety of harsh treatments and chemical agents, including boiling, guanidine hydrochloride, and 8M urea $[11,14,18,19]$. Accordingly, we and others hypothesize that the FlgE HMWC of $B$. burgdorferi and other spirochetes is attributed to covalent cross-linking among its individual proteins, which may be essential for optimum motility and virulence $[11,14]$.

The characterization of the spirochete FlgE HMWC has been limited. Because FlgE is normally in small amounts (less than $9 \mu \mathrm{g}$ per liter of cells of $B$. burgdorferi), chemical characterization is difficult. Several basic questions arise concerning these complexes. Are the HMWCs formed at all phases of $B$. burgdorferi in vitro growth, and are they formed in vivo in an infected animal? Are HMWCs stable to formic acid as are the head proteins of HK97 and pili of Gram positive bacteria $[18,19]$ ? Is there more than one protein, such as another basal body protein being part of the HMWC? Does the HMWC consist of a polymer of the complete FlgE protein, or is there truncation of either of its ends? In this communication, using the Lyme disease spirochete $B$. burgdorferi as a model that forms the FlgE HMWC, we answer the above questions.

\section{Materials and methods}

Bacterial strains and growth conditions. High passage, avirulent $B$. burgdorferi strain $\mathrm{B} 31 \mathrm{~A}[20]$, and low passage virulent strain B31A3 [21], were grown at $33^{\circ} \mathrm{C}$ (except as noted) in the presence of $3 \%$ carbon dioxide in BSKII growth medium [7]. Cell counts were determined using flow cytometry as previously described [22]. These strains were originally obtained from P. Rosa, Rocky Mountain Laboratories, MT. The virulent low 
passage strain $\mathrm{B} 31 \mathrm{MI}$ [23] was grown in vitro at $23^{\circ} \mathrm{C}, 37^{\circ} \mathrm{C}$, and in in vivo in dialysis membrane chambers (DMCs) in Sprague-Dawley rats [24]. The non-motile flgE insertion mutant SC-E1 derived from strain B31A was previously described [11]. For in vivo growth, sterilized dialysis membranes with a molecular weight cut-off of $8000 \mathrm{Da}$ were filled with $\sim 9 \mathrm{ml}$ BSKII medium containing late logarithmic phase B. burgdorferi strain B31MI diluted to a starting density of 3000 spirochetes $/ \mathrm{ml}$. DMCs were aseptically implanted into the peritoneal cavities of female Sprague Dawley rats, and then harvested 14 days post-implantation as previously described [24]. B. burgdorferi recombinant FlgE ( $\mathrm{rFlgE})$ was expressed in $\mathrm{E}$. coli $\mathrm{BL} 21$ cells grown at $37^{\circ} \mathrm{C}$ in LuriaBertani broth containing $100 \mu \mathrm{g} / \mathrm{ml}$ ampicillin and purified as previously described [11].

Construction of the $\Delta$ fliK1 mutant. The fliK mutant, $\Delta$ fliK1, was derived from strain B31A; it was constructed as follows: The fliK gene (gene locus bb0285; 1179 base pairs) is located in the large $f l g B$ operon consisting of 26 genes $[23,25]$. This gene overlaps with the upstream flgD gene by 14 base pairs and is separated from the downstream bb0286 gene by eight base pairs. fliK was inactivated by replacing its coding sequence using overlapping PCR with an aadA streptomycin/spectinomycin resistance coding cassette that results in non-polar insertions [26]. Specifically, PCR was used to amplify three regions. First, each DNA region was amplified separately using primer pairs P1-P2 (5'-flanking DNA, flgD-flgE), P3-P4 (aadA coding sequence), and P5-P6 (3'-flanking DNA, bb0286-bb0287, Table 1). Second, a PCR product was obtained using primers P1-P4 with the purified DNA products flgD-flgE and aadA as templates. Third, the desired PCR product was obtained using primers P1-P6 with the 
purified DNA products $f(g D-f l g E-a a d A$ and $b b 0286-b b 0287$ serving as templates. The final $2836 \mathrm{flg} D$-flgE-aadA-bb0286-bb0287 base pair PCR product was gel purified and cloned into the pGEM-T Easy vector (Promega Inc.) to yield the fliK:aadA-pGEM plasmid. The integrity of the fliK inactivation plasmid was confirmed by PCR and restriction mapping. A PCR-amplified linear DNA product containing the fliK inactivation region was electroporated into B31A competent cells [20]. The electroporated cells were spread on semisolid BSKII medium containing $80 \mu \mathrm{g} / \mathrm{ml}$ streptomycin. Resistant clones were picked and analyzed by PCR using primers P1-P6 to confirm deletion of flik. One clone, $\Delta$ flik1, was found to have the desired mutation and further characterized.

TABLE 2.1. Primers used to generate the $\Delta$ fliK mutant*

\begin{tabular}{|l|l|l|l|}
\hline Primer \# & Name & Direction & Sequence $\left(5^{\prime}-3^{\prime}\right)$ \\
\hline 1 & FliK KO F & Forward & agattacaagcaaaagtaac \\
\hline 2 & FliK-Str-KO-Part 2-F Reverse & ggtagtcggcaaataagaattttcttacgatgtagata \\
\hline 3 & FliK-Strep-R & Forward & catcgtaagaaaattcttatttgccgactaccttggtg \\
\hline 4 & FliK-Str-F & Reverse & tggagtagtgtgtatatgagggaagcggtgatcgccga \\
\hline 5 & FliK-Str-KO-Part 1-F Forward & \multicolumn{1}{c|}{ caccgcttccctcatatacacactactccaatgaact } \\
\hline 6 & FliK KO R2 & Reverse & tagaacctactttcgaaagctaagcg \\
\hline
\end{tabular}

*Underlined sequences indicate overlapping base pairs.

SDS-PAGE and western blot analysis. SDS-PAGE and immuoblotting were conducted using standard techniques $[11,27]$. Molecular weight markers were obtained from Bio-Rad (cat no. 161-0376). All samples except as noted were boiled in sample buffer for at least $5 \mathrm{~min}$. Samples were electrophoresed in $8 \%$ polyacrylamide gels, and silver stained with Protea Biosciences, Inc. silver staining kit or with Bio-rad Sypro protein gel stain. For western blotting, $1 \mu \mathrm{g}$ total protein (unless noted otherwise), as determined by the Bradford protein assay (Bio-Rad), was subjected to SDS-PAGE and transferred onto polyvinylidene difluoride (PVDF) membranes. Immunoblots were 
probed with rabbit polyclonal antibody directed against $B$. burgdorferi FlgE [11], and secondary horse radish peroxidase (HRP)-labeled polyclonal donkey anti-rabbit antibodies obtained from GE Healthcare. FlaB was detected using monoclonal antibody H9724 to B. burgdorferi FlaB as previously described $[7,28]$. An enhanced chemiluminescent detection system was used to assay for reactivity (Pierce). Relative amounts of FlgE were determined by densitometry. After film development, films were scanned, and relative band intensities were determined using Image Quant software (GE Healthcare Life Sciences).

PFs and polyhook isolation. The PF isolation method of Sal et al. [11] was modified to increase the yield of the FlgE HMWC and to purify polyhooks. One liter of late logarithmic phase wild-type or $\Delta$ flik 1 mutant cells at a density of $1.5 \times 10^{8}$ cells $/ \mathrm{ml}$ were divided into four $250 \mathrm{ml}$ portions. Cells from each portion were harvested by centrifugation $\left(8,000 \times \mathrm{g}, 20 \mathrm{~min}, 4^{\circ} \mathrm{C}\right)$, and the cell pellet was suspended in $28 \mathrm{ml}$ phosphate buffered saline (PBS) and centrifuged $\left(8,000 \times \mathrm{g}, 15 \mathrm{~min}, 4^{\circ} \mathrm{C}\right)$. After suspending each pellet in $30 \mathrm{ml} 0.15 \mathrm{M}$ Tris, $\mathrm{pH} 6.8$, the cells were centrifuged as indicated above, then suspended in $15 \mathrm{ml} 0.15 \mathrm{M}$ Tris, $\mathrm{pH}$ 6.8. The cell suspension was stirred for $10 \min \left(25^{\circ} \mathrm{C}\right)$, and Triton $\mathrm{X}-100$ was added ( $20 \%$ stock in sterile water) to a $2 \%$ final concentration. The cell suspension was stirred for $30-60$ min at $23^{\circ} \mathrm{C}$, or until the outer membranes were disrupted as observed by darkfield microscopy. Such spirochetes appeared thinner after treatment. Darkfield microscopy was carried out as previously described [29]. Mutanolysin (Sigma cat no M9901-50KU) was slowly added from a $200 \mu \mathrm{g} / \mathrm{ml}$ stock in $\mathrm{H}_{2} 0$ to $20 \mathrm{ug} / \mathrm{ml}$ final concentration and stirred $\left(2 \mathrm{hr} ., 23^{\circ} \mathrm{C}\right.$, 
followed by overnight, $4^{\circ} \mathrm{C}$ ). Cells were completely lysed at this stage as revealed by darkfield microscopy. $\mathrm{MgSO}_{4}$ was added to a final concentration of $1.7 \mathrm{mM}$ followed by stirring for $10 \mathrm{~min}$ at $23^{\circ} \mathrm{C}$. The suspension was centrifuged at $17,000 \mathrm{xg}$ for $15 \mathrm{~min}$ at $4^{\circ} \mathrm{C}$ to remove cell debris. The supernatant was carefully removed and $20 \%$ polyethylene glycol (PEG 8000) in $1 \mathrm{M} \mathrm{NaCl}$ was added to $2 \%$ final concentration and thoroughly mixed. After incubation on ice for $30 \mathrm{~min}$, the solution was centrifuged $\left(27,000 \mathrm{xg}, 30 \mathrm{~min}, 4^{\circ} \mathrm{C}\right)$, and the supernatant fluid was discarded. The PFs or polyhooks were resuspended in $0.1 \mathrm{M} \mathrm{KCl}, 0.5 \mathrm{M}$ sucrose, $0.1 \%$ Triton X-100, $50 \mathrm{mM}$ sodium bicarbonate, $\mathrm{pH} 11$ for 1 hour at $23^{\circ} \mathrm{C}$ [30], and the final products were recovered by centrifugation at $80,000 \times \mathrm{g}, 45 \mathrm{~min}, 4^{\circ} \mathrm{C}$. The isolated PFs or polyhooks were pooled, resuspended in a small volume of water $(\sim 1 \mathrm{ml})$, and stored at $4^{\circ} \mathrm{C}$ with $0.2 \%$ sodium azide.

Electron microscopy. Cryo-electron microscopy (Cryo-EM) was used to localize polyhooks within cells, and to test for the integrity of isolated PFs and polyhooks [9]. Briefly, samples were mixed with $15 \mathrm{~nm}$ gold clusters for size reference and adsorbed on fresh carbon grids. Grids containing samples were frozen rapidly and stored in liquid ethane at $-180^{\circ} \mathrm{C}$. Imaging was conducted at $300 \mathrm{kV}$ using a Polara G2 electron microscope (FEI company) connected to a 16 megapixel charged coupled device camera (Tvips GmbH, Germany). 
Mass spectrometry (MS) analysis. For mass spectrometry analysis (Protea Biosciences, Inc.), periplasmic or polyhook samples were subjected to SDS-PAGE, and the gels were silver- or Sypro-stained, followed by in-gel digestion with trypsin. Gel bands of interest were excised, washed with $150 \mathrm{mM}$ ammonium bicarbonate and acetonitrile, and lyophilized. The dried gel bands were treated with dithiothreitol and iodoacetamide followed by digestion with $12.5 \mathrm{ng} / \mu \mathrm{l}$ trypsin. The digested peptides were analyzed by LC-ESI MS using a QTrap5500 (AB Sciex Toronto, Canada). Peptides were separated at $35^{\circ} \mathrm{C}$ on a Kinetex $100 \times 2.1 \mathrm{~mm} \mathrm{C}{ }_{18}$ column on a Shimadzu LC20AD HPLC (Tokyo, Japan) using a 120-minute gradient. The mass range acquired $(\mathrm{m} / \mathrm{z})$ was 100-1000, and the three most intense multiply charged ions with ion intensities above 50,000 in each MS scan were subjected to MS/MS. The MS/MS data were searched for matches to protein databases using ABI Protein Pilot software 3.0. Only those peptides that were identified with $>95 \%$ confidence were considered.

\section{RESULTS AND DISCUSSION}

FlgE HMWC formation during different phases of growth. We first tested if the HMWC was synthesized at all phases of growth. Conceivably, cross-linking could occur in a specific growth phase analogous to, for example, Escherichia coli modifying its preformed unsaturated fatty acids by cyclopropanation primarily in stationary phase [31]. Furthermore, specific $\sigma^{S}$-dependent genes have been shown to be upregulated in B. burgdorferi in stationary phase and during growth under specific conditions [32-34]. Accordingly, samples were taken throughout the in vitro growth cycle of B. burgdorferi, 
the cells were lysed, and then tested for the HMWC by western blot (Figure 2.1 A, B). We found that the HMWC was present in all phases of growth. Trace amounts of the monomer were detected in all phases of growth. No differences were seen in the HMWC formation throughout the cycle compared to the monomer. These results suggest that FlgE HMWC formation is not growth phase dependent.
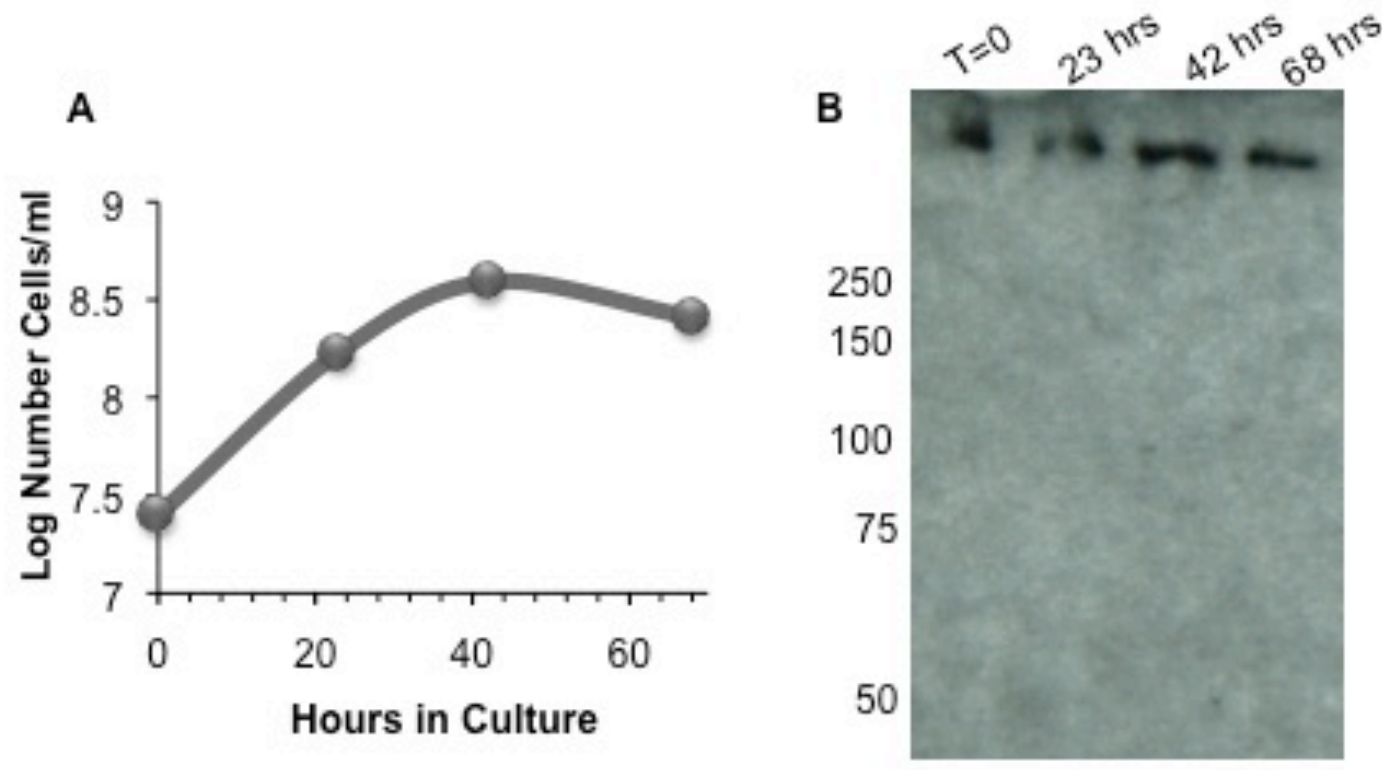

Figure 2.1. Synthesis of the HMWC under different phases of growth at $33^{\circ} \mathrm{C}$. (A) Growth curve of $B$. burgdorferi B31A and (B) accompanying immunoblots of whole cell lysates probed with anti-FlgE, with samples taken at designated time points.

FIgE HMWC formation at different temperatures and growth in vivo. Both the tick and mammal are the main habitats of $B$. burgdorferi in nature [34-36], and protein expression markedly varies in these two hosts. $[34,36]$. In addition, many of the genes 
that are encoded by the 21 circular and linear plasmids present in B. burgdorferi are differentially expressed in the tick and mammal [35]. We tested whether HMWC formation occurred under conditions that mimic growth in the tick $\left(23^{\circ} \mathrm{C}\right)$ and the mammal $\left(37^{\circ} \mathrm{C}\right)$. In these experiments, we used a strain of $B$. burgdorferi which was virulent (B31M1), as such strains, in contrast to avirulent strains, show major differences in protein profiles when cultured under these two temperatures [37]. We found that the $\mathrm{B} 31 \mathrm{MI}$ strain grown in vitro at $23^{\circ} \mathrm{C}$ and at $37^{\circ} \mathrm{C}$ formed the HMWC (Fig. 2.2). Similar results were found with cloned virulent strain B31A3 (K. Miller and N. Charon, not shown). These results indicate that the HMWC was synthesized under conditions that mimic growth in the tick and mammal. In addition, the results also indicate that the change in the protein profile that accompanies growth under these two conditions does not influence HMWC formation. We also asked if HMWC formation was a result of in vitro growth. B. burgdorferi cells grown in vivo are known to markedly change their transcriptional and protein profile compared to cells grown in vitro [24,34-36]; conceivably, the HMWC may not form in the mammal. Accordingly, we tested if the HMWC is synthesized in vivo by implanting B31Ml cells in DMC chambers in rats [24]. The cells were harvested at 14 days, centrifuged, and analyzed as before using immunoblotting. We found that the FlgE HMWC was present in cells grown in vivo in the DMCs similar to cells grown in vitro (Fig. 2.2). In sum, the FlgE HMWC was synthesized in B. burgdorferi in all in vitro growth conditions tested and also in vivo. 


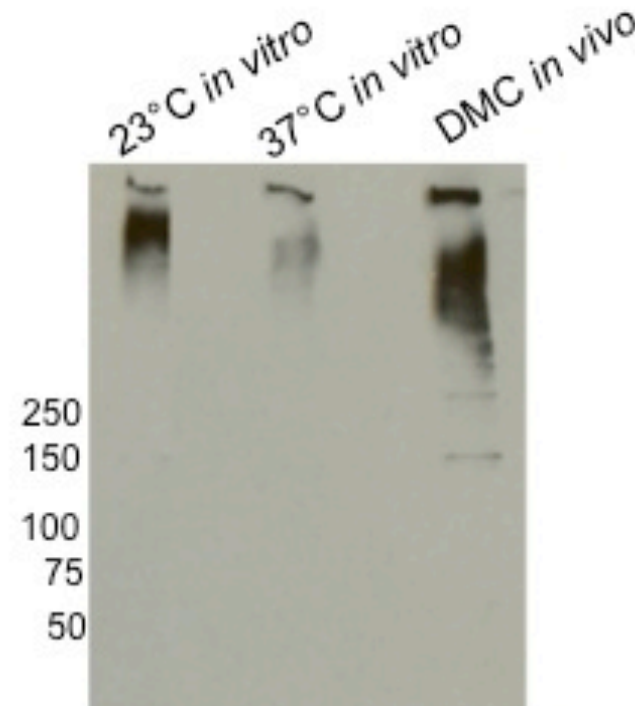

Figure 2.2. Synthesis of the HMWC under different growth conditions. Immunoblots probed with anti-FlgE of strain B31MI grown at designated temperatures in vitro, and in vivo in DMCs in rats.

Optimization of PFs and FlgE isolation. We began characterization of the HMWC. In our initial studies of $B$. burgdorferi FlgE, we used a method of lysing cells with myristate followed by lysozyme to purify PFs [11]. We found that this method was inadequate for chemical analysis of the HMWC (the yield was less than $1 \mu \mathrm{g}$, which is estimated to be less than $10 \%$ of the total FlgE protein in a liter of cells). Several modifications were made for optimization. These included substituting Triton X-100 for myristate, and mutanolysin for lysozyme. Triton X-100 has been shown to successfully remove the outer membranes of several spirochete species, including T. phagedenis [38], T. pallidum [39], T. denticola [40], and B. burgdorferi [41]. Although mutanolysin and lysozyme both hydrolyze the $\beta$-N-acetylmuramyl- $(1 \rightarrow 4)-N$-acetylglucosamine linkage of the bacterial cell wall polymer peptidoglycan-polysaccharide, their activities are differentially effected by peptidoglycan modifications. Specifically, $\mathrm{N}$ - and O-acetylation inhibit lysozyme activity in a concentration dependent manner; however, mutanolysin maintains its effectiveness in the presence of these modifications [42-46]. We found that these changes increased the yield of the HMWC greater than three-fold (Fig. 2.3). We 
also found that isolated PFs were often contaminated with lipid material as seen in cryoEM. Using an alkaline wash as done for S. enterica flagella [30], isolated PFs were free of the lipid contaminating material (Fig. 2.4 A,B). The total yield of PFs from a liter of cells varied from 2-4 mg.

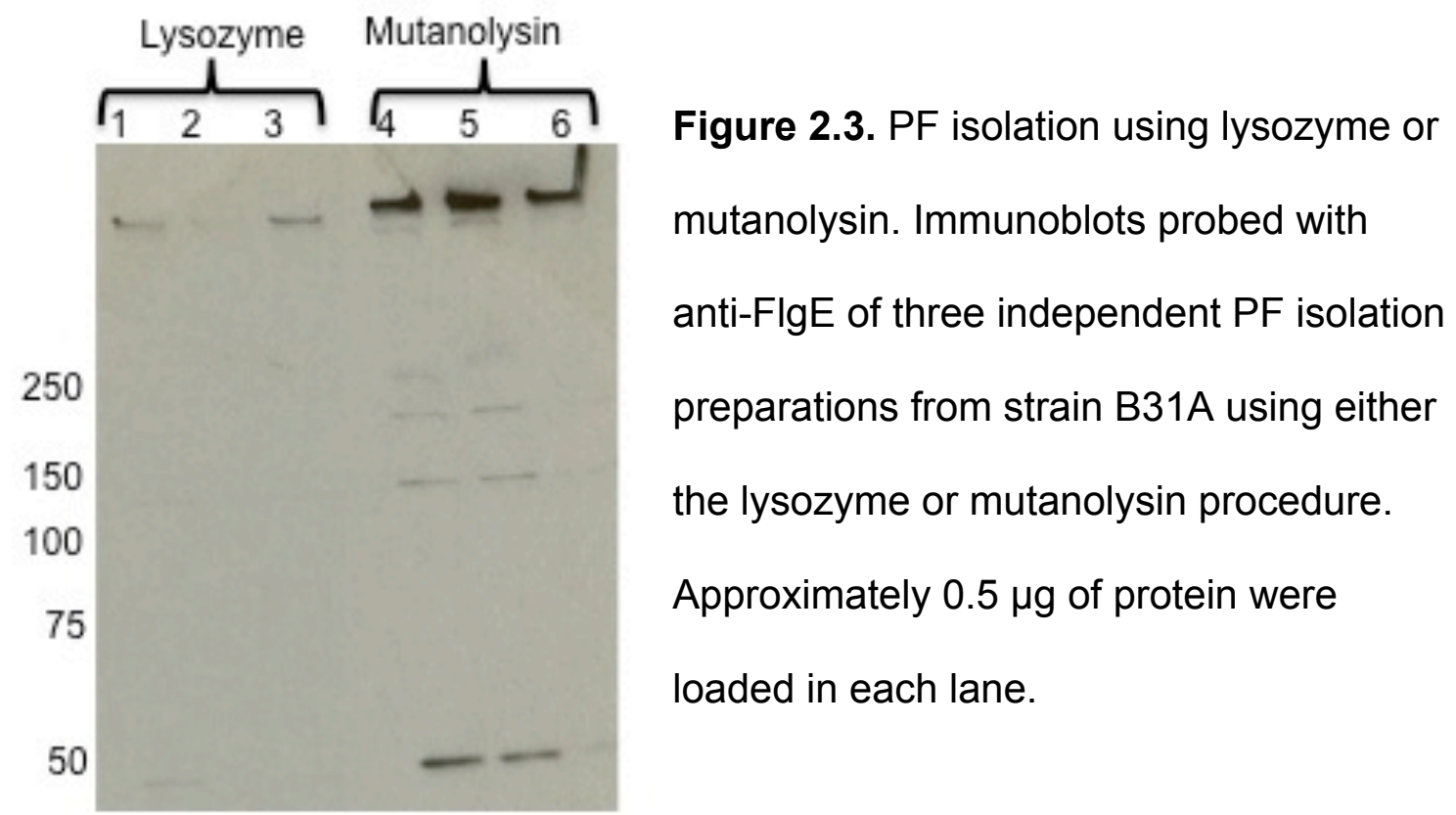



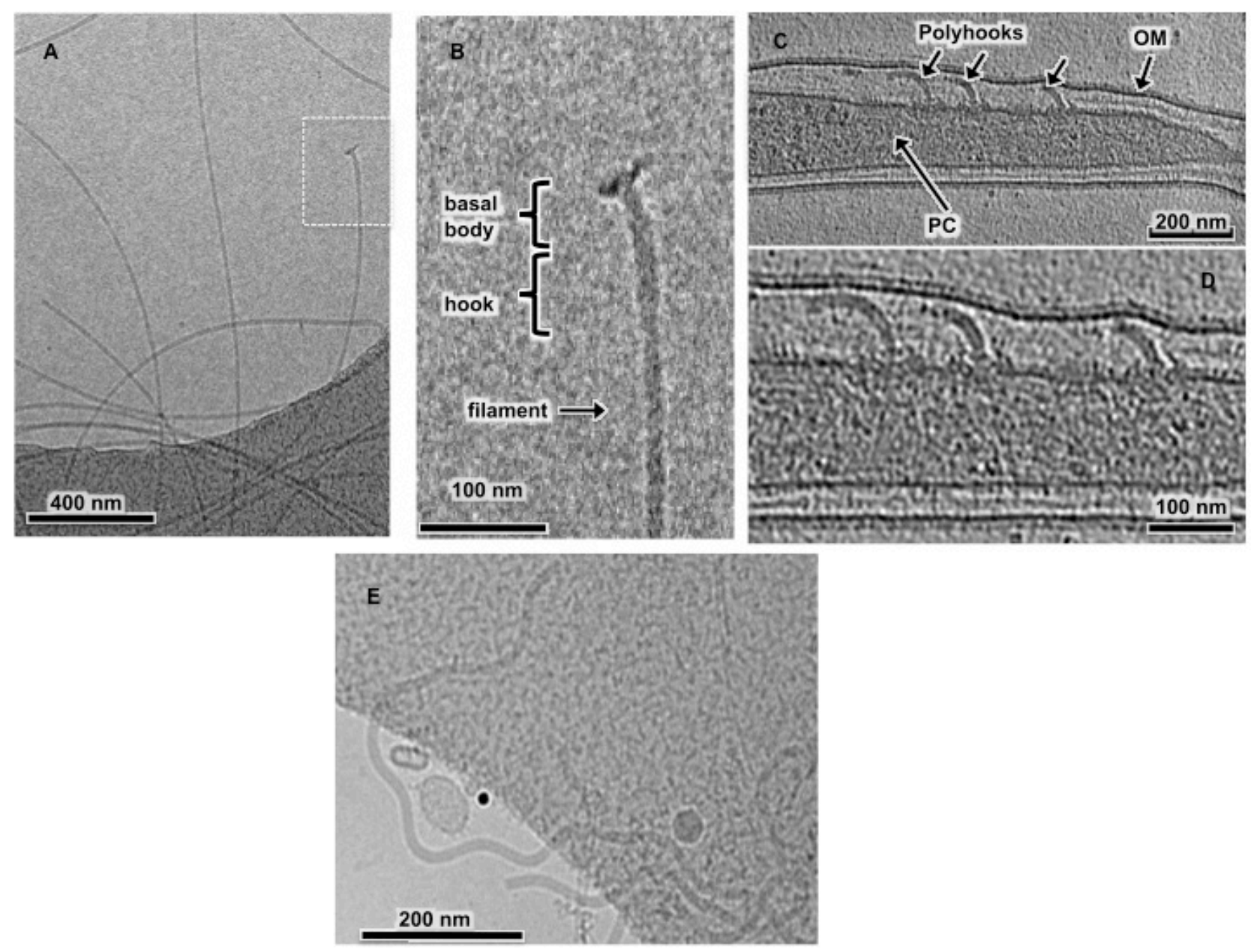

Figure 2.4. Cryo-EM image of PFs, $\triangle$ fliK mutant, and polyhooks. (A) PFs isolated from wild-type B.burgdorferi B31A. (B) The hook basal body structure that is boxed in A is enlarged in B and accompanying structures identified. (C, D) The $\Delta$ flik mutant with three flagellar polyhooks (50 - $150 \mathrm{~nm}$ in length) localized in the periplasmic space between the outer membrane (OM) and protoplasmic cell cylinder (PC). (D) an enlargement of (C). (E) Polyhooks isolated from the $\Delta f l i K$ mutant using the mutanolysin procedure.

To begin characterization of the HMWC, we purified PFs, and subjected the fraction obtained to formic acid treatment. Stability to formic acid is the hallmark method used to show protein crosslinking of Gram positive pili [19]. As can be seen in 
figure $2.5 \mathrm{~A}$, boiling for 15 minutes with or without $88 \%$ formic acid failed to disrupt the HMWC. Additionally, the FlgE HMWC was observed when the samples were treated with formic acid without boiling, indicating that the HMWC is not an artifact produced by boiling (Fig. 2.5 A). These results support the conclusion that the HMWC is the result of covalent protein-protein cross-linking.

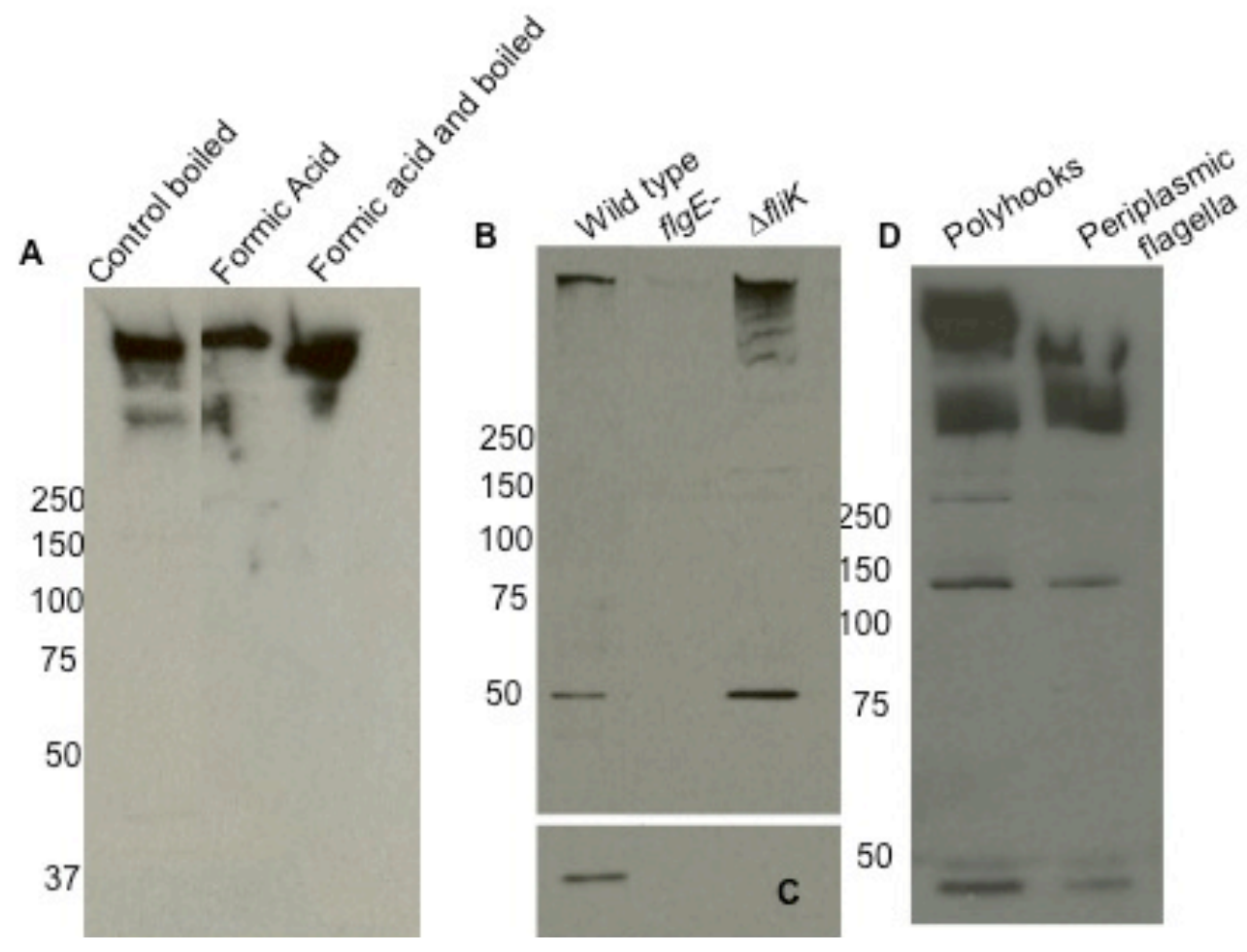

Figure 2.5. Immunoblot analysis of PFs and $\Delta$ fliK mutant. (A) Isolated PFs were treated with formic acid for $2 \mathrm{hrs}$ at room temperature (lane 2 ) or $100^{\circ} \mathrm{C}$ for 15 minutes (lane 3). After formic acid treatment, sample buffer was added and the gel was loaded without additional boiling. The control was boiled for $15 \mathrm{~min} .1 \mu \mathrm{g}$ protein was loaded per lane, and the blot was probed with FlgE antisera. (B) Whole cell lysates $(1.0 \mu \mathrm{g})$ of wild-type and mutants probed with FlgE and (C) FlaB antisera. Reactivity was at $42 \mathrm{kDa}$ with anti-FlaB. (D) Isolated polyhooks and PFs probed with FlgE antiserum. 
Analysis of a fliK mutant. The characterization of the spirochete FlgE HMWC has been limited because FlgE is normally in limiting amounts. Therefore, we considered the possibility that polyhooks obtained from $B$. burgdorferi would be a rich source of the HMWC. Although flik mutants in other bacteria including S. enterica $[47,48]$ and $T$. denticola [13] produce large polyhook structures, we did not know if a similar mutant in B. burgdorferi would also produce polyhooks. In addition, we were curious if the polyhooks that are synthesized by the mutant would form FlgE HMWCs. Accordingly, we constructed a non-polar $\Delta$ flik1 mutant of $B$. burgdorferi by allelic exchange mutagenesis. The $\triangle$ flik1 mutant was non-motile and cryo-EM indicated long polyhook structures that were produced and localized to the periplasmic space (Fig 2.4 C, D); furthermore, flagellar filaments did not appear to be attached to the polyhooks (Fig. 2.4 $C, D)$ These results suggest that the $\Delta$ flik mutant of $B$. burgdorferi is similar to those found in other bacteria, except in this case, the polyhooks are located in the periplasmic space rather than externally in the medium.

The $\Delta$ flik mutant was further analyzed. Western blot analysis of whole cell lysates indicated that whereas a previously described flgE mutant failed to react with the polyclonal antiserum as expected [11], most of the reactivity of both the wild-type and the $\triangle$ flik mutant formed a HMWC near the top of the gel, greater than $250 \mathrm{kDa}$ (Fig 2.5 B). Small amounts of the monomer were detected in the mutant, as with the wild-type. Based on densitometry analysis, we estimate that the $\Delta f l i K 1$ mutant produces $4-5$ times the HMWC per cell compared to wild-type. We also tested if the $\triangle f l i K 1$ mutant produced flagellin by probing cell lysates with FlaB antiserum. In other species of bacteria, flik mutants vary in their ability to continue to synthesize flagellin [49-52]. Although strong 
reactivity was noted with the wild-type, no reactivity was noted in the mutant (Fig. 2.5 C), consistent with cryo-EM images (Fig. 2.4 C, D). These results are similar to those of S. enterica flik mutant cells, as such mutants fail to produce flagella filaments [53,54]. We purified the polyhooks from the $\Delta$ flik1 mutant for further immunoblot and cryo-EM analysis. Similar to results with whole cell lysates, FlgE antibody reactivity remained at the HMWC, with some reactivity with the monomer and at approximately 270 and 150 kDa (Fig. 2.5 D). This pattern was similar to that seen with isolated wild-type PFs. CryoEM of this fraction identified large polyhook structures $(>200 \mathrm{~nm}, \mathrm{n}=15)$ similar to those found in other bacteria [13,54] (Fig. $2.4 \mathrm{E}$ ) with a diameter of $16 \mathrm{~nm}$. The $\Delta$ fliK1 mutant yielded 1-2 mg protein per liter in the isolated polyhook fraction, indicating that it would be an excellent source of the HMWC.

Finding polyhooks produced by this mutant is intriguing for several reasons. In bacteria, the length of the hook is tightly controlled. In the model system of S. enterica, interactions of FliK with FlhB determine hook length [47,49,54-57]. FliK acts as a molecular ruler that is secreted into the medium, and when the hook reaches proper length, FlhB is cleaved, and FlgE ceases to be added to the end of the forming hook. The cell then begins $\sigma^{28}$-initiated transcription, and synthesis of the filament protein FliC then commences with concomitant secretion to the growing flagellum [57]. $B$. burgdorferi does have a FlhB homolog (bb0272), so it is likely that a similar mechanism exists. However, because the PFs reside in the periplasmic space, if the $S$. enterica model applies to $B$. burgdorferi, FliK would be excreted into this space rather than into the medium as occurs in $S$. enterica. Furthermore, $B$. burgdorferi is unique, as it lacks the transcription cascade control of flagella gene regulation $[2,3,11,58,59]$. It lacks, for 
example, both the $\sigma^{28}$ transcription factor and the corresponding promoter recognition sequences $[2,3,23]$. Several lines of evidence indicate that $B$. burgdorferi relies instead on translational control for flagella synthesis $[11,58,59]$. Conceivably, perhaps there is a translational control switch that allows flaB to be translated once the proper hook length is formed. In support of this notion, because the $\Delta f l i K 1$ mutant is unable to stop synthesis of the hook once it reaches its proper length, we find that the resulting mutant also lacks FlaB (Fig. 2.5 C).

MS of the HMWC. The revised PF and polyhook purification procedure allowed us to obtain sufficient material for MS analysis of the HMWC. We wanted to determine if other proteins were associated with this complex. We also wanted to determine if formation of the crosslinked HMWC resulted in truncation of either end of FlgE protein, analogous to the sortase-catalyzed reaction in gram-positive pili [60]. The protein composition of the HMWCs obtained from PFs and polyhooks was assessed directly by in-gel trypsin digestion followed by MS analysis (Fig. 2.6). The MS pattern of one of the peptides is illustrated (Fig. 2.6 A). In 17 MS analyses of the HMWC, no other proteins were consistently identified in the HMWCs, and in many experiments, FlgE was the sole protein. For example, in one experiment with the HMWC obtained from PFs, 27 different peptides were identified, and all were derived from FlgE (Appendix Table 1). Similarly, in an experiment with the polyhook, 15 different peptides were identified, and again all were FlgE derived (Appendix Table 2). These results indicate that FlgE is the sole protein of the HMWC. We also asked if the $\mathrm{N}$ - and $\mathrm{C}$-terminal regions were present in the HMWC. As can be seen from Fig $2.6 \mathrm{~B}, 85 \%$ of the FlgE sequence was present in the complex, including peptides at the $\mathrm{N}$ - and $\mathrm{C}$-terminal regions. These results suggest 
that the HMWC is not a cross-linked product of truncated FlgE. Now that we can obtain sufficient material for MS analysis from both wild-type cells and from a $\Delta$ fliK mutant, we are actively determining which amino acids form the cross-link, and the precise mechanism of this cross-linking.

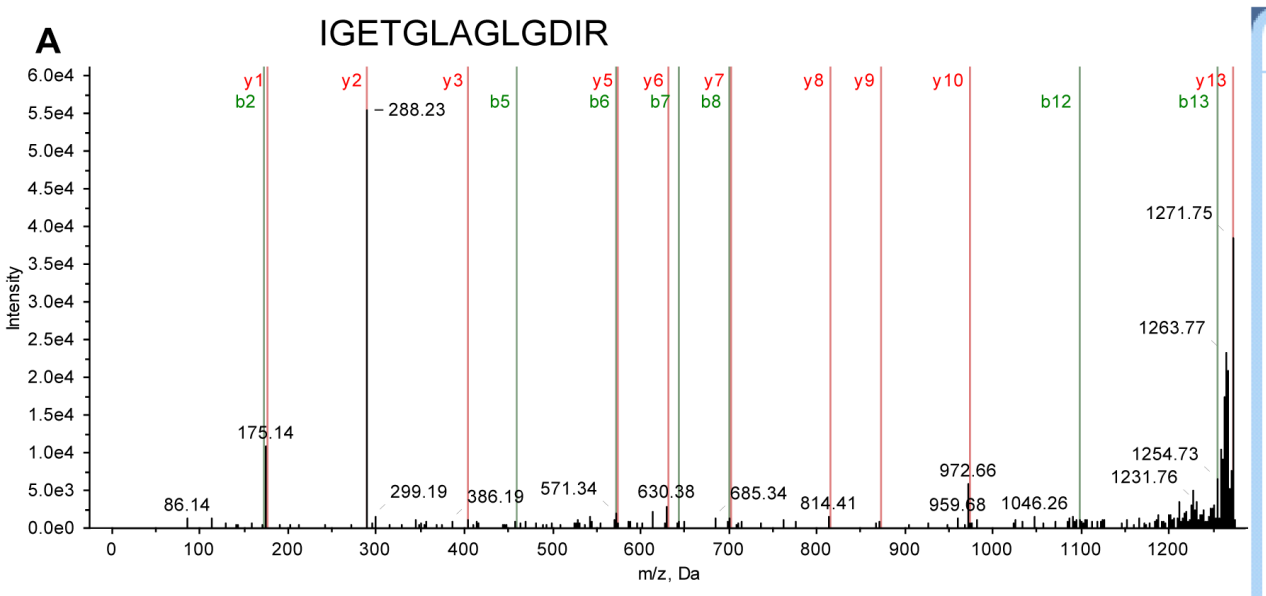

B
10
$2 \underline{0}$
$3 \underline{0}$
$4 \underline{0}$
$5 \underline{0}$
$6 \underline{0}$

MMR* SLYSGVS GLONHOTR $*$ MD VVGNNIANVN TIGFK*K*GR*VN FQDMISOSIS GASRPTDAR $*$ G

Fragmentation Evidence

W IGETGLAGLGDIR

\begin{tabular}{|l|r|r|}
\hline Residue & \multicolumn{1}{c|}{ b } & \multicolumn{1}{c|}{$\mathbf{y}$} \\
\hline \hline & 114.0913 & 1271.6954 \\
\hline$G$ & 171.1128 & 1158.6113 \\
\hline E & 300.1554 & 1101.5899 \\
\hline$T$ & 401.2031 & 972.5473 \\
\hline$G$ & 458.2245 & 871.4996 \\
\hline$L$ & 571.3086 & 814.4781 \\
\hline A & 642.3457 & $\mathbf{7 0 1 . 3 9 4 1}$ \\
\hline$G$ & 699.3672 & 630.3570 \\
\hline$L$ & 812.4512 & 573.3355 \\
\hline$G$ & 869.4727 & 460.2514 \\
\hline$D$ & 984.4997 & 403.2300 \\
\hline L & $\mathbf{1 0 9 7 . 5 8 3 7}$ & 288.2030 \\
\hline$R$ & 1253.6848 & 175.1190 \\
\hline
\end{tabular}

GTNPK* QVGLG MNVASIDTIH TQGAFQSTQK ${ }^{*}$ ASDLGVSGNG FFILK*EGK* ${ }^{*}$ LLFTR ${ }^{*}$ AGAFDV

$$
\begin{array}{lllll}
13 \underline{0} & 14 \underline{0} & 15 \underline{0} & 16 \underline{0} & 17 \underline{0} \\
18 \underline{0}
\end{array}
$$

$\frac{\text { DSDR }}{*} \frac{\text { HLVNPA NGMR }}{190} \frac{\text { IQGWMA R* }}{200} \frac{\text { DLEGEK }}{2} \frac{\text { VIN TASDIEDLII PIGDK }}{20} \frac{\text { EGAK }}{230}$ TK* $\frac{\text { NVTFACNL }}{240}$

DK* ${ }^{*}{ }^{*}$ LPLIOEG ANPADIAR*GT WVVNK* SLYDS FGNVSVLELR* ${ }^{*}$ VVK ${ }^{*}$ DLNTPNL WNATVLINGE

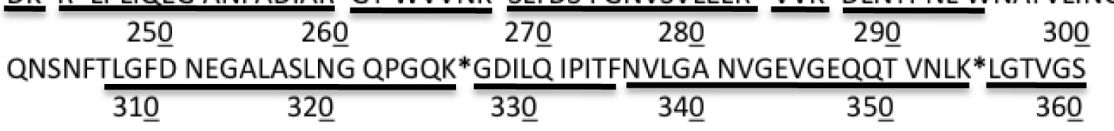

YTDSITOFAD SSSTK*AIIQD GYGMGYMENY EIDQNGVIVG IYSNGIR*R*DL GK*IALASFMN

$$
\begin{array}{llllll}
37 \underline{0} & 38 \underline{0} & 39 \underline{0} & 40 \underline{0} & 41 \underline{0} & 42 \underline{0}
\end{array}
$$

PGGLAK*SGDT NFVETSNSGQ VR $*$ IGETGLAG LGDIR*SGVLE MANVDLAEQF TDMIVTQR*GF $43 \underline{0} \quad 44 \underline{0}$

QANAK*TITTS DQLLQELVR*L K*N

Figure 2.6. MS analysis of the HMWCs isolated from PFs and polyhooks. The HMWCs were excised, trypsin-digested and analyzed by MS. (A) MS/MS peaks for one of the identified peptides and accompanying fragmentation evidence (aa 383-395). (B) Peptides identified on the FlgE sequence obtained by MS analysis of the HMWC are underlined. * indicate trypsin cut sites. 
Why would cross-linking occur in the flagellar hooks of spirochetes, but not in the hooks of bacteria with external flagella? Cross-linking of proteins in bacteria is rare, and when present it results in strengthening protein-protein interactions [61]. The hook acts as a universal joint, transferring the rotational motion of flagella motors to flagella filaments. In bacteria with external flagella this is easily accomplished, as the flagella freely rotate freely in the external environment. However, in spirochetes, the region in which the flagella reside and rotate is confined to the periplasmic space. $\ln B$. burgdorferi, the rigid PFs function as a cytoskeleton by pushing against the flexible cell cylinder to generate these waves $[2,4]$. We hypothesize that spirochete FlgE crosslinking is essential for the additional strength the hook requires to rotate the filaments and exert force against the cell cylinder to generate the waves responsible for motility.

\section{References}

1. Paster BJ (2001) Phylum XV. Spirochetes Garrity and Holt. In: Garrity G, editor. Bergey's Manual of Systematic Bacteriology. 2 ed. New York, New York.: Springer. pp. 471-566.

2. Charon NW, Cockburn A, Li C, Liu J, Miller KA, et al. (2012) The unique paradigm of spirochete motility and chemotaxis. Annu Rev Microbiol 66: 349-370.

3. Charon NW, Goldstein SF (2002) Genetics of motility and chemotaxis of a fascinating group of bacteria: the spirochetes. Annu Rev Genet 36: 47-73.

4. Vig DK, Wolgemuth CW (2012) Swimming dynamics of the lyme disease spirochete. Phys Rev Lett 109: 218104.

5. Li C, Sal M, Marko M, Charon NW (2010) Differential regulation of the multiple flagellins in spirochetes. J Bacteriol 192: 2596-2603. 
6. Li C, Wolgemuth CW, Marko M, Morgan DG, Charon NW (2008) Genetic analysis of spirochete flagellin proteins and their involvement in motility, filament assembly, and flagellar morphology. J Bacteriol 190: 5607-5615.

7. Motaleb MA, Corum L, Bono JL, Elias AF, Rosa P, et al. (2000) Borrelia burgdorferi periplasmic flagella have both skeletal and motility functions. Proc Natl Acad Sci U S A 97: 10899-10904.

8. Sultan SZ, Manne A, Stewart PE, Bestor A, Rosa PA, et al. (2013) Motility is crucial for the infectious life cycle of Borrelia burgdorferi. Infect Immun 81: 2012-2021. 9. Liu J, Lin T, Botkin DJ, McCrum E, Winkler H, et al. (2009) Intact flagellar motor of Borrelia burgdorferi revealed by cryo-electron tomography: evidence for stator ring curvature and rotor/C-ring assembly flexion. J Bacteriol 191: 5026-5036.

10. Murphy GE, Leadbetter JR, Jensen GJ (2006) In situ structure of the complete Treponema primitia flagellar motor. Nature 442: 1062-1064.

11. Sal MS, Li C, Motalab MA, Shibata S, Aizawa S, et al. (2008) Borrelia burgdorferi uniquely regulates its motility genes and has an intricate flagellar hook-basal body structure. J Bacteriol 190: 1912-1921.

12. Limberger RJ, Slivienski LL, El-Afandi MC, Dantuono LA (1996) Organization, transcription, and expression of the $5^{\prime}$ region of the fla operon of Treponema phagedenis and Treponema pallidum. J Bacteriol 178: 4628-4634.

13. Limberger RJ, Slivienski LL, Izard J, Samsonoff WA (1999) Insertional inactivation of Treponema denticola tap1 results in a nonmotile mutant with elongated flagellar hooks. J Bacteriol 181: 3743-3750. 
14. Limberger RJ, Slivienski LL, Samsonoff WA (1994) Genetic and biochemical analysis of the flagellar hook of Treponema phagedenis. J Bacteriol 176: 36313637.

15. Chi B, Limberger RJ, Kuramitsu HK (2002) Complementation of a Treponema denticola flgE mutant with a novel coumermycin A1-resistant $\mathrm{T}$. denticola shuttle vector system. Infect Immun 70: 2233-2237.

16. Bonifield HR, Yamaguchi S, Hughes KT (2000) The flagellar hook protein, FlgE, of Salmonella enterica serovar typhimurium is posttranscriptionally regulated in response to the stage of flagellar assembly. J Bacteriol 182: 4044-4050.

17. Dimmitt K, Simon MI (1971) Purification and partial characterization of Bacillus subtilis Flagellar hooks. J Bacteriol 108: 282-286.

18. Popa MP, McKelvey TA, Hempel J, Hendrix RW (1991) Bacteriophage HK97 structure: wholesale covalent cross-linking between the major head shell subunits. J Virol 65: 3227-3237.

19. Ton-That $\mathrm{H}$, Schneewind $\mathrm{O}$ (2003) Assembly of pili on the surface of Corynebacterium diphtheriae. Mol Microbiol 50: 1429-1438.

20. Bono JL, Elias AF, Kupko JJ, 3rd, Stevenson B, Tilly K, et al. (2000) Efficient targeted mutagenesis in Borrelia burgdorferi. J Bacteriol 182: 2445-2452.

21. Elias AF, Stewart PE, Grimm D, Caimano MJ, Eggers CH, et al. (2002) Clonal polymorphism of Borrelia burgdorferi strain B31 MI: implications for mutagenesis in an infectious strain background. Infect Immun 70: 2139-2150.

22. Bakker RG, Li C, Miller MR, Cunningham C, Charon NW (2007) Identification of specific chemoattractants and genetic complementation of a Borrelia burgdorferi 
chemotaxis mutant: flow cytometry-based capillary tube chemotaxis assay. Appl Environ Microbiol 73: 1180-1188.

23. Fraser CM, Casjens S, Huang WM, Sutton GG, Clayton R, et al. (1997) Genomic sequence of a Lyme disease spirochaete, Borrelia burgdorferi. Nature 390: 580586.

24. Akins DR, Bourell KW, Caimano MJ, Norgard MV, Radolf JD (1998) A new animal model for studying Lyme disease spirochetes in a mammalian host-adapted state. J Clin Invest 101: 2240-2250.

25. Ge Y, Old IG, Saint Girons I, Charon NW (1997) Molecular characterization of a large Borrelia burgdorferi motility operon which is initiated by a consensus sigma70 promoter. J Bacteriol 179: 2289-2299.

26. Motaleb MA, Pitzer JE, Sultan SZ, Liu J (2011) A novel gene inactivation system reveals altered periplasmic flagellar orientation in a Borrelia burgdorferi fliL mutant. J Bacteriol 193: 3324-3331.

27. Laemmli UK (1970) Cleavage of structural proteins during the assembly of the head of bacteriophage T4. Nature 227: 680-685.

28. Barbour AG, Hayes SF, Heiland RA, Schrumpf ME, Tessier SL (1986) A Borreliaspecific monoclonal antibody binds to a flagellar epitope. Infect Immun 52: 549554.

29. Charon NW, Goldstein SF, Curci K, Limberger RJ (1991) The bent-end morphology of Treponema phagedenis is associated with short, left-handed, periplasmic flagella. J Bacteriol 173: 4820-4826. 
30. Aizawa SI, Dean GE, Jones CJ, Macnab RM, Yamaguchi S (1985) Purification and characterization of the flagellar hook-basal body complex of Salmonella typhimurium. J Bacteriol 161: 836-849.

31. Cronan JE, Jr. (2002) Phospholipid modifications in bacteria. Curr Opin Microbiol 5: 202-205.

32. Caimano MJ, Eggers CH, Hazlett KR, Radolf JD (2004) RpoS is not central to the general stress response in Borrelia burgdorferi but does control expression of one or more essential virulence determinants. Infect Immun 72: 6433-6445.

33. Yang X, Goldberg MS, Popova TG, Schoeler GB, Wikel SK, et al. (2000) Interdependence of environmental factors influencing reciprocal patterns of gene expression in virulent Borrelia burgdorferi. Mol Microbiol 37: 1470-1479.

34. Brooks CS, Hefty PS, Jolliff SE, Akins DR (2003) Global analysis of Borrelia burgdorferi genes regulated by mammalian host-specific signals. Infect Immun 71: $3371-3383$

35. Radolf JD, Caimano MJ, Stevenson B, Hu LT (2012) Of ticks, mice and men: understanding the dual-host lifestyle of Lyme disease spirochaetes. Nat Rev Microbiol 10: 87-99.

36. Caimano MJ (2005) Cultivation of Borrelia burgdorferi in dialysis membrane chambers in rat peritonea. Curr Protoc Microbiol Chapter 12: Unit 12C 13.

37. Lybecker MC, Samuels DS (2007) Temperature-induced regulation of RpoS by a small RNA in Borrelia burgdorferi. Mol Microbiol 64: 1075-1089.

38. Limberger RJ, Charon NW (1986) Treponema phagedenis has at least two proteins residing together on its periplasmic flagella. J Bacteriol 166: 105-112. 
39. Cockayne A, Bailey MJ, Penn CW (1987) Analysis of sheath and core structures of the axial filament of Treponema pallidum. J Gen Microbiol 133: 1397-1407.

40. Ruby JD, Li H, Kuramitsu H, Norris SJ, Goldstein SF, et al. (1997) Relationship of Treponema denticola periplasmic flagella to irregular cell morphology. J Bacteriol 179: $1628-1635$.

41. Ge Y, Li C, Corum L, Slaughter CA, Charon NW (1998) Structure and expression of the FlaA periplasmic flagellar protein of Borrelia burgdorferi. J Bacteriol 180: 2418-2425.

42. Pfeffer JM, Strating H, Weadge JT, Clarke AJ (2006) Peptidoglycan O acetylation and autolysin profile of Enterococcus faecalis in the viable but nonculturable state. J Bacteriol 188: 902-908.

43. Dupont C, Clarke AJ (1991) Dependence of lysozyme-catalysed solubilization of Proteus mirabilis peptidoglycan on the extent of O-acetylation. Eur J Biochem 195: 763-769.

44. Swim SC, Gfell MA, Wilde CE, 3rd, Rosenthal RS (1983) Strain distribution in extents of lysozyme resistance and O-acetylation of gonococcal peptidoglycan determined by high-performance liquid chromatography. Infect Immun 42: 446452.

45. Laaberki MH, Pfeffer J, Clarke AJ, Dworkin J (2011) O-Acetylation of peptidoglycan is required for proper cell separation and S-layer anchoring in Bacillus anthracis. J Biol Chem 286: 5278-5288. 
46. Bernard E, Rolain T, Courtin P, Guillot A, Langella P, et al. (2011) Characterization of O-acetylation of $\mathrm{N}$-acetylglucosamine: a novel structural variation of bacterial peptidoglycan. J Biol Chem 286: 23950-23958.

47. Chevance FF, Hughes KT (2008) Coordinating assembly of a bacterial macromolecular machine. Nat Rev Microbiol 6: 455-465.

48. Muramoto K, Makishima S, Aizawa SI, Macnab RM (1998) Effect of cellular level of FliK on flagellar hook and filament assembly in Salmonella typhimurium. J Mol Biol 277: 871-882.

49. Erhardt M, Hirano T, Su Y, Paul K, Wee DH, et al. (2010) The role of the FliK molecular ruler in hook-length control in Salmonella enterica. Mol Microbiol 75: $1272-1284$

50. Kamal N, Dorrell N, Jagannathan A, Turner SM, Constantinidou C, et al. (2007) Deletion of a previously uncharacterized flagellar-hook-length control gene flik modulates the sigma54-dependent regulon in Campylobacter jejuni. Microbiology 153: 3099-3111.

51. Ryan KA, Karim N, Worku M, Penn CW, O'Toole PW (2005) Helicobacter pylori flagellar hook-filament transition is controlled by a FliK functional homolog encoded by the gene HP0906. J Bacteriol 187: 5742-5750.

52. West MA, Dreyfus G (1997) Isolation and ultrastructural study of the flagellar basal body complex from Rhodobacter sphaeroides WS8 (wild type) and a polyhook mutant PG. Biochem Biophys Res Commun 238: 733-737. 
53. Williams AW, Yamaguchi S, Togashi F, Aizawa SI, Kawagishi I, et al. (1996) Mutations in fliK and flhB affecting flagellar hook and filament assembly in Salmonella typhimurium. J Bacteriol 178: 2960-2970.

54. Hirano T, Yamaguchi S, Oosawa K, Aizawa S (1994) Roles of FliK and FlhB in determination of flagellar hook length in Salmonella typhimurium. J Bacteriol 176: 5439-5449.

55. Minamino T, Moriya N, Hirano T, Hughes KT, Namba K (2009) Interaction of FliK with the bacterial flagellar hook is required for efficient export specificity switching. Mol Microbiol 74: 239-251.

56. Morris DP, Roush ED, Thompson JW, Moseley MA, Murphy JW, et al. (2010) Kinetic characterization of Salmonella FliK-FlhB interactions demonstrates complexity of the Type III secretion substrate-specificity switch. Biochemistry 49: 6386-6393.

57. Erhardt M, Singer HM, Wee DH, Keener JP, Hughes KT (2011) An infrequent molecular ruler controls flagellar hook length in Salmonella enterica. EMBO J 30: 2948-2961.

58. Motaleb MA, Sal MS, Charon NW (2004) The decrease in FlaA observed in a flaB mutant of Borrelia burgdorferi occurs posttranscriptionally. J Bacteriol 186: 37033711.

59. Sze CW, Morado DR, Liu J, Charon NW, Xu H, et al. (2011) Carbon storage regulator $\mathrm{A}(\mathrm{Csr} \mathrm{A}(\mathrm{Bb}))$ is a repressor of Borrelia burgdorferi flagellin protein FlaB. Mol Microbiol 82: 851-864. 
60. Hendrickx AP, Budzik JM, Oh SY, Schneewind O (2011) Architects at the bacterial surface - sortases and the assembly of pili with isopeptide bonds. Nat Rev Microbiol 9: 166-176.

61. Kang HJ, Coulibaly F, Clow F, Proft T, Baker EN (2007) Stabilizing isopeptide bonds revealed in gram-positive bacterial pilus structure. Science 318: 1625-1628. 
Chapter 3: The biochemistry of the Treponema denticola FlgE high molecular weight complex

Kelly Ann Miller ${ }^{1}$, Chunhau Li ${ }^{2}$, Milinda James ${ }^{1}$, Justin Hettick ${ }^{3}$, Michael R. Miller ${ }^{4}$, and Nyles W. Charon ${ }^{1}$

${ }^{1}$ Department of Microbiology, Immunology, and Cell Biology Robert C. Byrd Health Sciences Center, West Virginia University, Morgantown, WV, 26506

${ }^{2}$ Department of Oral Biology, State University of New York, Buffalo, NY 14214

${ }^{3}$ National Institute of Occupational Safety and Health, Health Effects Laboratory

Division, Morgantown, WV 26505

${ }^{4}$ Department of Biochemistry, Robert C. Byrd Health Sciences Center, West Virginia University, Morgantown, WV, 26506 


\begin{abstract}
The structure of the spirochete periplasmic flagellum is unique when compared to the externally located flagellum of other bacteria. One unusual characteristic is the flagellar hook, which serves as a universal joint coupling rotation of the membrane bound motor complex to the flagellar filament. The hook is comprised of approximately $120 \mathrm{FlgE}$ monomers, and in most bacteria these structures readily disassociate to monomers when treated with heat and detergent. However, in spirochetes the FlgE monomers form a large mass of over $250 \mathrm{kDa}$ (referred to as the high molecular weight complex (HMWC)) that is stable to these conditions. In this communication, we show that under certain conditions Treponema denticola FlgE over-expressed in Escherichia coli and purified ( $\mathrm{rFlgE}$ ) forms a similar HMWC in vitro, that this complex is stable to a variety of denaturants, that the mass spectrometry (MS) patterns for HMWC's from rFIgE and polyhooks are similar, and that in specific regions the MS patterns are different for the monomer and HMWC. Preliminary fragmentation of the HMWC unique mass identified one of the peptides involved in cross-linking. We examine the biochemical kinetics of and the effect of specific point mutations on in vitro cross-linking. Finally, we propose a mechanism that is consistent with the MS, biochemical, and mutational analyses. We hypothesize that FlgE cross-linking strengthens the hook structure for optimal spirochete motility.
\end{abstract}




\section{Introduction}

Treponema denticola resides in the oral cavity, and these anaerobic spirochetes are associated with poor dental health. Examples of dental problems include gingivitis, chronic peritonitis, and acute necrotizing ulcerative gingivitis (1-3). There is a positive correlation between the number of oral spirochetes (including $T$. denticola) located in the mouth and the severity of periodontal disease (4-11). T. denticola associates with both host cells and other bacteria (forming a biofilm) in order to cause disease (12-14). T. denticola, Porphyromonas gingivalis, and Tannerella forsythia form the periodontal "red complex"; there is a strong association between periodontal disease and the presence of these three organisms $(15,16)$.

T. denticola, like other spirochetes, uses periplasmic flagella as its means of motility $(17,18)$. Each periplasmic flagellum consists of three major parts: the basal body motor complex, hook, and the filament $(17,19)$. The hook is composed of $\sim 120$ copies of FlgE protein, and it functions as a universal joint that transmits torque from the basal body motor to the filament (20-22). Additionally, the hook serves a checkpoint in the regulation of flagellar assembly. Proper hook length is required for flagellar secretion to switch from early (hook/rod) to late (filament) substrates. For Salmonella enterica serovar Typhimirium, the proteins FliK and FlhB are involved in hook length determination; mutants in either of these genes produce polyhooks that are much longer than wild-type hooks and consequently lack flagellar filaments (23-26).

Multiple reports have suggested that the flagellar hook proteins (FlgE) of spirochetes form a stable high molecular weight complex (HMWC). Western blots of whole cell lysates of the spirochetes Borrelia burgdorferi, T. denticola, Treponema 
pallidum, and Treponema phagedenis probed with a polyclonal FlgE antibody showed reactivity at a HMWC (27-30). These results are different from what is observed in bacteria with external flagella, where western blots probed with FlgE antibody show reactivity exclusively at the molecular weight of monomeric FlgE ( 45-50 kDa) $(31,32)$. Previously, we have shown that the B. burgdorferi HMWC is composed solely of FlgE by mass spectrometry (Miller et al, submitted).

We hypothesize that the FlgE HMWC of $T$. denticola and other spirochetes is attributed to covalently cross-linking FlgE proteins to each other, and that this crosslinking is necessary for optimal motility and virulence. In this paper, we show that under certain conditions $T$. denticola FlgE over-expressed in Escherichia coli and purified (rFlgE) forms a HMWC in vitro, and that this complex is stable to a variety of denaturants. We also show that the mass spectrometry (MS) patterns for HMWC's from $\mathrm{rFlgE}$ and native hooks are similar, and that in specific regions the MS patterns are different for the monomer and HMWC. We examine the biochemical kinetics of and the effect of specific point mutations on in vitro cross-linking. Finally, we propose a mechanism that is consistent with the MS, biochemical, and mutational analyses.

\section{Materials and Methods}

Bacterial strains and growth conditions. T. denticola strain 35405 wild-type, which was originally obtained from ATCC, and the 35405 derived tap1 mutant (33), which was constructed by Yu Yang and Dr. C. Li, University of Buffalo, were grown at $33^{\circ} \mathrm{C}$ in a Coy anaerobic chamber that contained an internal atmosphere of $80 \%$ nitrogen, $10 \%$ carbon dioxide, $10 \%$ hydrogen (18). Cells were grown in NOS media as described 
previously (34). The tap $1^{-}$insertion mutant (33) and the flgE insertion mutant (35) were grown in NOS containing $50 \mu \mathrm{g} / \mathrm{ml}$ erythromycin as described. The T. denticola recombinant ( $\mathrm{rFlgE}$ ) was expressed in E. coli BL21 cells (Life Technologies) grown at $37^{\circ} \mathrm{C}$ in Luria-Bertani broth containing $100 \mu \mathrm{g} / \mathrm{ml}$ ampicillin.

\section{Sodium dodecyl sulfate polyacrylamide gel electrophoresis (SDS-PAGE) and} western blot analysis. SDS-PAGE was carried out using standard techniques (36). Samples were electrophoresed in $8 \%$ polyacrylamide gels, and proteins were Imperial stained (Thermo Scientific) following manufacturers protocol. For western blotting, $2 \mu \mathrm{g}$ total protein for periplasmic flagella or $0.5 \mu \mathrm{g}$ for recombinant FlgE, as determined by the Bradford protein assay (Bio-Rad) unless noted otherwise, was subjected to SDSPAGE and transferred onto polyvinylidene difluoride (PVDF) membranes. Immunoblots were probed with polyclonal rat antibody directed against $T$. denticola rFlgE, and secondary polyclonal goat anti-rat antibodies were obtained from GE Healthcare (cat no NA9350). The Pierce enhanced chemiluminescent detection system was used following manufacturers instructions. Relative amounts of FlgE were determined using densitometry. After film development, films were scanned using a Fotodyne densitometer, and relative band intensities were determined using Totalab Quant software (Totallab Life Sciences).

\footnotetext{
Recombinant FlgE ( $\mathrm{rFIgE}$ ) purification, construction of flgE mutants, and generation of polyclonal FlgE antisera. The strain over-expressing T. denticola FlgE in E. coli was constructed as follows. The entire sequence of $T$. denticola flgE was
} 
amplified using the following primers: Forward:

CACCATGATGGAGATCATTATTTTCGGG and Reverse:

CTATCGTTTCAAGTTCAAGAC, and the PCR product was subsequently ligated and cloned into the expression vector pet100 (Life Technologies). The vector encoding the $\mathrm{N}$-terminal His-tag containing flgE was transformed into BL21 cells, which were grown in LB broth containing $100 \mu \mathrm{g} / \mathrm{ml}$ ampicillin. Once cells reached logarithmic phase, $\mathrm{rFlgE}$ expression was induced using $1 \mathrm{mM}$ isopropyl- $\beta$-thiogalactoside (IPTG) for 4 hours; rFlgE was purified using a nickel agarose column (Qiagen) under denaturing conditions (8M urea), following manufacturers protocol (Quiagen Expressionist Protocol \# 10 and 17). For antisera production, rats were immunized with rFlgE. Wild-type and mutated FlgE sequences were confirmed via PCR and sequencing. Constructs containing wildtype and mutated $T$. denticola $\mathrm{rFlgE}$ and $T$. denticola polyclonal FlgE antisera were the kind gifts of Dr. C. Li and Jiange Bian (University of Buffalo, NY).

\section{Purification of periplasmic flagella, polyhooks, and hook basal body complexes.}

Periplasmic flagella (wild-type cells) and polyhooks (tap1 $1^{-}$cells) were purified from one liter of late log phase cells $\left(\sim 1 \times 10^{9}\right.$ cells $\left./ \mathrm{ml}\right)$ as described previously (Miller et al, submitted). Briefly, cells were washed three times with $28 \mathrm{ml}$ phosphate buffered saline (PBS). Pellets were re-suspended in $30 \mathrm{ml} 100 \mathrm{mM}$ Tris, pH 6.8. After stirring for 10 minutes, $20 \%$ Triton X-100 (2\% final concentration) was added. After the outer membranes were disrupted as observed by dark-field microscopy (30-60 minutes), mutanolysin (200 mg/ml stock solution in sterile water, Sigma cat no M9901-50KU) was added to $20 \mu \mathrm{g} / \mathrm{ml}$ final concentration to lyse the cells. After lysing at room temperature 
for 2 hours and $4{ }^{\circ} \mathrm{C}$ overnight, the samples were warmed to room temperature and $20 \%$ polyethylene glycol 8000 containing $1 \mathrm{M} \mathrm{NaCl}$ was added to pellet the periplasmic flagella or polyhooks. The periplasmic flagella or polyhooks were re-suspended in $0.1 \mathrm{M}$ $\mathrm{KCl}, 0.5 \mathrm{M}$ sucrose, $0.1 \%$ Triton $\mathrm{X}-100,50 \mathrm{mM}$ sodium bicarbonate, $\mathrm{pH} 11$ for 1 hour at $23^{\circ} \mathrm{C}(37)$, and the final products were recovered by centrifugation at $80,000 \times \mathrm{g}, 45$ $\min , 4^{\circ} \mathrm{C}$. To remove flagellar filaments, wild-type periplasmic flagella were treated with $8 \mathrm{M}$ urea for 2 hours, and hook basal body complexes were recovered by centrifugation at $100,000 \times \mathrm{g}, 1$ hour, $4^{\circ} \mathrm{C}$. Hook basal bodies were re-suspended in a small volume of sterile water ( 100 $\mu \mathrm{l} /$ liter beginning culture).

Mass Spectrometry and ultra-performance liquid chromatography. For mass spectrometry analysis, purified hook basal bodies, polyhooks, or rFlgE was electrophoresed in SDS-PAGE and subsequently Imperial-stained. Protease digestion and MS analysis were carried out by Dr. J. Hettick, NIOSH (Morgantown, WV) and Dr. Brian Crane, Cornell University (Ithaca, NY). Disulfide bonds were reduced by reaction with tributylphosphine for $15 \mathrm{~min}$ at room temperature with shaking (300 rpm), followed by alkylation with iodoacetamide for $30 \mathrm{~min}$ at room temperature with shaking (300 rpm). Porcine trypsin was suspended in $25 \mathrm{mM} \mathrm{NH}_{4} \mathrm{HCO}_{3}$ and added to each aliquot at a 40:1 (protein:trypsin) ratio. Samples were incubated overnight at $37^{\circ} \mathrm{C}$ with shaking (300 rpm). Samples were centrifuged at 14,000 rpm in a microcentrifuge (MiniSpin, Eppendorf, Hamburg, Germany) to pellet any insoluble material.

Enzymatic peptides were separated on a Waters (Milford, MA) nanoACQUITY ultra-performance liquid chromatography (UPLC) system. Aliquots $(1 \mu \mathrm{L})$ of the digest 


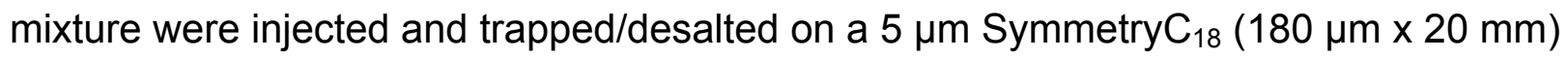
trapping column with 99.5/0.5 A/B (A:0.1\% formic acid; B:0.1\% formic acid in acetonitrile) at a flow rate of $15 \mu \mathrm{L} / \mathrm{min}$ for 1 minute. Separation was performed on a 1.7 $\mu \mathrm{m}$ BEH130 $\mathrm{C}_{18}(100 \mu \mathrm{m} \times 100 \mathrm{~mm})$ analytical column utilizing gradient elution at a flow rate of $400 \mathrm{~nL} / \mathrm{min}$ and a gradient of $99 / 1$ to $60 / 40 \mathrm{~A} / \mathrm{B}$ over $60 \mathrm{~min}$.

The eluent from the UPLC system was directed to the nanoelectrospray source of a Waters SYNAPT MS quadrupole time-of-flight (qTOF) mass spectrometer. Positive ion nanoelectrospray was performed utilizing $10 \mu \mathrm{m}$ PicoTip (Waters) emitters held at a potential of $+3.5 \mathrm{kV}$. The cone voltage was held constant at $+40 \mathrm{~V}$ for all experiments. Dry $\mathrm{N}_{2}$ desolvation gas was supplied to the instrument via a nitrogen generator (NitroFlowLab, Parker Hannifin Corp., Haverhill, MA). [Glu] ${ }^{1}$-Fibrinopeptide B (100 $\mathrm{fmol} / \mu \mathrm{L}$ in $75 / 25 \mathrm{~A} / \mathrm{B}$ ) was supplied to an orthogonal reference probe and the $[\mathrm{M}+2 \mathrm{H}]^{2+}$ ion $(\mathrm{m} / \mathrm{z}=785.84265 \mathrm{u})$ measured as an external calibrant at $30 \mathrm{sec}$ intervals. Collisioninduced dissociation (CID) was performed utilizing ultra-high purity (UHP) argon as collision gas. Spectra were acquired in an "MS" fashion (38). Briefly, alternating onesecond mass spectra are acquired. The first spectrum acquired at low $(6 \mathrm{eV})$ collision energy allows high mass accuracy precursor ion mass measurement. The second spectrum acquired at high (15-30 eV ramp) collision energy allows high mass accuracy fragment ion mass measurement. The fragment ion spectra may be temporally correlated with precursor spectra post-run. This method of data acquisition allows all precursor ions to be fragmented and analyzed, rather than so called "data dependent acquisition" methods that require real-time decisions to be made on which ions to select for fragmentation, and which may miss low-abundance precursor ions. 
MS Data analysis. Data were analyzed with ProteinLynx Global Server v. 2.4 (Waters), a software program for database searching-based protein identification and BioPharmaLynx v. 1.2 (Waters), a software program for analysis of peptide mass maps and identification of sites of modification on known protein sequences. Default peptide mass map analysis criteria of $30 \mathrm{ppm}$ mass error in both low and high collision energy mode were specified. Trypsin was specified as the digestion enzyme, and 2 missed cleavages were allowed.

In vitro rFlgE cross-linking experiments. Following nickel column purification, rFlgE was dialyzed overnight at $4^{\circ} \mathrm{C}$ against $1 \mathrm{xPBS}, \mathrm{pH} 7.4$ to remove urea. Experiments were started immediately following dialysis because rFlgE would spontaneously polymerize. For experiments, $\mathrm{rFlgE}$ (concentration of $0.2 \mathrm{mg} / \mathrm{ml}$ ) was diluted in buffer at pH $3.2(40 \mathrm{mM}$ acetate, $0.9 \% \mathrm{NaCl}), 7.4(1 \times \mathrm{PBS})$, or $\mathrm{pH} 8.5(40 \mathrm{mM}$ Tris, $0.9 \% \mathrm{NaCl})$ as indicated to a final concentration of $0.04 \mathrm{mg} / \mathrm{ml}$. Samples incubated at $4^{\circ} \mathrm{C}$ for the time points indicated in the results. For mutant rFlgE cross-linking experiments, rFlgE was dialyzed against $40 \mathrm{mM}$ Tris, $0.9 \% \mathrm{NaCl}, \mathrm{pH} 8.5$ and incubated at a concentration of $0.387 \mathrm{mg} / \mathrm{ml}$ unless indicated otherwise.

\section{Results}

The HMWC is present in whole cell lysates and purified periplasmic flagella from wild type cells and polyhooks from tap1 mutants but is not present in a flgE 
insertion mutant. We tested the specificity of our FlgE antibody by subjecting whole cell lysates of wild-type $T$. denticola strain 35405 , the flgE strain, and the tap $1^{-}$strain to SDS-PAGE and immunoblotting with FlgE antibody (Fig. 3.1). The tap1 strain has a fliK mutation that results in formation of polyhooks. Whole cell lysates of the wild-type strain (Figure 3.1A, lane 1) and the tap $1^{-}$strain (Fig. 3.1A, lane 3) reacted with the antibody in the stacking gel, but no reactivity occurred with the flgE- strain (Fig. 3.1A and B, lane 2). These results show that our antibody is specific to FlgE, and that the polyhook mutant (tap1 ${ }^{-}$strain) produces a HMWC similar to wild-type cells (Fig. 3.1). In order to obtain sufficient FlgE HMWC to study, we purified polyhooks from the tap1' strain using methods previously described (Miller et al, submitted). Purifying polyhooks resulted in $\sim 50 \mathrm{x}$ the FlgE protein yield compared to wild-type periplasmic flagella as determined by densitometry (Fig. 3.1B, C). Isolating polyhooks from B. burgdorferi also resulted in increased FlgE yield/cell compared to isolating wild-type periplasmic flagella (Miller et al, submitted). 


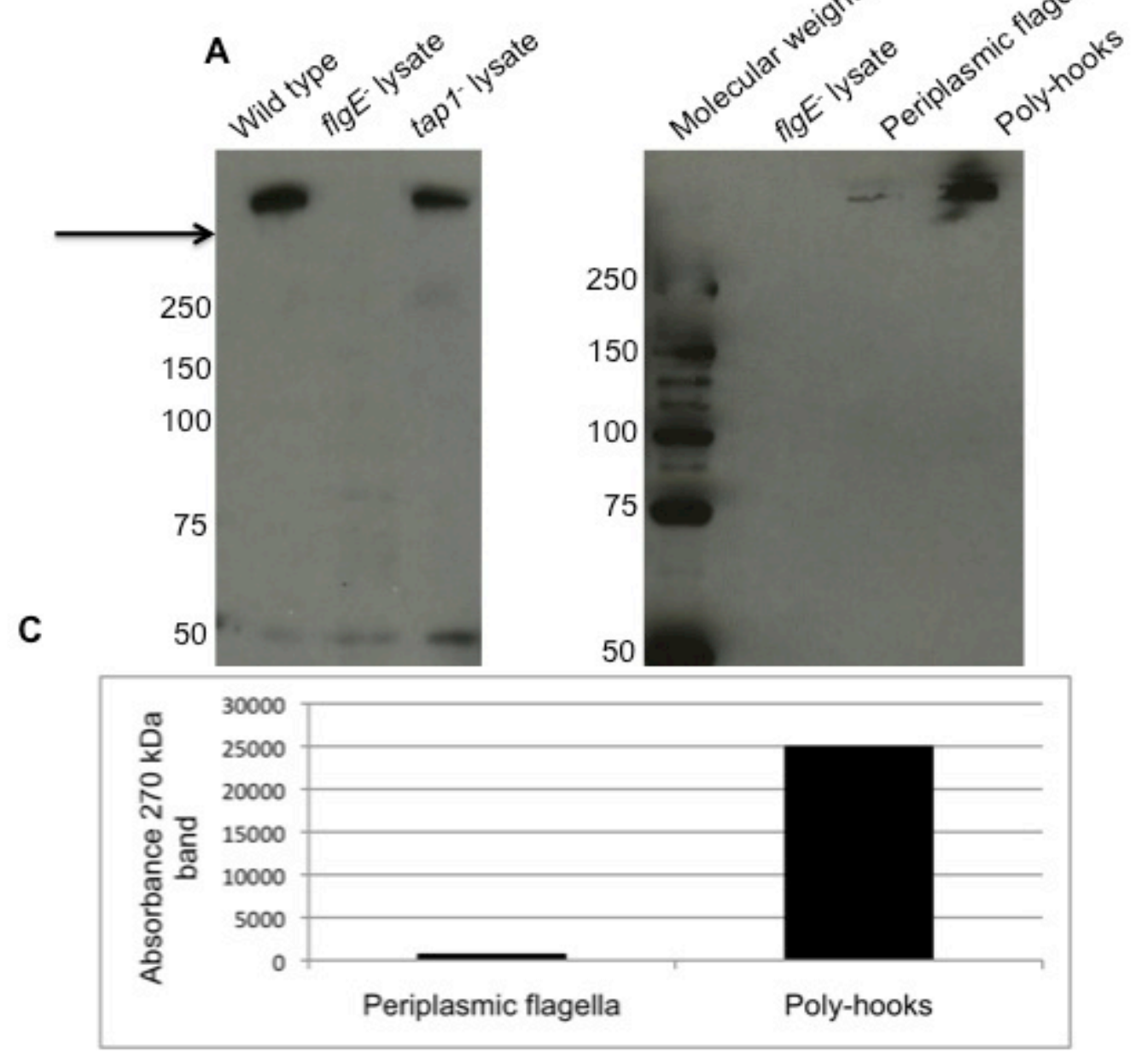

B

Figure 3.1. Expression of FlgE in $T$. denticola whole cell lysates ( $2 \mu \mathrm{g}$ protein/lane) (A) and purified periplasmic flagella (1 $\mu \mathrm{g}$ protein/lane) (B). Cell lysates from wild-type strain 35405 and mutant strains ( 35405 background) were analyzed by western blotting with polyclonal FlgE antibody. C) Densitometry of western in B.

The FlgE HMWC is stable to denaturant treatment. In order to test the stability of the HMWC, purified periplasmic flagella (Fig. 3.2) were treated with denaturing conditions that typically disassociate non-covalent bonds. These treatments include: boiling, low 
$\mathrm{pH}$, urea, guanidine hydrochloride $(\mathrm{GuHCl})$, and formic acid $(39,40)$. The HMWC from isolated periplasmic flagella is stable to treatment with $8 \mathrm{M}$ urea and $\mathrm{pH} 2.5$ at room temperature for 1 hour (Figure 2A). Figure 2 shows that the HMWC is stable to boiling for 15 minutes (Fig. 3.2B lane 4), 8M GuHCl (Fig. 3.2B lanes 5 and 6), 23N formic acid at room temperature for 2 hours (Fig. 3.2B, lane 7 ), and $1 \mathrm{~N}$ formic acid at both $65^{\circ} \mathrm{C}$ for 30 minutes and boiling in $1 \mathrm{~N}$ formic acid for 15 minutes (Fig. 3.2C, lanes 3 and 4).

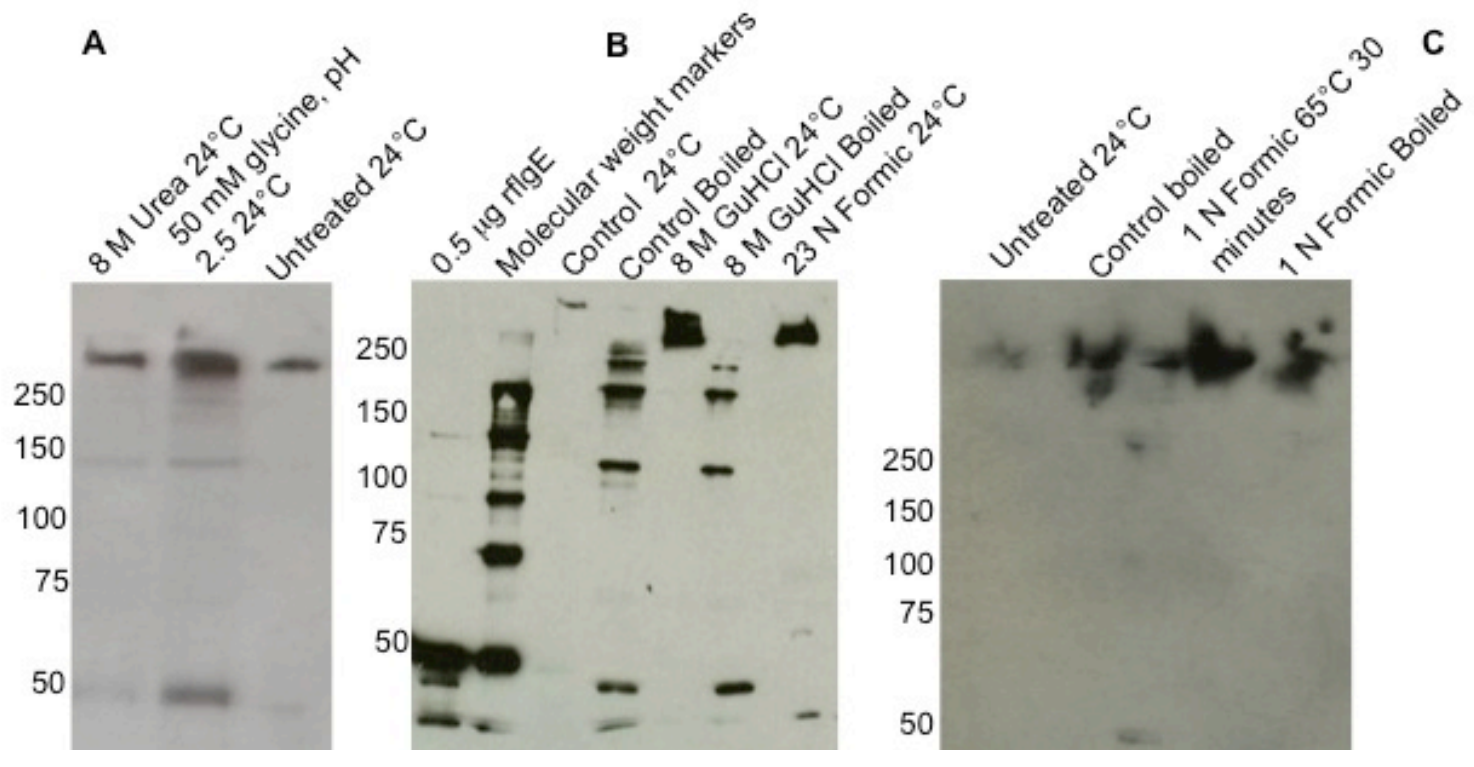

Figure 3.2. FlgE western blot analysis of periplasmic flagella either boiled or treated with chemical denaturants. (A) Periplasmic flagella incubated with the indicated denaturants for a total of 1 hour at $24^{\circ} \mathrm{C}$ and centrifuged for 1 hour at $100,000 \mathrm{xg}$. The pellets following centrifugation were suspended in sample buffer and boiled for 5 minutes prior to gel loading (2 $\mu \mathrm{g} / \mathrm{lane})$. (B) and (C) Effect of boiling and denaturants. Samples were treated with the indicated denaturants for a total of 2 hours. Indicated samples were boiled in the denaturant for 15 minutes. Lanes were equally loaded for protein $(5 \mu \mathrm{g})$ after adding sample buffer, without additional boiling. Formic acid treated samples were neutralized by the addition of $4 \mathrm{M} \mathrm{NaOH}$ prior to loading. 
The monomer, which is predicted to be $49 \mathrm{kDa}$, is produced without HMWC when spirochete FlgE is over-expressed in E. coli (Fig. 3.3); however, over time at pH 7.4 we observed purified $T$. denticola $\mathrm{rFlgE}$ (concentration of $0.56 \mathrm{mg} / \mathrm{ml}$ ) to polymerize at $4^{\circ} \mathrm{C}$ (Fig. 3.5A, lane 2). Therefore, we tested whether the rFlgE HMWC formed in vitro is stable to the same denaturants as the HMWC from periplasmic flagella (Fig. 3.4). The rFlgE HMWC was stable to treatment with $\mathrm{GuHCl}$, urea, and formic acid. The stability of the HMWC to these strong denaturant treatments that disrupt non-covalent protein-protein interactions is consistent with our hypothesis that the FlgE proteins in spirochetes are covalently cross-linked to each other. Formation of the rFlgE HMWC in vitro suggests that cross-links may form auto-catalytically in vivo.

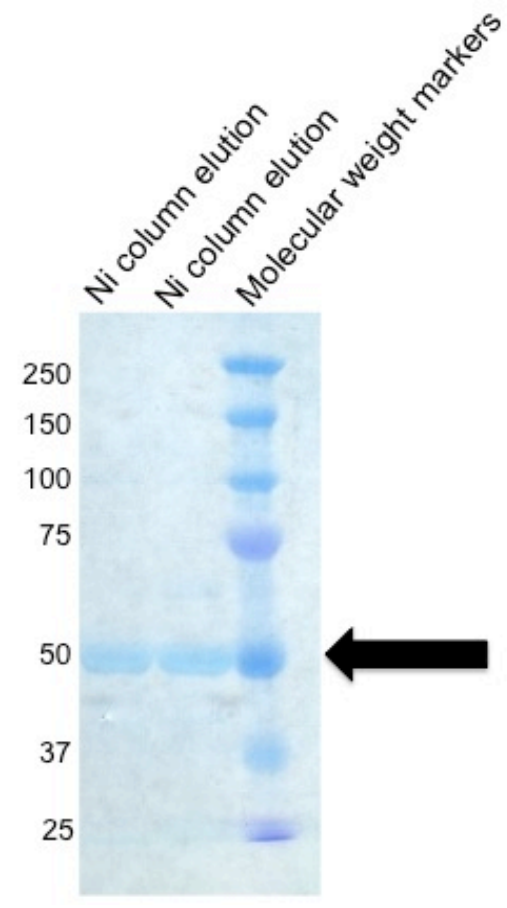

Figure 3.3. Coomassie stained SDS-

PAGE of purified $T$. denticola rFlgE.

$10 \mu \mathrm{g}$ protein was loaded per lane.

Arrow is pointing to $\mathrm{rFlgE}$. 


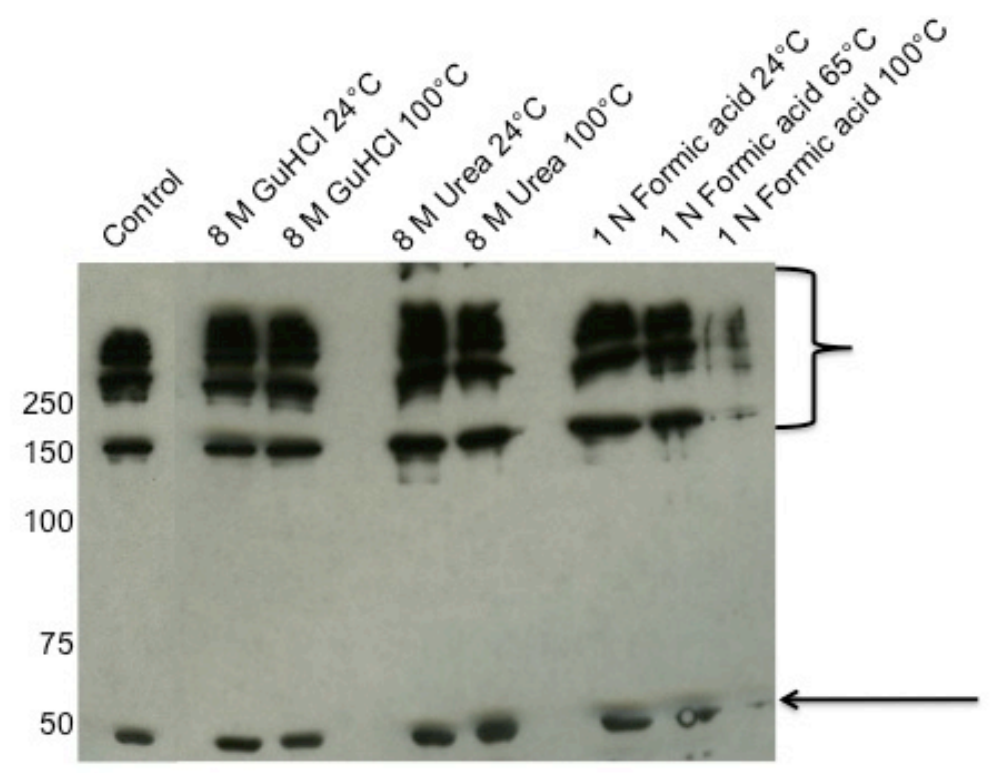

Figure 3.4. Western blot analysis of the rFlgE HMWC treated with denaturants using polyclonal FlgE antibody. $T$. denticola $\mathrm{rFlgE}$ had previously polymerized at $\mathrm{pH} 7.4,4^{\circ} \mathrm{C}$ at a concentration of $0.56 \mathrm{mg} / \mathrm{ml}$ over a 2 month period. Samples incubated with the indicated denaturants for 1 hour, and were loaded immediately without boiling. The control sample was not treated, but was boiled in sample buffer for 5 minutes prior to gel loading. Samples were equally loaded for total protein $(0.5 \mu \mathrm{g} / \mathrm{lane})$. Arrow is pointing to monomeric FlgE, and the HMWC is indicated by the bracket.

MS analysis of monomeric FIgE and the HMWC. Figure 3.5A shows one gel that was used for MS analysis at $\mathrm{NIOSH}$ (Morgantown, WV), and figure 3.6 shows the $T$. denticola FlgE sequence. Polyhooks and rFlgE were electrophoresed on SDS-PAGE and Imperial-stained. The bands highlighted by the boxes were excised, in gel digested with trypsin, and the resultant peptides were analyzed by UPLC-QTOF-MS/MS. 
Appendix table A3 shows the peptides identified with $>95 \%$ confidence at $\mathrm{NIOSH}$. All of the identified peptides correspond to $T$. denticola FlgE. The digest patterns were similar for the three HMWC's analyzed (Fig 3.5 A red boxes). Differences were observed between the monomer (black box) and the HMWC's (Fig. 3.5), and the corresponding locations in the protein sequence are shown in figure 3.6. Specifically, trypsin fragment 15 (ATTSVNYACNL) was highly prevalent in the monomer but rarely identified in the HMWC (Fig. 3.5B). Additionally, the HMWC contained trypsin fragment 13 (IINTSGQTEDLNIPIGQK) and 14 (LDAK) joined to each other but not individually, whereas trypsin fragment 14 (LDAK) was never observed in the monomer. We speculate that this is due to the $\mathrm{C}$-terminal lysine $(\mathrm{K})$ residue of trypsin fragment 13 being involved directly in the cross-link; cross-linking of this amino acid would prevent trypsin from cutting this site. Furthermore, there is an anomalous mass of $3732.9 \mathrm{Da}$ present in the HMWC from both native hooks and rFlgE but absent in the monomer (Fig. 3.5C,D). That mass equals the sum of trypsin fragments 13,14 , and 15 minus ammonia. The anomalous mass could possibly be the result of a cross-link between K165 on trypsin fragment 13 to an asparagine $(\mathrm{N})$ residue on trypsin fragment 15. Those specific differences between monomeric and HMWC FlgE were identified in several MS runs. Preliminary fragmentation of the 3732.9 Da mass in collaboration with Dr. Brian Crane, Cornell University (Ithaca, NY) identified the N-terminus sequence (IINTSGQT) of tryptic fragment 13 of the in vitro formed HMWC (Fig. 3.6). This partial sequence information is highly suggestive that the cross-linked peptide contains tryptic fragments 13-15. Obtaining additional sequence data for the anomalous mass is in 
progress and should allow for identification of the peptides involved and the nature of the cross-link.

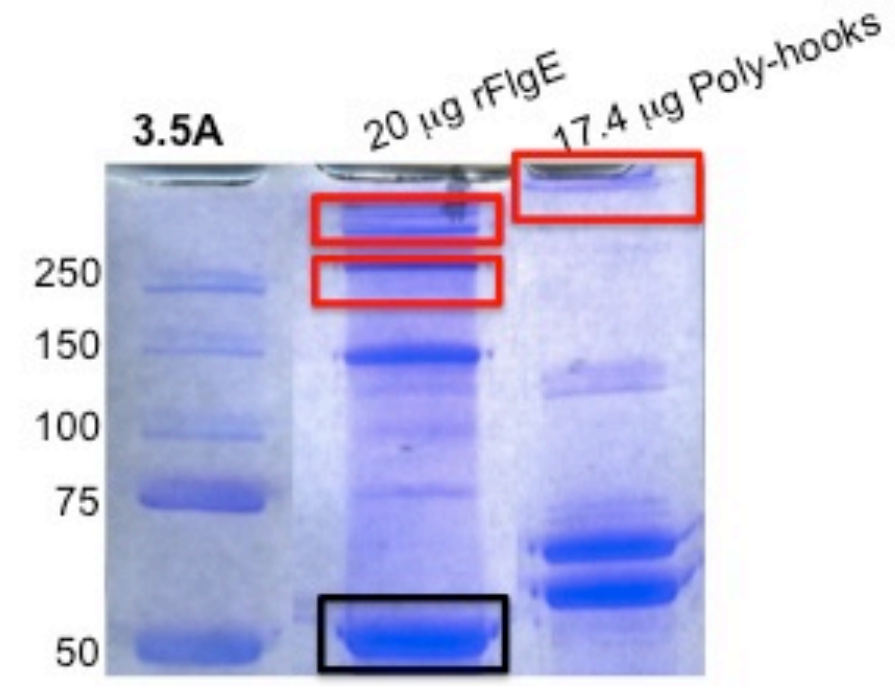




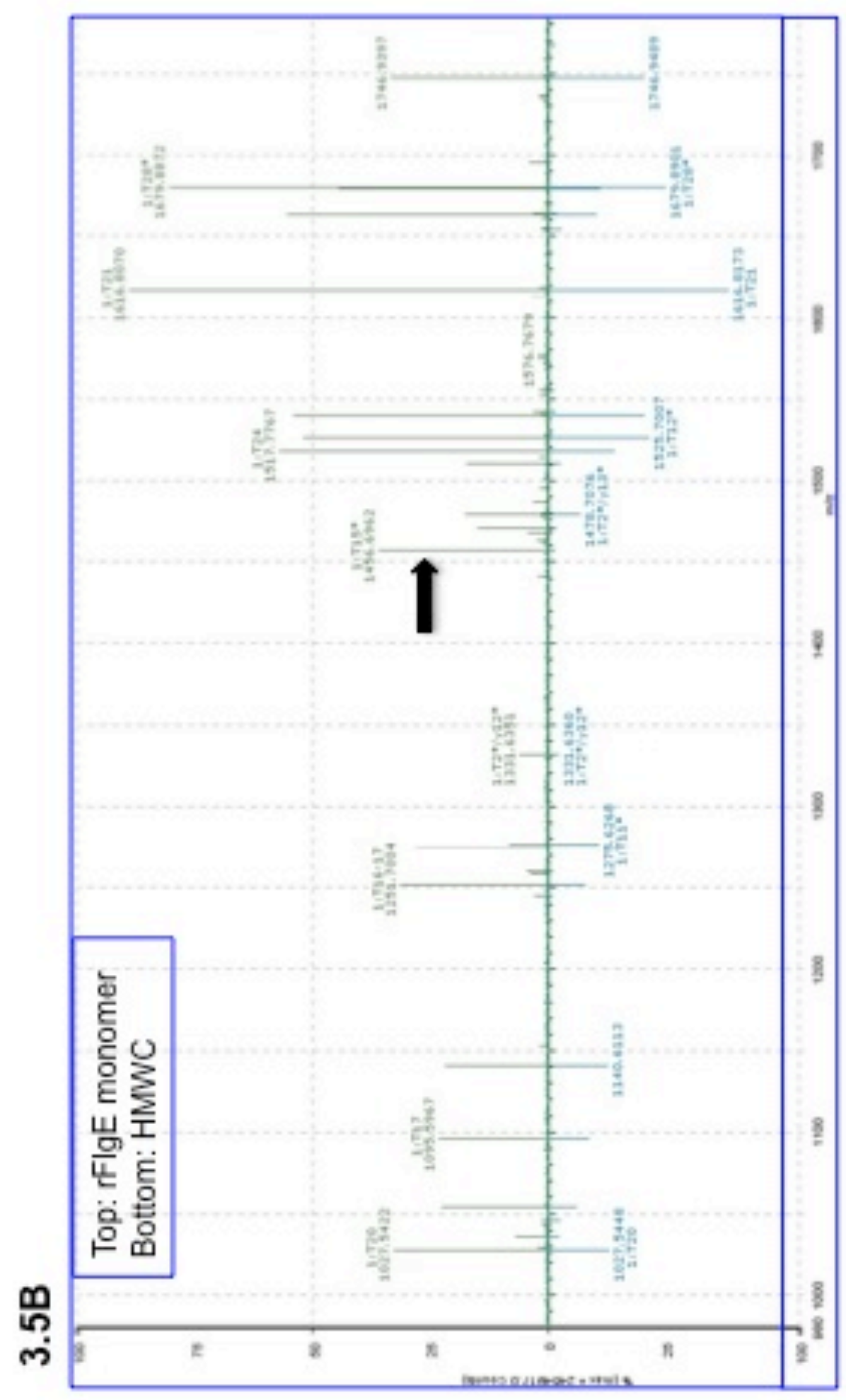




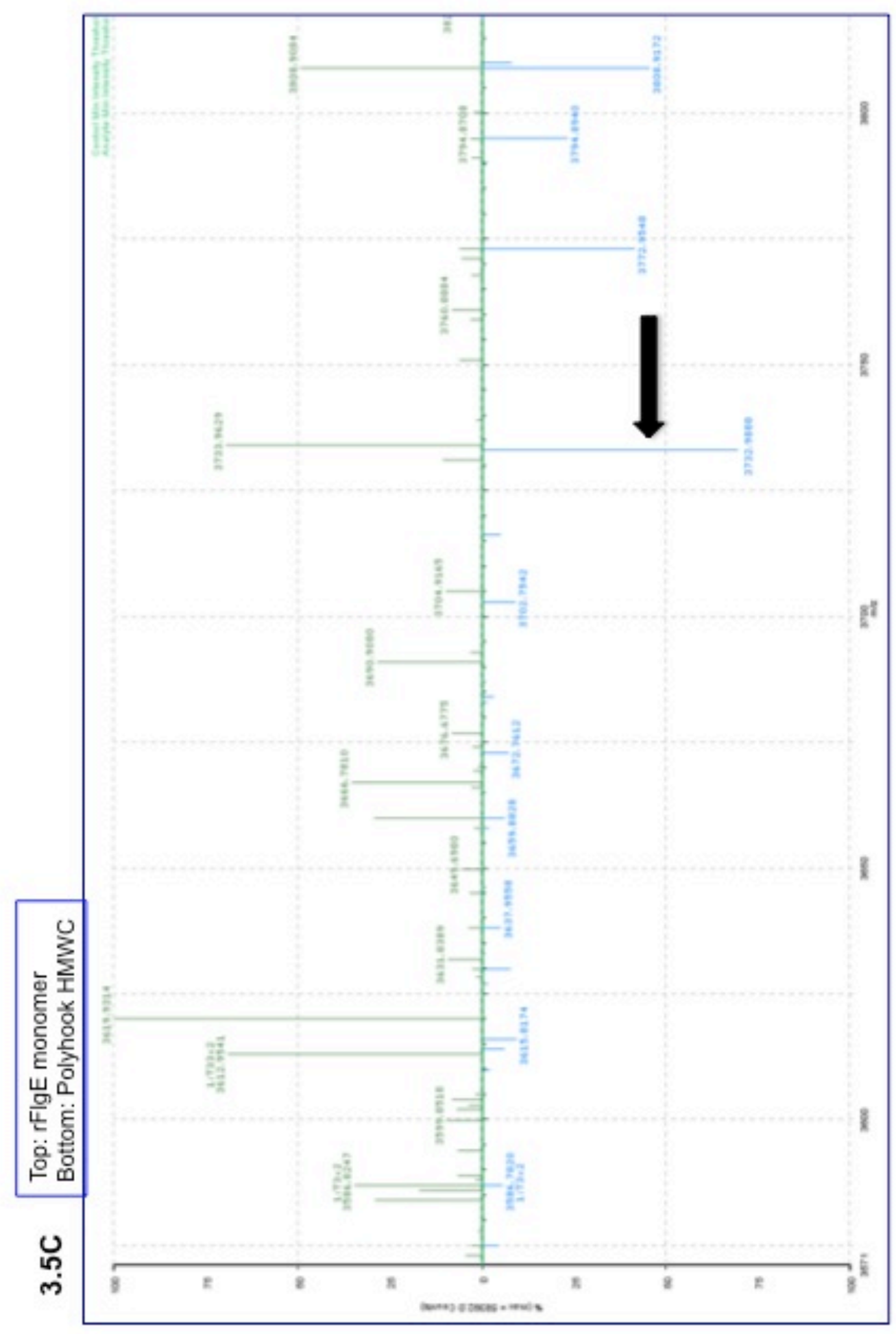




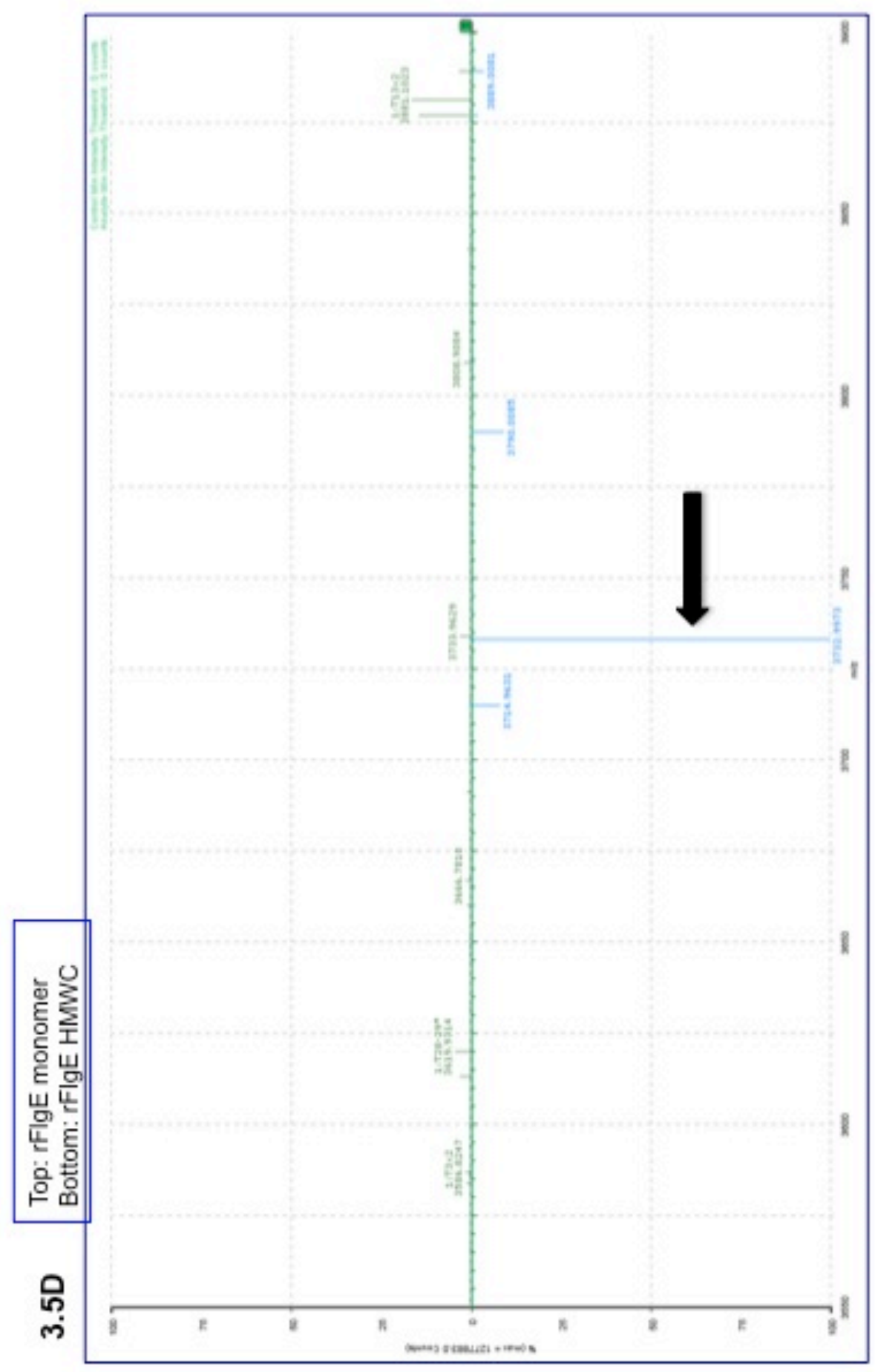


Figure 3.5. MS analysis of $\mathrm{rFlgE}$ and polyhooks isolated from tap1- mutant cells. (A) Imperial stained SDS-PAGE. rFlgE incubated at $\mathrm{pH} 7.4$ for 2 months at $4^{\circ} \mathrm{C}$. Boxes indicate samples that were excised, digested with trypsin and analyzed by MS/MS. (B,C,D) Screen shots of the mass spectrum. (B) Mirror image of mass range from 10002000. Arrow is highlighting the peptide (trypsin fragment 15) that is over-represented in the monomer. ( $C$ and $D)$ Mirror image of mass range from 3500-3800 with arrow pointing to anomalous mass (3732.9) that is unique to the FlgE HMWC. (C) HMWC obtained from polyhooks. (D) HMWC obtained from rFlgE.

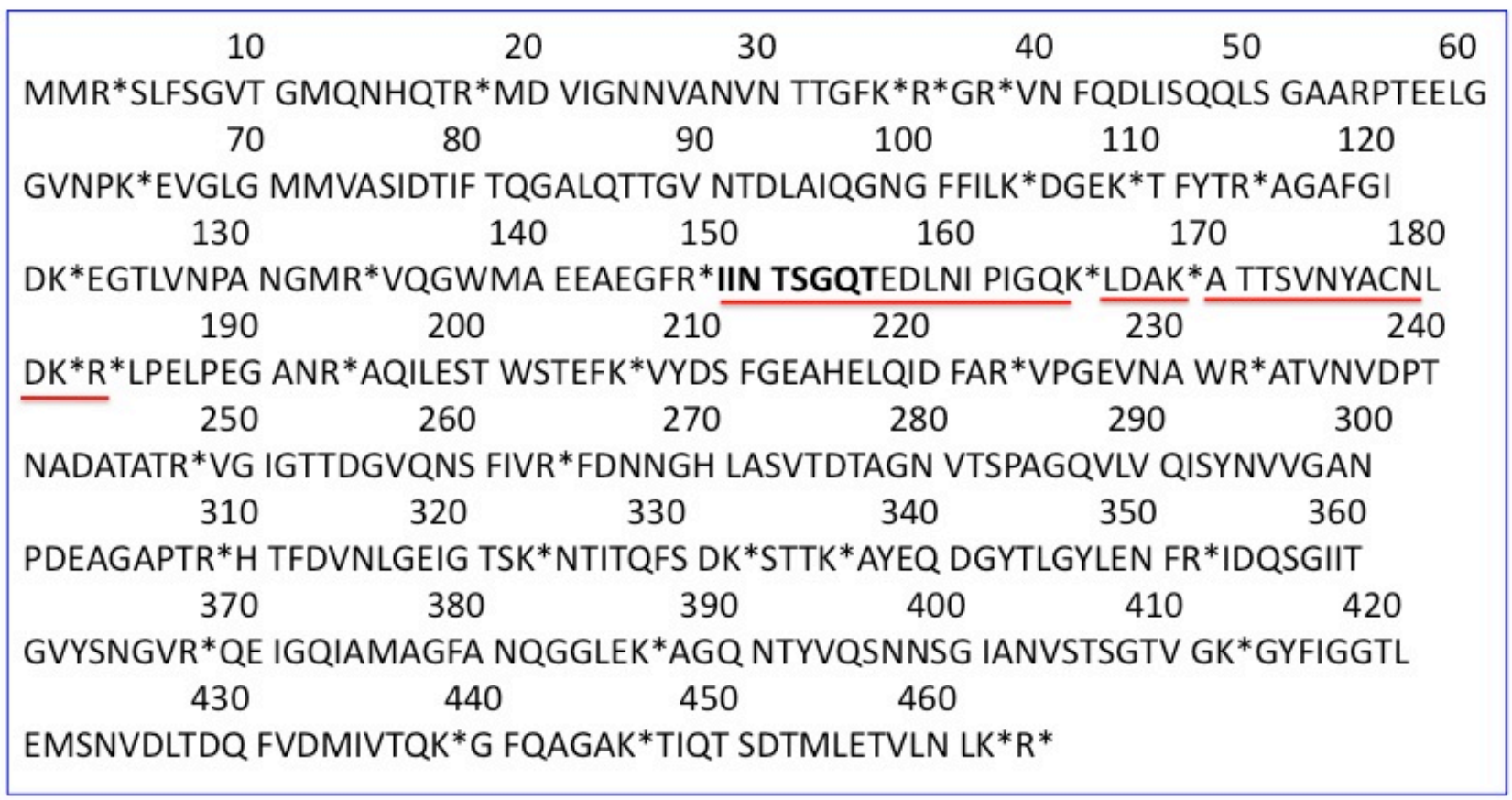

Figure 3.6. $T$. denticola FlgE primary sequence. Red underlines indicate peptides (trypsin fragments 13,14 , and 15) that are postulated to be involved in FlgE crosslinking. Tryptic fragment 14 (sequence LDAK) is not observed in the monomer. Residues in bold are those identified by preliminary fragmentation of the $3732.9 \mathrm{Da}$ mass that is unique to the HMWC. 
Kinetics of rFlgE cross-linking. The rFlgE monomer is produced without HMWC when spirochete FlgE is over-expressed in E. coli (Fig. 3.3); however, over time at pH 7.4 we observed purified $T$. denticola rFlgE (concentration of $0.56 \mathrm{mg} / \mathrm{ml}$ ) to polymerize at $4^{\circ} \mathrm{C}$ (Fig. 3.5A, lane 2). This phenomenon was first observed 2 months after rFlgE purification. Formation of the rFlgE HMWC in vitro suggests that cross-links may form auto-catalytically. We therefore investigated conditions that induce or inhibit crosslinking; such information should facilitate determination of the chemistry/mechanism of the cross-linking reaction.

Heating monomeric $\mathrm{rFIgE}$ reduces HMWC formation. To test if the in vitro reaction is enzymatic (Most enzymes are heat sensitive and denatured by boiling), we heated rFlgE monomer at $90^{\circ} \mathrm{C}$ for 5 minutes (Fig. 3.7). Following heating, samples incubated at $\mathrm{pH} 8.5$ and were analyzed by western blotting with polyclonal $T$. denticola FlgE antibody at the indicated time points. At all time points examined, polymerization is much greater in the control samples than the heated samples (Fig. 3.7). Similar results were observed when rFlgE was boiled for 15 minutes. Because $\mathrm{FlgE}$ is the only protein present in these samples (Fig. 3.3), these results indicate that rFlgE cross-linking is autocatalytic. 
A

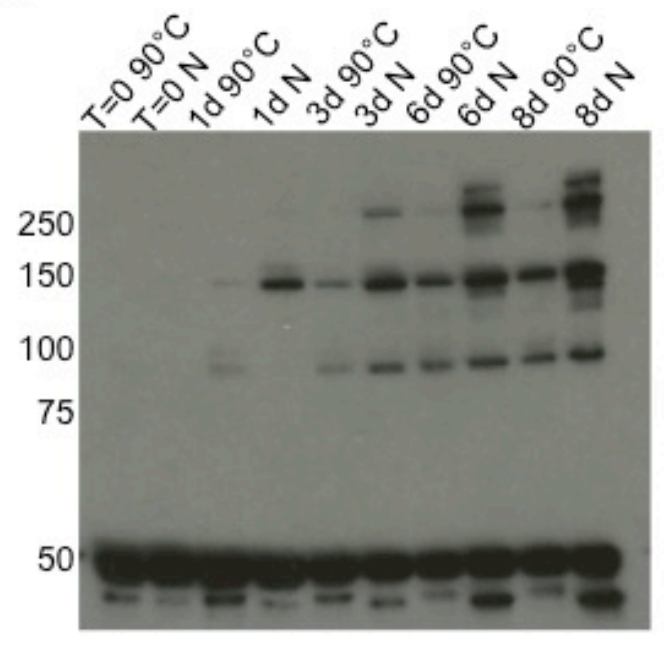

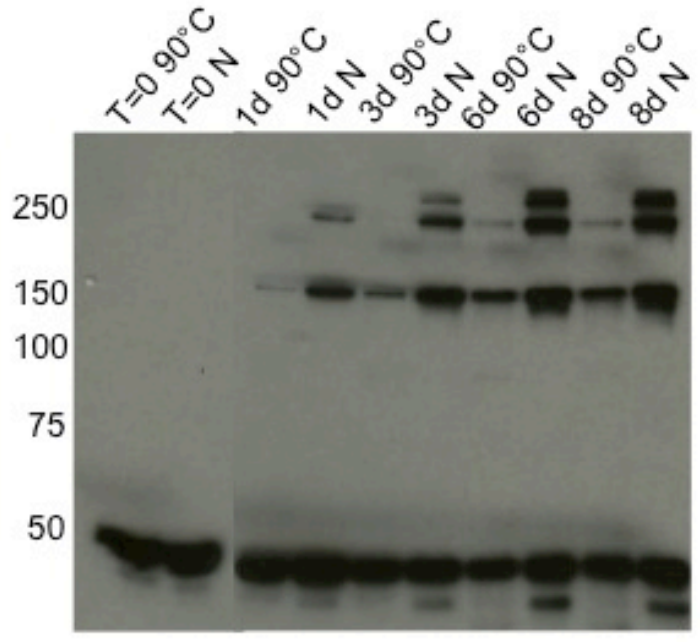

Figure 3.7. Effect of heating monomeric rFlgE on HMWC formation. After indicated samples were heated at $90^{\circ} \mathrm{C}$ for 5 minutes (Non-heated samples $(\mathrm{N})$ incubated at room temperature), samples incubated at $4^{\circ} \mathrm{C}(\mathrm{A})$ or $24^{\circ} \mathrm{C}(\mathrm{B})$ for the time periods indicated at $\mathrm{pH}$ 8.5. For western blot analysis, $0.5 \mu \mathrm{g}$ protein/lane was loaded.

Ammonium sulfate stimulates HMWC formation. Salmonella FlgE protein forms long hook like structures (polymerized FlgE monomers but not cross-linked) in vitro when incubated with sodium citrate or ammonium sulfate at room temperature or $4^{\circ} \mathrm{C}(41,42)$. Therefore, we treated $T$. denticola rFlgE with various concentrations of ammonium sulfate at $4^{\circ} \mathrm{C}, \mathrm{pH} 8.5$ and analyzed HMWC formation by immuno-blotting with FlgE antibody. Samples were subjected to SDS-PAGE and western blotting. Figure 3.8 shows that $1 \mathrm{M}$ ammonium sulfate is optimal for $T$. denticola rFlgE polymerization. 

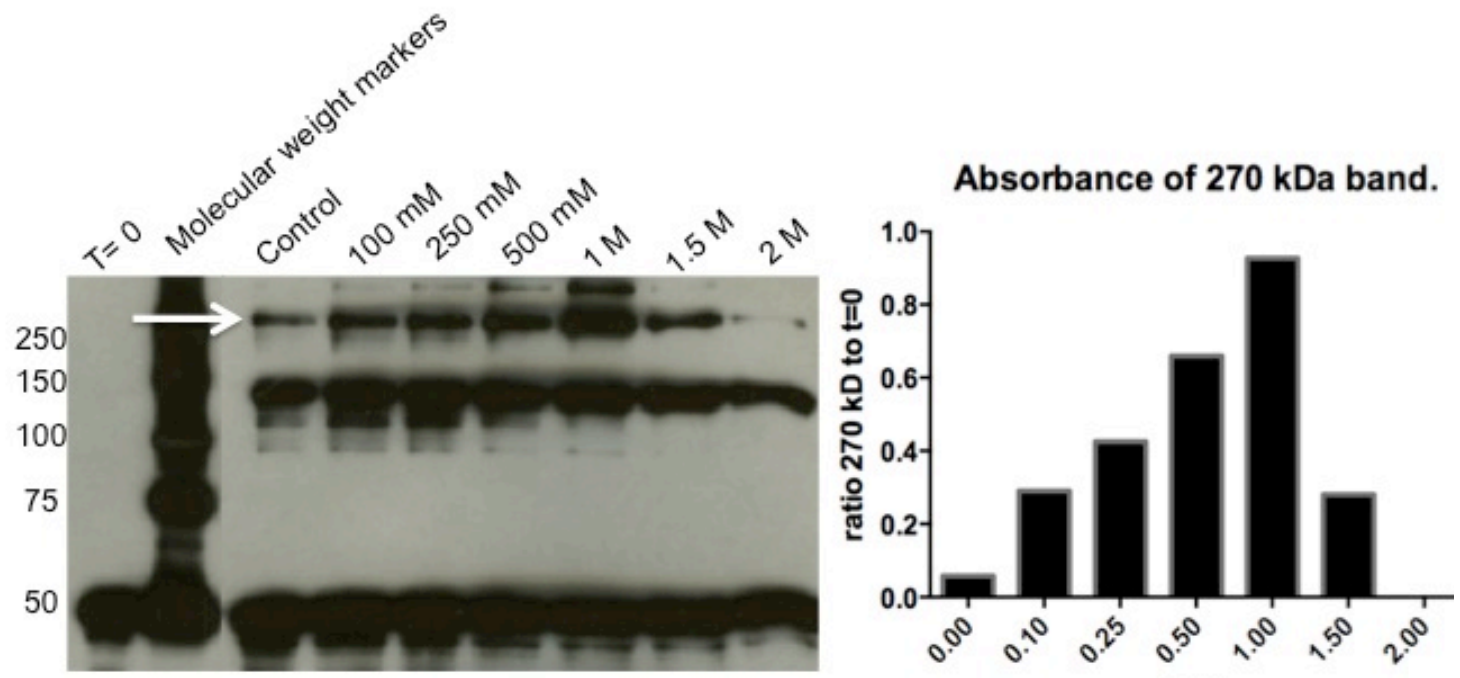

[AS]

Flgure 3.8. Effect of ammonium sulfate (AS) concentration on rFlgE HMWC formation. Samples incubated with the indicated concentrations of $\mathrm{AS}$ at $\mathrm{pH} 8.5,4^{\circ} \mathrm{C}$ for 3 days. For western blot analysis (left panel), $0.5 \mu \mathrm{g}$ protein/lane was loaded, and the corresponding densitometry for the $270 \mathrm{kDa}$ band (indicated by arrow) is shown in the right panel.

Sodium chloride does not effect HMWC formation. Ammonium sulfate stimulated polymerization; therefore, we tested the effect of a different salt on polymerization by using various concentrations of $\mathrm{NaCl}$ at $4^{\circ} \mathrm{C}, \mathrm{pH}$ 8.5. FlgE polymerization was not stimulated in the presence of $\mathrm{NaCl}(0.1-2.0 \mathrm{M})$, whereas ammonium sulfate $(1.0 \mathrm{M})$ reproducibly stimulated formation of the rFlgE HMWC (Figs. 3.8,3.9). These results suggest that ammonium sulfate-induced polymerization is not a general salt effect; the increase in polymerization could be due to ammonium sulfate-induced protein aggregation. These results are in agreement with studies on polymerization of 
Salmonella hooks in vitro into long hook-like structures $(41,42)$. Perhaps, ammonium sulfate stimulates $T$. denticola hook polymerization in vitro in a similar manner.

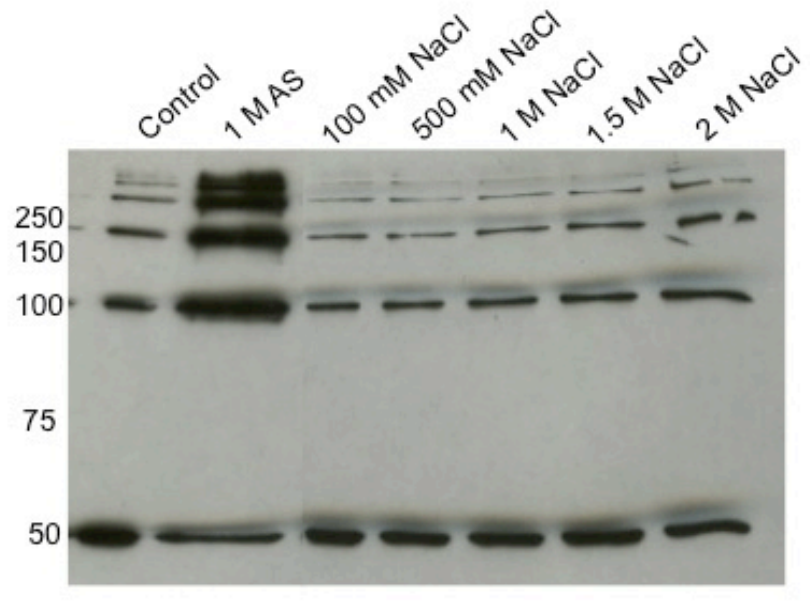

Figure 3.9. Effect of $\mathrm{NaCl}$ on rFlgE HMWC formation. Samples were treated with the indicated salt concentrations and incubated at $\mathrm{pH} 8.5,4^{\circ} \mathrm{C}$ for 7 days. For western blot analysis, $0.5 \mu \mathrm{g}$ protein/lane was loaded onto SDS-PAGE, and the blot was probed with polyclonal FlgE antibody.

rFlgE HMWC formation is influenced by $\mathrm{pH}$. We compared the effects of $\mathrm{pH}$ and ammonium sulfate on $\mathrm{rFlgE}$ polymerization. $T$. denticola $\mathrm{rFlgE}$ was incubated in the presence or absence of $1 \mathrm{M}$ ammonium sulfate for 10 days at $4^{\circ} \mathrm{C}$ at $\mathrm{pH} 3.2$ or $\mathrm{pH} 8.5$ (Fig. 3.10). Only the monomeric form is present at pH 3.2 (Figure 3.10A); this could be due to inability of $\mathrm{rFlgE}$ to polymerize at low $\mathrm{pH}$ or the degradation of the HMWC at low $\mathrm{pH}$. To test the latter possibility, we exposed rFlgE HMWC that had previously polymerized at $\mathrm{pH} 7.4,4^{\circ} \mathrm{C}$ to $\mathrm{pH} 3.2$ and $\mathrm{pH} 8.5$ to determine if low $\mathrm{pH}$ was promoting degradation of the rFlgE HMWC. Figure 3.11 shows no difference between low $\mathrm{pH}$ and alkaline $\mathrm{pH}$ on previously formed $\mathrm{rFlgE} \mathrm{HMWC}$. Together, these results demonstrate 
that low $\mathrm{pH}$ inhibits polymerization of monomeric FlgE and are in agreement with the stability of the HMWC as noted in the formic acid experiments of isolated periplasmic flagella and rFlgE (Figs. 3.2, 3.4).

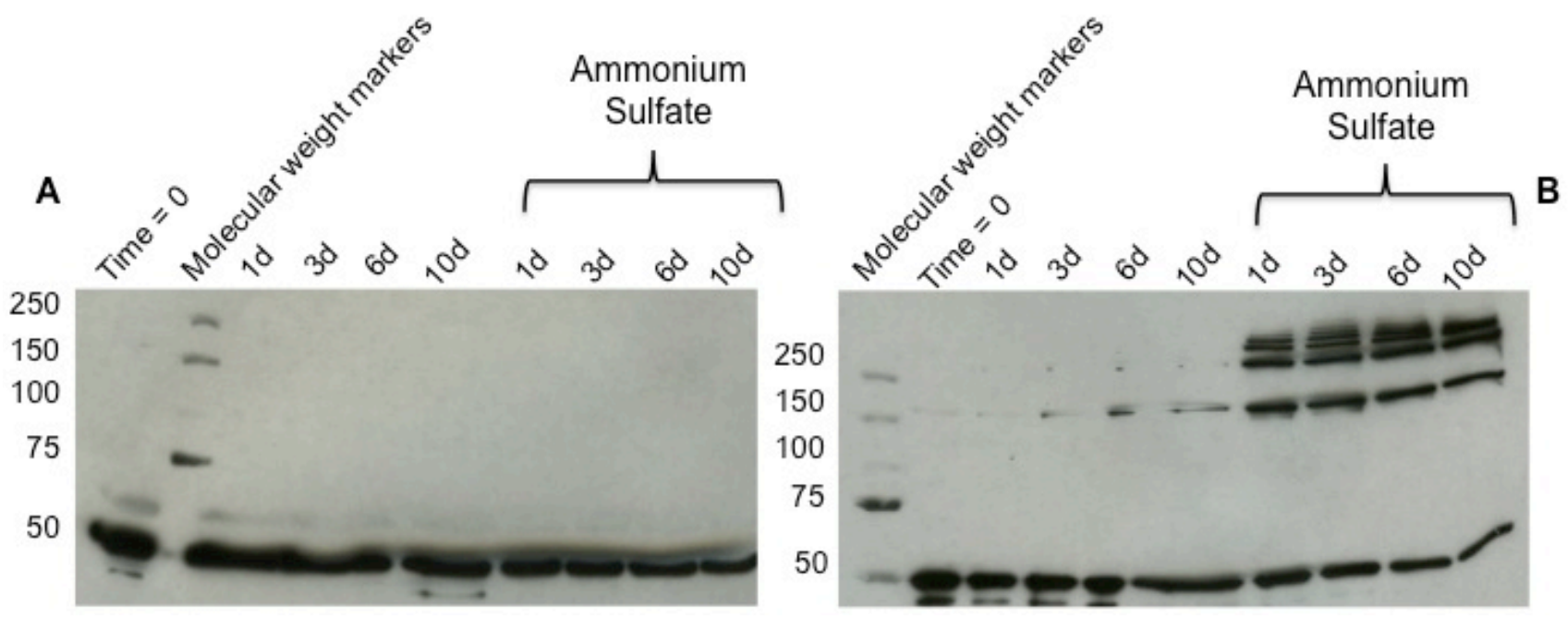

Figure 3.10. Effect of $\mathrm{pH}$ and ammonium sulfate (AS) on rFlgE HMWC formation. Samples incubated at $4^{\circ} \mathrm{C}$ at $\mathrm{pH} 3.2(\mathrm{~A})$ or $\mathrm{pH} 8.5(\mathrm{~B})$ for 10 days (D). For western blot analysis, $0.5 \mu \mathrm{g}$ protein/lane was loaded. Samples incubated with or without AS and were taken at the indicated time points. 


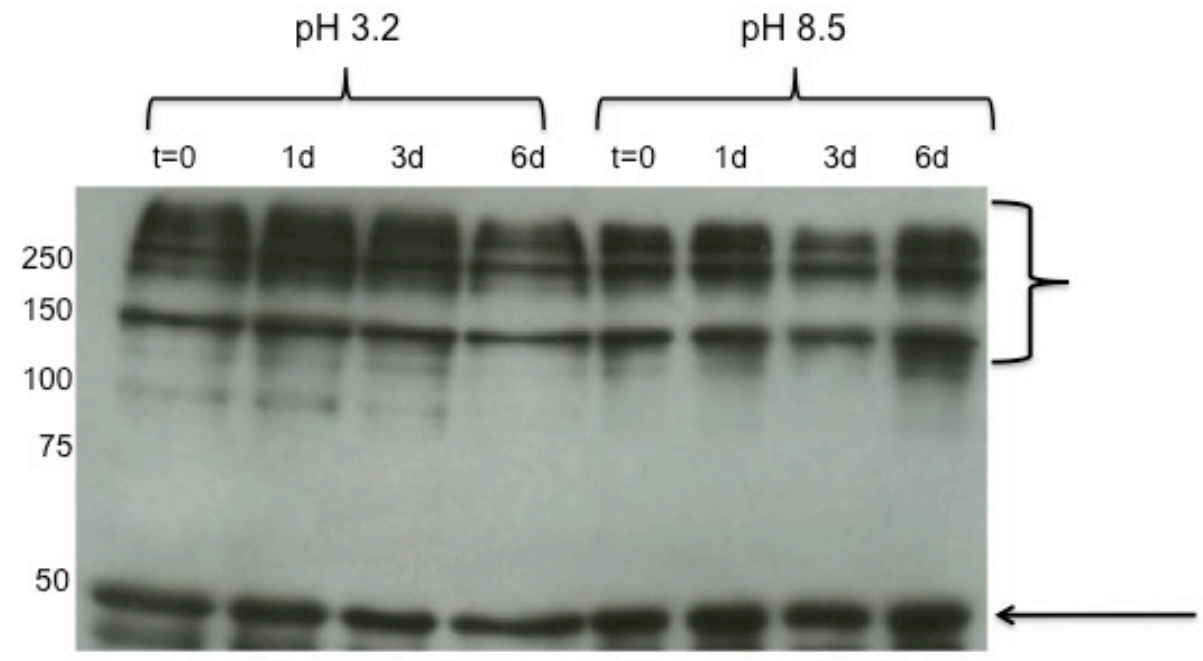

Figure 3.11. Effect of $\mathrm{pH}$ on the rFlgE HMWC. T denticola rFlgE that had previously polymerized at $\mathrm{pH} 7.4,4^{\circ} \mathrm{C}$ was incubated at $\mathrm{pH} 3.2$ or 8.5 for the indicated number of days. Samples were equally loaded for total protein $(0.5 \mu \mathrm{g} / \mathrm{lane})$. Arrow is pointing to monomeric FlgE, and the HMWC is indicated by the bracket.

Mercaptoethanol ( $\beta \mathrm{ME})$ reduces HMWC formation. There were several reasons to test the effect of a reducing agent on rFlgE polymerization in vitro. 1) Cysteine (C) residues are rather rare in flagellar hook proteins, but the single $\mathrm{C}$ residue in $T$. denticola FlgE is conserved in all spirochetes (B. burgdorferi, $T$. denticola, $T$. phagedenis, T. pallidum) shown to cross-link their flagellar hook proteins (based on BLAST and Clustal analyses). 2) MS data in combination with the $S$. enterica flagellar hook structure (20) both suggest that the cross-linking occurs in the region of the protein that is near the $\mathrm{C}$ residue. In the $\mathrm{S}$. enterica hook structure there are close contacts between amino acid residues of the six-start helix of the D2 domain, which strengthens 
the hook without impairing flexibility (20). Clustal alignment places the spirochete Cys in the D2 domain. 3) The periplasm is an oxidizing environment (43); therefore, an oxidative environment may stimulate FlgE cross-linking. We found that $\beta M E$ reduced formation of the HMWC greater than $250 \mathrm{kDa}$ but did not inhibit rFlgE polymerization at 150 kDa (Fig.3.12).

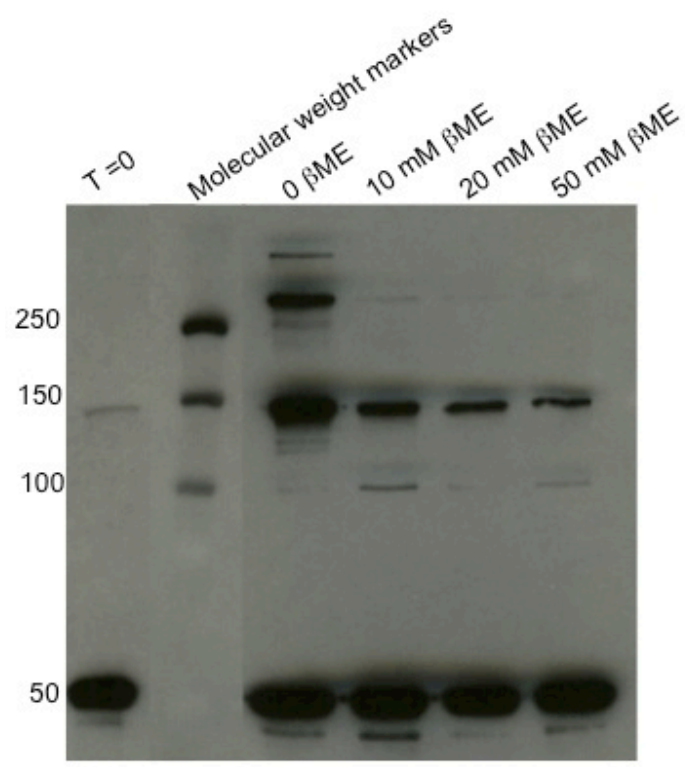

Figure 3.12. Effect of $\beta M E$ on $r F I g E ~ H M W C$ formation. Samples were treated with the indicated concentrations of bME for 7 days at $4^{\circ} \mathrm{C}, \mathrm{pH}$ 8.5. For western blot analysis, $0.5 \mu \mathrm{g}$ protein/lane was loaded onto SDS-PAGE, and the blot was probed with polyclonal FlgE antibody.

Site-directed mutagenesis impairs in vitro rFIgE HMWC formation. Trypsin fragment 15 was highly prevalent in the FlgE monomer but rarely identified in the HMWC; therefore, we generated point mutations of residues that are located in this fragment in order to determine if mutation of specific residues altered rFlgE HMWC 
formation (Figs 3.13-3.15). In collaboration with C. Li and J. Bian (University of Buffalo), we mutated the following residues to alanine (A): D181, N175, N179, and C178. In addition to single point mutations, a double mutant (N175AN179A) was generated due to possibility that either of these residues could participate in the cross-link.

The substitution mutants varied in their ability to polymerize (Figs 3.13-3.15). Mutating D181 had the most profound effect (Fig. 3.13). HMWC formation was completely abolished in the D181A mutant in the presence or absence of ammonium sulfate (Fig. 3.13). N175A HMWC formation was similar to wild-type HMWC formation (Fig. 3.14A), whereas, HMWC formation in the N179A mutant was greatly reduced (Fig. 3.14B). rFlgE HMWC polymerization was completely abolished in the N175AN179A double mutant (Fig. 3.14C). The effect of mutating C178 was interesting. The C178A mutant was unable to form a HMWC in the absence of ammonium sulfate (Fig. 3.15A); however, $\mathrm{C} 178 \mathrm{~A}$ formed a HMWC in the presence of ammonium sulfate but at a greatly reduced level compared to wild-type rFlgE (Fig. 3.15B). These results are in agreement with the $\beta M E$ experiment (Fig.3.12) and suggest that the $C 178$ residue either catalyzes the cross-linking reaction, or is part of the required microenvironment for the reaction to occur. 
B

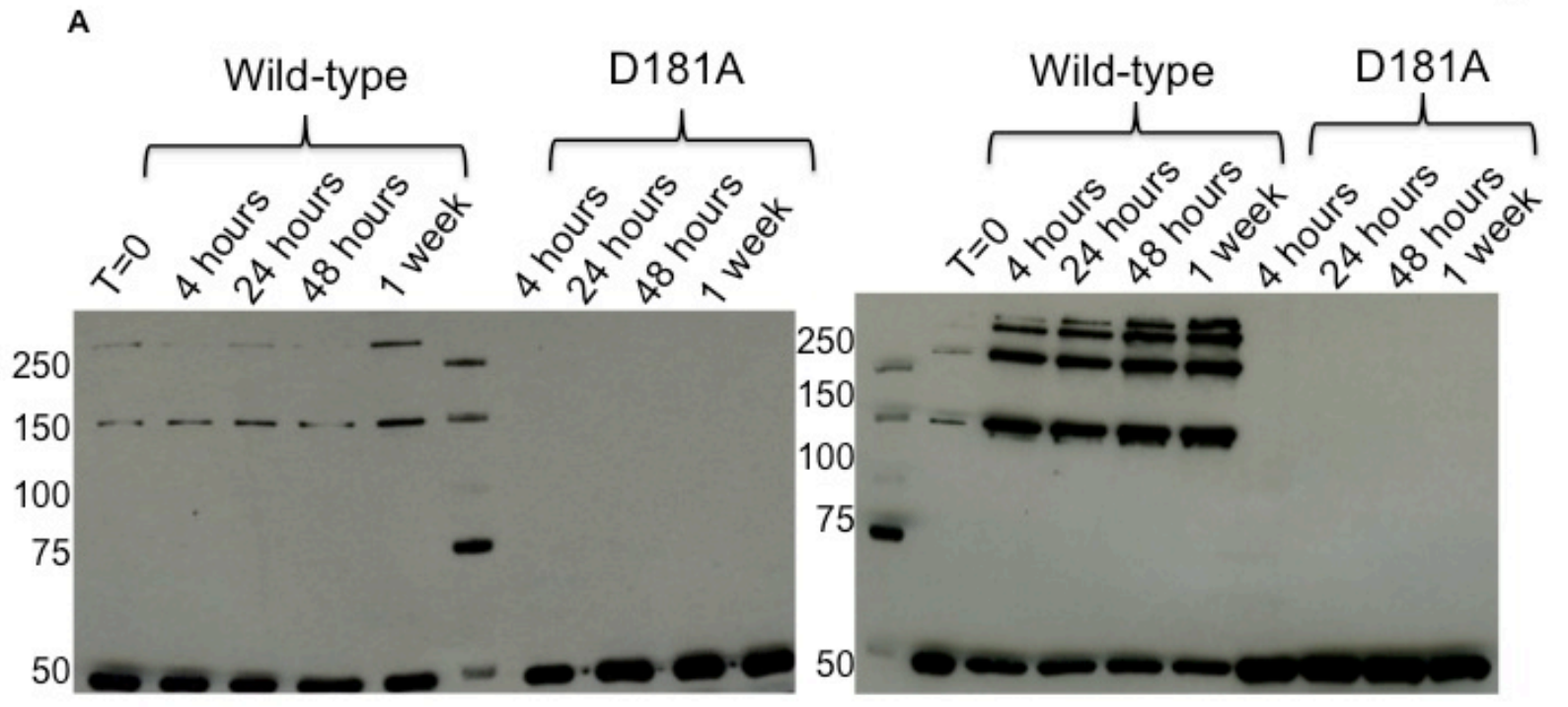

Figure 3.13. Effect of D181A substitution mutation on rFlgE HMWC formation. For western blot analysis, $0.5 \mu \mathrm{g}$ protein/lane was loaded onto SDS-PAGE, and the blot was probed with polyclonal FlgE antibody. Samples incubated at $4^{\circ} \mathrm{C}$ at $\mathrm{pH} 8.5$ without $(\mathrm{A})$ or with ammonium sulfate $(B)$ and were taken at the indicated time points. 

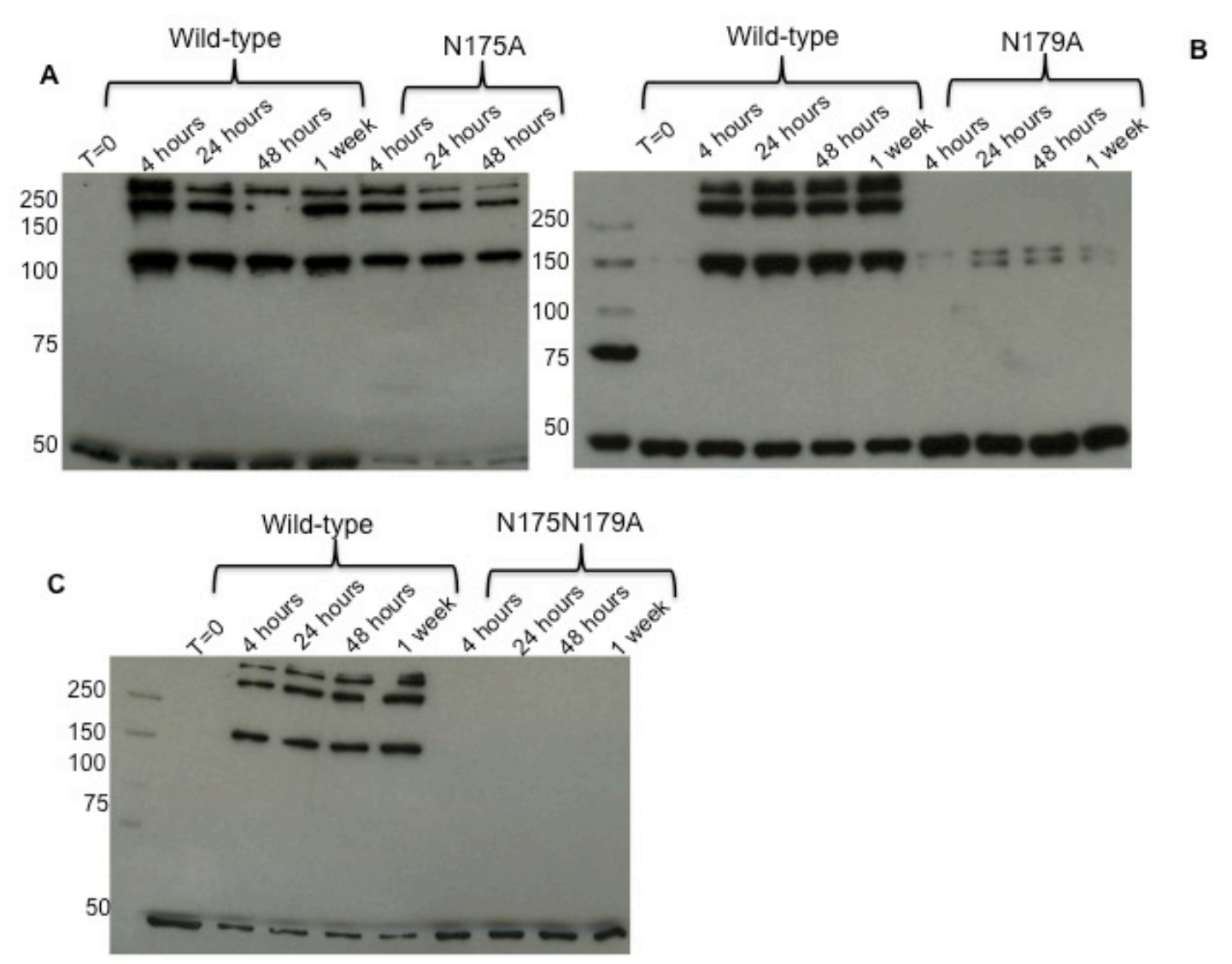

Figure 3.14. For western blot analysis, $0.5 \mu \mathrm{g}$ protein/lane was loaded onto SDSPAGE, and the blot was probed with polyclonal FlgE antibody. Effect of N175A (A), N179A (B) substitution mutations and a double N175AN179A substitution mutant (C) on rFlgE HMWC formation. Samples incubated at $4^{\circ} \mathrm{C}$ at $\mathrm{pH} 8.5$ with ammonium sulfate, and aliquots were taken at the indicated time points. 
A

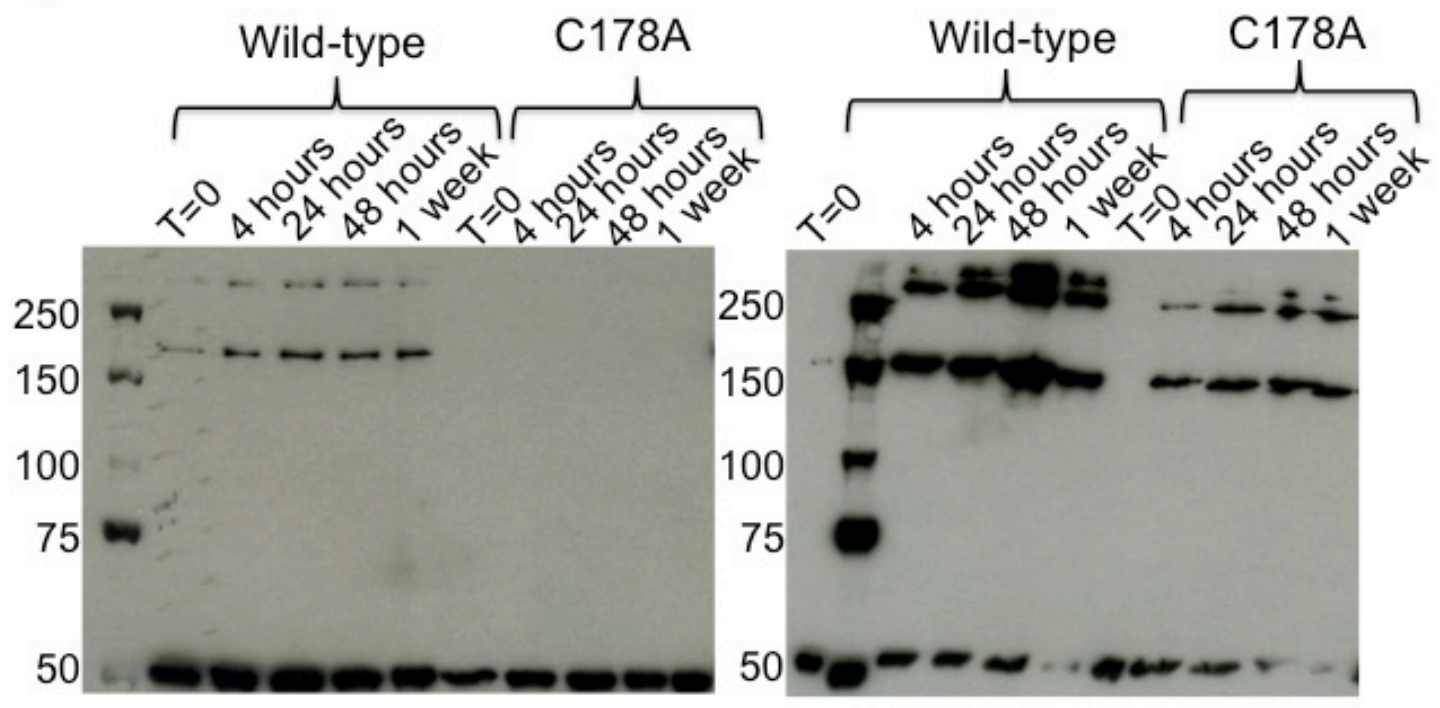

Figure 3.15. Effect of $\mathrm{C} 178 \mathrm{~A}$ substitution mutation on rFlgE HMWC formation. For western blot analysis, $0.5 \mu \mathrm{g}$ protein/lane was loaded onto SDS-PAGE, and the blot was probed with polyclonal FlgE antibody. Effect of C178A substitution mutation on rFIgE HMWC formation. Samples incubated at $4^{\circ} \mathrm{C}$ at $\mathrm{pH} 8.5$ without $(\mathrm{A})$ or with ammonium sulfate $(B)$ at the indicated time points.

\section{Discussion}

Polymerization of $T$. denticola rFlgE in vitro forming a stable HMWC was unexpected. Studying this phenomenon has three major advantages compared to studying hook basal body complexes, assuming that the process is the same as in vivo. First, it provided a means to identify inducers and inhibitors of FlgE polymerization. Previously, this was not possible because FlgE isolated from growing spirochetes is always present as a HMWC (27-30) (Miller et al, submitted) (Fig. 3.1). Second, rFlgE polymerization generated large amounts of material that could readily to be used for MS 
analysis. Over-expressing rFlgE in E. coli resulted in milligrams of FlgE protein compared to obtaining micrograms by harvesting hook basal body complexes or polyhooks (as determined by protein assay). Third, it provides an efficient means to screen mutants for HMWC formation and identify those residues responsible for crosslinking.

Studying polymerization of monomeric FlgE into the HMWC over time has provided some insight into the mechanism of the cross-linking reaction through identification of inducers and inhibitors of cross-linking. The ability for $T$. denticola rFlgE to polymerize in vitro is highly suggestive that the cross-linking reaction is autocatalytic; there is no external enzyme required. In support of this hypothesis, FlgE was the only peptide consistently identified in MS analysis of native hooks, and in several experiments was the sole protein identified.

The cross-linking mechanism of bacteriophage HK97 head proteins and the cross-linking within pili of gram-positive bacteria is autocatalytic with either a glutamic (E) or aspartic (D) acid catalyzing the reaction $(44,45)$. Both the ability for $T$. denticola rFlgE to polymerize in vitro (Figs. 3.4-5, 3.7-15) and the reduction of polymerization by heating (Fig. 3.7) indicate that $T$. denticola FlgE cross-linking is autocatalytic with FlgE acting as the enzyme. The inability for rFlgE to polymerize at low pH (Fig. 3.10) also supports the possibility of a $\mathrm{D}$ or $\mathrm{E}$ residue catalyzing the reaction. At $\mathrm{pH} 3.2$, the side chain belonging to either of these amino acids would be protonated, and as a result would be unable to catalyze isopeptide formation as in HK97. There are multiple D and E residues in the region of the protein that was suggested to be involved in cross-linking by MS (Fig. 3.6, red lines). Furthermore, the abolition of HMWC polymerization in the 
D181A rFlgE mutant suggests that D181 is required for cross-linking (Fig. 3.13).

Whether D181A is essential for catalysis (similar to the HK-97 and pili mechanism) or is one of the cross-linked amino acids is yet to be determined.

One possible source of the isopeptide bond is a cross-link between a lysine $(\mathrm{K})$ and an asparagine (N). In HK97 cross-linking, an ammonia is lost when an isopeptide bond is formed between K169 and N356 (44). The size of the anomalous mass (3732.9 Da) identified by the MS data is equal to trypsin fragments $13-14$ being cross-linked to trypsin fragment 15 minus ammonia. There are several $\mathrm{K}$ and $\mathrm{N}$ residues in this region of the protein (Fig. 3.6). Site directed mutagenesis of $r F I g E$ suggests that N179 is the preferred site for cross-linking, and that N175 can be used alternatively in the absence of N179. However, the in vitro cross-linking reaction may be more promiscuous than the reaction in spirochete hooks. Alternatively, the $\mathrm{N}$ mutations may simply affect the conformation of the protein.

The cross-link could possibly be between N179 and K165 (C-teminus of trypsin fragment 13). A cross-link involving K165 would explain why both trypsin fragments 13 and 14 are linked to trypsin fragment 15; a cross-link at that location would prevent trypsin from cutting between fragments 13 and 14 . The MS data is consistent with this possibility. Fragment 13 is identified individually in monomeric FlgE, and fragment 14 is never observed. Homology modeling (Fig. 3.16) of T. denticola FlgE onto the Salmonella model (20) is also consistent with this possibility. The $\mathrm{K}$ residues from tryptic fragments 13 and 14 on one FlgE subunit appear to be in close proximity to N179 and D181 on another subunit (Fig. 16). Modeling was done by Dr. Brian Crane, Cornell University (Ithaca, NY). Obtaining sequence data for the 3732.9 Da mass unique to the 
FlgE HMWC is needed to either confirm or disprove this speculation. Preliminary fragmentation of the 3732.9 Da mass has identified the $\mathrm{N}$-terminus of tryptic fragment 13 (Fig. 3.6, sequence highlighted in bold), and additional studies are in process.

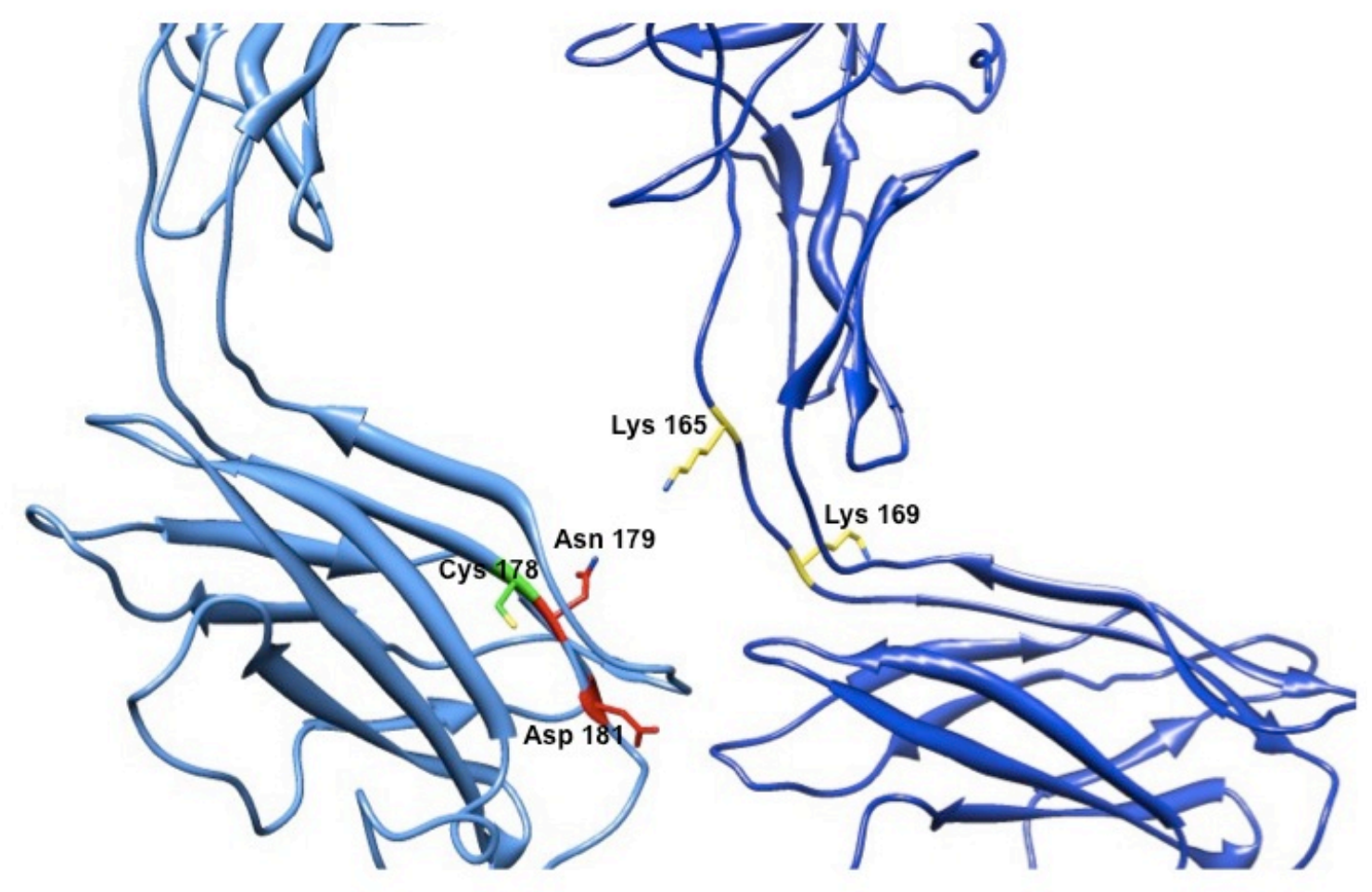

Figure 3.16. Homology Modeling of $T$. denticola FlgE onto the Salmonella model (20). Tryptic fragment 15 residues Asn 179 and Asp 181 on one FlgE subunit are located in close proximity to Lys 165 and Lys 169 on another FlgE subunit.

A cross-link between $\mathrm{K} 165$ and N179 could occur by multiple mechanisms consistent with both the MS and mutagenesis data (Fig. 3.17). For example, D181 could remove a proton from C178 resulting in a nucleophilic C. C178 then could attack N179 (from the same FlgE subunit), releasing $\mathrm{NH}_{3}$ and forming a thio-ester intermediate. K165 from a different FlgE could attack the thio-ester, releasing C178 and forming a K165-N179 isopeptide bond (Fig. 3.17A). An alternative mechanism (Fig. 3.17 B) also 
begins with $\mathrm{D} 181$ removing a proton from $\mathrm{C} 178$. C178 could then remove a proton from K165 from the second FlgE subunit, making K165 a strong nucleophile. K165 then attacks N179 in the first FlgE subunit forming the K165-N179 isopeptide bond.

A

1.

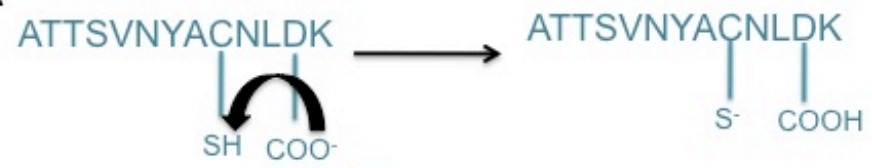

2.

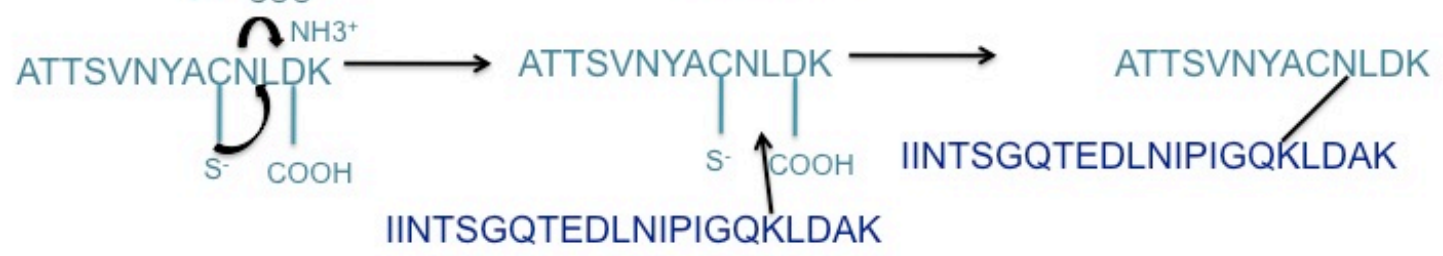

B

1. ATTSVNYACNLDK
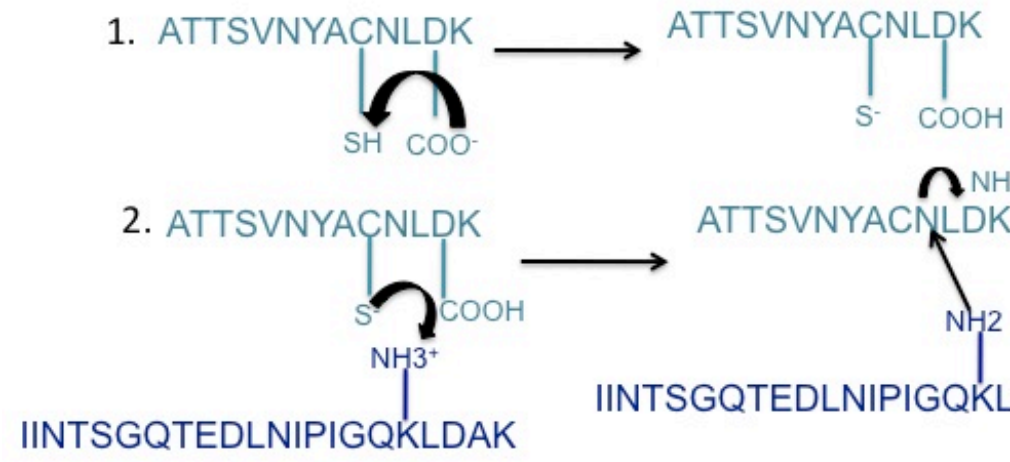

$\boldsymbol{n}^{\mathrm{NH}^{+}}$

ATTSVNYACNLLK

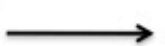

ATTSVNYACNLDK IINTSGQTEDLNIPIGQKLDAK

Figure 3.17. Mechanisms that could possibly account for an isopeptide bond between N179 of one FlgE subunit (teal) and K165 of another subunit (blue). Tryptic fragment 15 residues are teal. Tryptic fragment $13-14$ is shown in blue.

Spirochete motility is unique compared to the well-studied model of $S$. enterica motility. The sub-terminally attached flagella are not externally located; rather the flagella reside in the periplasmic space (periplasmic flagella), between the outer membrane sheath and the protoplasmic cell cylinder; as a result the flagella wrap 
around and push against the cell cylinder for motility to occur $(17,19)$. The periplasmic flagella influence cell structure in several spirochete species. In $T$. denticola there are two periplasmic flagella located at each end of the cell that overlap in the middle. Wildtype cells often have a twisted, irregular shape (some cells were right handed helices) but mutants that lack flagella fail to form the twisted-like morphology (18). Additionally, spirochetes swim faster in highly viscous, gel-like medium than in low-viscosity medium; this is the opposite pattern of what is observed in most bacteria containing external flagella $(19,46-49)$. Perhaps, FlgE cross-linking is required for optimal spirochete motility. Spirochete FlgE cross-linking may be required for the additional strength the hook requires for the filaments to exert force against the cell cylinder to generate the waves. Periplasmic flagella, although similar with respects to the flagella of other bacteria, have distinct structural peculiarities. For example, the motor $\mathrm{C}$ ring complex is larger than that found in most bacteria, and it is thought that this is related to the necessity of generating more torque needed for optimal motility $(50,51)$. Furthermore, there is an unusual structure associated with the motor, referred to as the collar, which is unique to spirochetes $(50,51)$. Its function is presently unknown. Finally, as reported in this communication, the FlgE subunits appear to cross-link to one another. Future studies are needed to determine the role of flagellar hook cross-linking in spirochete motility and virulence. 


\section{References}

1. Ellen RP, Galimanas VB. 2005. Spirochetes at the forefront of periodontal infections. Periodontology 2000 38:13-32.

2. Sela MN. 2001. Role of Treponema denticola in periodontal diseases. Crit Rev Oral Biol Med 12:399-413.

3. Riviere GR, Wagoner MA, Baker-Zander SA, Weisz KS, Adams DF, Simonson L, Lukehart SA. 1991. Identification of spirochetes related to Treponema pallidum in necrotizing ulcerative gingivitis and chronic periodontitis. The New England journal of medicine 325:539-543.

4. Newman HN. 1990. Plaque and chronic inflammatory periodontal disease. A question of ecology. J Clin Periodontol 17:533-541.

5. Simonson LG, Goodman CH, Morton HE. 1990. Quantitative immunoassay of Treponema denticola serovar C in adult periodontitis. J Clin Microbiol 28:14931496.

6. Simonson LG, Goodman CH, Bial JJ, Morton HE. 1988. Quantitative relationship of Treponema denticola to severity of periodontal disease. Infection and immunity 56:726-728.

7. Listgarten MA, Hellden L. 1978. Relative distribution of bacteria at clinically healthy and periodontally diseased sites in humans. J Clin Periodontol 5:115132.

8. Riviere GR, DeRouen TA. 1998. Association of oral spirochetes from periodontally healthy sites with development of gingivitis. J Periodontol 69:496501. 
9. Riviere GR, DeRouen TA, Kay SL, Avera SP, Stouffer VK, Hawkins NR. 1997. Association of oral spirochetes from sites of periodontal health with development of periodontitis. J Periodontol 68:1210-1214.

10. Riviere GR, Smith KS, Carranza N, Jr., Tzagaroulaki E, Kay SL, Dock M. 1995. Subgingival distribution of Treponema denticola, Treponema socranskii, and pathogen-related oral spirochetes: prevalence and relationship to periodontal status of sampled sites. J Periodontol 66:829-837.

11. Socransky SS, Haffajee AD, Smith C, Dibart S. 1991. Relation of counts of microbial species to clinical status at the sampled site. J Clin Periodontol 18:766775.

12. Grenier D. 1992. Demonstration of a bimodal coaggregation reaction between Porphyromonas gingivalis and Treponema denticola. Oral microbiology and immunology 7:280-284.

13. Kolenbrander PE, Parrish KD, Andersen RN, Greenberg EP. 1995. Intergeneric coaggregation of oral Treponema spp. with Fusobacterium spp. and intrageneric coaggregation among Fusobacterium spp. Infection and immunity 63:4584-4588.

14. Yao ES, Lamont RJ, Leu SP, Weinberg A. 1996. Interbacterial binding among strains of pathogenic and commensal oral bacterial species. Oral microbiology and immunology 11:35-41.

15. Socransky SS, Haffajee AD, Cugini MA, Smith C, Kent RL, Jr. 1998. Microbial complexes in subgingival plaque. J Clin Periodontol 25:134-144. 
16. Darveau RP. 2010. Periodontitis: a polymicrobial disruption of host homeostasis. Nature reviews. Microbiology 8:481-490.

17. Charon NW, Cockburn A, Li C, Liu J, Miller KA, Miller MR, Motaleb MA, Wolgemuth CW. 2012. The unique paradigm of spirochete motility and chemotaxis. Annu Rev Microbiol 66:349-370.

18. Ruby JD, Li H, Kuramitsu H, Norris SJ, Goldstein SF, Buttle KF, Charon NW. 1997. Relationship of Treponema denticola periplasmic flagella to irregular cell morphology. Journal of bacteriology 179:1628-1635.

19. Charon NW, Goldstein SF. 2002. Genetics of motility and chemotaxis of a fascinating group of bacteria: the spirochetes. Annu Rev Genet 36:47-73.

20. Fujii T, Kato T, Namba K. 2009. Specific arrangement of alpha-helical coiled coils in the core domain of the bacterial flagellar hook for the universal joint function. Structure 17:1485-1493.

21. Samatey FA, Matsunami H, Imada K, Nagashima S, Shaikh TR, Thomas DR, Chen JZ, Derosier DJ, Kitao A, Namba K. 2004. Structure of the bacterial flagellar hook and implication for the molecular universal joint mechanism. Nature 431:1062-1068.

22. Brown MT, Steel BC, Silvestrin C, Wilkinson DA, Delalez NJ, Lumb CN, Obara B, Armitage JP, Berry RM. 2012. Flagellar hook flexibility is essential for bundle formation in swimming Escherichia coli cells. Journal of bacteriology 194:3495-3501.

23. Chevance FF, Hughes KT. 2008. Coordinating assembly of a bacterial macromolecular machine. Nature reviews. Microbiology 6:455-465. 
24. Erhardt M, Hirano T, Su Y, Paul K, Wee DH, Mizuno S, Aizawa S, Hughes KT. 2010. The role of the FliK molecular ruler in hook-length control in Salmonella enterica. Molecular microbiology 75:1272-1284.

25. Hirano T, Yamaguchi S, Oosawa K, Aizawa S. 1994. Roles of FliK and FlhB in determination of flagellar hook length in Salmonella typhimurium. Journal of bacteriology 176:5439-5449.

26. Koroyasu S, Yamazato M, Hirano T, Aizawa SI. 1998. Kinetic analysis of the growth rate of the flagellar hook in Salmonella typhimurium by the population balance method. Biophys J 74:436-443.

27. Chi B, Limberger RJ, Kuramitsu HK. 2002. Complementation of a Treponema denticola flgE mutant with a novel coumermycin A1-resistant $\mathrm{T}$. denticola shuttle vector system. Infection and immunity 70:2233-2237.

28. Limberger RJ, Slivienski LL, Samsonoff WA. 1994. Genetic and biochemical analysis of the flagellar hook of Treponema phagedenis. Journal of bacteriology 176:3631-3637.

29. Limberger RJ, Slivienski LL, El-Afandi MC, Dantuono LA. 1996.

Organization, transcription, and expression of the 5 ' region of the fla operon of Treponema phagedenis and Treponema pallidum. Journal of bacteriology 178:4628-4634.

30. Sal MS, Li C, Motalab MA, Shibata S, Aizawa S, Charon NW. 2008. Borrelia burgdorferi uniquely regulates its motility genes and has an intricate flagellar hook-basal body structure. Journal of bacteriology 190:1912-1921. 
31. Bonifield HR, Yamaguchi S, Hughes KT. 2000. The flagellar hook protein, FlgE, of Salmonella enterica serovar typhimurium is posttranscriptionally regulated in response to the stage of flagellar assembly. Journal of bacteriology 182:4044-4050.

32. Dimmitt K, Simon MI. 1971. Purification and partial characterization of Bacillus subtilis Flagellar hooks. Journal of bacteriology 108:282-286.

33. Limberger RJ, Slivienski LL, Izard J, Samsonoff WA. 1999. Insertional inactivation of Treponema denticola tap1 results in a nonmotile mutant with elongated flagellar hooks. Journal of bacteriology 181:3743-3750.

34. Leschine SB, Canale-Parola E. 1980. Rifampin as a selective agent for isolation of oral spirochetes. J Clin Microbiol 12:792-795.

35. Li H, Ruby J, Charon N, Kuramitsu H. 1996. Gene inactivation in the oral spirochete Treponema denticola: construction of an flgE mutant. Journal of bacteriology 178:3664-3667.

36. Laemmli UK. 1970. Cleavage of structural proteins during the assembly of the head of bacteriophage T4. Nature 227:680-685.

37. Aizawa SI, Dean GE, Jones CJ, Macnab RM, Yamaguchi S. 1985. Purification and characterization of the flagellar hook-basal body complex of Salmonella typhimurium. Journal of bacteriology 161:836-849.

38. Chakraborty AB, Berger SJ, Gebler JC. 2007. Use of an integrated MS-multiplexed MS/MS data acquisition strategy for high-coverage peptide mapping studies. Rapid Commun Mass Spectrom 21:730-744. 
39. Popa MP, McKelvey TA, Hempel J, Hendrix RW. 1991. Bacteriophage HK97 structure: wholesale covalent cross-linking between the major head shell subunits. J Virol 65:3227-3237.

40. Ton-That H, Schneewind O. 2003. Assembly of pili on the surface of Corynebacterium diphtheriae. Molecular microbiology 50:1429-1438.

41. Aizawa SI, Kato S, Asakura S, Kagawa H, Yamaguchi S. 1980. In vitro polymerization of polyhook protein from Salmonella SJW880. Biochim Biophys Acta 625:291-303.

42. Kato S, Aizawa S, Asakura S. 1982. Reconstruction in vitro of the flagellar polyhook from Salmonella. J Mol Biol 161:551-560.

43. Depuydt M, Leonard SE, Vertommen D, Denoncin K, Morsomme P, Wahni K, Messens J, Carroll KS, Collet JF. 2009. A periplasmic reducing system protects single cysteine residues from oxidation. Science 326:1109-1111.

44. Dierkes LE, Peebles CL, Firek BA, Hendrix RW, Duda RL. 2009. Mutational analysis of a conserved glutamic acid required for self-catalyzed cross-linking of bacteriophage HK97 capsids. J Virol 83:2088-2098.

45. Kang HJ, Coulibaly F, Clow F, Proft T, Baker EN. 2007. Stabilizing isopeptide bonds revealed in gram-positive bacterial pilus structure. Science 318:16251628.

46. Kimsey RB, Spielman A. 1990. Motility of Lyme disease spirochetes in fluids as viscous as the extracellular matrix. The Journal of infectious diseases 162:12051208. 
47. Motaleb MA, Corum L, Bono JL, Elias AF, Rosa P, Samuels DS, Charon NW. 2000. Borrelia burgdorferi periplasmic flagella have both skeletal and motility functions. Proc Natl Acad Sci U S A 97:10899-10904.

48. Ruby JD, Charon NW. 1998. Effect of temperature and viscosity on the motility of the spirochete Treponema denticola. FEMS Microbiol Lett 169:251-254.

49. Pietrantonio F, Noble PB, Amsel R, Chan EC. 1988. Locomotory characteristics of Treponema denticola. Can J Microbiol 34:748-752.

50. Liu J, Lin T, Botkin DJ, McCrum E, Winkler H, Norris SJ. 2009. Intact flagellar motor of Borrelia burgdorferi revealed by cryo-electron tomography: evidence for stator ring curvature and rotor/C-ring assembly flexion. Journal of bacteriology 191:5026-5036.

51. Murphy GE, Leadbetter JR, Jensen GJ. 2006. In situ structure of the complete Treponema primitia flagellar motor. Nature 442:1062-1064. 


\section{Chapter 4: Discussion}

Spirochete motility is significantly different from the well-studied paradigm of S. enterica motility. Spirochete flagella are unique in both their location and structure $(1,2)$. The subterminally attached flagella reside in the periplasmic space, whereas, the flagella of the majority of bacteria are externally located, and consequently, the periplasmic flagella often play a structural role in addition to their motility function. In B. burgdorferi, wild-type cells form a flat wave, whereas mutants that do not produce flagellin ( $f l a B^{-}$, flgE-) are rod-shaped (3-5). In T. denticola, wild-type cells often have a twisted irregular shape (a minority of cells form right handed helices), but mutants that lack flagella fail to form the twisted like morphology (6).

The flagellar hook acts as a universal joint, transferring the rotational motion of flagella motors to the flagella filaments (7). In bacteria with external flagella this is easily accomplished, as the flagella rotate freely in the external environment; however in spirochetes, the region in which the flagella reside and rotate in is confined to the periplasmic space. As a result, spirochete flagella wrap around and push against the cell cylinder during motility $(2,8)$. Spirochete FlgE cross-linking may be required to strengthen the hook sufficiently for the filaments to exert the necessary force on the cell cylinder for motility to occur.

The long-term goals of this project are to better understand $B$. burgdorferi and $T$. denticola motility as it relates to pathogenesis and use that information to develop spirochete-specific antibiotics. The specific objectives of my dissertation were to 
analyze the FlgE cross-linking in B. burgdorferi and $T$. denticola. Below I discuss the major findings of my work: optimization of the procedure for isolating periplasmic flagella, mass spectrometry (MS) analysis of the FlgE high molecular weight complex (HMWC) and monomeric FlgE, characterization of the B. burgdorferi HMWC, the biochemical kinetics of $T$. denticola FlgE HMWC formation in vitro, and the effect of specific mutations on $T$. denticola HMWC formation in vitro.

\section{Optimization of periplasmic flagella and poly-hook isolation facilitates chemical} analysis of spirochete hooks. Previously, western blot analysis was the sole indication that spirochetes cross-link their flagellar hook (FlgE) proteins. The yield of FlgE using the published procedure for isolating periplasmic flagella was not sufficient for MS analysis. By making several modifications to the purification procedure, I was able to obtain enough hook protein of both B. burgdorferi (Ch. 2) and T. denticola (Ch. 3) for MS analysis. These modifications included substitution of Triton X-100 and mutanolysin for myristate and lysozyme, respectively, and incorporation of an alkaline wash (9). The MS analysis confirmed that the HMWC of spirochetes is composed of FlgE and identified FlgE as the primary protein in these complexes.

Application of the optimized protocol for isolating periplasmic flagella is not limited to this work. Motility is essential for several spirochete species to cause disease (10-15). By using this procedure, our lab and others are now able to more efficiently isolate the spirochetes' periplasmic flagella. Optimization of periplasmic flagella purification has facilitated visualization of flagellar assembly in B. burgdorferi by cryo-EM (Zhao et al, 
PNAS in press). Cryo-EM was used to compare isolated periplasmic flagella with those in situ. Combining cryo-electron tomography with mutational analysis permitted determination of the location of several flagellar structures and visualization of flagellar assembly. Assembly of the MS ring, rod, hook, and filament were examined, and as a result an additional difference between periplasmic flagella and the external flagella of S. enterica was observed. Both the organization and length of the rod differ between $B$. burgdorferi (length of $\sim 4 \mathrm{~nm})$ and S. enterica $(\sim 15 \mathrm{~nm})$. Supplying Dr. Liu with purified periplasmic flagella deciphering the molecular structure of the entire $B$. burgdorferi flagellar motor in fine detail and the specific formation of the flagellar rod (Proofs of this article are located in the appendix). Deciphering the structure of the periplasmic flagella is likely to increase our understanding of spirochete motility and subsequently pathogenesis.

\section{MS analysis of spirochete hooks identifies differences between the HMWC and}

monomeric FlgE. Peptide digestion and MS have been used to identify the crosslinked peptides of HK97 phage head proteins and Gram positive pili (Spa) proteins (1618), and site-directed mutagenesis is used for confirmation of the residues involved (16, 19, 20). The majority of possible tryptic peptides were identified by MS in both the HMWC and monomeric FlgE. There were a few peptides that were present in lower abundance in the FlgE HMWC than in the FlgE monomer (ie tryptic fragment 15). Tryptic fragment 13 was found individually in the monomer, but was connected to tryptic fragment 14 in the HMWC. We hypothesize that the lower frequency of these peptides is the result of a cross-link. Additionally, we have observed an anomalous mass (3732.9 
Da) that is present in both the $T$. denticola FlgE HMWC from cells and the in vitro formed HMWC but absent in FlgE monomer. Sequencing of this anomalous peptide is needed to verify the amino acids involved in the cross-link. Preliminary fragmentation has identified the $\mathrm{N}$-terminus of trypsin fragment 13 as present in the anomalous mass.

Characterization of FlgE cross-linking in B. burgdorferi. The life cycle of $B$. burgdorferi includes mammalian and arthropod hosts, and protein expression varies under these two conditions (21-23). Consequently, I tested whether or not the HMWC was present in two virulent strains (B31A3 and B31MI) at temperatures that correspond to the arthropod $\left(23^{\circ} \mathrm{C}\right)$ and the mammalian $\left(37^{\circ} \mathrm{C}\right)$ hosts as well as cells grown in vivo. The FlgE HMWC was present in all in vitro growth conditions tested and in cells grown in vivo. These results indicate that the HMWC is not an artifact of in vitro growth. Because the HMWC is present in virulent cells grown in vivo, it is possible that FlgE cross-linking is required for optimal motility and virulence of $B$. burgdorferi. Experiments with mutants that produce monomeric FlgE (fail to cross-link) are needed to determine the role of cross-linking in motility and virulence.

FlgE cross-linking is an autocatalytic mechanism. Studying polymerization of monomeric $\mathrm{rFlgE}$ has provided some insight into the mechanism of the cross-linking reaction. There are three lines of evidence that indicate that there is no external enzyme required for FlgE cross-linking. 1) Purified $T$. denticola rFlgE forms a HMWC in vitro (in the absence of other proteins). 2) Heating or boiling decreases the ability of $T$. denticola rFlgE to form a HMWC. 3) MS analysis of hooks from both B. burgdorferi and $T$. 
denticola identify FlgE as the sole protein present in the HMWC. The cross-linking of HK97 head proteins and the cross-linking within Gram-positive pili both utilize an autocatalytic mechanism $(16,19)$, whereas, the cross-linking between pili requires sortases (16).

\section{Site-directed mutagenesis of $T$. denticola rFlgE effects on in vitro HMWC}

formation. Based on MS and modeling analyses we tested the effect of several point mutations on rFlgE HMWC formation. These mutants varied in their ability to form a HMWC. HMWC formation in vitro provides an efficient means to screen amino acid substitution mutants for HMWC formation. HMWC formation in vitro was completely abolished in the D181A and N175AN179A mutants, and was nearly abolished in the N179A mutant. Studying the phenotype of these mutants in $T$. denticola is required to determine the role of these residues on the structure and cross-linking of the hook. Subsequently, mutants that do not cross-link their hook proteins but continue to produce monomeric FlgE should be assayed for effects on motility and virulence.

\section{Proposed Mechanism of Cross-Linking}

Cross-linking of spirochete flagellar hook proteins appears to be unique. At this time the data is too premature to define the mechanism of the cross-link, but it is possible to generate hypotheses consistent with the data obtained thus far. Cross-linking appears to share characteristics with the cross-linking mechanisms of both HK97 and pili. FlgE cross-linking appears to be autocatalytic (similar to HK97), but a C (cysteine) residue appears to be involved. There is no $\mathrm{C}$ involved in the HK97 reaction (19). C is involved 
in the sortase reaction of Gram-positive pili (24), but there appears to be no enzyme required for flagellar hook cross-linking. Additionally, there is no sortase motif in $B$. burgdorferi or T. denticola FlgE, and the MS data suggests the entire FlgE protein is present (unlike the sortase reaction where a signal sequence is cleaved (25). The current data suggests the possibility of both an D (aspartic acid) residue and a C residue being responsible for the catalysis of a peptide cross-link between a $\mathrm{K}$ (lysine) and an N (asparagine). A cross-link between these residues occurs both in HK97 (19) and Gram positive pili (16), but the process of generating the cross-link appears unique. Additional studies are needed to determine the precise mechanism of cross-linking and the residues involved.

Finding a unique mechanism of cross-linking has profound implications for treatment of spirochetal diseases. If the mechanism of cross-linking is indeed unique, an inhibitor of cross-link formation would also be unique. If spirochete flagellar crosslinking is unique and cross-linking is required for virulence, the development of spirochete-specific antibiotics that act by inhibiting the cross-link becomes possible. Spirochete mutagenesis studies that identify mutations that result in failure to cross-link (while maintaining production of FlgE) are needed to determine the role of FlgE crosslinking in motility and virulence.

\section{Summary and Implications for Future Work}

My work has increased our understanding of spirochete motility. Spirochete motility, which is mediated by periplasmic flagella, has several differences compared to externally located flagella. One of these distinctive characteristics is the cross-linking of 
flagellar hook (FlgE) proteins. The two major contributions I have made are 1) biochemical characterization of the FlgE HMWC in spirochetes (and rFlgE HMWC) and 2) optimization of periplasmic flagella purification. Both of these contributions serve as the basis for future experiments to be conducted regarding spirochete motility and pathogenesis.

The MS analysis of FlgE HMWC has indicates the majority of the protein sequence is not being cross-linked and also has identified a several peptides (tryptic fragments 1315) as likely being involved in the cross-link. Presently, studies are in progress to obtain additional sequence data for the unique 3732.9 mass, and K165A and K169A mutants are being constructed to determine if one (or both) of these Lys residues is involved in the cross-link. The information obtained from MS analysis and rFlgE point mutations will guide spirochete mutagenesis studies; these studies will allow determination of the role of FlgE cross-linking in motility and virulence.

The optimized periplasmic flagella isolation procedure is now the standard protocol for our laboratory as well as others. The optimized procedure has been used to isolate periplasmic flagella and poly-hooks successfully from both $B$. burgdorferi and $T$. denticola; therefore, it is likely applicable for isolating periplasmic flagella from other spirochete species. The ability to efficiently harvest periplasmic flagella will facilitate further characterization of these unique structures. 


\section{References}

1. Charon NW, Goldstein SF. 2002. Genetics of motility and chemotaxis of a fascinating group of bacteria: the spirochetes. Annu Rev Genet 36:47-73.

2. Charon NW, Cockburn A, Li C, Liu J, Miller KA, Miller MR, Motaleb MA, Wolgemuth CW. 2012. The unique paradigm of spirochete motility and chemotaxis. Annu Rev Microbiol 66:349-370.

3. Motaleb MA, Corum L, Bono JL, Elias AF, Rosa P, Samuels DS, Charon NW. 2000. Borrelia burgdorferi periplasmic flagella have both skeletal and motility functions. Proc Natl Acad Sci U S A 97:10899-10904.

4. Sal MS, Li C, Motalab MA, Shibata S, Aizawa S, Charon NW. 2008. Borrelia burgdorferi uniquely regulates its motility genes and has an intricate flagellar hook-basal body structure. Journal of bacteriology 190:1912-1921.

5. Sultan SZ, Manne A, Stewart PE, Bestor A, Rosa PA, Charon NW, Motaleb MA. 2013. Motility is crucial for the infectious life cycle of Borrelia burgdorferi. Infection and immunity 81:2012-2021.

6. Ruby JD, Li H, Kuramitsu H, Norris SJ, Goldstein SF, Buttle KF, Charon NW. 1997. Relationship of Treponema denticola periplasmic flagella to irregular cell morphology. Journal of bacteriology 179:1628-1635.

7. Samatey FA, Matsunami H, Imada K, Nagashima S, Shaikh TR, Thomas DR, Chen JZ, Derosier DJ, Kitao A, Namba K. 2004. Structure of the bacterial flagellar hook and implication for the molecular universal joint mechanism. Nature 431:1062-1068. 
8. Vig DK, Wolgemuth CW. 2012. Swimming dynamics of the lyme disease spirochete. Phys Rev Lett 109:218104.

9. Aizawa SI, Dean GE, Jones CJ, Macnab RM, Yamaguchi S. 1985. Purification and characterization of the flagellar hook-basal body complex of Salmonella typhimurium. Journal of bacteriology 161:836-849.

10. Lux R, Miller JN, Park NH, Shi W. 2001. Motility and chemotaxis in tissue penetration of oral epithelial cell layers by Treponema denticola. Infection and immunity 69:6276-6283.

11. Li C, Xu H, Zhang K, Liang FT. 2010. Inactivation of a putative flagellar motor switch protein FliG1 prevents Borrelia burgdorferi from swimming in highly viscous media and blocks its infectivity. Molecular microbiology 75:1563-1576.

12. Rosey EL, Kennedy MJ, Yancey RJ, Jr. 1996. Dual flaA1 flaB1 mutant of Serpulina hyodysenteriae expressing periplasmic flagella is severely attenuated in a murine model of swine dysentery. Infection and immunity 64:4154-4162.

13. Lambert A, Picardeau M, Haake DA, Sermswan RW, Srikram A, Adler B, Murray GA. 2012. FlaA proteins in Leptospira interrogans are essential for motility and virulence but are not required for formation of the flagellum sheath. Infection and immunity 80:2019-2025.

14. Botkin DJ, Abbott AN, Stewart PE, Rosa PA, Kawabata H, Watanabe H, Norris SJ. 2006. Identification of potential virulence determinants by Himar1 transposition of infectious Borrelia burgdorferi B31. Infection and immunity 74:6690-6699. 
15. Sultan SZ, Manne A, Stewart PE, Bestor A, Rosa PA, Charon NW, Motaleb MA. 2013. Motility is crucial for the infectious life cycle of Borrelia burgdorferi. Infect Immun.

16. Kang HJ, Coulibaly F, Clow F, Proft T, Baker EN. 2007. Stabilizing isopeptide bonds revealed in gram-positive bacterial pilus structure. Science 318:16251628.

17. Duda RL, Hempel J, Michel H, Shabanowitz J, Hunt D, Hendrix RW. 1995. Structural transitions during bacteriophage HK97 head assembly. J Mol Biol 247:618-635.

18. Popa MP, McKelvey TA, Hempel J, Hendrix RW. 1991. Bacteriophage HK97 structure: wholesale covalent cross-linking between the major head shell subunits. J Virol 65:3227-3237.

19. Dierkes LE, Peebles CL, Firek BA, Hendrix RW, Duda RL. 2009. Mutational analysis of a conserved glutamic acid required for self-catalyzed cross-linking of bacteriophage HK97 capsids. J Virol 83:2088-2098.

20. Duda RL, Martincic K, Hendrix RW. 1995. Genetic basis of bacteriophage HK97 prohead assembly. J Mol Biol 247:636-647.

21. Brooks CS, Hefty PS, Jolliff SE, Akins DR. 2003. Global analysis of Borrelia burgdorferi genes regulated by mammalian host-specific signals. Infection and immunity 71:3371-3383.

22. Ojaimi C, Brooks C, Casjens S, Rosa P, Elias A, Barbour A, Jasinskas A, Benach J, Katona L, Radolf J, Caimano M, Skare J, Swingle K, Akins D, Schwartz I. 2003. Profiling of temperature-induced changes in Borrelia 
burgdorferi gene expression by using whole genome arrays. Infection and immunity 71:1689-1705.

23. Caimano MJ. 2005. Cultivation of Borrelia burgdorferi in dialysis membrane chambers in rat peritonea. Curr Protoc Microbiol Chapter 12:Unit 12C 13.

24. Ton-That H, Schneewind O. 2003. Assembly of pili on the surface of Corynebacterium diphtheriae. Molecular microbiology 50:1429-1438.

25. Hendrickx AP, Budzik JM, Oh SY, Schneewind O. 2011. Architects at the bacterial surface - sortases and the assembly of pili with isopeptide bonds. Nature reviews. Microbiology 9:166-176. 
Appendix Table A1: Sample Protea MS analysis of B. burgdorferi HMWC from wildtype periplasmic flagella. All identified peptides matched FlgE. Corresponding sequences and confidence values are shown.

\begin{tabular}{|c|c|c|}
\hline Name of Protein Identified in Wild Type Bb & Confidence & Sequence \\
\hline flagellar hook protein FlgE [Borrelia burgdorferi B31] & 99.0 & AGAFDVDSDR \\
\hline flagellar hook protein FlgE [Borrelia burgdorferi B31] & 99.0 & ALASFMNPGGLAK \\
\hline flagellar hook protein FlgE [Borrelia burgdorferi B31] & 99.0 & ASDLGVSGNGFFILK \\
\hline flagellar hook protein FlgE [Borrelia burgdorferi B31] & 99.0 & GDILQIPITFN \\
\hline flagellar hook protein FlgE [Borrelia burgdorferi B31] & 99.0 & IALASFMNPGGL \\
\hline flagellar hook protein FlgE [Borrelia burgdorferi B31] & 99.0 & IALASFMNPGGLAK \\
\hline flagellar hook protein FlgE [Borrelia burgdorferi B31] & 99.0 & IGETGLAGLGDIR \\
\hline flagellar hook protein FlgE [Borrelia burgdorferi B31] & 99.0 & LGTVGSYTDSITQFADSSSTK \\
\hline flagellar hook protein FlgE [Borrelia burgdorferi B31] & 99.0 & LPLIQEGANPADIAR \\
\hline flagellar hook protein FlgE [Borrelia burgdorferi B31] & 99.0 & MDVVGNNIANVNTIGFK \\
\hline flagellar hook protein FlgE [Borrelia burgdorferi B31] & 99.0 & QVGLGMNVASIDTIHTQGAFQSTQK \\
\hline flagellar hook protein FlgE [Borrelia burgdorferi B31] & 99.0 & RLPLIQEGANPADIAR \\
\hline flagellar hook protein FlgE [Borrelia burgdorferi B31] & 99.0 & SGDTNFVETSNSGQVR \\
\hline flagellar hook protein FlgE [Borrelia burgdorferi B31] & 99.0 & SGVSGLQNHQTR \\
\hline flagellar hook protein FlgE [Borrelia burgdorferi B31] & 99.0 & SIDTIHTQGAF \\
\hline flagellar hook protein FlgE [Borrelia burgdorferi B31] & 99.0 & SIDTIHTQGAFQSTQK \\
\hline flagellar hook protein FlgE [Borrelia burgdorferi B31] & 99.0 & SLYDSFGNVSVLELR \\
\hline flagellar hook protein FlgE [Borrelia burgdorferi B31] & 99.0 & SLYSGVSGLQNHQTR \\
\hline flagellar hook protein FlgE [Borrelia burgdorferi B31] & 99.0 & TITTSDQLLQELVR \\
\hline flagellar hook protein FlgE [Borrelia burgdorferi B31] & 99.0 & VGEVGEQQTVNLK \\
\hline flagellar hook protein FlgE [Borrelia burgdorferi B31] & 99.0 & VINTASDIEDLIIPIGDK \\
\hline flagellar hook protein FlgE [Borrelia burgdorferi B31] & 99.0 & VINTASDIEDLIIPIGDKEGAK \\
\hline flagellar hook protein FlgE [Borrelia burgdorferi B31] & 99.0 & VNFQDMISQSISGASR \\
\hline flagellar hook protein FlgE [Borrelia burgdorferi B31] & 99.0 & VNFQDMISQSISGASRPTDAR \\
\hline flagellar hook protein FlgE [Borrelia burgdorferi B31] & 99.0 & YDSFGNVSVLELR \\
\hline flagellar hook protein FlgE [Borrelia burgdorferi B31] & 99.0 & YSGVSGLQNHQTR \\
\hline flagellar hook protein FlgE [Borrelia burgdorferi B31] & 90.0 & VGEVGEQQTVN \\
\hline flagellar hook protein FlgE [Borrelia burgdorferi B31] & 89.0 & AGAFDVDSDRHLVNPANGMR \\
\hline flagellar hook protein FlgE [Borrelia burgdorferi B31] & 80.0 & HLVNPANGMR \\
\hline flagellar hook protein FlgE [Borrelia burgdorferi B31] & 37.0 & GNVSVLELR \\
\hline flagellar hook protein FlgE [Borrelia burgdorferi B31] & 21.0 & GRVNFQDMISQSISGASR \\
\hline flagellar hook protein FlgE [Borrelia burgdorferi B31] & 5.0 & PLIQEGANPADIAR \\
\hline flagellar hook protein FlgE [Borrelia burgdorferi B31] & 4.0 & IQGWMAR \\
\hline
\end{tabular}


Appendix Table A2: Sample Protea MS analysis of B. burgdorferi HMWC from polyhooks. All identified peptides matched FlgE. Corresponding sequences and confidence values are shown.

\begin{tabular}{|c|c|c|}
\hline Name of Protein Identified in Bb FliK- mutant & Confidence & Sequence \\
\hline flagellar hook protein FlgE [Borrelia burgdorferi B31] & 99 & AGAFDVDSDR \\
\hline flagellar hook protein FlgE [Borrelia burgdorferi B31] & 99 & ASDLGVSGNGFFILK \\
\hline flagellar hook protein FlgE [Borrelia burgdorferi B31] & 99 & HLVNPANGMR \\
\hline flagellar hook protein FlgE [Borrelia burgdorferi B31] & 99 & IALASFMNPGGLAK \\
\hline flagellar hook protein FlgE [Borrelia burgdorferi B31] & 99 & IGETGLAGLGDIR \\
\hline flagellar hook protein FlgE [Borrelia burgdorferi B31] & 99 & LGTVGSYTDSITQFADSSSTK \\
\hline flagellar hook protein FlgE [Borrelia burgdorferi B31] & 99 & LPLIQEGANPADIAR \\
\hline flagellar hook protein FlgE [Borrelia burgdorferi B31] & 99 & MDVVGNNIANVNTIGFK \\
\hline flagellar hook protein FlgE [Borrelia burgdorferi B31] & 99 & RLPLIQEGANPADIAR \\
\hline flagellar hook protein FlgE [Borrelia burgdorferi B31] & 99 & SGDTNFVETSNSGQVR \\
\hline flagellar hook protein FlgE [Borrelia burgdorferi B31] & 99 & TITTSDQLLQELVR \\
\hline flagellar hook protein FlgE [Borrelia burgdorferi B31] & 99 & VGEVGEQQTVNLK \\
\hline flagellar hook protein FlgE [Borrelia burgdorferi B31] & 91 & IQGWMAR \\
\hline flagellar hook protein FlgE [Borrelia burgdorferi B31] & 90 & SLYSGVSGLQNHQTR \\
\hline flagellar hook protein FlgE [Borrelia burgdorferi B31] & 45 & NLFYTR \\
\hline flagellar hook protein FlgE [Borrelia burgdorferi B31] & 17 & GTWVVNK \\
\hline flagellar hook protein FlgE [Borrelia burgdorferi B31] & 80 & IQEGANPADIAR \\
\hline flagellar hook protein FlgE [Borrelia burgdorferi B31] & 11 & VNFQDMISQSISGASRPTDAR \\
\hline flagellar hook protein FlgE [Borrelia burgdorferi B31] & 99 & GLAGLGDIR \\
\hline flagellar hook protein FlgE [Borrelia burgdorferi B31] & 15 & NIANVNTIGFK \\
\hline flagellar hook protein FlgE [Borrelia burgdorferi B31] & 1 & VNFQDMISQSISGASR \\
\hline flagellar hook protein FlgE [Borrelia burgdorferi B31] & 99 & AGAFDVDSDR \\
\hline flagellar hook protein FlgE [Borrelia burgdorferi B31] & 7 & AGAFDVDSDR \\
\hline flagellar hook protein FlgE [Borrelia burgdorferi B31] & 9 & GTWVVNK \\
\hline flagellar hook protein FlgE [Borrelia burgdorferi B31] & 99 & HLVNPANGMR \\
\hline flagellar hook protein FlgE [Borrelia burgdorferi B31] & 99 & IALASFMNPGGLAK \\
\hline flagellar hook protein FlgE [Borrelia burgdorferi B31] & 99 & IALASFMNPGGLAK \\
\hline flagellar hook protein FlgE [Borrelia burgdorferi B31] & 99 & IALASFMNPGGLAK \\
\hline flagellar hook protein FlgE [Borrelia burgdorferi B31] & 45 & IALASFMNPGGLAK \\
\hline flagellar hook protein FlgE [Borrelia burgdorferi B31] & 99 & IGETGLAGLGDIR \\
\hline flagellar hook protein FlgE [Borrelia burgdorferi B31] & 99 & IGETGLAGLGDIR \\
\hline flagellar hook protein FlgE [Borrelia burgdorferi B31] & 99 & IGETGLAGLGDIR \\
\hline flagellar hook protein FlgE [Borrelia burgdorferi B31] & 82 & IQGWMAR \\
\hline flagellar hook protein FlgE [Borrelia burgdorferi B31] & 40 & IQGWMAR \\
\hline flagellar hook protein FlgE [Borrelia burgdorferi B31] & 1 & IQGWMAR \\
\hline flagellar hook protein FlgE [Borrelia burgdorferi B31] & 1 & IQGWMAR \\
\hline flagellar hook protein FlgE [Borrelia burgdorferi B31] & 99 & LGTVGSYTDSITQFADSSSTK \\
\hline flagellar hook protein FlgE [Borrelia burgdorferi B31] & 99 & LPLIQEGANPADIAR \\
\hline
\end{tabular}




\begin{tabular}{|l|c|c|}
\hline flagellar hook protein FlgE [Borrelia burgdorferi B31] & 99 & LPLIQEGANPADIAR \\
\hline flagellar hook protein FlgE [Borrelia burgdorferi B31] & 99 & LPLIQEGANPADIAR \\
\hline flagellar hook protein FlgE [Borrelia burgdorferi B31] & 2 & LPLIQEGANPADIAR \\
\hline flagellar hook protein FlgE [Borrelia burgdorferi B31] & 99 & MDVVGNNIANVNTIGFK \\
\hline flagellar hook protein FlgE [Borrelia burgdorferi B31] & 37 & NLFYTR \\
\hline flagellar hook protein FlgE [Borrelia burgdorferi B31] & 2 & NVSVLELR \\
\hline flagellar hook protein FlgE [Borrelia burgdorferi B31] & 99 & RLPLIQEGANPADIAR \\
\hline flagellar hook protein FlgE [Borrelia burgdorferi B31] & 6 & RLPLIQEGANPADIAR \\
\hline flagellar hook protein FlgE [Borrelia burgdorferi B31] & 99 & SGDTNFVETSNSGQVR \\
\hline flagellar hook protein FlgE [Borrelia burgdorferi B31] & 99 & SGDTNFVETSNSGQVR \\
\hline flagellar hook protein FlgE [Borrelia burgdorferi B31] & 99 & SGDTNFVETSNSGQVR \\
\hline flagellar hook protein FlgE [Borrelia burgdorferi B31] & 99 & SGDTNFVETSNSGQVR \\
\hline flagellar hook protein FlgE [Borrelia burgdorferi B31] & 99 & SGDTNFVETSNSGQVR \\
\hline flagellar hook protein FlgE [Borrelia burgdorferi B31] & 11 & SLYSGVSGLQNHQTR \\
\hline flagellar hook protein FlgE [Borrelia burgdorferi B31] & 1 & SLYSGVSGLQNHQTR \\
\hline flagellar hook protein FlgE [Borrelia burgdorferi B31] & 78 & TITTSDQLLQELVR \\
\hline flagellar hook protein FlgE [Borrelia burgdorferi B31] & 64 & TITTSDQLLQELVR \\
\hline
\end{tabular}


Appendix Table A3: Sample NIOSH analysis of $T$. denticola HMWC from poly-hooks. All identified peptides matched FlgE. All peptides listed below were identified with > $95 \%$ confidence.

\begin{tabular}{|c|c|}
\hline Name of Protein Identified & Peptide Sequence \\
\hline FlgE_Tdenticola & AYEQDGYTLGYLENFR \\
\hline FlgE_Tdenticola & IDQSGIITGVYSNGVR \\
\hline FlgE_Tdenticola & AQILESTWSTEFK \\
\hline FlgE_Tdenticola & VQGWMAEEAEGFR \\
\hline FlgE_Tdenticola & RLPELPEGANR \\
\hline FlgE_Tdenticola & EGTLVNPANGMR \\
\hline FlgE_Tdenticola & VYDSFGEAHELQIDFAR \\
\hline FlgE_Tdenticola & IINTSGQTEDLNIPIGQK \\
\hline FlgE_Tdenticola & TIQTSDTMLETVLNLK \\
\hline FlgE_Tdenticola & HTFDVNLGEIGTSK \\
\hline FlgE_Tdenticola & MDVIGNNVANVNTTGFK \\
\hline FlgE_Tdenticola & IDQSGIITGVYSNGVR \\
\hline FlgE_Tdenticola & EGTLVNPANGMR \\
\hline FlgE_Tdenticola & HTFDVNLGEIGTSK \\
\hline FlgE_Tdenticola & LSGAARPTEELGGVNPK \\
\hline FlgE_Tdenticola & GRVNFQDLISQQLSGAARPTEELGGVNPK \\
\hline FlgE_Tdenticola & LPELPEGANR \\
\hline FlgE_Tdenticola & VGIGTTDGVQNSFIVR \\
\hline FlgE_Tdenticola & IDQSGIITGVYSNGVR \\
\hline FlgE_Tdenticola & VQGWMAEEAEGFR \\
\hline FlgE_Tdenticola & TIQTSDTMLETVLNLK \\
\hline FlgE_Tdenticola & EGTLVNPANGMR \\
\hline FlgE_Tdenticola & NVANVNTTGFK \\
\hline FlgE_Tdenticola & EGTLVNPANGMR \\
\hline FlgE_Tdenticola & TFYTRAGAFGIDK \\
\hline FlgE_Tdenticola & TVNVDPTNADATATR \\
\hline FlgE_Tdenticola & ATVNVDPTNADATATR \\
\hline FlgE_Tdenticola & IDQSGIITGVYSNGVR \\
\hline FlgE_Tdenticola & IINTSGQTEDLNIPIGQK \\
\hline FlgE_Tdenticola & HTFDVNLGEIGTSKNTITQFSDKSTTK \\
\hline FlgE_Tdenticola & GYFIGGTLEMSNVDLTDQFVDMIVTQK \\
\hline FlgE_Tdenticola & SLFSGVTGMQNHQTR \\
\hline FlgE_Tdenticola & NTITQFSDK \\
\hline FlgE_Tdenticola & FSGVTGMQNHQTR \\
\hline FlgE_Tdenticola & MDVIGNNVANVNTTGFK \\
\hline FlgE_Tdenticola & MDVIGNNVANVNTTGFK \\
\hline FlgE_Tdenticola & GANR \\
\hline FlgE_Tdenticola & EGTLVNPANGMR \\
\hline FlgE_Tdenticola & MDVIGNNVANVNTTGFK \\
\hline FlgE_Tdenticola & MDVIGNNVANVNTTGFK \\
\hline FlgE_Tdenticola & MDVIGNNVANVNTTGFK \\
\hline FlgE_Tdenticola & MDVIGNNVANVNTTGFKRGR \\
\hline FlgE_Tdenticola & ATVNVDPTNADATATR \\
\hline FlgE_Tdenticola & GFQAGAKTIQTSDTMLETVLNLK \\
\hline FlgE_Tdenticola & NTITQFSDKSTTK \\
\hline FlgE_Tdenticola & NTITQFSDKSTTK \\
\hline FlgE_Tdenticola & EGTLVNPANGMR \\
\hline FlgE Tdenticola & RLPELPEGANR \\
\hline
\end{tabular}




\begin{tabular}{|c|c|}
\hline FlgE_Tdenticola & LDAK \\
\hline FlgE_Tdenticola & NHQTR \\
\hline FlgE_Tdenticola & TFYTR \\
\hline FlgE_Tdenticola & GFQAGAK \\
\hline FlgE_Tdenticola & HTFDVNLGEIG \\
\hline FlgE_Tdenticola & TFYTRAGAFGI \\
\hline FlgE_Tdenticola & TIQTSDTMLET \\
\hline FlgE_Tdenticola & TFYTRAGAFGIDK \\
\hline FlgE_Tdenticola & TFYTRAGAFGIDK \\
\hline FlgE_Tdenticola & NTITQFSDKSTTK \\
\hline FlgE_Tdenticola & NTITQFSDKSTTK \\
\hline FlgE_Tdenticola & GRVNFQDLISQQL \\
\hline FlgE_Tdenticola & VQGWMAEEAEGFR \\
\hline FlgE_Tdenticola & AQILESTWSTEFK \\
\hline FlgE_Tdenticola & ATTSVNYACNLDKR \\
\hline FlgE_Tdenticola & VGIGTTDGVQNSFIVR \\
\hline FlgE_Tdenticola & SLFSGVTGMQNHQTR \\
\hline FlgE_Tdenticola & VGIGTTDGVQNSFIVR \\
\hline FlgE_Tdenticola & VGIGTTDGVQNSFIVR \\
\hline FlgE_Tdenticola & MDVIGNNVANVNTTGFK \\
\hline FlgE_Tdenticola & TIQTSDTMLETVLNLK \\
\hline FlgE_Tdenticola & TIQTSDTMLETVLNLK \\
\hline FlgE_Tdenticola & MDVIGNNVANVNTTGFK \\
\hline FlgE_Tdenticola & MDVIGNNVANVNTTGFKR \\
\hline FlgE Tdenticola & AGAFGIDKEGTLVNPANGMR \\
\hline FlgE_Tdenticola & AGAFGIDKEGTLVNPANGMRVQGWMAEEAEGFR \\
\hline FlgE_Tdenticola & ATTSVNYACNLDK \\
\hline FlgE_Tdenticola & EGTLVNPANGMR \\
\hline FlgE_Tdenticola & MDVIGNNVANVNTTGFK \\
\hline FlgE_Tdenticola & SLFSGVTGMQNHQTR \\
\hline FlgE_Tdenticola & MDVIGNNVANVNTTGFK \\
\hline FlgE_Tdenticola & TIQTSDTMLETVLNLK \\
\hline FlgE_Tdenticola & GYFIGGTLEMSNVDLTDQFVDMIVTQK \\
\hline FlgE_Tdenticola & SLFSGVTGMQNHQTR \\
\hline FlgE_Tdenticola & EGTLVNPANGMR \\
\hline FlgE_Tdenticola & QEIGQIAMAGFANQGGLEK \\
\hline FlgE_Tdenticola & VQGWMAEEAEGFR \\
\hline FlgE_Tdenticola & NTITQFSDK \\
\hline FlgE_Tdenticola & GEIGTSK \\
\hline FlgE_Tdenticola & GYFIGGTLEMSNVDLTDQFVDMIVTQK \\
\hline FlgE_Tdenticola & NTITQFSDK \\
\hline FlgE_Tdenticola & VYDSFGEAHELQIDFAR \\
\hline FlgE_Tdenticola & MDVIGNNVANVNTTGFK \\
\hline FlgE_Tdenticola & EGTLVNPANGMR \\
\hline FlgE_Tdenticola & SLFSGVTGMQNHQTR \\
\hline FlgE_Tdenticola & EGTLVNPANGMR \\
\hline FlgE_Tdenticola & TIQTSDTMLETVLNLKR \\
\hline FlgE_Tdenticola & MDVIGNNVANVNTTGFK \\
\hline FlgE_Tdenticola & EGTLVNPANGMR \\
\hline
\end{tabular}




\begin{tabular}{|c|c|}
\hline FlgE_Tdenticola & MDVIGNNVANVNTTGFKR \\
\hline FlgE_Tdenticola & LSGAARPTEELGGVNPK \\
\hline FlgE_Tdenticola & ATVNVD \\
\hline FlgE_Tdenticola & VQGWMA \\
\hline FlgE_Tdenticola & IINTSGQ \\
\hline FlgE_Tdenticola & VYDSFGE \\
\hline FlgE_Tdenticola & TIQTSDTML \\
\hline FlgE_Tdenticola & PELPEGANR \\
\hline FlgE_Tdenticola & AQILESTWS \\
\hline FlgE_Tdenticola & VPGEVNAWR \\
\hline FlgE_Tdenticola & VPGEVNAWR \\
\hline FlgE_Tdenticola & LPELPEGANR \\
\hline FlgE_Tdenticola & TLVNPANGMR \\
\hline FlgE_Tdenticola & LPELPEGANR \\
\hline FlgE_Tdenticola & LPELPEGANR \\
\hline FlgE_Tdenticola & DGEKTFYTR \\
\hline FlgE_Tdenticola & MMRSLFSGVTG \\
\hline FlgE_Tdenticola & RLPELPEGANR \\
\hline FlgE_Tdenticola & EGTLVNPANGMR \\
\hline FlgE_Tdenticola & EGTLVNPANGMR \\
\hline FlgE_Tdenticola & EGTLVNPANGMR \\
\hline FlgE_Tdenticola & TFYTRAGAFGIDK \\
\hline FlgE_Tdenticola & ATTSVNYACNLDK \\
\hline FlgE_Tdenticola & NTITQFSDKSTTK \\
\hline FlgE_Tdenticola & HTFDVNLGEIGTSK \\
\hline FlgE_Tdenticola & HTFDVNLGEIGTSK \\
\hline FlgE_Tdenticola & AQILESTWSTEFK \\
\hline FlgE_Tdenticola & AQILESTWSTEFK \\
\hline FlgE_Tdenticola & FGEAHELQIDFAR \\
\hline FlgE_Tdenticola & GYFIGGTLEMSNVDL \\
\hline FlgE_Tdenticola & ATTSVNYACNLDKR \\
\hline FlgE_Tdenticola & ATVNVDPTNADATATR \\
\hline FlgE_Tdenticola & MDVIGNNVANVNTTGF \\
\hline FlgE_Tdenticola & RGRVNFQDLISQQL \\
\hline FlgE_Tdenticola & IDQSGIITGVYSNGVR \\
\hline FlgE_Tdenticola & VGIGTTDGVQNSFIVR \\
\hline FlgE_Tdenticola & SLFSGVTGMQNHQTR \\
\hline FlgE_Tdenticola & IDQSGIITGVYSNGVR \\
\hline FlgE_Tdenticola & IDQSGIITGVYSNGVR \\
\hline FlgE_Tdenticola & IDQSGIITGVYSNGVR \\
\hline FlgE_Tdenticola & TIQTSDTMLETVLNLK \\
\hline FlgE_Tdenticola & TIQTSDTMLETVLNLK \\
\hline FlgE_Tdenticola & MDVIGNNVANVNTTGFK \\
\hline FlgE_Tdenticola & MDVIGNNVANVNTTGFK \\
\hline FlgE_Tdenticola & MDVIGNNVANVNTTGFK \\
\hline FlgE_Tdenticola & TIQTSDTMLETVLNLK \\
\hline FlgE_Tdenticola & TIQTSDTMLETVLNLK \\
\hline FlgE_Tdenticola & TIQTSDTMLETVLNLK \\
\hline FlgE_Tdenticola & IINTSGQTEDLNIPIGQK \\
\hline
\end{tabular}




\begin{tabular}{|c|c|}
\hline FlgE_Tdenticola & QEIGQIAMAGFANQGGLEK \\
\hline FlgE_Tdenticola & VYDSFGEAHELQIDFAR \\
\hline FlgE Tdenticola & VYDSFGEAHELQIDFAR \\
\hline FlgE_Tdenticola & AGAFGIDKEGTLVNPANGMR \\
\hline FlgE Tdenticola & AGAFGIDKEGTLVNPANGMR \\
\hline FlgE_Tdenticola & AGAFGIDKEGTLVNPANGMR \\
\hline FlgE_Tdenticola & LDAKATTSVNYACNLDKR \\
\hline FlgE_Tdenticola & LDAKATTSVNYACNLDKR \\
\hline FlgE_Tdenticola & MMRSLFSGVTGMQNHQTR \\
\hline FlgE_Tdenticola & MDVIGNNVANVNTTGFKRGR \\
\hline FlgE_Tdenticola & LISQQLSGAARPTEELGGVNPK \\
\hline FlgE_Tdenticola & IINTSGQTEDLNIPIGQKLDAK \\
\hline FlgE_Tdenticola & IINTSGQTEDLNIPIGQKLDAK \\
\hline FlgE_Tdenticola & GFQAGAKTIQTSDTMLETVLNLK \\
\hline FlgE_Tdenticola & GFQAGAKTIQTSDTMLETVLNLKR \\
\hline FlgE_Tdenticola & TFYTRAGAFGIDKEGTLVNPANGMR \\
\hline FlgE_Tdenticola & RLPELPEGANRAQILESTWSTEFK \\
\hline FlgE_Tdenticola & RLPELPEGANRAQILESTWSTEFK \\
\hline FlgE_Tdenticola & VNFQDLISQQLSGAARPTEELGGVNPK \\
\hline FlgE_Tdenticola & VYDSFGEAHELQIDFARVPGEVNAWR \\
\hline FlgE_Tdenticola & VYDSFGEAHELQIDFARVPGEVNAWR \\
\hline FlgE_Tdenticola & GYFIGGTLEMSNVDLTDQFVDMIVTQK \\
\hline FlgE_Tdenticola & GRVNFQDLISQQLSGAARPTEELGGVNPK \\
\hline FlgE_Tdenticola & RGRVNFQDLISQQLSGAARPTEELGGVNPK \\
\hline FlgE_Tdenticola & SLFSGVTGMQNHQTRMDVIGNNVANVNTTGFKR \\
\hline FlgE_Tdenticola & GYFIGGTLEMSNVDLTDQFVDMIVTQKGFQAGAK \\
\hline FlgE_Tdenticola & GYFIGGTLEMSNVDLTDQFVDMIVTQKGFQAGAK \\
\hline FlgE_Tdenticola & VYDSFGEAHELQIDFAR \\
\hline FlgE_Tdenticola & HTFDVN \\
\hline FlgE_Tdenticola & IINTSGQTEDLNIPIGQK \\
\hline FlgE_Tdenticola & EGTLVNPANGMR \\
\hline FlgE_Tdenticola & SL \\
\hline FlgE_Tdenticola & TEDLNIPIGQKLDAK \\
\hline FlgE_Tdenticola & GVTGMQNHQTR \\
\hline FlgE_Tdenticola & SL \\
\hline FlgE_Tdenticola & TIQTSDTMLETVL \\
\hline FlgE_Tdenticola & AYEQDGYTLGYLENFR \\
\hline FlgE_Tdenticola & HTFDVNLGEI \\
\hline FlgE_Tdenticola & EGTLVNPANGMR \\
\hline FlgE_Tdenticola & HTFDVNLG \\
\hline FlgE_Tdenticola & TIQTSDTMLETVLNLK \\
\hline FlgE_Tdenticola & IINTSGQTEDLN \\
\hline FlgE_Tdenticola & EGTLVNPANGMR \\
\hline FlgE_Tdenticola & VYDSFGEAHELQIDFAR \\
\hline FlgE_Tdenticola & GIDK \\
\hline
\end{tabular}




\begin{tabular}{|l|l|}
\hline Name of Protein Identified & Peptide Sequence \\
\hline FlgE_Tdenticola & AYEQDGYTLGYLENFR \\
\hline FlgE_Tdenticola & IDQSGIITGVYSNGVR \\
\hline FlgE_Tdenticola & AQILESTWSTEFK \\
\hline FlgE_Tdenticola & VQGWMAEEAEGFR \\
\hline FlgE_Tdenticola & RLPELPEGANR \\
\hline FlgE_Tdenticola & EGTLVNPANGMR \\
\hline FlgE_Tdenticola & VYDSFGEAHELQIDFAR \\
\hline FlgE_Tdenticola & IINTSGQTEDLNIPIGQK \\
\hline FlgE_Tdenticola & TIQTSDTMLETVLNLK \\
\hline FlgE_Tdenticola & HTFDVNLGEIGTSK \\
\hline FlgE_Tdenticola & MDVIGNNVANVNTTGFK \\
\hline FlgE_Tdenticola & IDQSGIITGVYSNGVR \\
\hline FlgE_Tdenticola & EGTLVNPANGMR \\
\hline FlgE_Tdenticola & HTFDVNLGEIGTSK \\
\hline FlgE_Tdenticola & LSGAARPTEELGGVNPK \\
\hline FlgE_Tdenticola & GRVNFQDLISQQLSGAARPTEELGGVNPK \\
\hline FlgE_Tdenticola & LPELPEGANR \\
\hline FlgE_Tdenticola & VGIGTTDGVQNSFIVR \\
\hline FlgE_Tdenticola & IDQSGIITGVYSNGVR \\
\hline FlgE_Tdenticola & VQGWMAEEAEGFR \\
\hline FlgE_Tdenticola & TIQTSDTMLETVLNLK \\
\hline FlgE_Tdenticola & EGTLVNPANGMR \\
\hline FlgE_Tdenticola & NVANVNTTGFK \\
\hline FlgE_Tdenticola & EGTLVNPANGMR \\
\hline FlgE_Tdenticola & TFYTRAGAFGIDK \\
\hline FlgE_Tdenticola & TVNVDPTNADATATR \\
\hline FlgE_Tdenticola & ATVNVDPTNADATATR \\
\hline FlgE_Tdenticola & IDQSGIITGVYSNGVR \\
\hline FlgE_Tdenticola & IINTSGQTEDLNIPIGQK \\
\hline FlgE_Tdenticola & HTFDVNLGEIGTSKNTITQFSDKSTTK \\
\hline FlgE_Tdenticola & GYFIGGTLEMSNVDLTDQFVDMIVTQK \\
\hline FlgE_Tdenticola & SLFSGVTGMQNHQTR \\
\hline FlgE_Tdenticola & NTITQFSDK \\
\hline & \\
\hline
\end{tabular}




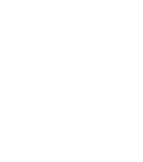
ANNUAL Further
REVIEWS

Click here for quick links to Annual Reviews content online, including:

- Other articles in this volume

- Top cited articles

- Top downloaded articles

- Our comprehensive search

Annu. Rev. Microbiol. 2012. 66:349-70

The Annual Review of Microbiology is online at micro.annualreviews.org

This article's doi:

10.1146/annurev-micro-092611-150145

Copyright (C) 2012 by Annual Reviews. All rights reserved

0066-4227/12/1013-0349\$20.00

\section{The Unique Paradigm of Spirochete Motility and Chemotaxis}

\section{Nyles W. Charon, ${ }^{1}$ Andrew Cockburn, ${ }^{1}$ Chunhao Li, ${ }^{3}$ Jun Liu, ${ }^{4}$ Kelly A. Miller, ${ }^{1}$ Michael R. Miller, ${ }^{2}$ Md. A. Motaleb, ${ }^{5}$ and Charles W. Wolgemuth ${ }^{6}$}

\author{
${ }^{1}$ Department of Microbiology, Immunology, and Cell Biology, ${ }^{2}$ Department of Biochemistry, \\ West Virginia University, Health Sciences Center, Morgantown, West Virginia 26506-9177; \\ email: ncharon@hsc.wvu.edu, acockbur@mail.wvu.edu, kamiller@hsc.wvu.edu, \\ mmiller@hsc.wvu.edu \\ ${ }^{3}$ Department of Oral Biology, The State University of New York at Buffalo, New York \\ 14214-3092; email: cli9@buffalo.edu \\ ${ }^{4}$ The University of Texas-Houston Medical School, Department of Pathology and Laboratory \\ Medicine, Houston, Texas 77030; email: jun.liu.1@uth.tmc.edu \\ ${ }^{5}$ Department of Microbiology and Immunology, Brody School of Medicine, East Carolina \\ University, Greenville, North Carolina 27834; email: motalebm@ecu.edu \\ ${ }^{6}$ Department of Cell Biology and Center for Cell Analysis and Modeling, University of \\ Connecticut Health Center, Farmington, Connecticut 06030-3505; \\ email: cwolgemuth@uchc.edu
}

\section{Keywords}

Borrelia, Lyme disease, motor, flagella

\begin{abstract}
Spirochete motility is enigmatic: It differs from the motility of most other bacteria in that the entire bacterium is involved in translocation in the absence of external appendages. Using the Lyme disease spirochete Borrelia burgdorferi $(B b)$ as a model system, we explore the current research on spirochete motility and chemotaxis. $B b$ has periplasmic flagella $(\mathrm{PFs})$ subterminally attached to each end of the protoplasmic cell cylinder, and surrounding the cell is an outer membrane. These internal helix-shaped PFs allow the spirochete to swim by generating backward-moving waves by rotation. Exciting advances using cryoelectron tomography are presented with respect to in situ analysis of cell, PF, and motor structure. In addition, advances in the dynamics of motility, chemotaxis, gene regulation, and the role of motility and chemotaxis in the life cycle of $B b$ are summarized. The results indicate that the motility paradigms of flagellated bacteria do not apply to these unique bacteria.
\end{abstract}




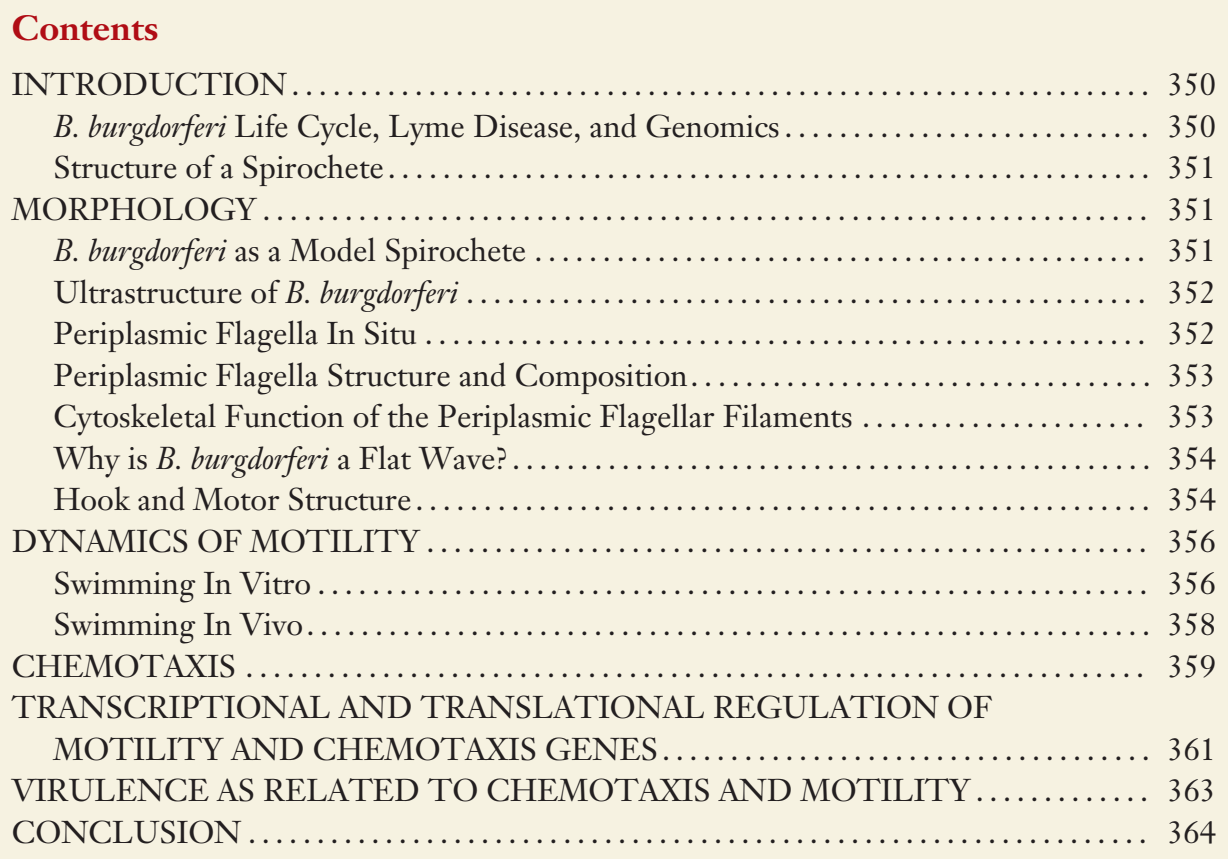

\section{INTRODUCTION}

A century ago Clifford Dobell (23) said "the movements of the Spirochaets are still surrounded in mystery." A half century later Claes Weibull (101) quoted Dobell and went on to say "it could be asked whether the situation has changed very much since those days." After yet another half century, although progress has been made, many intriguing questions about spirochete motility remain unanswered and some obscurity about their elegant motions still persists. Genomic analysis indicates that spirochetes are a monophyletic clade (72), so we expect that spirochete motility has some similarity across taxa. Several reviews have been published on spirochete motility and the reader is referred to these articles $(15,34,51,102)$. However, there has been some fresh and robust progress in several areas that focus on particular aspects of spirochete motility, especially on the spirochete Borrelia burgdorferi $(B b)$. This progress has been spurred by the increase in research interest in $B b$ because of the importance of the disease it causes and recent breakthroughs in genetic manipulation. Furthermore, owing to its small diameter, $B b$ is optimal for analysis utilizing the groundbreaking methodology of cryoelectron tomography (cryo-ET).

Bb: Borrelia burgdorferi

Cryo-ET:

cryoelectron

tomography

\section{B. burgdorferi Life Cycle, Lyme Disease, and Genomics}

$B b$ is the causative agent of the zoonosis called Lyme disease $(81,86,89)$. Small mammals such as mice and voles, and specific species of birds, serve as reservoirs of infection. Humans are accidental hosts. Transmission occurs via the bite of hard shell ticks of certain Ixodes species. In humans, Lyme disease has many manifestations, including a spreading rash (erythema migrans), acute and chronic arthritis, a skin disease (acrodermatitis), neurologic problems, and heart block. In the United States, Lyme disease is the most prevalent arthropod-borne human infection. Ten different species in $B b$ 


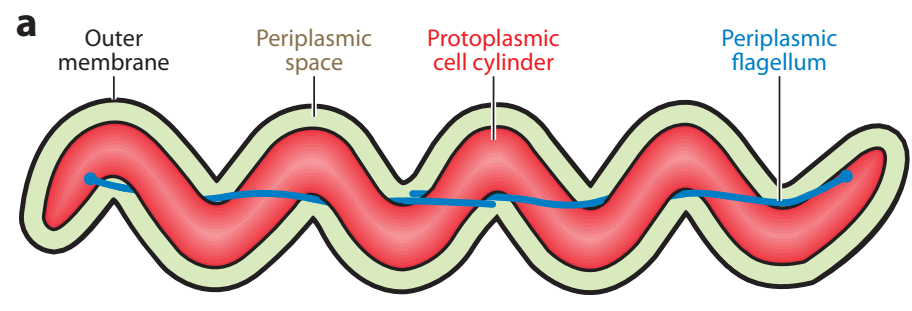

b

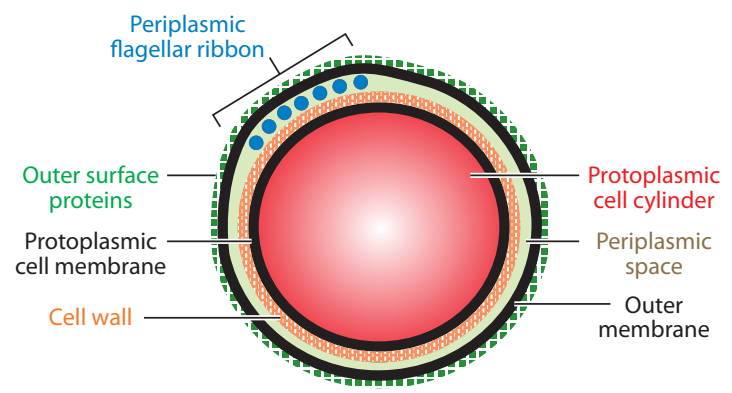

Figure 1

(a) Longitudinal diagram of a typical spirochete. Note that the periplasmic flagella overlap in the cell center.

(b) Cross-section diagram of Borrelia burgdorferi illustrating the component parts. Note that seven periplasmic flagella form a tightly packed ribbon that causes the outer membrane to bulge.

have been identified and are called the senso lato species complex. The species that is the most studied is $B b$ senso stricto (hereafter referred to as $B b$ ); it is the most prevalent species associated with disease in North America. Borrelia afzelii and Borrelia garinii are the species most commonly associated with Lyme disease in Eurasia. The genomes of $B b$ senso lato consist of one small, linear chromosome (approximately $950 \mathrm{~kb}$ ) and a variable number (7-21) of circular and linear plasmids. The plasmids compose approximately one-third of the spirochete's total genetic material. Because of its small genome, B. burgdorferi senso lato nutritional requirements is complex.

\section{Structure of a Spirochete}

What is a spirochete? In general, spirochetes have a unique and distinct structure; spirochetes are one of the few phyla of bacteria that can be recognized on the basis of morphology (72) (Figure 1a). Outermost is a lipid bilayer outer membrane (OM), and internal to the $\mathrm{OM}$ is the protoplasmic cell cylinder (PC). At each end of the PC are subterminally attached periplasmic flagella (PFs) that reside in the periplasmic space (PS). The PFs rotate in a manner similar to the flagella of externally flagellated bacteria $(15,16,33)$. The final shape of the cell, depending on the species, is either a helix or a flat wave. The size of the spirochete, the number of PFs attached at each end, and whether the PFs overlap at the middle of the cell vary from species to species. The overall morphology of spirochetes, with their flagella located internally, raises the long-standing questions: How do these bacteria swim and how do they carry out chemotaxis?

\section{MORPHOLOGY}

\section{B. burgdorferi as a Model Spirochete}

$B b$ fits the morphological description of a spirochete (Figure $\mathbf{1} b$ ). Both light-microscopy and highvoltage transmission electron microscopy (TEM) indicate that $B b$ has a flat-wave morphology (32, 33) (Supplemental Figure 1, Supplemental Movie 1; follow the Supplemental Material link
OM: outer membrane PC: protoplasmic cell cylinder

PF: periplasmic flagellum

PS: periplasmic space

TEM: transmission electron microscopy 
from the Annual Reviews home page at http://www.annualreviews.org). This planar wave form is similar to that of the syphilis spirochete Treponema pallidum $(22,39)$ but differs from the many helix-shaped members of the phylum such as the family Leptospiraceae (72, 77). Bb is long and thin, with a length between 10 and $20 \mu \mathrm{m}$ and a diameter of approximately $300 \mathrm{~nm}$ (32). Its shape is characterized as a planar, regular, periodic undulation of the cell body, with an amplitude of $0.78 \mu \mathrm{m}$ and a wavelength of $2.83 \mu \mathrm{m}$.

\section{Ultrastructure of $B$. burgdorferi}

The fine structure and general composition of $B b$ have been analyzed using several approaches. The composition of the $\mathrm{Bb} \mathrm{OM}$ is unusual. It lacks lipopolysaccharide but contains lipids uncommon in bacteria, such as cholesterol (8). Cryo-ET has been used extensively to analyze cell structure $(17,43,54)$. The $\mathrm{OM}$ also has a large number and variety of surface-exposed lipoproteins that are seen by cryo-ET as a layer surrounding the cell (54). The OM has a width of $4 \mathrm{~nm}$ and tightly fits around the PC. At the PC surface, the peptidoglycan forms a wall approximately $6.8 \mathrm{~nm}$ wide (54). As discussed below, for the spirochete to form a dynamic flat wave and carry out its remarkable motions as it swims, the wall must be astonishingly flexible. Little is known about the structure of the $B b$ peptidoglycan other than that it contains alanine, glycine, glutamic acid, and ornithine (7), and nothing is known about what imparts its highly flexible nature. Inside the wall layer is the 4-nm-wide protoplasmic cell membrane, which encloses the cytoplasm.

\section{Periplasmic Flagella In Situ}

Between 7 and 11 PFs are subterminally inserted into each end of the PC $(15,38,43,105)$ (Figure $\mathbf{1} \boldsymbol{b}$ and Figure 2). These PFs are structurally similar to the flagella of other bacteria. Each PF is composed of a motor, hook, and filament. The flagellar motors are linearly inserted along the long axis of the cell at each end and are 90 to $120 \mathrm{~nm}$ apart from each other (17, $43,54,105)$. The flagellar motor that is closest to the cell tip is approximately $150 \mathrm{~nm}$ from that end. Although previous TEM analyses indicate that the PFs form a bundle $(32,62)$, recent results with cryo-ET indicate that the flagellar filaments instead form an elegant ribbon in the PS (17) (Figure 1 b). The minimum thickness of the ribbon is equivalent to the diameter of a PF

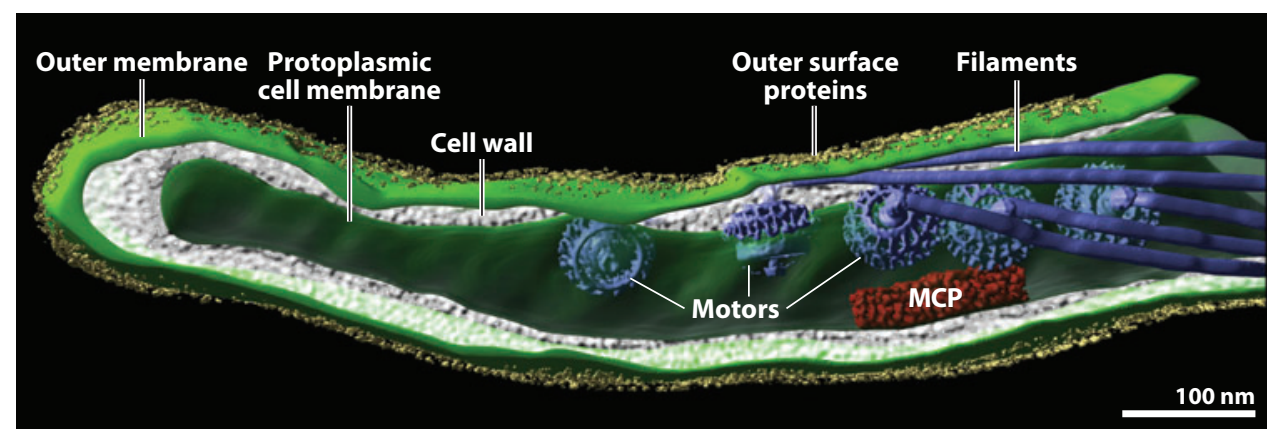

Figure 2

Cellular architecture of one end of Borrelia burgdorferi revealed by cryoelectron tomography. A threedimensional model was generated by manually segmenting the outer membrane, protoplasmic cell membrane, flagellar motors and filaments, methyl-accepting chemotaxis protein (MCP) array, and outer surface proteins. Reprinted and modified with permission from Reference 105. 
$(16-18 \mathrm{~nm})(38,43)$, but the ribbon can be thicker and multilayered. The filaments are closely packed, with approximately $3 \mathrm{~nm}$ of space between them. The ribbon also increases the thickness of the PS so that the OM bulges in its vicinity $(17,43,54)$. Thus, in regions of the cell where there are no PFs, the PS thickness is approximately $16 \mathrm{~nm}$. In contrast, the PS thickness is 42 to $49 \mathrm{~nm}$ in domains containing PFs $(17,54)$. High-voltage TEM and cryo-ET indicate that the ribbons wrap around the body axis (the longitudinal center of the cell, as if the cell is a sausage) clockwise (CW) and thus are right-handed $(17,32)$. However, along the cell axis (i.e., the abscissa, as the cell is in the form of a flat wave, or a sine wave), the PFs form a left-handed helix with a helix pitch (a complete helical turn) of approximately $2.83 \mu \mathrm{m}$, which is equivalent to the periodic wavelength of the cell (32). Recent results suggest that in short cells $(10 \mu \mathrm{m}$ in length) there are more PFs in the cell center than in long cells $(20 \mu \mathrm{m}$ in length) (C. Li, unpublished data). Evidently, the rate of growth of a given flagellar filament decreases as the cells become longer. Furthermore, the two opposing ribbons overlap in the central region. It is not clear whether the two ribbons form a continuous ribbon, or whether the ribbons are on opposite faces of the cell $(32,43,93)$.

\section{Periplasmic Flagella Structure and Composition}

Purified PFs have been analyzed in some detail. At neutral pH, PFs are left-handed and have a helix diameter of $0.28 \mu \mathrm{m}$ and a pitch of $1.48 \mu \mathrm{m}$; however, a small fraction have a helix diameter of $0.8 \mu \mathrm{m}$ and a pitch of $2.0 \mu \mathrm{m}(16,24)$. The flagellar filaments consist of a major $41-\mathrm{kDa}$ FlaB protein and a minor $38-\mathrm{kDa}$ FlaA protein $(15,31)$. FlaB shows sequence identity to $\mathrm{FlaB}$ of other spirochetes and to the flagellar filament proteins of other bacteria such as FliC of Escherichia coli. Sequence analysis indicates that FlaB is likely to be excreted into the PS by the Type III flagellinspecific pathway (15). FlaA has sequence identity to FlaA proteins that are present in PFs of other spirochetes. In contrast to FlaB, FlaA is likely to be excreted from the SecA-mediated pathway to the periplasm (15). In most spirochete species, FlaA forms a sheath that surrounds the FlaB core. The function of FlaA is presently unknown, but recent work on the spirochete Brachyspira byodysenteriae is instructive (49). flaA mutants of B. byodysenteriae have unsheathed PFs, are still motile, but swim more slowly than the wild type. In addition, the PFs from these mutants have a different helix pitch and diameter and are less rigid than those from the wild type. Thus, FlaA interacts with $\mathrm{FlaB}$ to augment filament shape and rigidity for optimal motility. However, in $B b$, so little FlaA is made relative to FlaB that only a small region of the filament has a sheath (31). TEM analysis comparing the wild type to the flaA mutant indicates that the FlaA sheath is localized adjacent to the flagellar hook (S. Shibata, S. Aizawa, M.A. Motaleb \& N. Charon, unpublished data). Perhaps flagellar rigidity near this region is essential for optimal PF rotation and motility.

\section{Cytoskeletal Function of the Periplasmic Flagellar Filaments}

The analysis of specific mutants indicates that the PFs have a major role in the overall morphology of $B b$. First, mutants in the following genes form a straight rod instead of a flat wave (Supplemental Table 1): $f l a B$, which encodes the major flagellin protein; $f l g E$, which encodes the flagellar hook; $f i F$, which encodes the MS ring of the motor; and $f i G 2$, which encodes a motor protein of the switch complex $(50,62,84)$. A mutant that overproduces the regulatory protein CsrA also forms a rod (see below) (93). Ultrastructure and Western blot analyses indicate that the one common deficit of all these mutants is the lack of flagellar filaments and filament proteins. Thus, the ability to form flat waves positively correlates with the presence of flagellar filaments and FlaB. Second, a mutant that has a shorter cellular wavelength and a smaller amplitude than that those of the wild type was recently isolated (93). This mutant, which has a deletion in the $\operatorname{csr} A$ regulatory gene, 
produces PFs that are considerably longer than those of the wild type. Cryo-ET analysis revealed that the flagellar ribbons in csr A mutants wrap around the PC more tightly than do ribbons in wild-type cells with a smaller helix pitch and diameter. In addition, the two ribbons interdigitate with one another. These results indicate that increasing the length of the PFs leads to cells with an altered flat-wave morphology (see below). Taken together, the results with the many filamentdeficient mutants and the $c s r A$ deletion mutant strongly support the concept that the PFs influence cell shape by having a skeletal function.

\section{Why is B. burgdorferi a Flat Wave?}

How do the PFs exert their skeletal function? Bacterial cells and flagella are elastic materials. When forces are applied these structures deform, and when the forces are removed these structures revert back to their original shape. Because the PC of $B b$ is a straight rod when the PFs are not present, and purified PFs are helical, evidently the interaction between the two components leads to the flat-wave morphology. The helix pitch of the PFs in situ $(2.83 \mu \mathrm{m})$ is markedly different from those that are purified away from the cell body $(1.43 \mu \mathrm{m}$ and $2.0 \mu \mathrm{m})(16,24,32)$. For the PFs to be contained within the PS, these structures must deform. The PC produces the force that bends the PFs. Concomitantly, the PFs exert an equal but opposite force back onto the PC, which causes the cell to bend into its characteristic shape. Mathematical modeling, which takes into consideration the elastic properties of the PFs and PC, has shown that the balance between these two forces is a cell with a flat-wave shape-it is not intuitive! However, this force balance conspires to produce the correct wavelength and amplitude only if the PFs are in the helical conformation that is observed less frequently in purified PFs (helix diameter of $0.8 \mu \mathrm{m}$ and a pitch of $2.0 \mu \mathrm{m}$ ) (24). How does the $\operatorname{cs}$ A deletion mutant that has longer PFs cause the cell to have a shorter wavelength and cell amplitude (93)? One possible explanation is that the increase in length of the PFs, and perhaps the interdigitation characteristic of the PF ribbons in the mutant, causes the PFs to flip into the helical state that is observed more frequently in purified PFs. This change in preferred conformation of the PFs is predicted to produce a flat-wave shape with a smaller wavelength and amplitude.

\section{Hook and Motor Structure}

The flagellar hook region in $B b$ and certain other spirochetes has some unique attributes. In other bacteria, the hook serves as a universal joint connecting the flagellar filament to the motor (85). In $B b$, the hook is a 61-nm-long hollow tube consisting of approximately $133 \mathrm{FlgE}$ units (84). As mentioned above, inactivation of $f g E$ results in cells that lack flagellar filaments, are nonmotile, and are rod shaped (84). In most bacteria, the FlgE subunits are held together by protein-protein interactions that are readily dissociated by denaturing agents. Surprisingly, FlgE in $B b$ and other spirochetes forms a stable, high-molecular-weight complex $(52,84)$. Several lines of evidence indicate that FlgE subunits in $B b$ are covalently cross-linked (84) (K. Miller, M. Miller $\&$ N. Charon, unpublished data). The flagellar hook and filament are likely to be under greater stress in spirochetes than in other bacteria, as the PFs deform the PC while they rotate (see below, Dynamics of Motility). Perhaps the hook proteins are cross-linked in spirochetes for added structural strength to perform this function.

The incredible methodology of cryo-ET is being exploited to analyze the intact $B b$ motor (44, $54)$, as well as other spirochetal motors $(53,69)$. The overall structures of spirochetal motors are similar to each other, consisting of the MS ring, the $\mathrm{C}$ ring, the rod, the export apparatus, and the stator (Figure 3) (Supplemental Movie 2). Bb exhibits a relatively large $\mathrm{C}$ ring, $\sim 57 \mathrm{~nm}$ in diameter, compared to the 45-nm C ring of E. coli and Salmonella enterica serovar Typhimurium 


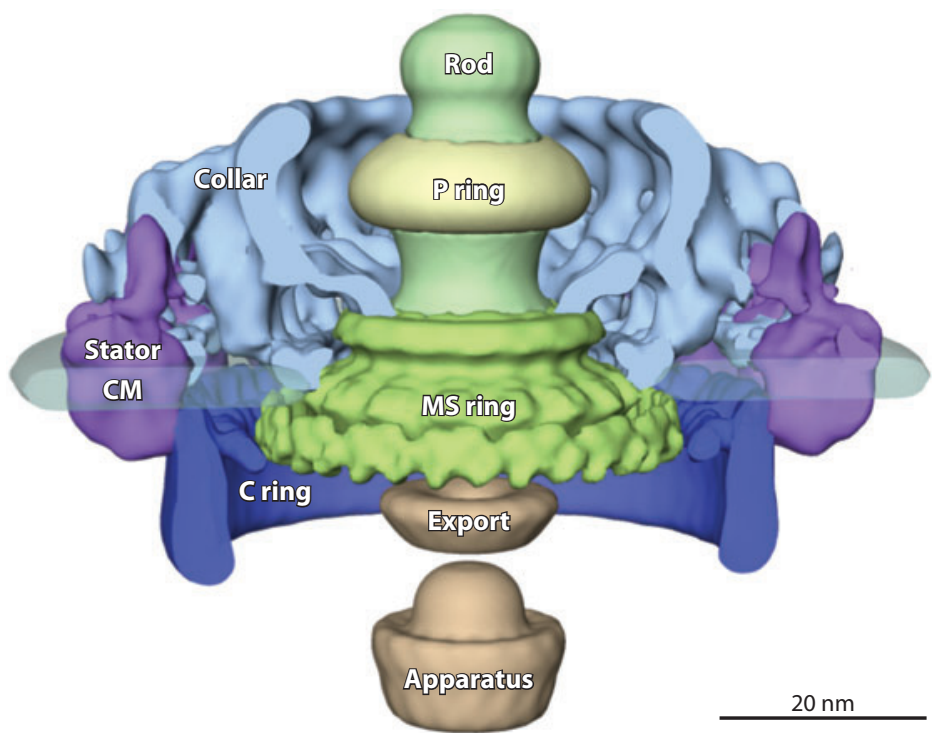

Figure 3

A three-dimensional reconstruction of the Borrelia burgdorferi flagellar motor. The major components (the rod, the stator, the $\mathrm{P}$ ring, and the MS ring) are labeled. The $\mathrm{C}$ ring is composed of FliG, FliM, and FliN. The "collar" is a spirochete-specific feature. The export apparatus is divided into two separate densities, although the boundary between the MS ring and the export apparatus is not well defined. Abbreviation: CM, protoplasmic cell membrane.

(95). This enlarged $\mathrm{C}$ ring shares similar features with the $S$. enterica structure: a cylindrical structure with a slightly bulky bottom and a Y-shaped extension at the top (95). Thus, the C ring is likely composed of multiple copies of FliG, FliM, and FliN proteins arranged in a manner similar to that of E. coli and S. enterica.

The stator, encoded by the $m o t A$ and $m o t B$ genes, is the motor force generator embedded in the protoplasmic cell membrane. The visualization of the stators in many species of bacteria is difficult (19), and this difficulty may in part be the result of the stator being dynamic and that its functional units freely interchange between the motors circulating in the protoplasmic cell membrane (46). In contrast, the stators of $B b$ and other spirochetes are clearly visualized (44, 53, 54, 69). Cryo-ET analysis of mot $A$ and $\operatorname{mot} B$ mutants of $B b$ provides the first structural evidence that these genes encode the 16 stators radially arranged around the rotor (Figure 3) (Supplemental Movie 2) (X. Zhao, T. Boquoi, M.A. Motaleb \& J. Liu, unpublished data). Conceivably, the stators in $B b$ and other spirochetes are relatively stable, or unit interchange occurs without disrupting the overall arrangement of the stator. Remarkably, the cytoplasmic domain of the stator is adjacent to the C-terminal domain of the C-ring rotor protein FliG. This stator-rotor interaction evidently induces an unexpected conformational change in FliG, and this change is likely to be a fundamental mechanism for flagellar rotation (X. Zhao, T. Boquoi, M.A. Motaleb \& J. Liu, unpublished data).

The $B b$ flagellar motor is a remarkable and complicated nanomachine consisting of at least 20 different proteins (Figure 3) (Supplemental Movie 2). To understand flagellar motor assembly and function, the structural and functional roles of all flagellar proteins must be determined. Fortunately, many mutants in motor genes have been constructed by either transposon mutagenesis or targeted mutagenesis (Supplemental Figure 2, Supplemental Table 1). fliE mutants are defective in rod assembly, and fliM mutants are deficient in the middle and the bottom of the C ring (X. Zhao, T. Boquoi, A. Manne, M.A. Motaleb \& J. Liu, unpublished data). fiI and 
CCW:

counterclockwise

fiH mutants are defective in the assembly of the bottom part of the export apparatus (X. Zhao, T. Lin \& S. Norris, unpublished data). FliL proteins localize between the stator and rotor, and these proteins are evidently involved in the proper orientation of the PFs within the PS (65). flgI mutants fail to form a hollow, torus-shaped structure around the rod. However, in contrast to other bacteria, these $f g I$ mutants are still fully motile; evidently, the $\mathrm{P}$ ring is not required for flagellar rotation (54). Instead, a spirochete-specific "collar" may function as a bushing that facilitates the rotation of the flagellum without disrupting the surrounding peptidoglycan layer. The identities of the specific genes encoding the "collar" have yet to be identified. In sum, the structure of the $B b$ flagellar motor is being characterized in some detail, and specific motor proteins and function are being correlated with specific genes in situ for the first time.

\section{DYNAMICS OF MOTILITY}

\section{Swimming In Vitro}

Given the structure of $B b$, the obvious first question with respect to their motility is, What do swimming cells look like? Also, given that the PFs are located in the PS, how does PF rotation drive motility? The swimming behavior of $B b$ is more complicated than that of other bacteria as a result of their complex geometry. $B b$ has four motility modes based on the direction of flagellar rotation: two translational modes (with either end leading) and two nontranslational modes (Figure 4) (Supplemental Movie 3). In an isotropic environment, a given cell runs at least $90 \%$ of the time (M.A. Motaleb \& N. Charon, unpublished data). During a run, waves are propagated from the front to the back at a frequency of 5 to $10 \mathrm{~Hz}$ at room temperature. In contrast to eukaryotic flagella, propagating waves are full size at the anterior end instead of starting as small bends and increasing in size. These waves propagate at a speed of $34 \mu \mathrm{m} \mathrm{s}^{-1}$ relative to the cell (33). The cells swim at a mean speed of $4.25 \mu \mathrm{m} \mathrm{s}^{-1}$ in a pure liquid (33). The ratio of the swim speed to wave propagation is 0.12 ; i.e., in the time it takes a wave to travel the length of the cell, the cell advances $12 \%$ of its length through the medium. Thus, as $B b$ swims, waves are clearly evident as they swim in a given direction.

How are the waves generated, and what is the basis for the nontranslational forms? Everything points to the PFs. We know they are essential for motility, they rotate, they are helix shaped, and they have a skeletal function. Although it has not been directly proven, the following model is proposed (Supplemental Movie 4) (15, 32): During a run, the PFs of the anterior ribbon are predicted to rotate counterclockwise (CCW), and those of the posterior ribbon rotate in the $\mathrm{CW}$ direction (as a frame of reference, the PFs are viewed from their distal end to where they insert into the PC). Thus, the PFs of the two ribbons rotate asymmetrically relative to one another during a run. This rotation causes backward-moving waves to be propagated down the length of the cell. Reversals occur when the PFs of both ribbons change the direction of rotation. In addition, recent mathematical modeling suggests that during translation the rotating PFs are not in direct contact with the PC, but rather a thin layer of fluid separates these filaments from the PC (107). Forces between the PFs and the PC are therefore mediated by viscous forces in the fluid present in the PS. This hypothesis is based on the known elasticity of the PFs, PC, and the dynamics of swimming cells. The modeling predicts that the thin layer of fluid in the PS is essential for the smooth backward-propagating waves noted on translating cells. Otherwise, if the PFs interacted directly with the PC, the PFs would be predicted to easily tangle up with one another and the propagating wave would not be as regular as observed. Several questions arise with the overall model of translating $B b$. If the PFs are rotating CCW along the axis of the cell as viewed from behind the cell, is the cell rolling about the body axis CW to balance that torque as predicted 
a

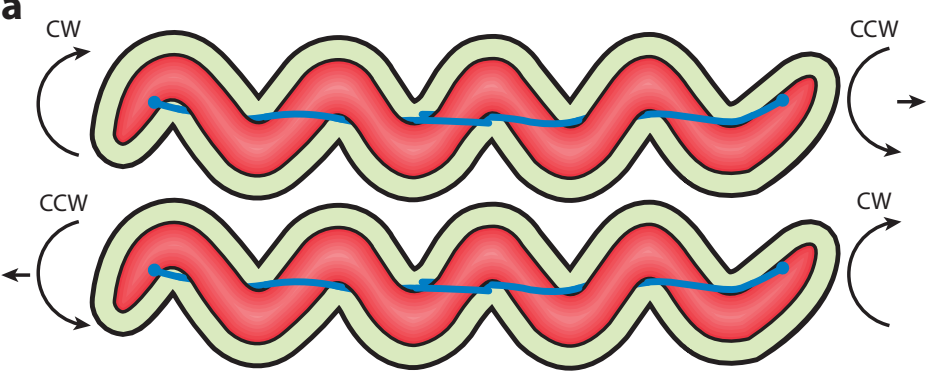

b

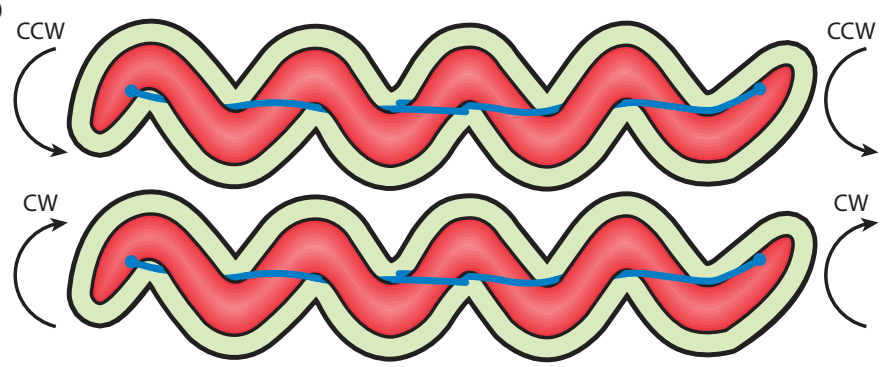

Figure 4

Swimming cells of Borrelia burgdorferi as a function of the direction in which the periplasmic flagella (PFs) rotate. Straight arrows at cell ends indicate direction of swimming. Curved arrows indicate the direction in which the PFs rotate. For simplification, only one PF is shown attached at each end of protoplasmic cell cylinder. Panel $a$ shows translational forms, and panel $b$ shows nontranslational forms. Reprinted and modified with permission from Reference 15. Abbreviations: CW, clockwise; CCW, counterclockwise.

$(15,32)$ ? What is happening to the OM? Cryo-ET indicates that it is held very close to the PC and even bulges in the vicinity of the PF ribbon. How is the tight fitting achieved, especially in light of evidence that the $\mathrm{OM}$ is a lipid bilayer? Are there bonds that form between the $\mathrm{OM}$ and $\mathrm{PC}$, and are those bonds broken as the PFs rotate?

In the nontranslational modes, the prediction is that the PFs from both ribbons rotate in the same direction: both rotate either CW or CCW. This stopped interval is referred to as a flex and is thought to be analogous to the tumble seen in externally flagellated bacteria. The cells often become distorted during this interval and may bend in the middle. It is difficult to distinguish cells with PFs at both ends rotating CCW from cells with PFs at both ends rotating CW. It is not clear exactly what is occurring in the PS that causes the cell to form a distorted morphology. Do the PFs from the opposite end wind around one another to cause the distorted shape? In other spirochete species, the distortion associated with flexing occurs only if the PFs overlap in the center of the cell (33), so this is a possibility.

The description of swimming given above comes largely from motility assays in liquid environments. Many of the natural environments that $B b$ encounters do not behave like a liquid. For example, spirochetes are deposited into the dermis of the mammal via the saliva of the tick. The dermis of the mammal is composed largely of a cross-linked collagen network. This gel-like environment responds to external forces from the bacterium with a combination of elastic and viscous forces; i.e., it is a viscoelastic material. Liquid media, on the other hand, only responds with viscous forces. One of the first investigations into the effect of viscoelasticity on the motility of $B b$ examined swimming in solutions of methylcellulose or hyaluronic acid (41). Swimming speed increases 
GFP: green

fluorescent protein

substantially as the concentration of methylcellulose or hyaluronic acid is increased. The increase in swimming speed with the viscoelasticity of the environment suggested that $B b$ motility may be optimized for migration through host tissue. In addition, $B b$, like several other spirochete species, can translate in highly viscoelastic medium that markedly slows or stops the motility of other flagellated bacteria. Liquid media and methylcellulose solutions, though, are poor facsimiles for many of the natural environments that $B b$ encounters. For example, collagen in the dermis forms a gel-like network (i.e., it is more elastic than viscous), whereas low-concentration methylcellulose solutions (less than a few percent) are viscoelastic fluids (i.e., they are more viscous than elastic) (12). The natural environments are differentiated further from liquid media and methylcellulose solutions because they contain cells and various extracellular matrix components, such as collagen, fibronectin, and decorin, to which $B b$ binds.

$B b$ in gelatin exhibited four motility states, which are determined by transient adhesion between the bacterium and the matrix (36). In addition to adhering to these substrates, spirochetes also migrate through the matrix, even though the pores in the gelatin matrices are significantly smaller than the diameter of the bacteria. As in previous reports, the undulation and migration speed of the bacteria depend strongly on the physical properties of the environment; however, the bacteria always swim slower in gelatin than in liquid media. Therefore, the unique motility mechanism of $\mathrm{Bb}$ enables it to penetrate dense tissues in its hosts, but the speed of the bacteria may not be enhanced in these natural environments.

\section{Swimming In Vivo}

We are at an early stage in sorting out the role of $B b$ motility in vivo. One of the major breakthroughs is the ability to track green fluorescent protein (GFP)-tagged virulent $B b$ in vivo using intravital microscopy and fluorescence spinning disc confocal microscopy. Soon after injection of $B b$ into mice, spirochetes are seen interacting with capillaries and veins (61). The movement of the organisms is stop and go, with the stops characterized by adherence to the endothelium. Approximately $90 \%$ of interactions with the endothelium are less than $1 \mathrm{~s}$, and about $10 \%$ are $1-20 \mathrm{~s}$. These interactions are mediated in part by the spirochete surface protein BBK32 and host fibronectin and glycosaminoglycans (70). In contrast, approximately $1 \%$ of the cells are stationary, with one end attached and partially embedded in the endothelium, often at the endothelial cell junctures, and the other end gyrating. These stationary cells resemble the often seen tethered spirochetes whereby the cells adhere to stationary ligands via an OM surface-associated component yet remain motile (18). The attached spirochetes eventually escape the endothelial cell lining and penetrate into connective tissue. In the liver, the spirochetes first interact with Kupffer cells, which then trap, immobilize, and engulf the spirochetes, and then present antigens to the invariant natural killer $\mathrm{T}$ cells (47). The role of motility and chemotaxis in both the adherence and penetration through blood vessels, and in the interaction of immune cells in the liver, is likely to be important. Future experiments with specific motility and chemotaxis mutants should be definitive.

Some remarkable imaging studies have examined GFP-tagged $B b$ in the tick host both before and after feeding on mice (26). In unfed nymphs, $B b$ cells are nonmotile and distributed throughout the midgut. By $72 \mathrm{~h}$ after feeding on mice, the density of $B b$ is high; however, the spirochetes remain nonmotile but are viable. Remarkably, the presence of a diffusible factor(s) in the tick midgut is likely to be responsible for their nonmotility. At $72 \mathrm{~h}$, only a small number of the spirochetes traverse the midgut basement membrane, enter the hemocoel, and colonize the salivary glands for transmission to mammals. These invasive spirochetes are motile. Why is $B b$ motility specifically inhibited in the tick midgut? Perhaps the tick developed a means of defense to keep the infection 
localized by inhibiting $B b$ motility. Future experiments to characterize the inhibitory factors should be enlightening.

\section{CHEMOTAXIS}

Chemotaxis (movement toward or away from a chemical stimulus) in spirochetes is unique. Bacteria undergo a biased random walk during chemotaxis, and this walk is achieved by modulating the direction or speed of flagellar rotation $(76,88,99)$. A two-component regulatory system mediates the biased walk up a gradient of attractant or away from a repellent. In the paradigmatic chemotaxis model of E. coli and S. enterica, variation in motor direction is determined as follows: The response regulator CheY is phosphorylated by the histidine kinase CheA to form CheY-P. CheA is part of the polarly located methyl-accepting chemotaxis protein $(\mathrm{MCP})$ receptor signal complexes. The probability that CheA phosphorylates $\mathrm{CheY}$ is a function of the occupancy level of an attractant or repellent that binds directly or indirectly to the MCPs in the PS. CheY-P diffuses through the cytoplasm and interacts with the flagellar switch protein FliM, causing the motor rotational biases to shift from the default rotation of $\mathrm{CCW}$ to $\mathrm{CW}$. If all the motors rotate $\mathrm{CCW}$, the cell swims. If one of the motors rotates CW, the cell tumbles (97). The motors are within $1 \mu \mathrm{m}$ of the MCP complexes. Thus, CheY-P can diffuse and bind to the motors within $0.1 \mathrm{~s}(98)$. The CheY-P formed has phosphatase activity associated with it. However, dephosphorylation of CheY-P, which restores the default CCW behavior such that the cell can immediately respond to changes in the environment, is enhanced by the action of the CheY-P-specific phosphatase CheZ.

Chemotaxis in $B b$ is different from this and other well-studied bacterial chemotaxis models. Two conundrums are evident. First, these spirochetes have two sets of flagellar motors: one at each cell end. As noted above, these sets of motors are located at a considerable distance from one another (between 10 and $20 \mu \mathrm{m}$ ). In addition, recent results using fluorescent antibodies and cryoET indicate that the MCP complexes are subpolarly located at each cell end (105) (Figure 2). If CheY-P is formed at one end of the cell at these complexes, it could readily diffuse to the adjacent motors. However, given a cell length of $10 \mu \mathrm{m}$, it would take at least $10 \mathrm{~s}$ for CheY-P to diffuse to the motors at the other end of the cell (67). Because the speed of these bacteria is at least $4 \mu \mathrm{m}$ $\mathrm{s}^{-1}$ (33), simple diffusion of CheY-P to the opposite end of the cell to coordinate the rotation of the PFs is unlikely. Furthermore, in $B b$, instead of runs and tumbling, there are four swim configurations based on the direction of flagellar rotation (Figure 4), all of which contribute to a higher level of complexity in swim behavior than that of most other bacteria. Thus, the first conundrum is, How does $B b$ coordinate the rotation of the PFs within the ribbons at both cell ends to effect chemotaxis?

Second, for the bacteria to swim in a given direction, the motors at each end must rotate in the opposite direction of those at the other end; i.e., if the PFs in one ribbon rotate CCW, the others rotate $\mathrm{CW}$. This asymmetrical rotation is markedly different from the swimming behavior of $E$. coli and S. enterica whereby all the motors rotate in the same direction during translation. Furthermore, as discussed below, in the absence of a functional CheY response regulator, $B b$ constantly runs. Thus, the second conundrum is, What is the basis for asymmetrical rotation of the PFs during translational swimming in the absence of $\mathrm{CheY}$ ?

Although significant progress has been made in understanding $B b$ chemotaxis, a palpable molecular model putting it all together is still in the developmental stage. To address the above questions, a capillary tube chemotaxis assay was developed using flow cytometry to enumerate cells, and several chemically defined chemoattractants were identified (4, 63). These attractants include $N$-acetylglucosamine, glucosamine, glucosamine dimers, and glutamate. The assay allowed
MCP: methylaccepting chemotaxis protein 
researchers to test whether specific genes were involved in chemotaxis. $B b$ has multiple copies of chemotaxis genes, including six mcp (two lack membrane-spanning regions), two $c h e A$, three $c h e Y$, two $c h e B$, two $c h e R$, and three $c h e W$ (29). It has only one CheY-P phosphatase gene commonly found in bacteria, cheX, which has an activity similar to that of cheZ found in E. coli $(64,74)$. The results of extensive gene targeting analysis indicated that the chemotaxis pathway involves MCPs, CheW3, CheA2, CheY3, and CheX (Supplemental Figure 2, Supplemental Table 1). Biochemical analysis supports the conclusion that CheA2 readily phosphorylates CheY3 (67) and CheX dephosphorylates CheY3-P (64, 74). Interestingly, the half-life of the CheY3-P is $10 \mathrm{~min}$ (67), which is considerably longer than the half-lives of most CheY-P of other bacteria such as E. coli, which is a few seconds (37). Most important, because $\mathrm{CheY}$ plays such a pivotal role in the chemotaxis of all known species of bacteria, CheY3 is concluded to be the key chemotaxis response regulator in $B b$.

An analysis of the swim behaviors of the chemotaxis mutants may yield a clue to the basis of asymmetrical rotation of the flagellar ribbons during translational motility. Both che $A 2$ and cheY3 mutants constantly run in one direction $(48,67)$ (Supplemental Table 1, Supplemental Movie 3). These results are similar to those of other bacteria such as E. coli and S. enterica; che $A$ and $c h e Y$ mutants in these bacteria also constantly run. However, in $B b$ the motors rotate asymmetrically at one end relative to the other during a run, whereas in E. coli all the motors are rotating CCW. Evidently, in the default state, i.e., when no CheY3-P are present, the motors at one cell end are different from those at the other, as they rotate in opposite directions. Perhaps there is a protein that interacts with motors at one cell end such that in the default state the PFs rotate in the opposite direction relative to those at the other end. There is precedent for protein localization of this type, as some bacteria-specific proteins localize at the old cell end and not at the new cell end (6). A candidate protein is FliG1 (50). Bb and many other spirochetes have two $f l i G$ genes encoded in their genomes, fliG1 and fliG2 (29, 50). FliG is involved in motor rotation in other bacteria, is essential for flagellar assembly and motility, and plays a major role in determining the direction of motor rotation (55). fliG2 likely plays this role in $B b$, as mutants in this gene are nonmotile and lack PFs; FliG2 has all the essential sequence and structural domains common to other bacterial FliGs (50). However, FliG1 lacks some of the essential residues common to FliG of other bacteria. fliG1 mutants are still motile but are unable to swim in highly viscous media containing methylcellulose; only one of the cell ends is able to gyrate. Interestingly, GFP-tagged FliG1 localizes at only one cell end (50). It will be interesting to determine whether FliG1 is partly responsible for the asymmetrical rotation of the PFs.

The phenotypes of other specific mutants complicate this scenario. The cheX mutant constantly flexes (64), which is analogous to the constantly tumbling che $Z$ mutants of E. coli(10). A cheX mutant is predicted to have a higher CheY3-P concentration than the wild type does. One expectation of the protein localization model is that cells with a high CheY3-P concentration should also run, not flex. For example, those motors that run $\mathrm{CW}$ in the default state should reverse and rotate CCW under a high CheY3-P concentration, and those motors that run CCW in the default state should run CW. Perhaps there is another CheY-P phosphatase that has not been identified in $B b$, and as result, the cheX mutant could have an intermediate level of CheY3-P that results in flexing. In $B$. subtilis, FliY and CheC have CheY-P phosphatase activity, but $B b$ lacks homologs to these genes (68).

$\mathrm{Bb}$ also has a gene encoding $\mathrm{CheD}$. CheD in other bacteria augments the phosphatase activity of $\mathrm{CheC}$, binds to and deamidates glutamine residues on MCPs, and regulates the activity of CheA kinase. cheD mutants in other bacteria have a decreased activity of CheA kinase, leading to lower levels of CheY-P (78). CheD may have a similar function in $B b$, as a cheD mutant has a nonchemotactic, constantly running phenotype, similar to the $\operatorname{cheY} 3$ and cheA2 mutants that are also expected to decrease CheY3-P concentration (M.A. Motaleb \& N. Charon, unpublished 
data). However, because $\mathrm{CheD}$ in other bacteria has functions in addition to activating the CheA kinase, its role in $B b$ chemotaxis is presently unclear.

The second messenger, $3^{\prime}, 5^{\prime}$-cyclic-diguanosine monophosphate (c-di-GMP), is emerging as a major factor influencing motility and possibly chemotaxis (see Transcriptional and Translational Regulation of Motility and Chemotaxis Genes, below). Certain mutants involved in c-di-GMP synthesis, degradation, and effector binding have aberrant swim behavior, such that some mutants (e.g., $p d e A$ ) constantly run, whereas others (e.g., $p d e B$ ) have a high flex rate (90, 91). c-di-GMP and its effector protein bind to the flagellar motor protein in other bacteria and influence the direction and speed of flagellar rotation $(9,21,27,73)$. At this time it is difficult to determine how c-di-GMP influences $B b$ swimming behavior at a molecular level.

The results accumulated indicate the following conclusions: First, $\mathrm{CheY} 3$ is the major response regulator, and the pathway leading to its phosphorylation and dephosphorylation involves MCPs, CheW3, CheA2, CheX, and possibly CheD. Second, the asymmetrical rotation of the PFs in the default state can best be explained by differences in the motors at each end of the cell, but support for this hypothesis awaits experimental evidence. Third, it is too early to understand the basis of flagellar coordination mediated by $\mathrm{CheY} 3$ that results in chemotaxis, although many hypotheses are conceivable. As previously mentioned, diffusion of CheY3-P from one cell end to the other is too slow to coordinate the rotation of the PFs at the distal end. As an alternative, perhaps there is a cytoskeletal structure whereby CheY-P moves rapidly from one end to the other. There is precedence for this possibility: In Myxococcus xanthus, the protein AglZ mediates gliding motility by moving from one cell end to the other by way of the MreB cytoskeleton (58). Because completion of this internal cell migration of $\mathrm{AglZ}$ is on the order of several minutes, a $\mathrm{CheY} 3$ transport system in $B b$ would have to be considerably faster.

Another model possibility for coordinating the PFs at each end relates to a mechanosensing mechanism. Perhaps there is an interaction between the PFs at one end of the cell and those at the other such that rotation of the PFs at one end influences the rotation of the PFs at the other end. This possibility is conceivable, as the PFs in $B b$ overlap in the center of the cell. However, this hypothesis does not apply to all spirochetes, as Leptospira interrogans has PFs that are short and do not overlap (102), yet these spirochetes are chemotactic (110) (N. Takahashi \& N. Charon, unpublished data). CheY3-P could act at another, unknown site such that the membrane potential is altered when the cell is undergoing chemotaxis, and this change in potential might allow coordination of the PFs (35). Alternatively, perhaps CheY3-P together with c-di-GMP coordinates PF rotation.

Finally, conceivably there is no internal signal that coordinates the motors at both cell ends: Flagellar coordination and chemotaxis are achieved by the attractant binding to either one or both of the MCP clusters at the cell ends. The change in CheY3-P concentration generated by this binding specifically affects the direction of rotation of the motors that are adjacent to those MCPs. For example, if the attractant binds the MCPs at one cell end, it causes the motors only at that end of the cell to change their direction of rotation, and the cell flexes. In contrast, if attractant molecules simultaneously bind to the MCPs at both cell ends, the motors at both ends change directions and the cell runs. In closing, now that specific compounds that serve as attractants are known, and that $\mathrm{CheY} 3$ is the functional response regulator, the basis for coordinating $\mathrm{PF}$ rotation for chemotaxis can finally be determined.

\section{TRANSCRIPTIONAL AND TRANSLATIONAL REGULATION OF MOTILITY AND CHEMOTAXIS GENES}

The genetic map indicating the genes that are involved in motility and chemotaxis is presented in Supplemental Figure 2. Most motility genes are present in single copies (except for fliG, the
c-di-GMP: $3^{\prime},-5^{\prime}-$ cyclic-diguanosine monophosphate 
motor control protein). As noted above, there are multiple copies of chemotaxis genes. The analysis of mutants described above indicates that the $B b$ cluster che $A 2-c h e W 3-c h e X-c h e Y 3$ is involved in chemotaxis under standard laboratory conditions. This cluster is closely related to chemotaxis gene systems in the other spirochetes and is probably inherited from a common ancestor $(15,48$, 103). The other cluster consisting of cheW2-bb0566-cheA1-cheB2-bb0569-cheY2 may be a recent gene transfer from the Proteobacteria $(48,103)$. The function of this second cluster is not known, but it may be involved in chemotaxis under different environmental conditions.

The regulation of the motility and chemotaxis genes of $B b$ is unique. In other bacteria, there is cascade control of gene regulation of motility gene expression (20). For example, at least 50 genes are involved in the motility and chemotaxis of E. coli and S. enterica, and these genes fall into three classes (class I, II, and III), which are under the tight regulation of a transcriptional hierarchy. Within this regulatory cascade, the class I master regulator (FlhDC), in conjunction with the housekeeping sigma factor $\left(\sigma^{70}\right)$, directs RNA polymerase to initiate the transcription of the class II genes. Class II genes encode the structural proteins involved in the motor-hook complexes, and two regulatory elements: the flagellum-specific sigma factor FliA $\left(\sigma^{28}\right)$ and the antagonist of FliA $\left(\right.$ anti- $\left.-\sigma^{28}\right)$, FlgM. Prior to the completion of the hook assembly, FlgM binds to FliA to prevent premature synthesis of the class III genes encoding the flagellin and the chemotaxis proteins. Upon completion of the hook structure, FlgM is excreted by the flagellum-export apparatus, thereby allowing FliA to initiate the transcription of the class III genes. The last step allows for completion of flagellar assembly and chemotaxis gene expression. In contrast, in silico analysis indicates that no FliA, FlgM, or $\sigma^{28}$ promoter consensus sequences are present in the genome of $B b(15,29)$. All the motility and chemotaxis genes identified thus far fall under the regulation of $\sigma^{70}$ (Supplemental Figure 2). These and other results indicate that $B b$ does not employ a transcription cascade to regulate its motility genes. Instead, these genes are regulated primarily by a posttranscriptional mechanism. Two key studies that lead to this conclusion stand out. First, in a flaB filament mutant, the amount of FlaA synthesized is only $13 \%$ of the wild-type level despite equivalent levels of $f a A$ transcript (66). Second, in a $f g E$ mutant, FlaA and FlaB accumulation are decreased by more than $80 \%$, whereas the levels of their respective encoding mRNA are equivalent to those of the wild type (84). Furthermore, although FlaA is slowly degraded in the $f g E$ mutant, there is no turnover of FlaB. The conclusion is that translational control and not protein turnover is responsible for the lack of accumulation of $\mathrm{FlaB}$ and possibly that of FlaA in the $f g E$ mutant.

Recent experiments indicate that the $B b$ carbon storage regulator $\mathrm{A}(\mathrm{CsrA})$ is a major regulator of translational control of FlaB (93). The Csr system is present in many bacterial species (3, 80), and its importance in carbon metabolism, virulence, biofilm formation, and motility is well established (2, 56, 80). In E. coli, the Csr system comprises an RNA binding protein, CsrA; two noncoding RNAs, CsrB and CsrC; and a regulatory protein, CsrD. CsrA functions through binding to the consensus sequence RUACARGGAUGU, which is present within the leader region of its targeted transcripts and subsequently regulates gene expression posttranscriptionally $(25,60)$. In E. coli, CsrA positively regulates flagellar synthesis by serving as an activator of $f l h D C$ expression (100). However, in B. subtilis, CsrA has an opposite effect-it negatively regulates flagellin synthesis at a posttranscriptional level by binding to mRNA and inhibiting translation (106). In a similar manner, $B b$ CsrA is a negative regulator of FlaB. CsrA binds to two sites present in the leader region of the $f l a B$ transcript, with one of them overlapping the Shine-Dalgarno sequence. Binding of CsrA to these regions leads to translation inhibition of FlaB, presumably via blocking ribosomes from accessing the Shine-Dalgarno sequence of $f a B$ mRNA. Thus, the amount of FlaB in a cell may be controlled at the translational level by CsrA (93).

The two-component regulatory system called HK2/Rrp2 is involved in motility gene expression in $B b(42,71,104)$. Acetyl-phosphate, an intermediate product from acetate metabolism, 
autophosphorylates Rrp2, the response regulator of the HK2/Rrp2, and in doing so activates $\mathrm{RpoN}$, a $\sigma^{54}$ transcription factor. RpoN in turn upregulates RpoS (the Rrp2-RpoN-RpoS pathway) (104). CsrA serves as a repressor of phosphoacetyltransferase (Pta), one of the key proteins in acetate metabolism, and indirectly modulates the level of acetyl-phosphate in $B b$ as well as the subsequent activation of the Rrp2-RpoN-RpoS pathway (92). Microarray analysis of $r p p 2, r p o N$, and $r p o S$ mutants has revealed a potential role for the Rrp2-RpoN-RpoS network in the regulation of chemotaxis gene expression $(14,28,71)$. For instance, the transcription of eight chemotaxis genes is regulated by the Rrp2-RpoN-RpoS network (71). Interestingly, Rrp2-RpoN-RpoS activity is maximally induced under conditions that mimic the mammalian host environment (108). Regulation of chemotaxis proteins via the Rrp2 pathway may allow the spirochete to modulate its chemotaxis genes expression while being transmitted between different hosts to aid in colonization as well as dissemination.

Recent studies in $B b$ indicate a link between the signaling molecule second-messenger c-diGMP and cell motility $(42,75,90,91)$. In $B b$, the c-di-GMP metabolism pathway consists of Rrp1, a sole diguanylate cyclase (42, 83); two phosphodiesterases, PdeA and PdeB (90, 91); and PlzA $(30,75)$, a c-di-GMP binding protein. A mutation in any of the genes of the c-di-GMP pathway alters both cell motility and chemotaxis, but many different phenotypes are generated. For example, disruption of Rrp1 causes cells to constantly run and have an attenuated chemotactic response (42). Mutations in the phosphodiesterase genes result in two different phenotypes: A pdeA mutant runs and pauses but fails to reverse, and a $p d e B$ mutant has increased flexing frequency $(90,91)$. A plz $A$ mutant has a defect in motility in agar but has the wild-type swimming behavior (75). Remarkably, the $p l z A p d e B$ double mutant constantly flexes (90). Taken together, c-di-GMP clearly affects motor function in $B b$, but as previously stated, how this occurs is unclear.

In summary, our understating of the regulation of chemotaxis and motility gene expression in $B b$ is still in its infancy. Translational control of motility gene expression appears to be crucial, with CsrA and c-di-GMP emerging as major regulators of chemotaxis and motility. Many questions remain unanswered. What is the interplay between the identified regulatory elements in modulating gene expression? How do environmental cues play a role in differential gene expression within the two hosts, and what are those cues?

\section{VIRULENCE AS RELATED TO CHEMOTAXIS AND MOTILITY}

The role of motility and chemotaxis during the infection and disease processes has been examined in several species of pathogenic bacteria. In many species, mutant analysis indicates that motility and chemotaxis are essential for infection and invasion $(13,40,59,109)$. Among the spirochetes, motility-deficient mutants of Brachyspira byodysenteriae are attenuated in a mouse model of swine dysentery (82). In Treponema denticola, motility- and chemotaxis-deficient mutants are less invasive than their parent in a human gingival keratinocyte monolayer cell penetration model (57). Recent results suggest that motility is essential for L. interrogans to cause disease in the hamster model for leptospirosis (45; E. Wunder \& A. Ko, unpublished data).

Motility and chemotaxis are likely to be important factors for $B b$ to survive in nature. Genomic analysis suggests that over 50 genes $(5-6 \%$ of the genome) are potentially involved in motility and chemotaxis $(15,29)$. In addition, approximately $10 \%$ of the total cellular protein is FlaB $(66)$. These results imply $B b$ dedicates a significant proportion of its energy to motility and chemotaxis, and they further support the concept that these processes are necessary for the survival of the spirochete. In addition, during mammalian infection, and when growing $B b$ under conditions that mimic in vivo conditions, motility and chemotaxis proteins are upregulated and some are among 
the most potent immunogens $(5,79,96)$. Evidently the synthesis of these proteins is not turned off soon after infection as in some species of bacteria (1).

Motility and chemotaxis are likely to be important for $B b$ to participate in several steps in completing the host-vector cycle. First, after transmission from the tick to a vertebrate host, $B b$ disseminates through skin and migrates to an appropriate target tissue such as the joint. These sites allow for persistence and evasion of the expanding adaptive immune response. Second, after residing in the vertebrate host for weeks to years, $B b$ possibly detects the presence of feeding ticks, and then migrates to those sites to enter the blood meal of those ticks. Finally, during the blood meal of an infected tick, the spirochetes need to migrate from the tick gut to the salivary glands to restart the cycle.

Although using a genetic approach to determine the contribution of motility and chemotaxis to the life cycle of $B b$ is difficult $(15,65)$, significant progress is being made. One key study focused on the presumed motor protein $f l G 1$ gene from a virulent strain of $B b(11,50)$. Mutations in this gene result in motility-deficient cells and are unable to establish an infection in mice. These studies are the first to show that motility is involved in the virulence of $B b$. In another ongoing study, targeted $f l a B$ mutants from a virulent strain of $B b$ are nonmotile as expected, but they are also noninfectious in mice (S. Sultan, M.A. Motaleb, P. Stewart, P. Rosa \& N. Charon, unpublished data). These preliminary results, coupled with those with the fliG1 mutant, suggest that motility plays a critical role in the disease process.

Recent results suggest that chemotaxis may also be involved in $B b$ virulence. $B b$ is attracted to tick salivary extract (87). In a recent study, a nonchemotactic che $A 2$ mutant failed to infect either immunocompetent or immunodeficient mice and was quickly eliminated from the initial inoculation sites. Furthermore, tick-mouse infection studies revealed that although the mutant was able to survive in ticks, it failed to establish a new infection in mice via tick bites (94). The altered phenotypes were restored when the mutant was complemented. In addition, both a nonchemotactic cheY3 mutant (M.A. Motaleb, unpublished data) and a c-di-GMP pde $A$ mutant that constantly runs were unable to infect mice (91). Collectively, these data demonstrate that $B b$ needs chemotaxis to establish mammalian infection and to accomplish its natural enzootic cycle. We expect that the analysis of other motility and chemotaxis mutants will lead to a better understanding of these processes with respect to tick transmission and mammalian infection and disease.

\section{CONCLUSION}

In this review we summarize the developments made in understanding spirochete motility and chemotaxis with $\mathrm{Bb}$ chosen as the model. Significant progress has been made since the times of Dobell and Weibull, but many questions still remain. Spirochetes cause dreadful diseases prevalent throughout the world including syphilis, leptospirosis, relapsing fever, and Lyme disease. The tragedy is that so little is known about these terrifying bacteria: We cannot even grow the syphilis spirochete in the laboratory, and only a handful of laboratories in the world are doing basic studies on Treponema pallidum. We can only hope that in another half century (or sooner!) sufficient progress in our understanding of the biology of these enigmatic pathogens will lead to new means of disease prevention and treatment such that these diseases are eliminated.

\section{SUMMARY POINTS}

1. Cryo-ET allows for exquisitely detailed analysis of the $B b$ flagellar motor.

2. When $B b$ swims in one direction in the absence of the response regulator CheY3-P, it rotates the PFs of the polar ribbons asymmetrically. 
3. $B b$ is so long that chemotaxis models as described in other bacteria do not directly apply.

4. $B b$ lacks the cascade control of motility and chemotaxis gene expression and relies on translational control.

5. Initial gene targeting experiments indicate that motility and chemotaxis play important roles in the life cycle of $B b$ in both tick and mammalian hosts.

\section{FUTURE ISSUES}

1. What are the functions of each motor protein in generating flagellar rotation?

2. What is the molecular basis for asymmetrical flagellar rotation in the absence of CheY3$\mathrm{P}$ ?

3. What is the molecular mechanism of chemotaxis in $B b$ and how is the direction of flagellar rotation controlled?

4. What are the details of motility and chemotaxis gene expression in $B b$, and how do CsrA and c-di-GMP exert their activities?

5. What are the precise points of involvement of motility and chemotaxis in the life cycle of $B b$ ?

\section{DISCLOSURE STATEMENT}

The authors are not aware of any affiliations, memberships, funding, or financial holdings that might be perceived as affecting the objectivity of this review.

\section{ACKNOWLEDGMENTS}

The authors dedicate this review to Professor Stuart F. Goldstein in honor of his forthcoming retirement from the University of Minnesota. His contributions have been crucial in understanding spirochete motility and in moving the field forward. We appreciate the comments and suggestions by J. Coburn, S. Goldstein, M. James, R. Silversmith, V. Sourjik, and M. Wooten. The research in this review was supported by Public Health Service grants AI078958 to C.L., GM0072004 to C.W., AR060834 to M.A.M., AI29743 and AI093917 to N.W.C. and M.R.M., and AI087946 and a Welch Foundation grant (AU-1714) to J.L. K.A.M. is supported by an American Heart Association graduate fellowship and WVNano.

\section{LITERATURE CITED}

1. Akerley BJ, Cotter PA, Miller JF. 1995. Ectopic expression of the flagellar regulon alters development of the Bordetella-host interaction. Cell 80:611-20

2. Babitzke P, Baker CS, Romeo T. 2009. Regulation of translation initiation by RNA binding proteins. Annu. Rev. Microbiol. 63:27-44

3. Babitzke P, Romeo T. 2007. CsrB sRNA family: sequestration of RNA-binding regulatory proteins. Curr. Opin. Microbiol. 10:156-63 
15. Provides a general review of motility and chemotaxis of spirochetes.

20. Reviews the control of assembly of the flagellar motor.
4. Bakker RG, Li C, Miller MR, Cunningham C, Charon NW. 2007. Identification of specific chemoattractants and genetic complementation of a Borrelia burgdorferi chemotaxis mutant: a flow cytometry-based capillary tube chemotaxis assay. Appl. Environ. Microbiol. 73:1180-88

5. Barbour AG, Jasinskas A, Kayala MA, Davies DH, Steere AC, et al. 2008. A genome-wide proteome array reveals a limited set of immunogens in natural infections of humans and white-footed mice with Borrelia burgdorferi. Infect. Immun. 76:3374-89

6. Bardy SL, Maddock JR. 2007. Polar explorations: recent insights into the polarity of bacterial proteins. Curr. Opin. Microbiol. 10:617-23

7. Beck G, Benach JL, Habicht GS. 1990. Isolation, preliminary chemical characterization, and biological activity of Borrelia burgdorferi peptidoglycan. Biochem. Biophys. Res. Commun. 167:89-95

8. Ben-Menachem G, Kubler-Kielb J, Coxon B, Yergey A, Schneerson R. 2003. A newly discovered cholesteryl galactoside from Borrelia burgdorferi. Proc. Natl. Acad. Sci. USA 100:7913-18

9. Boehm A, Kaiser M, Li H, Spangler C, Kasper CA, et al. 2010. Second messenger-mediated adjustment of bacterial swimming velocity. Cell 141:107-16

10. Boesch KC, Silversmith RE, Bourret RB. 2000. Isolation and characterization of nonchemotactic CheZ mutants of Escherichia coli. 7. Bacteriol. 182:3544-52

11. Botkin DJ, AbbottAN, Stewart PE, Rosa PA, Kawabata H, et al. 2006. Identification of potential virulence determinants by Himar1 transposition of infectious Borrelia burgdorferi B31. Infect. Immun. 74:6690-99

12. Brau RR, Ferrer JM, Lee H, Castro E, Tam BK, et al. 2007. Passive and active microrheology with optical tweezers. 7. Opt. A 9:S103-12

13. Butler SM, Camilli A. 2005. Going against the grain: chemotaxis and infection in Vibrio cholerae. Nat. Rev. Microbiol. 3:611-20

14. Caimano MJ, Iyer R, Eggers CH, Gonzalez C, Morton EA, et al. 2007. Analysis of the RpoS regulon in Borrelia burgdorferi in response to mammalian host signals provides insight into RpoS function during the enzootic cycle. Mol. Microbiol. 65:1193-217

15. Charon NW, Goldstein SF. 2002. Genetics of motility and chemotaxis of a fascinating group of bacteria: the spirochetes. Annu. Rev. Genet. 36:47-73

16. Charon NW, Goldstein SF, Block SM, Curci K, Ruby JD, et al. 1992. Morphology and dynamics of protruding spirochete periplasmic flagella. F. Bacteriol. 174:832-40

17. Charon NW, Goldstein SF, Marko M, Hsieh C, Gebhardt LL, et al. 2009. The flat-ribbon configuration of the periplasmic flagella of Borrelia burgdorferi and its relationship to motility and morphology. 7. Bacteriol. 191:600-7

18. Charon NW, Lawrence CW, O'Brien S. 1981. Movement of antibody-coated latex beads attached to the spirochete Leptospira interrogans. Proc. Natl. Acad. Sci. USA 78:7166-70

19. Chen S, Beeby M, Murphy GE, Leadbetter JR, Hendrixson DR, et al. 2011. Structural diversity of bacterial flagellar motors. EMBO 7. 30:2972-81

20. Chevance FF, Hughes KT. 2008. Coordinating assembly of a bacterial macromolecular machine. Nat. Rev. Microbiol. 6:455-65

21. Christen M, Christen B, Allan MG, Folcher M, Jeno P, et al. 2007. DgrA is a member of a new family of cyclic diguanosine monophosphate receptors and controls flagellar motor function in Caulobacter crescentus. Proc. Natl. Acad. Sci. USA 104:4112-17

22. Cox CD. 1972. Shape of Treponema pallidum. F. Bacteriol. 109:943-44

23. Dobell C. 1912. Researches on the spirochaets and related organisms. Arch. Protistenk. 26:117-239

24. Dombrowski C, Kan W, Motaleb MA, Charon NW, Goldstein RE, Wolgemuth CW. 2009. The elastic basis for the shape of Borrelia burgdorferi. Biophys. 7. 96:4409-17

25. Dubey AK, Baker CS, Romeo T, Babitzke P. 2005. RNA sequence and secondary structure participate in high-affinity CsrA-RNA interaction. RNA 11:1579-87

26. Dunham-Ems SM, Caimano MJ, Pal U, Wolgemuth CW, Eggers CH, et al. 2009. Live imaging reveals a biphasic mode of dissemination of Borrelia burgdorferi within ticks. F. Clin. Invest. 119:3652-65

27. Fang X, Gomelsky M. 2010. A post-translational, c-di-GMP-dependent mechanism regulating flagellar motility. Mol. Microbiol. 76:1295-305 
28. Fisher MA, Grimm D, Henion AK, Elias AF, Stewart PE, et al. 2005. Borrelia burgdorferi sigma ${ }^{54}$ is required for mammalian infection and vector transmission but not for tick colonization. Proc. Natl. Acad. Sci. USA 102:5162-67

29. Fraser CM, Casjens S, Huang WM, Sutton GG, Clayton R, et al. 1997. Genomic sequence of a Lyme disease spirochaete, Borrelia burgdorferi. Nature 390:580-86

30. Freedman JC, Rogers EA, Kostick JL, Zhang H, Iyer R, et al. 2010. Identification and molecular characterization of a cyclic-di-GMP effector protein, PlzA (BB0733): additional evidence for the existence of a functional cyclic-di-GMP regulatory network in the Lyme disease spirochete, Borrelia burgdorferi. FEMS Immunol. Med. Microbiol. 58:285-94

31. Ge Y, Li C, Corum L, Slaughter CA, Charon NW. 1998. Structure and expression of the FlaA periplasmic flagellar protein of Borrelia burgdorferi. 7. Bacteriol. 180:2418-25

32. Goldstein SF, Buttle KF, Charon NW. 1996. Structural analysis of Leptospiraceae and Borrelia burgdorferi by high-voltage electron microscopy. 7. Bacteriol. 178:6539-45

33. Goldstein SF, Charon NW, Kreiling JA. 1994. Borrelia burgdorferi swims with a planar waveform similar to that of eukaryotic flagella. Proc. Natl. Acad. Sci. USA 91:3433-37

34. Goldstein SF, Li C, Liu J, Miller MR, Motaleb MA, et al. 2010. The chic motility and chemotaxis of Borrelia burgdorferi. In Borrelia: Molecular Biology, Host Interaction, and Pathogenesis, ed. D Scott Samuels, JD Radolf, pp. 167-87. Norfolk, UK: Calister Acad.

35. Goulbourne EA Jr, Greenberg EP. 1981. Chemotaxis of Spirochaeta aurantia: involvement of membrane potential in chemosensory signal transduction. F. Bacteriol. 148:837-44

36. Harman MW, Dunham-Ems SM, Caimano MJ, Belperron AA, Bockenstedt LK, et al. 2012. The heterogeneous motility of the Lyme disease spirochete in gelatin mimics dissemination through tissue. Proc. Natl. Acad. Sci. USA. 109:3059-64

37. Hess JF, Oosawa K, Kaplan N, Simon MI. 1988. Phosphorylation of three proteins in the signaling pathway of bacterial chemotaxis. Cell 53:79-87

38. Hovind-Hougen K. 1984. Ultrastructure of spirochetes isolated from Ixodes ricinus and Ixodes dammini. Yale 7. Biol. Med. 57:543-48

39. Izard J, Renken C, Hsieh C, Desrosiers DC, Dunham-Ems S, et al. 2009. Cryo-electron tomography elucidates the molecular architecture of Treponema pallidum, the syphilis spirochete. 7 . Bacteriol. 191:7566-80

40. Josenhans C, Suerbaum S. 2002. The role of motility as a virulence factor in bacteria. Int. 7. Med. Microbiol. 291:605-14

41. Kimsey RB, Spielman A. 1990. Motility of Lyme disease spirochetes in fluids as viscous as the extracellular matrix. F. Infect. Dis. 162:1205-8

42. KostickJL, Szkotnicki LT, Rogers EA, Bocci P, Raffaelli N, Marconi RT. 2011. The diguanylate cyclase, Rrp1, regulates critical steps in the enzootic cycle of the Lyme disease spirochetes. Mol. Microbiol. 81:21931

43. Kudryashev M, Cyrklaff M, Baumeister W, Simon MM, Wallich R, Frischknecht F. 2009. Comparative cryo-electron tomography of pathogenic Lyme disease spirochetes. Mol. Microbiol. 71:1415-34

44. Kudryashev M, Cyrklaff M, Wallich R, Baumeister W, Frischknecht F. 2010. Distinct in situ structures of the Borrelia flagellar motor. F. Struct. Biol. 169:54-61

45. Lambert A, Picardeau M, Haake DA, Sermswan RW, Srikram A, et al. 2012. FlaA proteins in Leptospira interrogans are essential for motility and virulence but are not required for formation of the flagellum sheath. Infect. Immun. 80:2019-25

46. Leake MC, Chandler JH, Wadhams GH, Bai F, Berry RM, Armitage JP. 2006. Stoichiometry and turnover in single, functioning membrane protein complexes. Nature 443:355-58

47. Lee WY, Moriarty TJ, Wong CH, Zhou H, Strieter RM, et al. 2010. An intravascular immune response to Borrelia burgdorferi involves Kupffer cells and iNKT cells. Nat. Immunol. 11:295-302

48. Li C, Bakker RG, Motaleb MA, Sartakova ML, Cabello FC, Charon NW. 2002. Asymmetrical flagellar rotation in Borrelia burgdorferi nonchemotactic mutants. Proc. Natl. Acad. Sci. USA 99:6169-74

49. Li C, Wolgemuth CW, Marko M, Morgan DG, Charon NW. 2008. Genetic analysis of spirochete flagellin proteins and their involvement in motility, filament assembly, and flagellar morphology. 7. Bacteriol. 190:5607-15 


\section{Detailed examination of the $B b$ motor in situ at a resolution of $3.5 \mathrm{~nm}$ using cryo-ET.}

69. First examination of the flagellar motor in situ using cryo-ET.
50. Li C, Xu H, Zhang K, Liang FT. 2010. Inactivation of a putative flagellar motor switch protein FliG1 prevents Borrelia burgdorferi from swimming in highly viscous media and blocks its infectivity. Mol. Microbiol. 75:1563-76

51. Limberger RJ. 2004. The periplasmic flagellum of spirochetes. 7. Mol. Microbiol. Biotechnol. 7:30-40

52. Limberger RJ, Slivienski LL, Samsonoff WA. 1994. Genetic and biochemical analysis of the flagellar hook of Treponema phagedenis. 7. Bacteriol. 176:3631-37

53. Liu J, Howell JK, Bradley SD, Zheng Y, Zhou ZH, Norris SJ. 2010. Cellular architecture of Treponema pallidum: novel flagellum, periplasmic cone, and cell envelope as revealed by cryo electron tomography. 7. Mol. Biol. 403:546-61

54. Liu J, Lin T, Botkin DJ, McCrum E, Winkler H, Norris SJ. 2009. Intact flagellar motor of Borrelia burgdorferi revealed by cryo-electron tomography: evidence for stator ring curvature and rotor/C-ring assembly flexion. F. Bacteriol. 191:5026-36

55. Lloyd SA, Tang H, Wang X, Billings S, Blair DF. 1996. Torque generation in the flagellar motor of Escherichia coli: evidence of a direct role for FliG but not for FliM or FliN. F. Bacteriol. 178:223-31

56. Lucchetti-Miganeh C, Burrowes E, Baysse C, Ermel G. 2008. The post-transcriptional regulator CsrA plays a central role in the adaptation of bacterial pathogens to different stages of infection in animal hosts. Microbiology 154:16-29

57. Lux R, Miller JN, Park NH, Shi W. 2001. Motility and chemotaxis in tissue penetration of oral epithelial cell layers by Treponema denticola. Infect. Immun. 69:6276-83

58. Mauriello EM, Mignot T, Yang Z, Zusman DR. 2010. Gliding motility revisited: How do the myxobacteria move without flagella? Microbiol. Mol. Biol. Rev. 74:229-49

59. McGee DJ, Langford ML, Watson EL, Carter JE, Chen YT, Ottemann KM. 2005. Colonization and inflammation deficiencies in Mongolian gerbils infected by Helicobacter pylori chemotaxis mutants. Infect. Immun. 73:1820-27

60. Mercante J, Edwards AN, Dubey AK, Babitzke P, Romeo T. 2009. Molecular geometry of CsrA (RsmA) binding to RNA and its implications for regulated expression. F. Mol. Biol. 392:511-28

61. Moriarty TJ, Norman MU, Colarusso P, Bankhead T, Kubes P, Chaconas G. 2008. Real-time high resolution 3D imaging of the Lyme disease spirochete adhering to and escaping from the vasculature of a living host. PLoS Pathog. 4:e1000090

62. Motaleb MA, Corum L, Bono JL, Elias AF, Rosa P, et al. 2000. Borrelia burgdorferi periplasmic flagella have both skeletal and motility functions. Proc. Natl. Acad. Sci. USA 97:10899-904

63. Motaleb MA, Miller MR, Bakker RG, Li C, Charon NW. 2007. Isolation and characterization of chemotaxis mutants of the Lyme disease spirochete Borrelia burgdorferi using allelic exchange mutagenesis, flow cytometry, and cell tracking. Methods Enzymol. 422:419-37

64. Motaleb MA, Miller MR, Li C, Bakker RG, Goldstein SF, et al. 2005. CheX is a phosphorylated CheY phosphatase essential for Borrelia burgdorferi chemotaxis. F. Bacteriol. 187:7963-69

65. Motaleb MA, Pitzer JE, Sultan SZ, Liu J. 2011. A novel gene inactivation system reveals altered periplasmic flagellar orientation in a Borrelia burgdorferi fliL mutant. F. Bacteriol. 193:3324-31

66. Motaleb MA, Sal MS, Charon NW. 2004. The decrease in FlaA observed in a flaB mutant of Borrelia burgdorferi occurs posttranscriptionally. F. Bacteriol. 186:3703-11

67. Motaleb MA, Sultan SZ, Miller MR, Li C, Charon NW. 2011. CheY3 of Borrelia burgdorferi is the key response regulator essential for chemotaxis and forms a long-lived phosphorylated intermediate. 7. Bacteriol. 193:3332-41

68. Muff TJ, Ordal GW. 2008. The diverse CheC-type phosphatases: chemotaxis and beyond. Mol. Microbiol. 70:1054-61

69. Murphy GE, Leadbetter JR, Jensen GJ. 2006. In situ structure of the complete Treponema primitia flagellar motor. Nature 442:1062-64

70. Norman MU, Moriarty TJ, Dresser AR, Millen B, Kubes P, Chaconas G. 2008. Molecular mechanisms involved in vascular interactions of the Lyme disease pathogen in a living host. PLoS Pathog. 4:e1000169

71. Ouyang Z, Blevins JS, Norgard MV. 2008. Transcriptional interplay among the regulators Rrp2, RpoN and RpoS in Borrelia burgdorferi. Microbiology 154:2641-58 
72. Paster BJ. 2011. Phylum XV. Spirochaetes Garrity and Holt 2001. In Bergey's Manual of Systematic Bacteriology, ed. NR Krieg, W Ludwig, WB Whitman, BP Hedlund, BJ Paster, et al., 4:471-566. New York: Springer

73. Paul K, Nieto V, Carlquist WC, Blair DF, Harshey RM. 2010. The c-di-GMP binding protein YcgR controls flagellar motor direction and speed to affect chemotaxis by a "backstop brake" mechanism. Mol. Cell 38:128-39

74. Pazy Y, Motaleb MA, Guarnieri MT, Charon NW, Zhao R, Silversmith RE. 2010. Identical phosphatase mechanisms achieved through distinct modes of binding phosphoprotein substrate. Proc. Natl. Acad. Sci. USA 107:1924-29

75. Pitzer JE, Sultan SZ, Hayakawa Y, Hobbs G, Miller MR, Motaleb MA. 2011. Analysis of the Borrelia burgdorferi cyclic-di-GMP-binding protein PlzA reveals a role in motility and virulence. Infect. Immun. 79:1815-25

76. Porter SL, Wadhams GH, Armitage JP. 2011. Signal processing in complex chemotaxis pathways. Nat. Rev. Microbiol. 9:153-65

77. Raddi G, Morado DR, Yan J, Haake DA, Yang XF, Liu J. 2012. Three-dimensional structures of pathogenic and saprophytic Leptospira species revealed by cryo-electron tomography. 7. Bacteriol.194:1299-306

78. Rao CV, Glekas GD, Ordal GW. 2008. The three adaptation systems of Bacillus subtilis chemotaxis. Trends Microbiol. 16:480-87

79. Revel AT, Talaat AM, Norgard MV. 2002. DNA microarray analysis of differential gene expression in Borrelia burgdorferi, the Lyme disease spirochete. Proc. Natl. Acad. Sci. USA 99:1562-67

80. Romeo T. 1998. Global regulation by the small RNA-binding protein CsrA and the non-coding RNA molecule CsrB. Mol. Microbiol. 29:1321-30

81. Rosa PA, Tilly K, Stewart PE. 2005. The burgeoning molecular genetics of the Lyme disease spirochaete. Nat. Rev. Microbiol. 3:129-43

82. Rosey EL, Kennedy MJ, Yancey RJJr. 1996. Dual flaA1 flaB1 mutant of Serpulina byodysenteriae expressing periplasmic flagella is severely attenuated in a murine model of swine dysentery. Infect. Immun. 64:415462

83. Ryjenkov DA, Tarutina M, Moskvin OV, Gomelsky M. 2005. Cyclic diguanylate is a ubiquitous signaling molecule in bacteria: insights into biochemistry of the GGDEF protein domain. F. Bacteriol. 187:1792-98

84. Sal MS, Li C, Motalab MA, Shibata S, Aizawa S, Charon NW. 2008. Borrelia burgdorferi uniquely regulates its motility genes and has an intricate flagellar hook-basal body structure. F. Bacteriol. 190:191221

85. Samatey FA, Matsunami H, Imada K, Nagashima S, Shaikh TR, et al. 2004. Structure of the bacterial flagellar hook and implication for the molecular universal joint mechanism. Nature 431:1062-68

86. Samuels DS, Radolf JD, eds. 2010. Borrelia: Molecular Biology, Host Interaction and Pathogenesis. Norfolk, UK: Calister Acad. 548 pp.

87. Shih CM, Chao LL, Yu CP. 2002. Chemotactic migration of the Lyme disease spirochete (Borrelia burgdorferi) to salivary gland extracts of vector ticks. Am. 7. Trop. Med. Hyg. 66:616-21

88. Sourjik V, Armitage JP. 2010. Spatial organization in bacterial chemotaxis. EMBO 7. 29:2724-33

89. Stanek G, Wormser GP, Gray J, Strle F. 2011. Lyme borreliosis. Lancet 379:461-73

90. Sultan SZ, Pitzer JE, Boquoi T, Hobbs G, Miller MR, Motaleb MA. 2011. Analysis of the HD-GYP domain cyclic dimeric GMP phosphodiesterase reveals a role in motility and the enzootic life cycle of Borrelia burgdorferi. Infect. Immun. 79:3273-83

91. Sultan SZ, Pitzer JE, Miller MR, Motaleb MA. 2010. Analysis of a Borrelia burgdorferi phosphodiesterase demonstrates a role for cyclic-di-guanosine monophosphate in motility and virulence. Mol. Microbiol. $77: 128-42$

92. Sze CW, Li C. 2011. Inactivation of $b 60184$, which encodes carbon storage regulator A, represses the infectivity of Borrelia burgdorferi. Infect. Immun. 79:1270-79

93. Sze CW, Morado DR, Liu J, Charon NW, Xu H, Li C. 2011. Carbon storage regulator A (CsrA $\mathrm{Bb})$ is a repressor of Borrelia burgdorferi flagellin protein FlaB. Mol. Microbiol. 82:851-64

94. Sze CW, Zhang K, Kariu T, Pal U, Li C. 2012. Borrelia burgdorferi needs chemotaxis to establish infection in mammals and to accomplish its enzootic cycle. Infect. Immun. 80:2485-92
76. Reviews chemotaxis in different species of bacteria.

\section{Discusses how} recent breakthroughs in the molecular genetics of $B b$ are leading to a better understanding of the pathogenesis of Lyme disease.

\section{Gives a} comprehensive analysis of the biology of $B b$ and Lyme disease. 
103. Provides an extensive genomic analysis of the evolution of chemotaxis genes in bacteria.

105. Uses light microscopy and cryo-EM to analyze one end of a $B b$ cell.
95. Thomas DR, Francis NR, Xu C, DeRosier DJ. 2006. The three-dimensional structure of the flagellar rotor from a clockwise-locked mutant of Salmonella enterica serovar Typhimurium. F. Bacteriol. 188:703948

96. Tokarz R, Anderton JM, Katona LI, Benach JL. 2004. Combined effects of blood and temperature shift on Borrelia burgdorferi gene expression as determined by whole genome DNA array. Infect. Immun. 72:5419-32

97. Turner L, Ryu WS, Berg HC. 2000. Real-time imaging of fluorescent flagellar filaments. F. Bacteriol. 182:2793-801

98. Vaknin A, Berg HC. 2004. Single-cell FRET imaging of phosphatase activity in the Escherichia coli chemotaxis system. Proc. Natl. Acad. Sci. USA 101:17072-77

99. Wadhams GH, Armitage JP. 2004. Making sense of it all: bacterial chemotaxis. Nat. Rev. Mol. Cell Biol. 5:1024-37

100. Wei BL, Brun-Zinkernagel AM, Simecka JW, Pruss BM, Babitzke P, Romeo T. 2001. Positive regulation of motility and $f h D C$ expression by the RNA-binding protein CsrA of Escherichia coli. Mol. Microbiol. 40:245-56

101. Weibull C. 1960. Movement. In The Bacteria, A Treatise on Structure and Function, ed. IC Gunsalas, RY Stanier, 1:153-234. New York/ London: Academic

102. Wolgemuth CW, Charon NW, Goldstein SF, Goldstein RE. 2006. The flagellar cytoskeleton of the spirochetes. F. Mol. Microbiol. Biotechnol. 11:221-27

103. Wuichet K, Zhulin IB. 2010. Origins and diversification of a complex signal transduction system in prokaryotes. Sci. Signal. 3:ra50

104. Xu H, Caimano MJ, Lin T, He M, Radolf JD, et al. 2010. Role of acetyl-phosphate in activation of the Rrp2-RpoN-RpoS pathway in Borrelia burgdorferi. PLoS. Pathog. 6:e1001104

105. Xu H, Raddi G, Liu J, Charon NW, Li C. 2011. Chemoreceptors and flagellar motors are subterminally located in close proximity at the two cell poles in spirochetes. $\mathcal{F}$. Bacteriol. 193:2652-56

106. Yakhnin H, Pandit P, Petty TJ, Baker CS, Romeo T, Babitzke P. 2007. CsrA of Bacillus subtilis regulates translation initiation of the gene encoding the flagellin protein ( $\mathrm{ag}$ ) by blocking ribosome binding. Mol. Microbiol. 64:1605-20

107. Yang J, Huber G, Wolgemuth CW. 2012. Forces and torques on rotating spirochete flagella. Phys. Rev. Lett. 107:268101

108. Yang X, Goldberg MS, Popova TG, Schoeler GB, Wikel SK, et al. 2000. Interdependence of environmental factors influencing reciprocal patterns of gene expression in virulent Borrelia burgdorferi. Mol. Microbiol. 37:1470-79

109. Young GM, Badger JL, Miller VL. 2000. Motility is required to initiate host cell invasion by Yersinia enterocolitica. Infect. Immun. 68:4323-26

110. Yuri K, Takamoto Y, Okada M, Hiramune T, Kikuchi N, Yanagawa R. 1993. Chemotaxis of leptospires to hemoglobin in relation to virulence. Infect. Immun. 61:2270-72

\section{RELATED RESOURCES}

Brisson D, Drecktrah D, Eggers CH, Samuels DS. 2012. Genetics of Borrelia burgdorferi. Annu. Rev. Genet. 46:In press

Hazelbauer GL. 2012. Bacterial chemotaxis: the early years of molecular studies. Annu. Rev. Microbiol. 66:285-303

Paul K, Gonzalez-Bonet G, Bilwes AM, Crane BR, Blair D. 2011. Architecture of the flagellar rotor. EMBO 7. 30:2962-71

Samuels DS. 2011. Gene regulation in Borrelia burgdorferi. Annu. Rev. Microbiol. 65:479-99

Tilly K, Rosa PA, Stewart PE. 2008. Biology of infection with Borrelia burgdorferi. Infect. Dis. Clin.

North Am. 22:217-34 
Annual Review of

Microbiology

Volume 66, 2012

\section{Contents}

A Fortunate Journey on Uneven Grounds Agnes Ullmann

Memories of a Senior Scientist: On Passing the Fiftieth Anniversary of the Beginning of Deciphering the Genetic Code

Peter Lengyel

Yeast ATP-Binding Cassette Transporters Conferring Multidrug Resistance Rajendra Prasad and Andre Goffeau

'Gestalt,' Composition and Function of the

Trypanosoma brucei Editosome

H. Ulrich Göringer

Physiology and Diversity of Ammonia-Oxidizing Archaea

David A. Stabl and Fosé R. de la Torre

Bacterial Persistence and Toxin-Antitoxin Loci

Kenn Gerdes and Etienne Maisonneuve

Activating Transcription in Bacteria

David 7. Lee, Stephen D. Minchin, and Stephen 7.W. Busby

Herpesvirus Transport to the Nervous System and Back Again

Gregory Smith

A Virological View of Innate Immune Recognition

Akiko Iwasaki

DNA Replication and Genomic Architecture in Very Large Bacteria

Esther R. Angert

Large T Antigens of Polyomaviruses: Amazing Molecular Machines

Ping An, Maria Teresa Sáenz Robles, and James M. Pipas

Peroxisome Assembly and Functional Diversity in Eukaryotic Microorganisms

Laurent Pieuchot and Gregory Fedd 
Microbial Population and Community Dynamics on Plant Roots and Their Feedbacks on Plant Communities Fames D. Bever, Thomas G. Platt, and Elise R. Morton

Bacterial Chemotaxis: The Early Years of Molecular Studies

Gerald L. Hazelbauer

RNA Interference Pathways in Fungi: Mechanisms and Functions

Sbwu-Shin Chang, Zhenyu Zhang, and Yi Liu

Evolution of Two-Component Signal Transduction Systems

Emily 7. Capra and Michael T. Laub

The Unique Paradigm of Spirochete Motility and Chemotaxis

Nyles W. Charon, Andrew Cockburn, Chunbao Li, Jun Liu,

Kelly A. Miller, Michael R. Miller, Md. A. Motaleb,

and Charles $W$. Wolgemuth

Vaginal Microbiome: Rethinking Health and Disease

Bing Ma, Larry F. Forney, and Facques Ravel

Electromicrobiology

Derek R. Lovley

Origin and Diversification of Eukaryotes

Laura A. Katz

Genomic Insights into Syntrophy: The Paradigm

for Anaerobic Metabolic Cooperation

Fessica R. Sieber, Michael F. McInerney, and Robert P. Gunsalus

Structure and Regulation of the Type VI Secretion System

Fulie M. Silverman, Yannick R. Brunet, Eric Cascales, and Foseph D. Mougous

Network News: The Replication of Kinetoplast DNA

Robert E. Fensen and Paul T. Englund

Pseudomonas aeruginosa Twitching Motility: Type IV Pili in Action

Lori L. Burrows

Postgenomic Approaches to Using Corynebacteria as Biocatalysts

Alain A. Vertès, Masayuki Inui, and Hideaki Yukawa

\section{Index}

Cumulative Index of Contributing Authors, Volumes 62-66 551

\section{Errata}

An online log of corrections to Annual Review of Microbiology articles may be found at http://micro.annualreviews.org/ 
6 Xiaowei Zhao ${ }^{1 \#}$, Kai Zhang ${ }^{2 \#}$, Tristan Boquoi ${ }^{3}$, Bo Hu ${ }^{1}$, Md A. Motaleb ${ }^{3}$, Kelly A. Miller ${ }^{4}$, Milinda E.

7 James ${ }^{4}$, Nyles W. Charon ${ }^{4}$, Michael D. Manson ${ }^{5}$, Steven J. Norris ${ }^{1}$, Chunhao Li ${ }^{2 *}$, and Jun Liu ${ }^{1 *}$

9 1. Department of Pathology and Laboratory Medicine, University of Texas Health Science Center at 10 Houston, Houston, TX 77030

11 2. Department of Oral Biology, State University of New York at Buffalo, Buffalo, NY 14214

12 3. Department of Microbiology and Immunology, East Carolina University, Greenville, NC 27834

13 4. Department of Microbiology, West Virginia University, Morgantown, WV 26506

14 5. Department of Biology, Texas A\&M University, College Station, TX 77843

16 \# X.Z. and K.Z. contributed equally to this work.

*Corresponding authors:

19 Jun Liu, Ph.D., Department of Pathology and Laboratory Medicine, University of Texas Medical 20 School at Houston, Houston, TX 77030, USA; Tel: 713-500-5342; Email: Jun.Liu.1@uth.tmc.edu

21 Chunhao Li, M.D., Department of Oral Biology, State University of New York at Buffalo, Buffalo, 22 NY 14214, USA; Tel: 716-829-6014; Email: cli9@buffalo.edu

24 Running Title: Cryo-electron tomography captures flagellar assembly in intact cells 


\section{ABSTRACT}

Periplasmic flagella are essential for the distinctive morphology, motility, and infectious life 28 cycle of the Lyme disease spirochete Borrelia burgdorferi. Here, we report work in which we 29 genetically trapped intermediates in flagellar assembly and determined three-dimensional structures of 30 the intermediates to $4 \mathrm{~nm}$ resolution by cryo-electron tomography. We provide structural evidence that 31 secretion of rod substrates triggers remodeling of the central channel in the flagellar secretion 32 apparatus from a closed to an open conformation. This open channel then serves both as a gateway and 33 template for flagellar rod assembly. The individual proteins assemble sequentially to form a modular 34 rod. The hook cap initiates hook assembly upon completion of the rod, and the filament cap facilitates 35 filament assembly after formation of the mature hook. Cryo-electron tomography and mutational 36 analysis thus combine synergistically to provide the first structural blueprint of the assembly process of 37 this intricate molecular machine in intact cells. 
lbody

\section{INTRODUCTION}

spirochete pathogen (1). Seven to eleven periplasmic flagella (PFs) are inserted near both cell poles (Fig. 1A). The PFs are essential for the flat-wave morphology, distinct motility, and infectious life

cycle of B. burgdorferi (2-6). They are strikingly different from external flagella (e.g., in Escherichia coli) in that both the hook and the filament are located in the periplasmic space. Nevertheless, the major components are remarkably similar among different bacterial species [Figs. 1B, C; see also (79)].

The flagellum is a sophisticated self-assembling molecular machine $(10,11)$. It contains at least 25 different proteins that form a rotary motor, a hook, and a helical filament (Fig. 1B, C) (11-13). The morphogenetic pathway for flagellar biosynthesis has been extensively studied in E. coli and Salmonella enterica serovar Typhimurium, in which a highly regulated expression of motility genes is coordinated with flagellar assembly $(10,11)$. Assembly is initiated by the insertion of the MS ring (consisting of FliF) into the cytoplasmic membrane. The MS ring then acts as a platform for assembly of the $\mathrm{C}$ ring (the switch complex), the stator (the torque generator), and the flagellum-specific type III secretion (T3S) apparatus. Most flagellar proteins are secreted by the T3S system, which is powered by the transmembrane ion-motive force $(14,15)$. The secretion and assembly of each substrate is highly ordered; flagellar assembly proceeds in a linear fashion from proximal rod to distal filament $(10,11)$. However, this progressive assembly process has not been visualized in detail in intact cells.

The flagellar rod is the first structure secreted by the T3S system, and it functions both as a hollow secretion channel and a drive shaft that transmits torque. The structure of the intact rod of $S$. Typhimurium was deduced by comparing electron microscopy images of purified flagellar basal bodies with MS ring complexes (16, 17). Five proteins (FliE, FlgB, FlgC, FlgF, and FlgG) are involved 
63 in assembly of the flagellar rod. FliE is postulated to be a structural adaptor between the MS ring and

64 the rod $(18,19)$. Moreover, assembly of FliE is required for exporting other substrates (20). It is 65 generally thought that the rod proteins assemble cooperatively to build a stable rod $(21,22)$. However, 66 no direct structural evidence has been reported, because rod mutations in $S$. Typhimurium result in 67 structural instability (22) and because it has been a technically formidable challenge to visualize the 68 rod assembly, either in vivo or in vitro, in any bacteria.

69 Upon completion of the rod, a cap protein is required for hook assembly. The hook-cap protein, $70 \quad \mathrm{FlgD}$, has been detected at the distal end of the hook (23). Hooks are thought to assemble at their distal 71 ends by inserting FlgE subunits underneath the hook cap. After the hook reaches its mature length $(\sim 55$ nm), two junction proteins, FlgK and FlgL, and a filament cap protein, FliD, are added sequentially to 73 the distal end of the hook (24). The filament cap is predicted to stay at the end of the growing filament 74 to facilitate polymerization of filament proteins (25). Understanding the intermediates in this complex 75 process will shed light on the polymerization activity that yields a functional assembly. flagellar assembly in B. burgdorferi likely resembles that of other bacterial species. The multiple 78 flagellar motors of $B$. burgdorferi are located close to both of its narrow (diameter $\leq 0.3 \mu \mathrm{m}$ ) cell poles, 79 locations optimal for cryo-electron tomography (cryo-ET) determination of the molecular architecture 80 of the flagellar motor in intact cells $(7-9,26,27)$. In this study, we selectively deleted individual genes 81 whose products play key roles in flagellar assembly and then used cryo-ET and subvolume averaging 82 to determine intermediate structures. This approach permitted a molecular characterization of the 83 nascent structures of flagellar intermediates, thereby providing detailed insights into the sequential 84 processes of T3S-mediated flagellar assembly. 
86

87

88

89

90

91

92

93

94

100

101

102

103

104

105

106

107

108

109

110

RESULTS

\section{Structural differences between the intact flagellar motor in situ and purified flagella}

In B. burgdorferi, multiple flagellar motors are embedded in the inner membrane (IM) (Fig. 1A, D; Movie S1). A $3.5 \mathrm{~nm}$ resolution structure of the intact flagellar motor (Fig. 1E) clearly shows the straight rod with a channel in the middle. The rod also adopts a tilted conformation (Fig. S9), suggesting that it is either intrinsically flexible or has at least two fixed orientations. The MS ring is associated with the export apparatus, the rod, the $\mathrm{C}$ ring, and the collar (Fig. 1B, E). To define the MS ring from the intact motor of B. burgdorferi, we purified PFs (Fig. 1G) and determined the 3-D structure of the basal body (Fig. 1H, I). The purified basal body was significantly smaller than the intact motor (Fig. 1E, F). Many membrane-associated and periplasmic structures of the intact motor were removed during PF purification (Fig. 1E, F). The remaining basal body is structurally comparable to the MS ring and rod of the $S$. Typhimurium basal body (16; Fig. S1). On this basis, we propose a model of the MS ring-rod complex in B. burgdorferi (Fig. 1F, J).

\section{Flagellar motor structure in a $\Delta f l i E$ mutant}

To define the boundary between the rod and the MS ring, we constructed a fliE deletion mutant $(\triangle f l i E)$ using recently reported gene-inactivation system that does not impose a polar effect on downstream gene expression (28). The $\Delta f l i E$ cells are rod-shaped and non-motile (Table S1), and there is no filament or hook in the periplasmic space (Fig. 2A; Movie S2). However, multiple flagellar motors are clearly visible at the cell poles (Fig. 2B, C). The motor structure from the $\Delta f l i E$ mutant (Fig. 2D-F) is significantly different from that of the wild-type motor, as the mutant lacks the rod, the hook, and the filament. Other components of the motor (the MS ring, the $\mathrm{C}$ ring, the stator, the export apparatus, and the collar) remain unaffected, suggesting that those motor components assemble independently of the T3S-mediated pathway. 
112 white arrows). It forms a well-defined pocket for anchoring the rod. Notably, the central channel of the

113 MS ring is closed in the $\Delta f l i E$ motor (Fig. 2D, G), whereas it is open in the wild-type motor (Fig. 1K, $1142 \mathrm{H})$. The outer diameter of the channel is $6 \mathrm{~nm}$ (Fig. 2H). Apparently, the rod assembles on top of the 115 open channel and forms an integrated complex with the MS ring (Fig. 1K, 2H).

117 Flagellar motor structures in the rod mutants $\Delta f \lg B, \Delta f l g C$, and $\Delta f l h O$

118 To investigate assembly of the rod in detail, we introduced non-polar mutations into each of the 119 rod genes $(f \lg B, f \lg C, f \operatorname{lh} O$ [a $f \lg F$ homolog], and $f \lg G)$. We also generated the double knockout 120 mutation $\triangle f \lg B C$ (Table S1). All of the mutant cells were rod-shaped and non-motile, and no flagellar 121 filament or hook was assembled in the periplasmic space of any of these rod mutants. As in the $\Delta f l i E$ 122 mutant, multiple motors were readily visible at the cell poles (Fig. S7). The central channel of the $\Delta f l g B$ flagellar motor remains in a closed conformation (Fig. 3A, D,

$124 \mathrm{G})$. In contrast, the channel is in an open conformation in the $\Delta f \lg C$ mutant (Fig. 3B, E, H). An 125 additional globular density is also evident in the $\Delta f \lg C$ mutant, suggesting that FlgB is secreted and 126 accumulates in that region. The globular density is more pronounced and extends beyond the MS-ring 127 128 Together, secretion of FlgB and FliE appears to trigger opening of the channel, which then permits the 129 secretion of other substrates.

\section{Proximal rod and distal rod structures in the $\Delta f l g G$ and $\Delta f l g E$ mutants}

133 previous mutants (Fig. 2, 3). Notably, a $13 \mathrm{~nm}$-long tube-shaped structure extends from the apex of the 134 central channel in the MS ring. It is significantly longer than the globular densities observed in the 
$135 \Delta f l g C$ and $\triangle f l h O$ mutants (Fig. 3B, C). The 3-D structure of the proximal rod (Fig. 4C) is derived from

136 the difference map between the $\Delta f \lg G$ motor and the $\Delta f l i E$ motor. Evidently, the rod undergoes a 137 transformative change from a globular density in the $\Delta f l h O$ mutant into a tube-like structure in the $138 \Delta f \lg G$ mutant, suggesting that FlhO is essential for the construction of a stable, tube-like proximal rod 139 (Fig. 4A).

140 To reveal the structure of the distal rod, we determined the motor structure from a mutant 141 deleted for the $f l g E$ gene, which encodes the major hook subunit (Fig. 4D, E). Comparative analysis of 142 the intact motor (Fig. $1 \mathrm{~K}$ ) and the $\Delta f \lg G$ and $\Delta f \lg E$ motors (Fig. 4) reveals that the intact rod is $\sim 17 \mathrm{~nm}$ 143 long, meaning that the distal rod is $\sim 4 \mathrm{~nm}$ in length (Fig. 4F). The torus-shaped P ring (9) is present in 144 the $\Delta f \lg E$ mutant (Fig. 4D) but not in the $\Delta f \lg G$ mutant (Fig. 4A), demonstrating that the distal rod is a 145 necessary substrate for the assembly of the P ring. The intact rod is completely bracketed by the MS 146 ring at the bottom and by the P ring at the top (Fig. 4E). The diameter and density of the intact rod vary 147 along its length. Therefore, the rod is not a simple cylindrical structure with a uniform diameter. 148 Instead, it is composed of modular cylinders, each with well-defined but variable diameters (Fig. 4F). A plug-like structure is inserted into the distal rod in the $\Delta f l g E$ motor (Fig. 4D, E). There is no 150 similar structure in either the intact motor (Fig. $1 \mathrm{~K}$ ) or the $\Delta f \lg G$ motor (Fig. 4A). In the absence of the 151 hook subunit FlgE, the assembly process presumably terminates right before the initiation of hook 152 assembly. Therefore, we hypothesize that the plug-like structure represents the hook cap, a structure 153 that is predicted to be required for hook assembly (23).

\section{Flagellar hook and hook-filament junction structures revealed in a flaB mutant} The flagellar filament of $B$. burgdorferi contains the major filament protein FlaB and the minor

157 filament protein FlaA $(29,30)$. B. burgdorferi flaB mutant cells are non-motile and rod-shaped, and 158 they are completely deficient in filament assembly $(2,6)$. Both flagellar motors and hooks are visible 159 near the cell poles in flaB cells (Fig. 5A). A $\sim 62 \mathrm{~nm}$ tube-like structure and a $\sim 14 \mathrm{~nm}$ cap-like structure 
160 are evident in the flaB mutant (Fig. 5B, C) and probably represent an assembly intermediate that

161 contains a mature hook and hook-filament junction associated with the filament cap, respectively.

162 The mature hook is $\sim 50 \mathrm{~nm}$ long (Fig. 5B), a length similar to that of the hook in $S$.

163 Typhimurium ( $\sim 55 \mathrm{~nm} ; 31)$. At the distal end of the hook, an additional $\sim 12 \mathrm{~nm}$ long structure differs

164 slightly from the hook in density and diameter (Fig. 5B and C); we postulate that this region represents

165 the hook-filament junction. Furthermore, a cap-like structure is connected to the distal end of the hook-

166 filament junction (Fig. 5C, D). The observed density of the cap is structurally similar to the filament

167 cap of $S$. Typhimurium (25). The filament cap is absent at the hook-filament junction in wild-type cells

168 (Fig. 5E-H), supporting the idea that the filament cap remains at the distal end of the growing filament $169(24,25)$.

170

\section{DISCUSSION}

172 The periplasmic flagellum is a sophisticated molecular machine that plays critical roles in the 173 distinct morphology, motility and infectivity of the Lyme disease spirochete B. burgdorferi and other 174 spirochetes (such as Treponema pallidum, the causative agent of syphilis (26)). Because B. burgdorferi 175 is genetically tractable, it has proven to be an excellent model for visualizing the sequential assembly 176 of flagella in intact spirochetes (Fig. 6A; Movie S3). The PFs of spirochetes have enough in common 177 with external bacterial flagella to serve as a global model for flagellar assembly.

178

179 MS ring assembly

180 The MS ring is the first stage in the assembly of the $\mathrm{C}$ ring, the export apparatus, the collar, and

181 the stator. Those components all assemble independently of the T3S-mediated export pathway (Fig. 182 6A). A socket and a central channel in the MS ring are well defined in the absence of any rod 183 components (Fig. 2). The socket appears similar in all motor structures, suggesting that it provides a 
184 compact and stable platform for rod assembly. A unique segment of FliF (residues $280-360$ in E. coli)

185 has been proposed to form the socket domain, and mutations targeting this region cause release of the 186 filament and the rod from the basal body $(17,32,33)$.

187 Prior to rod assembly, the channel of the MS ring is closed, providing an explanation for 188 observation that substrate secretion is very low in the absence of FliE (20). When the rod substrates 189 FliE and FlgB are secreted, the central channel adapts an open conformation that also serves as a 190 template for the initiation of the rod assembly (34). The open channel of the MS ring and the rod forms 191 a tightly integrated structure with no distinguishable boundary (Fig. 1K). The presence of heptad 192 repeats of hydrophobic residues in the terminal regions of the rod proteins (Table S3) may mean that 193 an $\alpha$-helical coiled-coil is the motif required to form a continuous mechanically stable axial structure $194(35,36)$. The sequence of residues 130 to 230 of FliF is highly conserved and contains hydrophobic 195 residues at several heptad positions (Table S4). Therefore, the rod proteins apparently assemble on top 196 of the open channel, probably through hydrophobic $\alpha$-helical coiled-coil interactions.

197

198 199 200

\section{Rod assembly}

The flagellar rod is a multi-component complex that functions as an export channel and drive shaft. It has been suggested that rod proteins assemble cooperatively in order to form an intact rod but that rod intermediates are unstable (22). Here, we were able to determine structures of corresponding to intermediate stages of rod assembly. The rod elongates sequentially in $\Delta f \lg B, \Delta f \lg C, \Delta f \operatorname{lh} O, \Delta f \lg G$ and $\triangle f \lg E$ mutants, implying that the rod assembles in the order FliE-FlgB-FlgC-FlhO-FlgG. The proximal rod forms a tube-like structure (Fig. 4A), whereas the intermediate structures visible in the $\Delta f \lg B, \Delta f \lg C$, and $\Delta f l h O$ mutants do not show any tube-like character (Fig. 3). Therefore, we conclude that the proximal rod forms sequentially and cooperatively and that the distal rod can be added subsequently and independently. 
Hook assembly (23) and filament assembly $(24,25)$ are mediated by the hook-cap protein 212 (FlgD) and the filament-cap protein (FliD), respectively. Assembly is blocked right before hook 213 formation in the $\triangle f \lg E$ mutant and before filament formation in the flaB mutant. Consequently, we 214 were able to capture intermediates containing the hook cap (Fig. 4D) and the filament cap (Fig. 5B), 215 respectively. Both the structures can be divided into cap and leg domains (Fig. 4D and Fig. 5B); a 216 similar cap-leg architecture was seen in a high-resolution structure of the filament cap (25). We 217 therefore suggest that the hook cap facilitates assembly of the hook by a rotational mechanism similar 218 to the one utilized by the filament cap to promote assembly of the filament (25).

\section{Modular architecture of the flagellar rod}

The flagellar rod is formed by five proteins, which interact through $\alpha$-helical coiled coils that

join the N-terminus of one subunit to the C-terminus of the adjacent subunit (35-38). The rod 224 assembles on top of the open channel in the MS ring, likely through similar hydrophobic interactions.

225 The rod is further reinforced by strong interactions with the socket of the MS ring and with the P ring 226 (Fig. 6B). This organization of rod components differs from that of external flagella (Fig. 6C). The 227 distal rod of external flagella is estimated to consist of four turns containing 26 FlgG subunits $(\sim 15 \mathrm{~nm}$ 228 in $S$. Typhimurium) $(11,39)$. In contrast, the distal $\operatorname{rod}(\sim 4 \mathrm{~nm})$ of PFs is too short to penetrate the 229 outer membrane (Fig. 6B). We conjecture that FlgG and the three other rods proteins (FlgB, FlgC, 230 FlhO) in B. burgdorferi polymerize for only one turn. The underlying mechanism for control of the 231 length of the distal rod must therefore be different during the formation of external flagella and PFs. The flagellum and the virulence-associated injectisome share an analogous architecture and 233 homologous T3S components (40). However, the structure and function of the rod are quite different in 234 the two systems. The rod of the injectisome is formed by one protein ( $\operatorname{PrgJ}$ in $S$. Typhimurium). Rod 235 assembly is required for proper anchoring of the needle structure (41). The function of the injectisome 
236 rod is to provide a conduit for protein transport from the bacterial cytoplasm to the host cell (Fig. 6D).

237 In contrast, the flagellar rod and its complex interactions with the MS and P rings (Fig. 6B) provide 238 dual functions: a hollow channel for protein secretion and a drive shaft to transmit torque between the 239 motor and filament.

240 In summary, high-throughput cryo-ET, coupled with mutational analysis, revealed a complete 241 series of high-resolution molecular snapshots of the periplasmic flagella in the Lyme disease 242 spirochete. The resulting composite picture provides the first set of structural blueprints depicting the 243 assembly process of this intricate molecular machine. This approach should be applicable in 244 determining the sequence of events in intact cells that generate a broad range of molecular machines.

EXPERIMENTAL PROCEDURES

\section{Bacterial strains}

High-passage avirulent Borrelia burgdorferi sensu stricto strain B31A (wild type) and its 250 isogenic mutants (Table S1) were grown in BSK-II liquid medium supplemented with $6 \%$ rabbit 251 serum or on semi-solid agar plates at $34{ }^{\circ} \mathrm{C}$ in the presence of 3-5\% carbon dioxide as previously 252 described (42). Genes flgB [bb0294], flgC [bb0293], fliE [bb0292], and flgE [bb0283] are located in 253 the $f \lg B$ operon (Figure S2), consisting of approximately 26 motility genes (43); flhO [bb0775, a 254 homolog of FlgF] and $f \lg G$ [bb0774] are located within the $f \operatorname{lhO}$ motility gene operon (42). To avoid 255 potential polar effect on a downstream gene expression, our recently reported gene replacement in256 frame deletion method (28) was used to construct the targeted mutagenesis in $f \lg B, f \lg C, f \lg B C$ 257 (deleting both $f l g B$ and $f l g C$ ), fliE, $f l g E$ and $f l h O$ genes.

\section{Cryo-electron tomography}


261 burgdorferi culture was centrifuged at $5,000 \times \mathrm{g}$ for $5 \mathrm{~min}$ and the resulting pellet were rinsed gently 262 with $1 \mathrm{ml}$ PBS. The cells were centrifuged again and were finally suspended in $30 \sim 50 \mu 1 \mathrm{PBS}$. The 263 cultures were mixed with $10 \mathrm{~nm}$ (or $15 \mathrm{~nm}$ ) colloidal fiducial gold markers and were then deposited 264 onto freshly glow-discharged, holey carbon grids for 1 min. Grids were blotted with filter paper and 265 then rapidly frozen in liquid ethane, using a homemade gravity-driven plunger apparatus.

266 Frozen-hydrated specimens were imaged at $-170^{\circ} \mathrm{C}$ using a Polara G2 electron microscope 267 (FEI) equipped with a field emission gun and a 16 megapixel CCD camera (TVIPS). The microscope 268 was operated at $300 \mathrm{kV}$ with a magnification of $31,000 \times$, resulting in an effective pixel size of $5.7 \AA$ 269 after $2 \times 2$ binning. Using the FEI "batch tomography" program, low-dose, single-axis tilt series were 270 collected from cell poles at -6 to $-9 \mu \mathrm{m}$ defocus with a cumulative dose of $\sim 100 \mathrm{e}^{-} / \AA^{2}$ distributed over 27187 images and covering an angular range of $-64^{\circ}$ to $+64^{\circ}$, with an angular increment of $1.5^{\circ}$. Tilt series 272 were automatically aligned and reconstructed using a combination of IMOD (44) and RAPTOR (45). 273 In total, 234,552 CCD images and 2,696 tomographic reconstructions were generated and used for 274 further processing (Table S2).

\section{Subvolume analysis}

Conventional imaging analysis, including $4 \times 4 \times 4$ binning, contrast inversion, and low-pass 278 filtering enhanced the contrast of binned tomograms (46). The subvolumes $(256 \times 256 \times 256$ voxels) of 279 the flagellar motors were extracted computationally from the tomograms and were further aligned as 280 previously described $(9,26,47,48)$. A total of 15,380 flagellar motor subvolumes were manually 281 selected from 2,696 reconstructions (Table S2). Class averages were computed in Fourier space, so the 282 missing wedge problem of tomography was minimized $(46,48)$. Fourier shell correlation coefficients 283 with a threshold of 0.5 were estimated by comparing the correlation between two randomly divided 284 halves of the aligned images used to generate the final maps (Table S2). 


\section{3-D visualization}

Segmentation of 3-D flagellar structure is based on the density maps and the difference maps 288 (as shown in Fig. S10). The software package UCSF Chimera (49) was mainly used for 3-D 289 visualization and surface rendering. Segmentations of cryo tomographic reconstructions from a wild 290 type cell and a $\Delta f l i E$ cell were constructed using the 3-D modeling software Amira (Visage Imaging). 291 The filaments, the outer and inner membranes, and the peptidoglycan layer were manually segmented 292 (Movies S1 and S2). The isosurface maps from the flagellar motor were computationally mapped back 293 into the original cellular context.

294

295

296

297

298

\section{ACKNOWLEDGMENTS}

We thank Drs. Ken Taylor and Jeff Actor for comments. This work was supported by grants 299 R01AI087946 from the NIAID and AU-1714 from the Welch Foundation. KZ and CL were supported 300 by grant R01AI078958 from the NIAID. KM, MJ, and NC were supported by the American Heart 301 Association and grant R21AI093917 from the NIAID. TB and MAM were supported by grant 302 R01AR060834 from the NIAMS. EM maps have been deposited in the EM Data Bank 303 (http://www.ebi.ac.uk/pdbe/emdb/) with Accession Numbers EMD-5627, EMD-5628, EMD-5629, 304 EMD-5630, EMD-5631, EMD-5632, and EMD-5633.

305

306 
1. Charon NW, et al. (2012) The unique paradigm of spirochete motility and chemotaxis. Annu

2. Motaleb MA, et al. (2000) Borrelia burgdorferi periplasmic flagella have both skeletal and

3. Sal MS, et al. (2008) Borrelia burgdorferi uniquely regulates its motility genes and has an

4. Sze CW, et al. (2011) Carbon storage regulator $\mathrm{A}(\mathrm{Csr} A(\mathrm{Bb}))$ is a repressor of Borrelia burgdorferi flagellin protein FlaB. Molecular microbiology 82(4):851-864.

5. Li C, Xu H, Zhang K, \& Liang FT (2010) Inactivation of a putative flagellar motor switch protein FliG1 prevents Borrelia burgdorferi from swimming in highly viscous media and blocks its infectivity. Molecular microbiology 75(6):1563-1576.

6. Sultan SZ, et al. (2013) Motility is crucial for the infectious life cycle of Borrelia burgdorferi. Infection and immunity.

7. Chen S, et al. (2011) Structural diversity of bacterial flagellar motors. EMBO J 30(14):29722981.

8. Kudryashev M, Cyrklaff M, Wallich R, Baumeister W, \& Frischknecht F (2010) Distinct in situ structures of the Borrelia flagellar motor. J Struct Biol 169(1):54-61.

9. Liu J, et al. (2009) Intact flagellar motor of Borrelia burgdorferi revealed by cryo-electron tomography: evidence for stator ring curvature and rotor/C-ring assembly flexion. Journal of bacteriology 191(16):5026-5036.

10. Chevance FF \& Hughes KT (2008) Coordinating assembly of a bacterial macromolecular machine. Nat Rev Microbiol 6(6):455-465.

11. Macnab RM (2003) How bacteria assemble flagella. Annu Rev Microbiol 57:77-100.

12. Berg HC (2003) The rotary motor of bacterial flagella. Annu Rev Biochem 72:19-54.

13. Terashima H, Kojima S, \& Homma M (2008) Flagellar motility in bacteria structure and function of flagellar motor. Int Rev Cell Mol Biol 270:39-85.

14. Minamino T \& Namba K (2008) Distinct roles of the FliI ATPase and proton motive force in bacterial flagellar protein export. Nature 451(7177):485-488.

15. Paul K, Erhardt M, Hirano T, Blair DF, \& Hughes KT (2008) Energy source of flagellar type III secretion. Nature 451(7177):489-492.

16. Francis NR, Sosinsky GE, Thomas D, \& DeRosier DJ (1994) Isolation, characterization and structure of bacterial flagellar motors containing the switch complex. J Mol Biol 235(4):12611270.

17. Suzuki H, Yonekura K, \& Namba K (2004) Structure of the rotor of the bacterial flagellar motor revealed by electron cryomicroscopy and single-particle image analysis. $J \mathrm{Mol} \mathrm{Biol}$ 337(1):105-113. 
18. Minamino T, Yamaguchi S, \& Macnab RM (2000) Interaction between FliE and FlgB, a proximal rod component of the flagellar basal body of Salmonella. J Bacteriol 182(11):30293036.

19. Muller V, Jones CJ, Kawagishi I, Aizawa S, \& Macnab RM (1992) Characterization of the fliE genes of Escherichia coli and Salmonella typhimurium and identification of the FliE protein as a component of the flagellar hook-basal body complex. J Bacteriol 174(7):2298-2304.

Minamino T \& Macnab RM (1999) Components of the Salmonella flagellar export apparatus 351 and classification of export substrates. J Bacteriol 181(5):1388-1394.

21. Jones CJ \& Macnab RM (1990) Flagellar assembly in Salmonella typhimurium: analysis with temperature-sensitive mutants. J Bacteriol 172(3):1327-1339.

22. Kubori T, Shimamoto N, Yamaguchi S, Namba K, \& Aizawa S (1992) Morphological pathway of flagellar assembly in Salmonella typhimurium. J Mol Biol 226(2):433-446.

23. Ohnishi K, Ohto Y, Aizawa S, Macnab RM, \& Iino T (1994) FlgD is a scaffolding protein needed for flagellar hook assembly in Salmonella typhimurium. J Bacteriol 176(8):2272-2281.

24. Homma M \& Iino T (1985) Locations of hook-associated proteins in flagellar structures of 359 Salmonella typhimurium. J Bacteriol 162(1):183-189.

25. Yonekura K, et al. (2000) The bacterial flagellar cap as the rotary promoter of flagellin selfassembly. Science 290(5499):2148-2152.

26. Liu J, et al. (2010) Cellular architecture of Treponema pallidum: novel flagellum, periplasmic cone, and cell envelope as revealed by cryo electron tomography. J Mol Biol 403(4):546-561.

27. Murphy GE, Leadbetter JR, \& Jensen GJ (2006) In situ structure of the complete Treponema primitia flagellar motor. Nature 442(7106):1062-1064.

28. Motaleb MA, Pitzer JE, Sultan SZ, \& Liu J (2011) A novel gene inactivation system reveals altered periplasmic flagellar orientation in a Borrelia burgdorferi fliL mutant. $J$ Bacteriol 193(13):3324-3331.

29. Ge Y, Li C, Corum L, Slaughter CA, \& Charon NW (1998) Structure and expression of the FlaA periplasmic flagellar protein of Borrelia burgdorferi. J Bacteriol 180(9):2418-2425.

30. Motaleb MA, Sal MS, \& Charon NW (2004) The decrease in FlaA observed in a flaB mutant of Borrelia burgdorferi occurs posttranscriptionally. J Bacteriol 186(12):3703-3711.

31. Hirano T, Yamaguchi S, Oosawa K, \& Aizawa S (1994) Roles of FliK and FlhB in determination of flagellar hook length in Salmonella typhimurium. J Bacteriol 176(17):54395449 .

32. Ueno T, Oosawa K, \& Aizawa S (1994) Domain structures of the MS ring component protein (FliF) of the flagellar basal body of Salmonella typhimurium. J Mol Biol 236(2):546-555.

33. Okino H, et al. (1989) Release of flagellar filament-hook-rod complex by a Salmonella typhimurium mutant defective in the M ring of the basal body. J Bacteriol 171(4):2075-2082.

34. Saijo-Hamano Y, Uchida N, Namba K, \& Oosawa K (2004) In vitro characterization of FlgB, $\mathrm{FlgC}$, FlgF, FlgG, and FliE, flagellar basal body proteins of Salmonella. J Mol Biol 339(2):423435.

35. Yonekura K, Maki-Yonekura S, \& Namba K (2003) Complete atomic model of the bacterial flagellar filament by electron cryomicroscopy. Nature 424(6949):643-650. 
36. Homma M, DeRosier DJ, \& Macnab RM (1990) Flagellar hook and hook-associated proteins of Salmonella typhimurium and their relationship to other axial components of the flagellum. $J$ Mol Biol 213(4):819-832.

37. Homma M, Kutsukake K, Hasebe M, Iino T, \& Macnab RM (1990) FlgB, FlgC, FlgF and FlgG. A family of structurally related proteins in the flagellar basal body of Salmonella typhimurium. $J$ Mol Biol 211(2):465-477.

38. Samatey FA, et al. (2004) Structure of the bacterial flagellar hook and implication for the molecular universal joint mechanism. Nature 431(7012):1062-1068.

39. Jones CJ, Macnab RM, Okino H, \& Aizawa S (1990) Stoichiometric analysis of the flagellar hook-(basal-body) complex of Salmonella typhimurium. J Mol Biol 212(2):377-387.

40. Erhardt M, Namba K, \& Hughes KT (2010) Bacterial nanomachines: the flagellum and type III injectisome. Cold Spring Harb Perspect Biol 2(11):a000299.

41. Marlovits TC, et al. (2006) Assembly of the inner rod determines needle length in the type III secretion injectisome. Nature 441(7093):637-640.

42. Zhang K, Tong BA, Liu J, \& Li C (2012) A single-domain FlgJ contributes to flagellar hook and filament formation in the Lyme disease spirochete Borrelia burgdorferi. J Bacteriol 194(4):866-874.

43. Ge Y \& Charon NW (1997) Identification of a large motility operon in Borrelia burgdorferi by semi-random PCR chromosome walking. Gene 189(2):195-201.

44. Kremer JR, Mastronarde DN, \& McIntosh JR (1996) Computer visualization of threedimensional image data using IMOD. $J$ Struct Biol 116(1):71-76.

45. Amat F, et al. (2008) Markov random field based automatic image alignment for electron tomography. J Struct Biol 161(3):260-275.

46. Liu J, Wright ER, \& Winkler H (2010) 3D visualization of HIV virions by cryoelectron tomography. Methods Enzymol 483:267-290.

47. Winkler $\mathrm{H}$ (2007) 3D reconstruction and processing of volumetric data in cryo-electron tomography. J Struct Biol 157(1):126-137.

48. Winkler $\mathrm{H}$, et al. (2009) Tomographic subvolume alignment and subvolume classification applied to myosin V and SIV envelope spikes. $J$ Struct Biol 165(2):64-77.

49. Pettersen EF, et al. (2004) UCSF Chimera--a visualization system for exploratory research and analysis. J Comp Chem 25(13):1605-1612. 


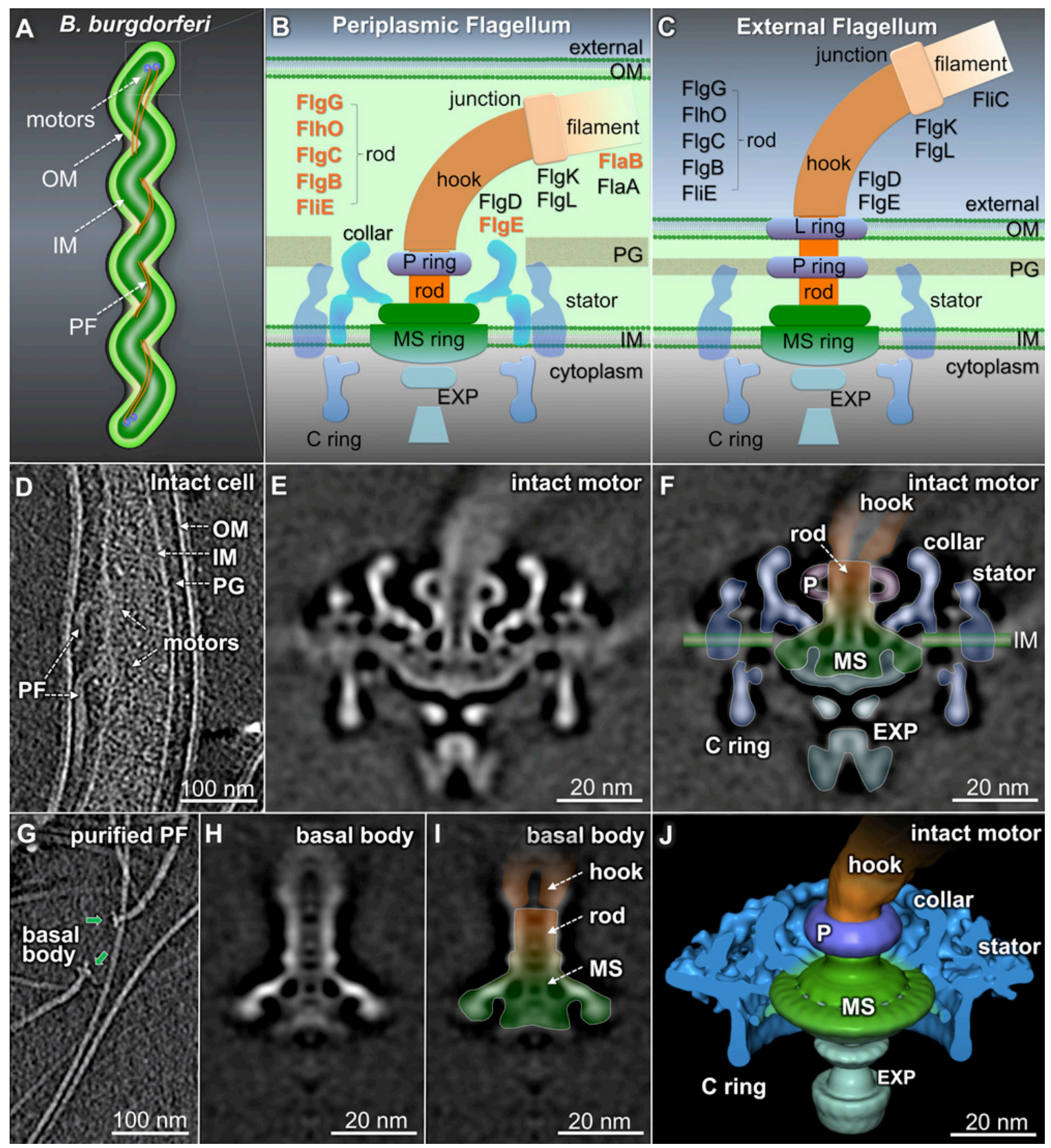

421 Fig. 1. Structural differences between the intact flagellar motor and the purified flagella.

422 (A) Model of a B. burgdorferi cell: outer membrane (OM), inner membrane (IM), and periplasmic

423 flagella (PFs). (B and C) Models of a PF and an external flagellum. (D) A section from a wild-type cell

424 tomogram. A central section (E) and an outline overlapping onto the map (F) of the intact motor. The

425 MS ring is colored green; the rod and hook are colored orange; the $\mathrm{P}$ ring $(\mathrm{P})$, the export apparatus 
426 (EXP), the stator and the collar are labeled accordingly. (G) A section from a purified PFs tomogram. 427 A section (H) and an outline (I) of the basal body. The MS ring-rod complex remains in both the basal 428 body (I) and the intact motor (F). (J) A 3-D surface rendering of the intact motor (F).

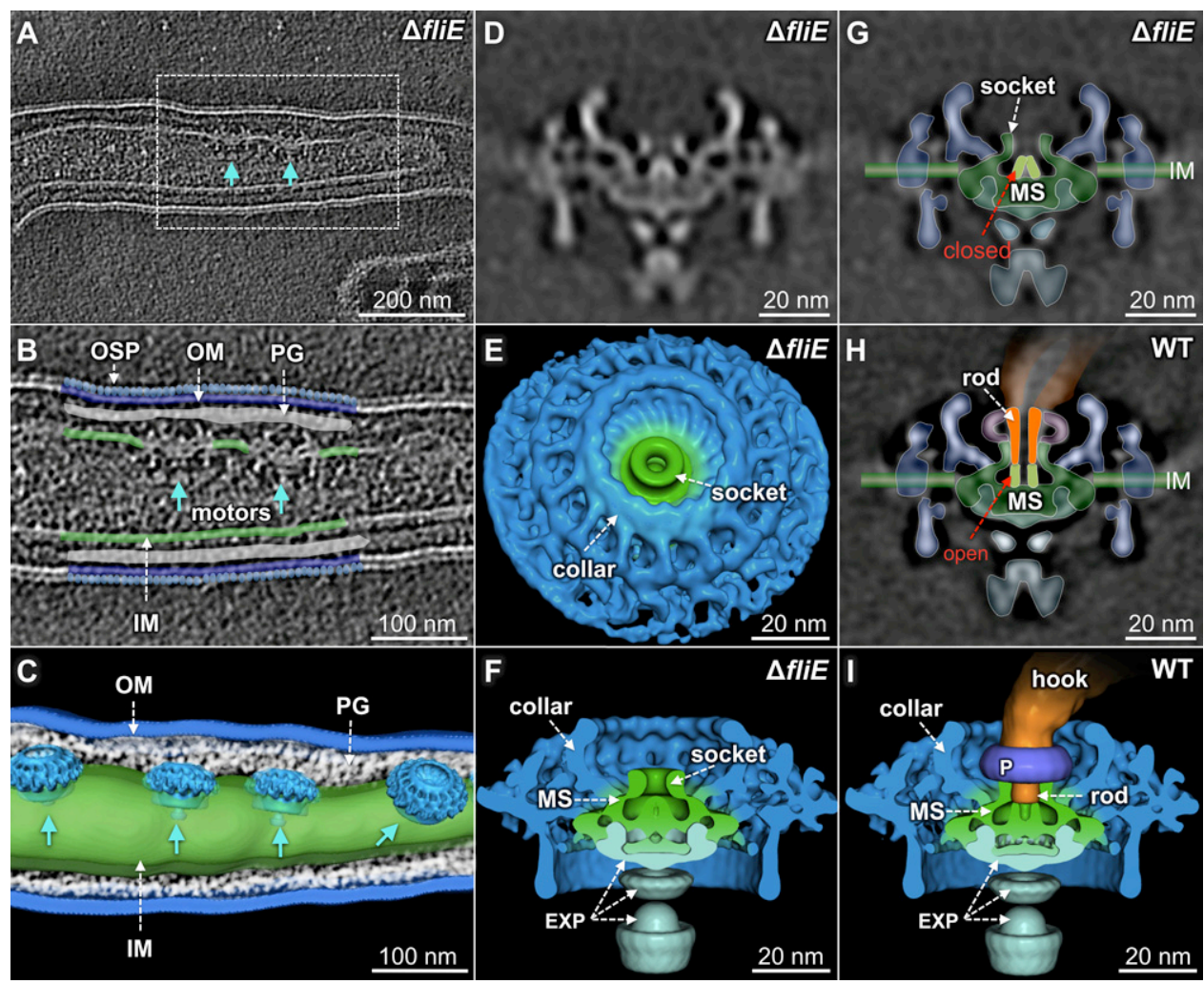

430 Fig. 2 . The flagellar motor structure of the $\Delta f l i E$ mutant reveals a closed conformation.

431 (A) Multiple flagellar motors are embedded in the IM. Enlarged image (B) and 3-D surface rendering 432 (C) of the region outlined in (A). A central section (D) and 3-D surface rendering in top (E) and side 433 views (F) of the $\Delta$ fliE motor. (G) A central channel domain (light green) is closed in the $\Delta f l i E$ mutant. 434 (H) Outline of the rod (orange), the MS ring (green) and 3-D surface rendering (I) of the wild-type 435 motor. The channel domain of the MS ring is in an open conformation, and the rod is assembled on top 436 of the channel domain. 


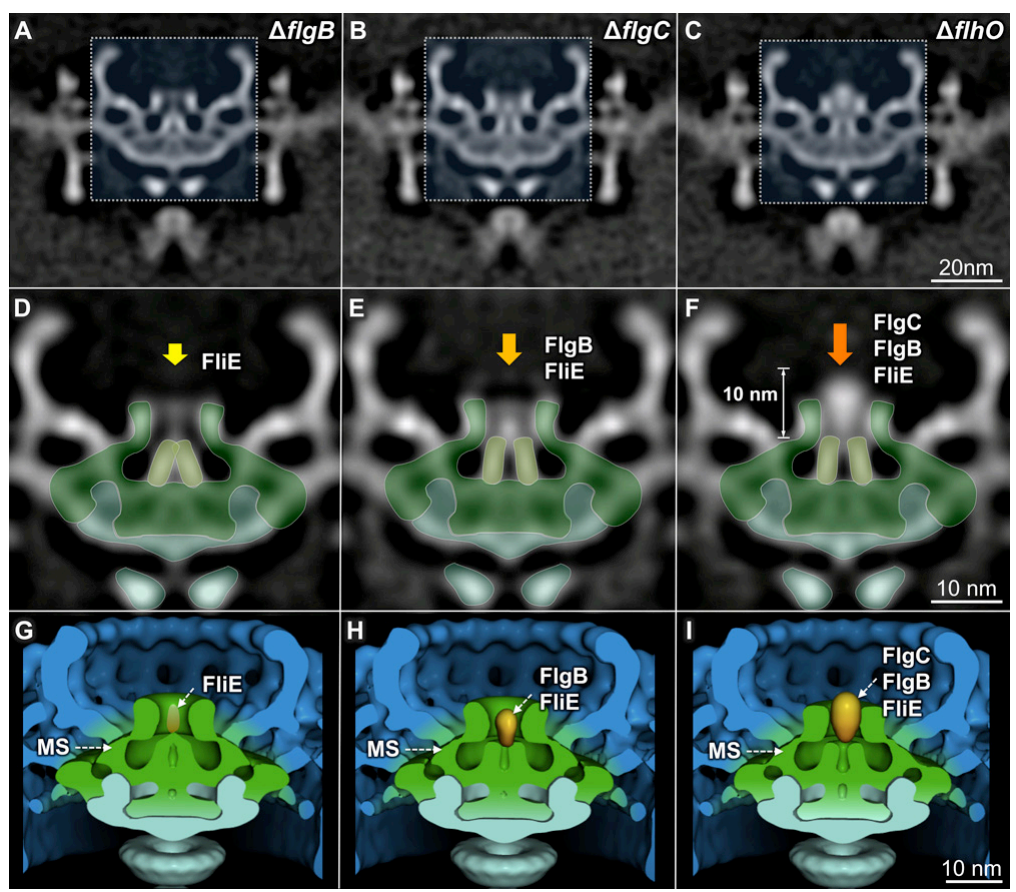

439

440 Fig. 3. Intermediate structures of the flagellar rod.

441 (A-C) 3-D maps of $\Delta f \lg B, \Delta f l g C$, and $\Delta f l h O$ flagellar motors. (D-F) Enlarged images of the regions 442 outlined in (A-C). In the $\triangle f \lg B$ mutant, the channel in the MS ring remains closed (D). In the $\Delta f \lg C$ 443 mutant, the channel is in an open conformation, and a globular density is visible (E). In the $\Delta f l h O$ 444 mutant, the globular density is larger and extends beyond the MS ring (F). (G-I) 3-D surface rendering 445 of the motors from $\triangle f \lg B, \Delta f \lg C$, and $\triangle f \operatorname{lh} O$ mutants. 


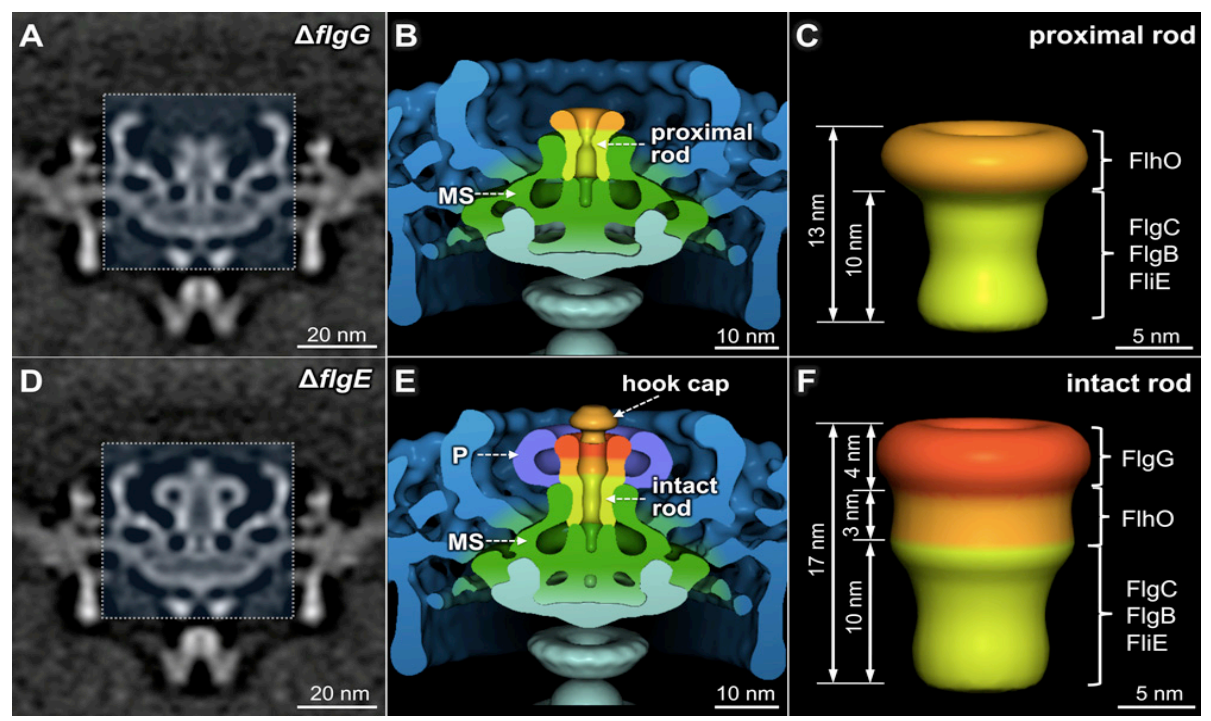

450 Fig. 4. 3-D structures of the proximal rod and fully assembled rod.

451 A section (A) and 3-D surface rendering (B) of the $\Delta f \lg G$ motor. A flanged tube structure is readily 452 observed above the channel domain of the MS ring. (C) 3-D map of the proximal rod. A section (D) 453 and 3-D surface rendering (E) of the $\Delta f \lg E$ motor. The fully assembled rod, the $\mathrm{P}$ ring, and a cap 454 structure (probably the hook cap) are revealed (F). 

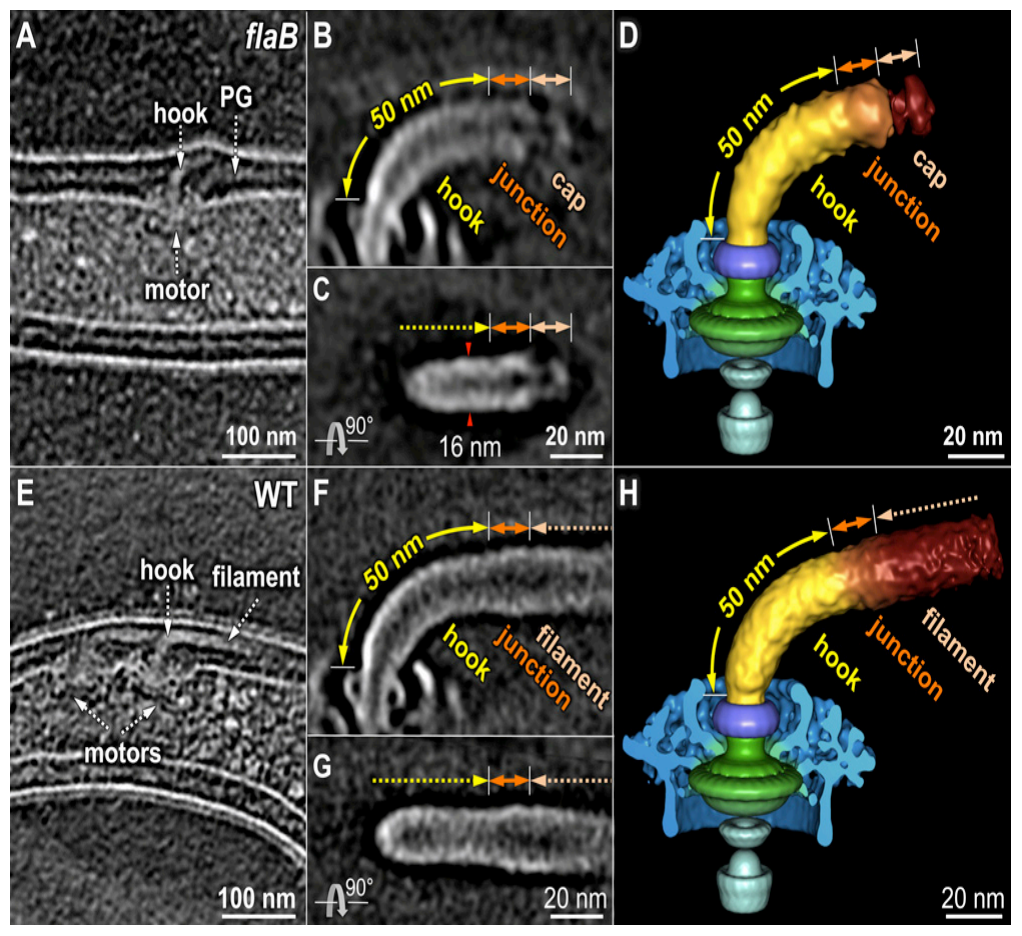

458 Fig. 5. 3-D structures of the hook and the hook-filament junction.

459 (A) Cryo-tomogram of a flaB mutant cell. The flagellar hook complex in two different orientations (B, $460 \mathrm{C})$. The hook length is estimated to be $\sim 50 \mathrm{~nm}$, and another $\sim 12 \mathrm{~nm}$ density is probably the hook461 filament junction, as labeled in B and C. (D) 3-D surface rendering of the flaB flagellar structure. The 462 hook (together with the hook-filament junction) and the filament cap are segmented. (E) Cryo463 tomogram of a wild-type cell showing the flagellar motor with a hook and filament. (F and G) 3-D 464 structures of the flagellar hook and filament in wild-type cells. The diameter of the axial structure 465 gradually becomes larger at the junction region. (H) 3-D surface rendering of an intact flagellum. 


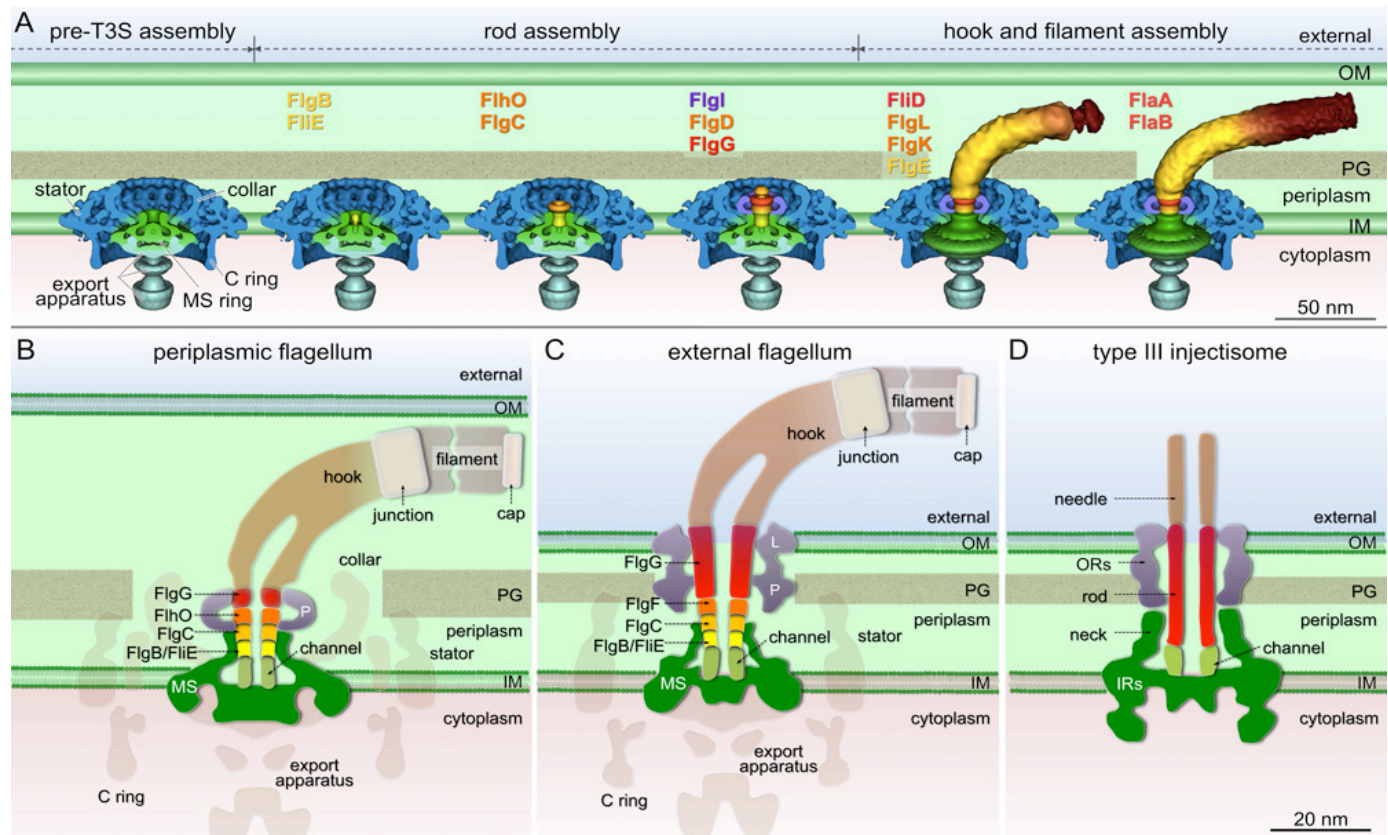

Fig. 6. Modular architecture and assembly blueprint of bacterial flagellum.

469 (A) A model of flagellar assembly in B. burgdorferi. In the pre-T3S assembly state, many flagellar 470 components assemble, including the MS ring, the $\mathrm{C}$ ring, the stators, the export apparatus, and the 471 collar. The secretion channel in the MS ring is closed (panel 1). In the presence of FliE, FlgB, rod 472 substrates can be secreted but are unable to form a stable structure (panel 2) until all the proximal rod 473 substrates (FliE, FlgB, FlgC, and FlhO) are present (panel 3). The distal rod protein FlgG adds onto the 474 proximal rod and polymerizes until it reaches a determined length (panel 4). A hook cap, composed of 475 FlgD, forms at the distal end of the rod (panel 4) and promotes hook assembly (panel 5). Assembly of 476 the filament (FlaA, FlaB) is promoted by the filament cap (FliD) (panel 6). (B) A cartoon model of a 477 periplasmic flagellum. Five rod proteins assemble sequentially on top of the channel domain of the MS 478 ring and are enclosed by the socket domain of the MS ring and the P ring. The FlgG distal rod in the $479 \mathrm{PF}$ is shorter than that in the external flagellum (C). (D) A cartoon model of Type III injectisome 480 shows that the rod is anchored on a structure similar to the channel domain of the flagellar motor. The 481 rod is a straight tube formed by one protein, PrgJ. 
483

484

176 


\section{Kelly Ann (Heintzelman) Miller \\ 570-898-4540 \\ kamiller@hsc.wvu.edu}

\section{Education/Training}

\begin{tabular}{|l|l|l|l|}
\hline Institution and Location & Degree & MM/YY & Field of Study \\
\hline $\begin{array}{l}\text { Lock Haven University of } \\
\text { Pennsylvania }\end{array}$ & BA & $05 / 03$ & Clinical Psychology \\
\hline $\begin{array}{l}\text { Lock Haven University of } \\
\text { Pennsylvania }\end{array}$ & BS & $05 / 07$ & $\begin{array}{l}\text { Molecular and Environmental } \\
\text { Biology }\end{array}$ \\
\hline $\begin{array}{l}\text { West Virginia University, } \\
\text { Morgantown, WV }\end{array}$ & PhD & Current & $\begin{array}{l}\text { Microbial Pathogenesis and } \\
\text { Immunology }\end{array}$ \\
\hline
\end{tabular}

\section{Research Interests}

Microbial pathogenesis: mechanisms by which bacteria cause disease and the host immune response to infection.

\section{Positions and Honors}

\section{Positions}

Undergraduate Independent Study, Lock Haven University of PA Department of Psychology, Fall 2002-Spring 2003. Evaluated number discrimination and counting in the squirrel monkey (Saimiri sciureus).

Undergraduate Independent Study, Lock Haven University of PA, Microbiology, Spring 2006. Investigated the application of constructed greenhouse model wetlands for the treatment of high nitrogen-load groundwater leachate from Clinton County landfill.

Microbiology Laboratory Assistant, Lock Haven University of PA Department of Biology, Fall 2006-2007. Provided students with hands on instruction during labs and set up labs for classes.

Predoctoral Trainee, WVU School of Medicine, 2007- present. Investigated the complex structure of the flagellar hook protein, FlgE, in Borrelia burgdorferi and Treponema denticola. Trained, supervised, and served as a mentor to 3 undergraduates and the laboratory technician.

Technical Experience: Mass spectrometry analysis, flow cytometry analysis, electron microscopy, recombinant DNA techniques, protein expression and purification. 


\section{Teaching Experience}

Peer tutor, Lock Haven University of PA, Departments of Psychology, Biology, Chemistry, and Statistics, 2000-2003 and 2005-2006. Provided small group and individual instruction to 10-15 students per semester in a variety of courses, which included: Principles of Biology I and II, Genetics, Organic Chemistry, Introduction to Psychology, and Applied Psychological Statistics.

Teaching Assistant, WVU School of Medicine, Microbiology 323 (Medical Technology Course), Spring 2009 and Spring 2011. Provided laboratory lectures, assisted students with completing laboratory experiments and exercises, graded exercises and exams.

WVU Summer Institution on Undergraduate Science Education, Participant, June 2009. Institute modeled after National Acadamies Summer Institute. Learned about innovations and research in undergraduate education. Developed peer-reviewed teaching materials.

Mentor, WVU Nano Summer Undergraduate Research Experience, Summer 2009. Served as a mentor to an undergraduate student conducting an independent research project.

Teaching Assistant, WVU School of Medicine, Microbiology 701 (Medical Student Course), Fall 2009. Provided laboratory lectures, assisted students with completing laboratory experiments and exercises, graded exercises and exams.

\section{Honors}

Lock Haven University, Honors Scholarships, 2000-2002.

Lock Haven University of PA, Presidential Honors Scholarship, 2002-2003.

Dean's List, 1999-2003 and 2005-2006.

Highest cumulative GPA graduating with a B.A., Lock Haven University of PA, Spring 2003.

Psychology Student of the year, Lock Haven University of PA, 2003.

Paul and Shirley Klens Scholarship Award for academic excellence in the biological sciences and community service, Lock Haven University of PA, 2006.

West Virginia University, STEM (Science Technology, Engineering, and Math) graduate fellowship, Spring, 2010 and Fall 2012.

American Heart Association Graduate Award, Summer 2010 to Summer 2012.

Allegheny Branch ASM, Oral presentation awarded first place. November 2012.

\section{Invited Seminars/Lectures}

West Virginia University Van Lier annual research symposium, February 28, 2013.

West Liberty University Biological Sciences Research Seminar Series, May 1, 2013. 
Annual Meeting American Society for Microbiology, May 2013.

Professional Societies

Phi Kappa Phi, National Honorary Society, 2002- present.

American Society for Microbiology, 2009- present.

\section{Presentations/Publications}

Manuscript under Review

Miller KA, Motaleb MA, Liu J, Hu B., Caimino MJ, MR, and Charon NW. Initial characterization of the FlgE high molecular weight complex of Borrelia burgdorferi. Submitted to PLOS One.

\section{Publications}

Zhao X, Zhang K, Boquoi T, Hu, B, Motaleb M, Miller K, James M, Charon NW, Manson M, Norris SJ, Li C, and Liu J. Visualizing the Sequential Assembly of Bacterial Flagellum in Borrelia burgdorferi by Cryo-Electron Tomography. Proc. Natl. Acad. Sci. In press.

\section{Invited Review Article}

Charon NW, Cockburn A, Li C, Liu J, Miller KA, Miller, MR, Motaleb M, and Wolgemuth C. Oct. 2012. The unique paradigm of spirochete motility and chemotaxis. Annu. Rev. Microbiol. 66: 349-370.

\section{Abstracts/Presentations at regional, national, and international scientific meetings}

Bacterial Locomotion and Signal Transduction (BLAST) X. January 2009. Cuernavaca, Mexico. "The complex hook basal body structure of the Lyme disease spirochete Borrelia burgdorferi." Kelly Ann Miller (Poster Presenter), Robert Duda, Roger Hendrix, Md. A. Motaleb, and Nyles W. Charon. West Virginia University.

Gordon Research Conference on the Biology of Spirochetes. January 2010. Ventura, CA. "The complex hook basal body structure of the Lyme disease spirochete Borrelia burgdorferi." Kelly Ann Miller (Poster Presenter), Robert Duda, Roger Hendrix, Michael Miller, and Nyles W. Charon. West Virginia University. 
form a high molecular weight complex". Kelly Ann Miller (oral presentation awarded first place), Michael Miller, Milinda James, and Nyles W. Charon. West Virginia University.

BLAST XII (Bacterial locomotion and signal transduction) Meeting. January 2013. Tucson, AZ. "3-D visualization of bacterial flagellar assembly in Borrelia burgdorferi." Xiaowei Zhao, Kai Zhang, Tristan Boquoi, Bo Hu, Chris Li, Md A. Motaleb, Kelly A. Miller, Nyles W. Charon, Steven J. Norris, and Jun Liu.

Mid-Atlantic Microbial Pathogenesis Meeting. January 2013. Wintergreen, VA. "The flagellar hook structure of the spirochetes Borrelia burgdorferi and Treponema denticola is unique from the hook of bacteria with external flagella; the FlgE proteins form a high molecular weight complex." Kelly Ann Miller (Poster Presenter), Michael R. Miller, Milinda James, Justin M. Hettick, MD Motaleb, and Nyles W. Charon.

Van Lier Convocation. February 28, 2013. Morgantown, WV. "Mass spectrometry suggests that the flagellar hook proteins of the spirochetes Borrelia burgdorferi and Treponema denticola are covalently cross-linked." Kelly Ann Miller (selected by committee to give an oral presentation), Michael R. Miller, Milinda James, and Nyles W. Charon.

PBM (Pittsburgh Bacterial Meeting). March 9, 2013. Pittsburgh, PA. "Mass spectrometry suggests that the flagellar hook proteins of the spirochetes Borrelia burgdorferi and Treponema denticola are covalently cross-linked." Kelly Ann Miller (Poster Presenter), Michael R. Miller, Milinda James, Justin M. Hettick, MD A. Motaleb, and Nyles W. Charon.

ASM (American Society Microbiology) General Meeting. May 2013. Denver, CO. "Mass spectrometry suggests that the flagellar hook proteins of the spirochetes Borrelia burgdorferi and Treponema denticola are covalently cross-linked." Kelly Ann Miller (selected for oral presentation), Michael R. Miller, Milinda James, Justin M. Hettick, MD A. Motaleb, and Nyles W. Charon.

ASMS Conference on Mass Spectrometry and Allied Topics. June 2013. Minneapolis, MN. "Characterization of flagellar hook protein from spirochetes using tandem mass spectrometry." Justin M. Hettick, KellyAnn Miller, Milinda James, Nyles W. Charon, and Michael R. Miller. 


\section{Research Support Pre-doctoral Fellowships}

WVU STEM fellowship. January 2010- July 2010 and July 2012-January 2013. The complex hook basal body structure of Borrelia burgdorferi and Treponema denticola. The goal of this study is to characterize the FlgE high molecular weight complex formation in order to better understand how spirochete motility relates to pathogenesis.

American Heart Association, 10PRE4170060. Role: PI. 2010-2012. July 2010-June 2012. Borrelia burgdorferi flagellar protein FlgE role in virulence of Lyme disease. The goal of this proposal is to characterize the covalent cross-linking that comprises the flagellar hook of Borrelia burgdorferi. 